\title{
Water Policy, Productivity and Economic Efficiency
}

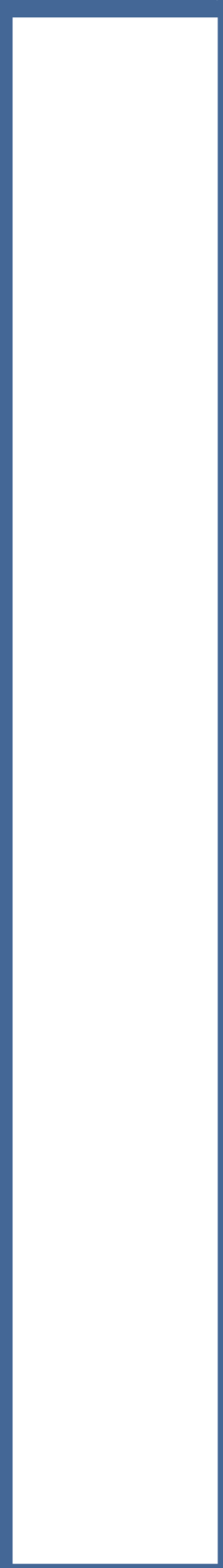

\section{Edited by}

Davide Viaggi, Meri Raggi \& Giacomo Zanni

Printed Edition of the Special Issue Published in Water

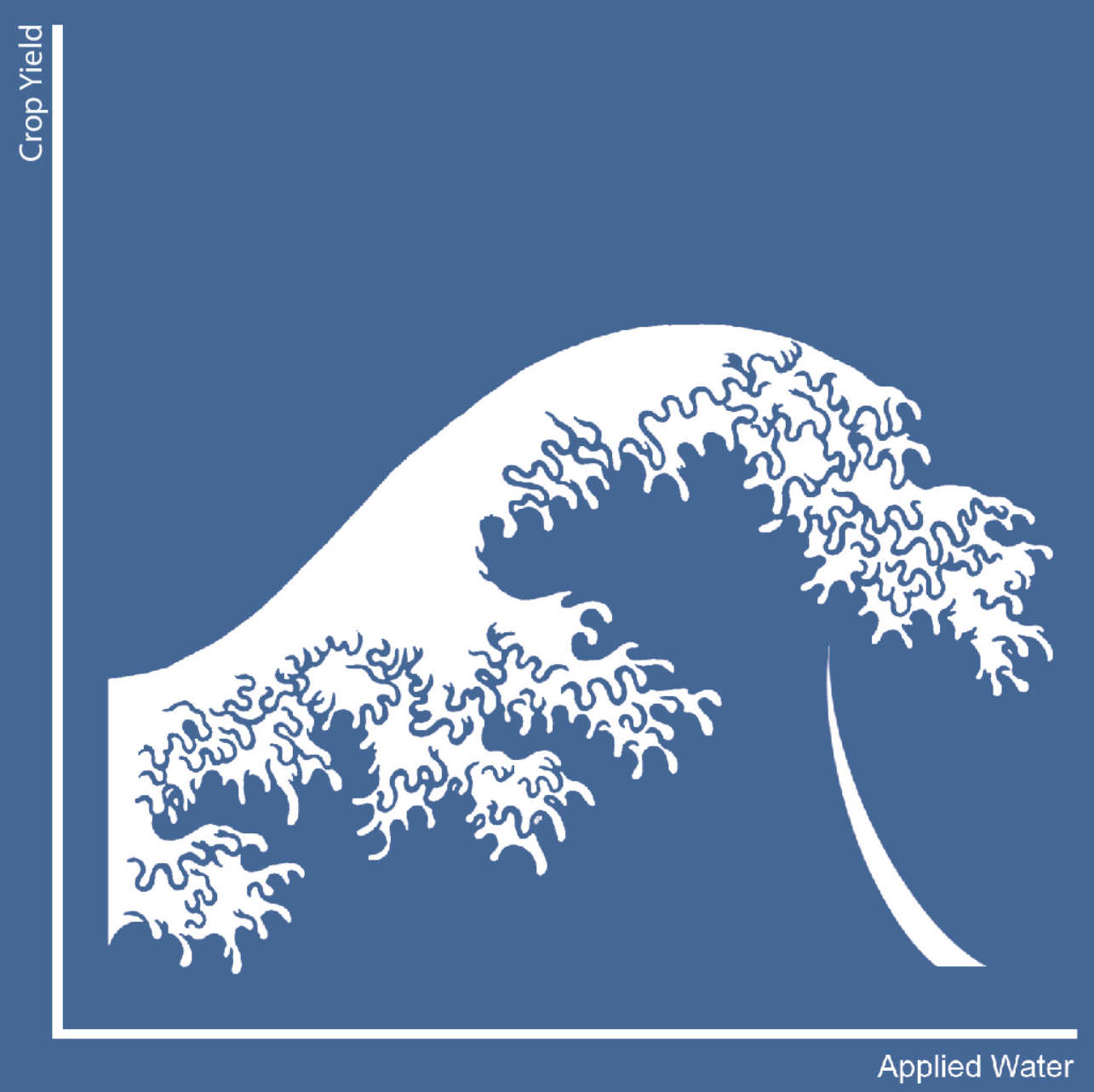


Davide Viaggi, Meri Raggi and Giacomo Zanni (Eds.)

\section{Water Policy, Productivity and Economic Efficiency}


This book is a reprint of the Special Issue that appeared in the online, open access journal, Water (ISSN 2073-4441) from 2013-2014 (available at:

http://www.mdpi.com/journal/water/special_issues/water_policy_prod_econom).

\section{Guest Editors}

Davide Viaggi

University of Bologna

Department of Agricultural Sciences

Viale Fanin, 50

40127 Bologna, Italy

Meri Raggi

University of Bologna

Department of Statistical Sciences

Via Belle Arti, 41

40126 Bologna, Italy
Giacomo Zanni

University of Ferrara

ENDIF - ENgineering Department In Ferrara

Via Saragat, 1

44100 Ferrara, Italy

\section{Editorial Office}

MDPI AG

Klybeckstrasse 64

Basel, Switzerland

Publisher

Shu-Kun Lin

Production Editor

Martyn Rittman

\section{Edition 2014}

MDPI • Basel • Beijing • Wuhan • Barcelona

ISBN 978-3-03842-012-5 (Hbk)

ISBN 978-3-03842-013-2 (PDF)

Cover illustration by Alessandro Canu

Articles in this volume are Open Access and distributed under the Creative Commons Attribution license (CC BY), which allows users to download, copy and build upon published articles even for commercial purposes, as long as the author and publisher are properly credited, which ensures maximum dissemination and a wider impact of our publications. The book taken as a whole is (c) 2014 MDPI, Basel, Switzerland, distributed under the terms and conditions of the Creative Commons by Attribution (CC BY-NC-ND) license (http://creativecommons.org/licenses/by-nc-nd/4.0/). 


\section{Table of Contents}

List of Contributors $\mathrm{V}$

Preface VII

\section{Davide Viaggi, Giacomo Zanni and Meri Raggi}

Editorial: Changing Perspectives on the Economics of Water

Reprinted from: Water 2014, 6(10), 2969-2977

http://www.mdpi.com/2073-4441/6/10/2969

\section{Productivity Assessment}

\section{Dennis Wichelns}

Do Estimates of Water Productivity Enhance Understanding of Farm-Level Water Management?

Reprinted from: Water 2014, 6(4), 778-795

http://www.mdpi.com/2073-4441/6/4/778

\section{Carlos Dionisio Pérez Blanco and Thomas Thaler}

An Input-Output Assessment of Water Productivity in the Castile and León Region (Spain) Reprinted from: Water 2014, 6(4), 929-944

http://www.mdpi.com/2073-4441/6/4/929

\section{Institutional Framework and Mechanisms}

\section{Ming-Feng Hung, Daigee Shaw and Bin-Tzong Chie}

Water Trading: Locational Water Rights, Economic Efficiency, and Third-Party Effect

Reprinted from: Water 2014, 6(3), 723-744

http://www.mdpi.com/2073-4441/6/3/723.

\section{Xueting Zeng, Yongping Li, Guohe Huang and Liyang Yu}

Inexact Mathematical Modeling for the Identification of Water Trading Policy under Uncertainty

Reprinted from: Water 2014, 6(2), 229-252 


\section{Francesco Galioto, Meri Raggi and Davide Viaggi}

Pricing Policies in Managing Water Resources in Agriculture: An Application of Contract Theory to Unmetered Water

Reprinted from: Water 2013, 5(4), 1502-1516

http://www.mdpi.com/2073-4441/5/4/1502

Francesco Galioto, Valentina Marconi, Meri Raggi and Davide Viaggi

An Assessment of Disproportionate Costs in WFD: The Experience of Emilia-Romagna

Reprinted from: Water 2013, 5(4), 1967-1995

http://www.mdpi.com/2073-4441/5/4/1967

\section{Luca Giraldo, Raffaele Cortignani and Gabriele Dono}

Simulating Volumetric Pricing for Irrigation Water Operational Cost Recovery under

Complete and Perfect Information

Reprinted from: Water 2014, 6(5), 1204-1220

http://www.mdpi.com/2073-4441/6/5/1204

\section{Christos Mattas, Konstantinos S. Voudouris and Andreas Panagopoulos}

Integrated Groundwater Resources Management Using the DPSIR Approach in a GIS

Environment Context: A Case Study from the Gallikos River Basin, North Greece

Reprinted from: Water 2014, 6(4), 1043-1068

http://www.mdpi.com/2073-4441/6/4/1043

\section{Governance Aspects}

\section{Alberto Asquer}

Understanding Subjectivities in the Regulation of Local Water Services: A Q-Methodology

Study of Elected Public Officers in Italy

Reprinted from: Water 2014, 6(3), 670-693

http://www.mdpi.com/2073-4441/6/3/670 


\section{List of Contributors}

Alberto Asquer: Department of Financial and Management Studies, School of Oriental and African Studies, University of London, Thornhaugh Street, Russell Square, London WC1H 0XG, UK; Dipartimento di Scienze Economiche e Aziendali, Facoltà di Scienze Economiche, Giuridiche e Politiche, Università di Cagliari, Viale Fra Ignazio 17, Cagliari 09123, Italy.

Bin-Tzong Chie: Department of Industrial Economics, Tamkang University, Tamsui District, New Taipei City 251, Taiwan.

Raffaele Cortignani: Department of Agriculture, Forests, Nature and Energy (DAFNE), University of Tuscia, via S.Camillo de Lellis, Viterbo 01100, Italy.

Gabriele Dono: Department of Agriculture, Forests, Nature and Energy (DAFNE), University of Tuscia, via S.Camillo de Lellis, Viterbo 01100, Italy.

Francesco Galioto: Department of Agricultural Sciences, University of Bologna, Viale Fanin 50, Bologna 40127, Italy.

Luca Giraldo: Department of Agriculture, Forests, Nature and Energy (DAFNE), University of Tuscia, via S.Camillo de Lellis, Viterbo 01100, Italy.

Guohe Huang: Ministry of Education Key Laboratory of Regional Energy Systems Optimization, Sino-Canada Resources and Environmental Research Academy, North China Electric Power University, Beijing 102206, China.

Ming-Feng Hung: Department of Industrial Economics, Tamkang University, Tamsui District, New Taipei City 251, Taiwan.

Yongping Li: Ministry of Education Key Laboratory of Regional Energy Systems Optimization, Sino-Canada Resources and Environmental Research Academy, North China Electric Power University, Beijing 102206, China.

Valentina Marconi: Department of Agricultural Sciences, University of Bologna, Viale Fanin 50, Bologna 40127, Italy.

Christos Mattas: Laboratory of Engineering Geology \& Hydrogeology, Department of Geology, Aristotle University, Thessaloniki GR 54124, Greece.

Andreas Panagopoulos: Hellenic Agricultural Organisation, Land Reclamation Institute, Sindos 57400, Greece.

Carlos Dionisio Pérez Blanco: Fondazione Eni Enrico Mattei and Centro EuroMediterraneo sui Cambiamenti Climatici, Isola di San Giorgio Maggiore n.8, Venice 30124, Italy.

Meri Raggi: Department of Statistical Sciences, University of Bologna, Via Belle Arti, 41, Bologna 40126, Italy.

Daigee Shaw: Institute of Economics, Academia Sinica, Nankang, Taipei City 115, Taiwan Thomas Thaler: Flood Hazard Research Centre, Middlesex University, North London Business Park, Oakleigh Road South, New Southgate, London N11 1NP, UK. 
Davide Viaggi: Department of Agricultural Sciences, University of Bologna, Viale Fanin 44, Bologna 40127, Italy.

Konstantinos S. Voudouris: Laboratory of Engineering Geology \& Hydrogeology, Department of Geology, Aristotle University, Thessaloniki GR 54124, Greece.

Dennis Wichelns: P.O. Box 2629, Bloomington, IN 47402, USA.

Liyang Yu: College of Art and Science, Millikin University, Decatur, IL 62522, USA.

Giacomo Zanni: ENDIF-Engineering Department In Ferrara, University of Ferrara, Via Saragat 1, Ferrara 44100, Italy.

Xueting Zeng: Ministry of Education Key Laboratory of Regional Energy Systems Optimization, Sino-Canada Resources and Environmental Research Academy, North China Electric Power University, Beijing 102206, China. 


\section{Preface}

Over the past few decades, water policies have undergone significant changes in many countries, notably due to the development of national and international political, social, and environmental issues, including globalization, trade liberalization, institutional and legal requirements, changing standards of living, management practices, and technological innovation. Policy changes include both "high level” views about water status and practical instruments, in particular with an emphasis on integrated basin management and economic policy instruments.

A relevant part of the water policy literature addresses this topic, mainly as an issue related to environmental conservation. However, water remains a major productive factor, particularly in agriculture. This role is made even more prominent in light of economic crises, increased competition across markets and climate change, as well as fossil energy limitations, which also highlight the water-energy nexus as a key resource issue for future economic viability.

The delay, in the past, in recognizing the economic consequences of a limited water supply, and in decoupling economic development from water demand and supply, has resulted in a water-dependent growth model, currently threatened by increasing scarcity and droughts. Consequently, there is now an urgent need for new perspectives for promoting a more sustainable and efficient use of water resources. This calls for, on the one hand, a comprehensive understanding of water efficiency and productivity and, on the other hand, an investigation of the linkages among economic sectors to illustrate trade-offs in water reallocations. In addition, this also points to the need to study the institutional innovations and economic evaluation instruments that are able to better assess policy performance and provide evidence for improved mechanism designs aimed specifically at water efficiency and productivity.

The objective of this Special Issue on "Water policy, productivity and economic efficiency" is to provide an overview of future perspectives on these issues, in the context of alternative uses and perspective scenarios. This set of papers mainly takes an economic perspective; in this sense, it is intended to be complementary to other disciplinary views and to contribute to interdisciplinary approaches. The Special Issue aims to interpret the complexity of the relevant social and environmental issues, which are of great importance for a thorough understanding of the role of water in the welfare of society. The selected papers cover a wide a range of relevant economic issues, which are inherently linked to the fact that water is at the heart of sustainable human development and needs to be studied from multiple perspectives. The papers can be divided into three chapters, namely: "Productivity assessment”, "Institutional framework and mechanisms," and "Governance aspects”.

Davide Viaggi, Meri Raggi and Giacomo Zanni Guest Editors 



\section{Changing Perspectives on the Economics of Water}

\section{Davide Viaggi, Giacomo Zanni and Meri Raggi}

Abstract: This paper provides an overview of the special issue on "Water policy, productivity and economic efficiency". In particular, it includes an overview of key topics on the future of water as a productive factor, in the context of alternative uses and perspective scenarios. The selected papers cover a wide range of relevant economic issues and are presented in three categories: productivity assessment, institutional framework and mechanisms, and governance aspects. The paper concludes by discussing future research challenges in this field.

Reprinted from Water. Cite as: Viaggi, D.; Zanni, G.; Raggi, M. Changing Perspectives on the Economics of Water. Water 2014, 6, 2969-2977.

\section{Introduction}

Over the past few decades, water policies have undergone significant changes in many countries notably due to the development of national and international political, social and environmental issues, including globalisation, trade liberalisation, institutional and legal requirements, changing standards of living, management practices and technological innovation. Policy changes include both "high level" views about water status and practical instruments, in particular with an emphasis on integrated basin management and economic policy instruments.

Since 1992, in virtue of the Dublin Statements, the international community has officially recognised water as a scarce resource. Specifically, it has been asserted that water resources are vulnerable and not infinite [1].

In particular, Principle 4 of these statements defines water as an economic good. On the other hand, the first principle of the 1992 Rio Statements [2], that supplemented the Dublin Principles, implies that water is also a social good (for a "healthy and productive life, in harmony with nature"). It follows that the humans are entitled to at least certain levels of water, in terms of both quantity and quality, and from a point of view of both environmental and productive uses, under the responsibility of their respective governments $[3,4]$.

A relevant part of the water policy literature addresses this topic mainly as an issue related to environmental conservation. However, water remains a major productive factor, particularly in agriculture. This role is made even more prominent in light of economic crises, increased competition across markets and climate change, as well as fossil energy limitations, which also highlight the water-energy nexus as a key resource issue for future economic viability.

The delay, in the past, in recognising the economic consequences of a limited water supply, and in decoupling economic development from water demand and supply, has resulted in a water-dependent growth model, currently threatened by increasing scarcity and droughts. Consequently, there is now an urgent need for new perspectives in order to promote a more sustainable and efficient use of water resources. This calls for, on the one hand, a comprehensive understanding of water efficiency and productivity and, on the other hand, an investigation of the linkages among economic sectors to illustrate trade-offs in water reallocations. In addition, this also points to the need to study 
institutional innovations and economic evaluation instruments able to better assess policy performance and provide evidence for improved mechanism designs aimed specifically at water efficiency and water productivity.

The objective of this special issue on "Water policy, productivity and economic efficiency" is to provide an overview of future perspectives on these issues, in the context of alternative uses and perspective scenarios. This set of papers mainly takes an economic perspective; in this sense, it is intended to be complementary to other disciplinary views and contributing to interdisciplinary approaches, aimed at interpreting the complexity of the relevant social and environmental issues, of great importance for a thorough understanding of the role of water in the welfare of society.

The selected papers cover a wide a range of relevant economic issues, inherently linked to the fact that water is at the heart of sustainable human development and needs to be studied from multiple perspectives. This introductory paper is organised as follows: in Section 2, we briefly outline the main themes from the special issue that have been emphasised in the international literature. Based on this, we then propose a reasoned analysis of the contributions of this special issue (Section 3), as the basis of a discussion of selected future scientific challenges in this field (Section 4).

\section{Changing Context and Research Challenges}

Integrated water management has been a cornerstone of the water literature and water policy trends for many years. The complexity of integrated water management and the variety of scales and perspectives of analysis was exacerbated at the beginning of this century by a number of issues related to population growth, climate change and resource limitations, in the context of an increasingly complex world economy [5]. For the agricultural sector in particular, which is the most important sector with respect to water use in many countries, the challenge of feeding a growing population has become a key issue in the agenda, while at the same time, the farming sector has proved to be the sector most exposed to climate change [6]. In reconciling these needs, water productivity is a key topic, particularly in water scarce areas (see e.g., [7]). Water also affects the productivity of other resources, such as soil and fertilisers. For agriculture as a whole, in order to face these needs, new productivity-related concepts, such as sustainable intensification, are emerging [8].

A key emerging topic is the water-agriculture-energy nexus (in turn connected to climate change), in which agriculture uses water for food production, as well as for producing feedstocks for renewable energy production, both of which are affected by climate change and, in turn, can affect climate change through emissions of GHG gasses [9]. The development of the bioeconomy could increase the relevancy of this issue by extending the role of agriculture to the production of feedstocks for biobased industries, potentially increasing pressures on water (or dependency on water availability) and trade-offs with other sectors.

In order to come to terms with this context, together with water allocation issues (e.g., minimum vital flow) and supply side measures (e.g., water reservoirs), water policy is increasingly focused on increasing water efficiency [10]. The direction taken by the European Commission is a good example. It has recently developed a comprehensive strategy aimed at improving water efficiency. This strategy provides, in addition to pricing and cost recovery policies, a number of additional actions, such as: "water accounts", at basin and sub-basin levels, to increase the information base on which 
to build locally specific measures; "water stress targets and indicators", developed for each relevant sector (industry, energy production, agriculture, households, etc.), in order to avoid possible rebound effects; "Eco-Design guidelines", to promote more efficient water devices and products on the market, clearly labelled on the basis of their efficiency; "irrigation efficiency measures" in the CAP, including "minimum water use reductions"; "best practices on Sustainable Economic Leakage Levels" to adapt water infrastructure to climate change; and water trading guidelines, to help the development of water trading in the Member States that choose to employ it [10].

These areas of intervention not only demonstrate the variety and complexity of the issues at stake, but also touch upon a number of open issues for research. An example is the concept of "efficiency and productivity". First, efficiency can have different disciplinary perspectives ranging from crop physiology to economics [11]. Second, different definitions exist of both water productivity and water efficiency and their appropriate application depends on different scales and domains of water use $[12,13]$ and on the different meanings assigned to these concepts [14]. Taking into account these differences in meaning and avoiding an overly standardised and simplified use of these complex concepts would help to minimise the risk of justifying policies and projects that ignore the specificities of local contexts and underestimate relevant social and environmental trade-offs between different water uses and different water users.

Another example is that of the different scales and perspectives of analysis. While the farm scale is a typical case for agriculture, attention to agricultural systems is also important, and the basin scale has become a key scale of analysis in order to account for inter-sector connections, whilst maintaining a clear relationship with a meaningful hydrological unit. However, over time, the interconnections among economic activities and the emergence of global phenomena such as climate change have led to an increasing number of modelling exercises using even regional, national or global scales (see e.g., [15-17]). Different scales may yield completely different pictures due to interconnections among sectors, but also highlight the urgency for compensation and displacement effects.

While there are numerous ways to encourage water using sectors to move in the right direction, the key issue is how to make this happen via appropriate incentives that are ultimately connected to policy instruments and governance systems. In particular, both economic policy instruments and appropriate governance settings have attracted the attention of economists in recent years, in part due to the coming into force of major legal instruments promoting tangible change, such as the Water Framework Directive [18].

A good deal of attention has been attracted by putting in place appropriate price setting mechanisms, as a means of incentivizing efficiency in water use [10,19]. Research in this field is still characterised by several open issues and is largely driven by the discrepancy between ideal water prices and actual prices for use (particularly with respect to volumetric pricing).

On the other hand, the changing context referred to above is starting to challenge established ways of looking at water policy. Issues include: the increased dynamics of water use technologies, which is linked to the renewed emphasis on innovation; the need to consider wider economic effects beyond simple profit for businesses, including overall sector viability; the consideration of wider flows of water (e.g., virtual water), the interconnection with social and ethical issues related to water distribution; soft factors such as governance; and social innovation, and uncertainty. Scale is of 
particular importance as is the consideration of the interlinked effects of different policy areas, which require a comprehensive view of water and the economy as a whole [20].

Based on these innovative themes, which have been progressively grafted onto the more established ones, a non-exhaustive list of relevant topics has been compiled, including: (i) economic analysis of experiences and open issues related to innovative water management for crop production; (ii) the production and efficiency effects of innovative policy instruments and mechanisms; (iii) ex-post and ex-ante policy evaluation approaches, methods and tools, and their application to cost-benefit and cost-effectiveness analyses of water policy measures from the point of view of economic efficiency and productivity; (iv) the efficiency effects of coordination between water policy and specific sector policies; (v) water policy and the viability of economic sectors in the context of drought and climate change management; (vi) water policy and wider economic and social issues; and (vii) water policy and competitiveness.

The proposals submitted partially cover the range of suggested topics. Among these, nine were selected, the contents of which are analysed in the following section.

\section{The Main Contribution of this Special Issue}

The nine selected works can be divided into three categories, which are the three main areas of the theme "Water Policy, Productivity and Economic Efficiency", namely: "Productivity assessment", "Institutional framework and mechanisms" and "Governance aspects".

The first category is represented by two works on the assessment of water productivity, the first at farm level and the second at the sectorial comparison level. In [21], Wichelns asks whether, given the complexity and uncertainty inherent in the farm's strategic decisions, maximizing the productivity of water is coherent with farm level goals. Based on the analysis of published production functions, he concludes that the estimates of water productivity contain too little information to improve the understanding of water management at the farm level.

In [22], Perez Blanco and Thaler estimate the intertemporal water productivity by way of the Hypothetical Extraction Method. The work confirms the existence of a productivity gap between agriculture and other sectors that are still largely dependent on agricultural production. The results suggest the existence of a "Verdoorn's Law" (a positive relationship between the growth of output and the growth of productivity) effect for water.

The second, and largest, category includes contributions aimed at investigating the issue of the productivity and efficiency of water, with reference to the various policy instruments and allocation mechanisms. These can be defined as the set of institutional frameworks and rules that determine the amount of water that users have the right to use: basically, markets and public administration. Each institutional setting provides water through a pricing mechanism (volumetric, not volumetric, etc.). The interest in this topic is notoriously linked to the fact that water possesses, as an economic good, unique characteristics that make its allocation particularly complicated. This category includes six studies. Two of these are focused on the analysis of efficiency of the institutional framework of the water market. In [23], Ming-Feng Hung et al., using an agent-based model simulation, estimate the potential economic benefits of implementing an innovative system of water trading in the Choushui River basin (Taiwan) where agriculture is highly developed and domestic/industrial water demands 
have increased rapidly. The particularity of this model stems from the fact that it was designed according to "locational water rights", taking into account the river flow's unidirectionality.

In [24], Zeng et al., develop a two-stage inexact credibility-constrained programming (TICP) method for identifying the efficiency of water trading under multiple uncertainties. On the basis of a real case of water resource allocation management and planning (in the arid region of Kaidu-kongque River Basin, Northwest China), the paper shows that, under some designated situations, trading is much more optimal and effective than non-trading, in terms of economic benefits and in terms of incentives for adopting water saving policies.

The other four papers in this group are placed within the framework of public water in Europe and investigate aspects of water management, more or less closely related to the rules laid down by the Water Framework Directive (WFD) 60/2000.

In [25], Galioto et al., explore how agricultural water pricing could contribute to lowering water demand under asymmetric information (when uses are unobserved). The study applies a Principal-Agent model, implemented as a mathematical non-linear programming model to the pricing policies of a Reclamation and Irrigation Board in Northern Italy. Given the current pricing structure and assuming zero transaction costs, the paper compares the performance of both an actual regulator's goals and the cost recovery objective of an ideal regulator driven by WFD principles. The results show a relevant increase in net benefits for the ideal scenario with respect to the actual one as water use costs increase. However, the existence of non-zero transaction costs related to the control of water uses points to the need for further research.

In [26], Galioto et al., develop a procedure consistent with the guidelines of the Directive. The assessment methodology takes into account the interdependencies between water bodies and the interactions between measures and pressures. The cost-effectiveness analysis, integrated into a cost-benefit analysis, makes it possible to select an efficient combination of measures, to evaluate the economic viability of the actions and to identify the areas where disproportionate costs are more likely to occur. Disproportionality tends to increase from foothill regions to plain areas, where the sources of pressure are most frequently located.

In [27], Giraldo et al., evaluate the implementation of a volumetric and cost-recovery pricing method for irrigation water under symmetric information conditions. In the first step, a cost function (translog) was estimated for irrigation water supplied by a water user association to a typical Mediterranean agricultural area. In the second step, the economic impact of a pricing method designed according to this cost function was simulated using a mathematical programming territorial model for the same agricultural area. The authors conclude that a performance assessment of pricing methods must take into account differences in implementation costs, as it is possible that an inefficient per-area pricing method could outperform an efficient volumetric pricing method.

In the sixth and final paper of this group, which is mainly a methodological one [28], Christos Mattas et al., adopt the DPSIR (Driving forces, Pressures, States, Impacts, Responses) framework to investigate the main causes and origins of pressures (overexploitation of aquifers, water quality degradation, and decreases in river discharge) to optimize the measures for sustainable management of water resources in that basin. The application of the DPSIR analysis links the socioeconomic drivers to the water resource pressures, the responses based on the WFD and the national legislation, 
hence demonstrating that this model is a useful tool for land-use planning and decision making in the area of water protection.

The third category includes the study of Asquer, who investigates various less-studied issues related to governance in the water sector. In [29], the author explores the behaviour of institutions responsible for the regulation of water services at the local level. In particular, using a Q-methodology on the opinions expressed by elected public officials, this study shows the multiplicity of subjective points of view regarding the design of local water policies in Italy. It helps to explain the frequent changes and instability in the overall regulatory design including, for example, the formulation of tariff rules.

\section{Final Remarks and Outlook}

The main messages from this special issue reinforce several well-established notions about current research in the field of water policy. In the face of a number of major world challenges, new solutions must be sought for water management. Such solutions must go beyond the traditional trade-off between economic and environmental values in order to find innovative solutions to reconcile productive/economic aims and environmental/resource conservation objectives.

A number of new concepts are emerging in this direction, including sustainable intensification and the quest for win-win solutions. The pathway is not straightforward, yet some specific research challenges may be identified from the collection of papers in this special issue, along the same lines as the classification of papers reported above.

First, there is the issue of properly representing technologies linking water and its physical productivity. Even basic concepts in economics (such as production functions) are not easily usable when it comes to numerical exercises, largely due to the lack of data, but also because of the difficulties in capturing variability over time and space for the actual performance of technology. In addition, the prominence of technological innovation tends to accelerate the pace of change of such relationships. The solutions to this challenge seem to rest in a mix of awareness of the basics (e.g., well established analysis tools and theory, transparent assumptions and first-hand experience of reality) and new techniques to account for dynamics and variability, or to measure relevant relationships.

Second, there is the challenge of attaching economic values to water uses, given their connection to monetary or non-monetary evaluations of non-market goods, or to the economic effects of water use throughout the economy. As this is strictly connected to the provision of proper incentives, it is clearly a major point of departure for economic research related to policy design and decision making. However, it is also connected to the significant challenge inherent in policy analysis, which is to properly represent agents' behaviour and the effects of policy on this behaviour. The existing analyses concerning the water sector seem to suffer from the simplification of neoclassical approaches and challenges when seeking appropriate solutions to better represent the real world.

Third is the issue of achieving results through appropriate governance at different levels and the integration of different stakeholders' viewpoints, and which ultimately goes beyond economic values and social, political and ethical issues. In spite of the emphasis given to participatory processes in water-related decision-making, research on appropriate procedures and tools is lacking. 
From the point of view of economic research, the challenge is the growing need to address these three challenges contemporaneously. This justifies increased attention being dedicated to mixed-method approaches and the use of integrated modelling approaches.

Even in the absence of concerted efforts, individual studies increasingly emphasise the tension between very specialised and focused tools, very specific policy mechanisms and maintaining a clear vision of the overall picture. This will likely remain a distinct feature of water policy research in the years to come.

\section{Acknowledgments}

The authors of this paper and the editors of the special issue wish to thank the journal editors, all authors submitting papers and the referees who have contributed to paper selection and improvement. However, the usual disclaimer applies.

\section{Conflicts of Interest}

The authors declare no conflict of interest.

\section{References}

1. World Meteorology Organization (WMO). The Dublin Statement on Water and Sustainable Development. 2007. Available online: https:/www.wmo.int/pages/prog/hwrp/documents/ english/icwedece.html (accessed on 1 September 2014).

2. United Nations (UN). Rio Declaration on Environment and Development, UN Doc. A/CONF.151/26 (vol. I)/31 ILM 874, 1992.

3. Dinar, A.; Saleth, R.M. Issues in Water Pricing Reforms: From Getting Correct Prices to Setting Appropriate Institutions. In The International Yearbook of Environmental and Resource Economics 2005/2006; Folmer, H., Titenberg, T., Eds.; Edward Elgar: Cheltenham, UK, 2005.

4. Dudu, H.; Chumi, S. Economics of Irrigation Water Management: A Literature Survey with Focus on Partial and General Equilibrium Models; Policy Research Working Paper 4556; The World Bank: Washington, DC, USA, March 2008.

5. Bouwer, H. Integrated Water Management for the 21st Century: Problems and Solutions. J. Irrig. Drain Eng. 2002, 128, 193-202.

6. Godfray, H.C.J.; Beddington, J.R.; Crute, I.R.; Crute, I.R.; Haddad, L.; Lawrence, D.; Muir, J.F.; Pretty, J.; Robinson, S.; Thomas, S.M.; et al. Food security: The challenge of feeding 9 billion people. Science 2010, 327, 812-818.

7. Qadir, M.; Noble, A.D.; Chartres, C. Adapting to Climate Change by Improving Water Productivity of Soils in Dry Areas. Land Degrad. Dev. 2013, 24, 12-21.

8. Schulte, R.P.O.; Creamer, R.E.; Donnellan, T.; Farrelly, N.; Fealy, R.; O’Donoghue, C.; O'hUallachain, D. Functional land management: A framework for managing soil-based ecosystem services for the sustainable intensification of agriculture. Environ. Sci. Policy 2014, $38,45-58$. 
9. OECD. Climate Change, Water And Agriculture: Towards Resilient Agricultural And Water Systems, COM/TAD/CA/ENV/EPOC(2013)21/FINAL, 2014.

10. European Commission. A Blueprint to Safeguard Europe's Water Resources, COM(2012) 673 final, Brussels, Belgium, 2012.

11. Nair, S.; Johnson, J.; Wang, C. Efficiency of Irrigation Water Use: A Review from the Perspectives of Multiple Disciplines. Agron. J. 2013, 105, 351-363.

12. Van Halsema, G.E.; Vincent, L. Efficiency and productivity terms for water management: A matter of contextual relativism versus general absolutism. Agric. Water Manag. 2012, 108, 9-15.

13. Kambou, D.; Xanthoulis, D.; Ouattara, K.; Degré, A. Concepts d'efficience et de productivité de l'eau (synthèse bibliographique). Biotechnol. Agron. Soc. Environ. 2014, 18, 108-120.

14. Boelens, R.; Vos, J. The danger of naturalizing water policy concepts: Water productivity and efficiency discourses from field irrigation to virtual water trade. Agric. Water Manag. 2012, 108, 16-26.

15. Berrittella, M.; Hoekstra, A.Y.; Rehdanz, K.; Roson, R.; Tol, R.S.J. The economic impact of restricted water supply: A computable general equilibrium analysis. Water Res. 2007, 41, 1799-1813.

16. González, J.F. Assessing the Macroeconomic Impact of Water Supply Restrictions through an Input-Output Analysis. Water Resour. Manag. 2011, 25, 2335-2347.

17. Luckmann, J.; Grethe, H.; McDonald, S.; Orlov, A.; Siddig, K. An integrated economic model of multiple types and uses of water. Water Resour. Res. 2014, 50, 3875-3892.

18. European Commission. Directive 2000/60/EC (Water Framework Directive); Official of the European Communities: Brussels, Belgium, 2000.

19. Johansson, R.C.; Tsur, Y.; Roe, T.L.; Doukkali, R.; Dinar, A. Pricing Irrigation Water: A review of theory and practice. Water Policy 2002, 4, 173-179.

20. Dinar, A. Water and Economy-Wide Policy Interventions. Found. Trends ${ }^{\circledR}$ Microecon. 2014, 10, 85-165, doi:10.1561/0700000059.

21. Wichelns, D. Do Estimates of Water Productivity Enhance Understanding of Farm-Level Water Management? Water 2014, 6, 778-795.

22. Perez Blanco, C.D.; Thaler, T. An Input-Output Assessment of Water Productivity in the Castile and León Region (Spain). Water 2014, 6, 929-944.

23. Hung, M.-F.; Shaw, D.; Chie, B.-T. Water Trading: Locational Water Rights, Economic Efficiency, and Third-Party Effect. Water 2014, 6, 723-744.

24. Zeng, X.; Li, Y.; Huang, G.; Yu, L. Inexact Mathematical Modeling for the Identification of Water Trading Policy under Uncertainty. Water 2014, 6, 229-252.

25. Galioto, F.; Raggi, M.; Viaggi, D. Pricing Policies in Managing Water Resources in Agriculture: An Application of Contract Theory to Unmetered Water. Water 2013, 5, 1502-1516.

26. Galioto, F.; Marconi, V.; Raggi, M.; Viaggi, D. An Assessment of Disproportionate Costs in WFD: The Experience of Emilia-Romagna. Water 2013, 5, 1967-1995.

27. Giraldo, L.; Cortignani, R.; Dono, G. Simulating Volumetric Pricing for Irrigation Water Operational Cost Recovery under Complete and Perfect Information. Water 2014, 6, 1204-1220. 
28. Mattas, C.; Voudouris, K.S.; Panagopoulos, A. Integrated Groundwater Resources Management Using the DPSIR Approach in a GIS Environment Context: A Case Study from the Gallikos River Basin, North Greece. Water 2014, 6, 1043-1068.

29. Asquer, A. Understanding Subjectivities in the Regulation of Local Water Services: A Q-Methodology Study of Elected Public Officers in Italy. Water 2014, 6, 670-693. 


\title{
1. Productivity Assessment
}

\section{Do Estimates of Water Productivity Enhance Understanding of Farm-Level Water Management?}

\section{Davide Viaggi, Giacomo Zanni and Meri Raggi}

\begin{abstract}
Estimates of water productivity are appearing with increasing frequency in the literature pertaining to agronomy, water management, and water policy. Some authors report such estimates as one of the outcome variables of experiment station studies, while others calculate water productivities when comparing regional crop production information. Many authors suggest or imply that higher values of water productivity are needed to ensure that future food production goals are achieved. Yet maximizing water productivity might not be consistent with farm-level goals or with societal objectives regarding water allocation and management. Farmers in both rainfed and irrigated settings must address a complex set of issues pertaining to risk, uncertainty, prices, and opportunity costs, when selecting activities and determining optimal strategies. It is not clear that farmers in either setting will or should choose to maximize water productivity. Upon examining water productivity, both conceptually and empirically, using published versions of crop production functions, I conclude that estimates of water productivity contain too little information to enhance understanding of farm-level water management.
\end{abstract}

Reprinted from Water. Cite as: Wichelns, D. Do Estimates of Water Productivity Enhance Understanding of Farm-Level Water Management? Water 2014, 6, 778-795.

\section{Motivation}

Many authors have called for improvements in water use efficiency or increases in water productivity in rainfed and irrigated settings, with the goal of increasing agricultural output to meet future food demands [1-5]. Some of the phrases that appear often in the agricultural and water management literature include the need to produce "more food with less water" and to generate "more crop per drop" [6-9]. The motivating rationale for such phrases is clear and legitimate. We must produce more food in future to support a larger global population. The competition for water is increasing in many sectors and water is a critical input in agriculture. Thus we must use the resource wisely to ensure that future generations will have access to reliable and affordable food supplies [10-15].

The notion of increasing crop water productivity is compelling at first glance, precisely because it suggests we need to generate more agricultural output per unit of the water input. Yet, focusing on water alone might not be sufficient to fully understand current crop production activities or to gain insight regarding the best measures for increasing crop yields or agricultural incomes in future.

Water is just one of many inputs in agriculture. Plant and crop responses to water generally depend on the availability of other inputs, such as nutrients, sunshine, and management effort [2,16-18]. Farmers seeking to increase crop yields or to achieve some other objective must optimize over an array of agricultural inputs, while considering also their market opportunities. In addition, farmers in 
both rainfed and irrigated settings must manage the risk and uncertainty inherent in their production activities, to determine optimal choices.

My goal in this paper is to consider whether estimates of crop water productivity are helpful in gaining a better understanding of water management in agriculture, and whether they are useful in evaluating crop production opportunities at the farm level. My primary concern is that estimates of crop water productivity lack the depth and breadth of information needed to understand a crop's response to water and a farmer's response to the natural, policy, and market environments in which he or she operates. By considering only one of many inputs, measures of crop water productivity omit much of the information that farmers consider and many of the issues that influence crop response to rainfall, irrigation, and cultural practices.

I hope also to motivate greater consideration of the risk and uncertainty many smallholder farmers face when making decisions regarding water and other inputs. In many developing countries, small-scale farmers struggle to gain access to irrigation water, to increase crop and livestock output, and enhance their livelihoods [19-23]. They operate in an environment of considerable risk and uncertainty. It is not clear that they could or should endeavor to maximize water productivity. Both farmers and policy makers must incorporate risk and uncertainty in their analyses of production opportunities and in decisions regarding natural resources.

I begin by describing measures of water productivity in the context of crop water production functions, with the goal of distinguishing between average and marginal measures of crop responses to farm inputs. Using published crop water production functions, I show that farmers seeking to maximize water productivity would generate less yield and smaller net income than if they sought to maximize net revenue. Thus, it is not clear that farmers would pursue the goal of maximizing water productivity, as proposed or implied by many authors. In cases in which water is limiting, relative to land, the profit-maximizing solution will be the same as that which maximizes the average productivity of water, but that is a special case result of the more general objective of maximizing net revenue.

I discuss also the random nature of measures of water productivity. Both the numerator and denominator of the estimated ratios contain deterministic and stochastic components. Crop yields and evapotranspiration are influenced by farmer decisions and input use, and also by random effects due to weather, pests, and disease. Thus, estimates of crop water productivity are random variables that represent point estimates from underlying probability distributions.

I also depict the challenge of comparing any two estimates of water productivity, whether they pertain to different settings or different times. The information contained in point estimates of water productivity is not sufficient for declaring that observations reflecting higher measures of water productivity should be preferred over those with lower measures. It is not clear that we gain helpful information or insight by comparing water productivities across locations or over time.

\section{Average vs. Marginal Productivity}

Crop water productivity, as defined by most authors, is the ratio of crop yield or crop value, to a selected measure of water consumed, applied, or evaporated in the process of growing a crop [2,24]. As such, the ratio represents the average productivity of the input, rather than the incremental 
productivity. For example, when the ratio of interest is the water productivity of applied water, the ratio often is defined as:

$$
\mathrm{WP}_{\mathrm{AW}}=\text { Crop yield }(\text { tons } / \text { ha }) / \text { Applied water }\left(\mathrm{m}^{3} / \mathrm{ha}\right)
$$

If the crop yield is 4 tons per ha and the applied water is $8000 \mathrm{~m}^{3}$ per ha, then the crop water productivity is 0.0005 tons per $\mathrm{m}^{3}$. In addition to neglecting consideration of other inputs, this measure of average productivity is not sufficient for determining whether the application rate of 8000 $\mathrm{m}^{3}$ per ha is optimal from the farm-level or societal perspective. The question of optimality can be addressed only by considering the marginal (or incremental) productivity of water, in comparison with its marginal cost. If the marginal productivity of water is 0.004 tons per $\mathrm{m}^{3}$, and the price of the crop is $\$ 1,000$ per ton, then the decision to apply the last $\mathrm{m}^{3}$ of water is sensible, provided the marginal cost of water is less than or equal to $\$ 4.00$ per $\mathrm{m}^{3}$.

The average and marginal productivities of water can be depicted readily in the context of a crop water production function. This context is helpful also for describing why average productivities are not sufficient for determining optimal levels of water use. A typical crop water production function resembles the following diagram, which describes crop yield as a function of applied water.

The slope of a ray from the origin, through any point on the production function, depicts the average productivity of that amount of applied water. For example, as depicted in Figure 1, the average productivity of $\mathrm{AW}_{1}\left(\mathrm{~m}^{3}\right.$ per ha) is calculated by dividing $\mathrm{Y}_{1}$ by $\mathrm{AW}_{1}$. That calculation is precisely the slope of the ray from the origin through the production function. Thus, the slope of the ray also represents the value of $\mathrm{WP}_{\mathrm{AW}}$ in this example, or the crop water productivity when applying $\mathrm{AW}_{1}$ units of water.

Beginning from $\mathrm{AW}_{0}$, the value of $\mathrm{WP}_{\mathrm{AW}}$ will increase with larger volumes of applied water, to a point, before beginning to decline. The point at which the value of $\mathrm{WP}_{\mathrm{AW}}$ reaches its maximum is precisely the point at which a ray from the origin is just tangent to the production function. This occurs where the amount of applied water is AW MAX (Figure 2). Beyond this level of applied water, the estimated water productivity will decline throughout the remaining range of applied water values. One can infer from the diagram that the point of maximum water productivity might be very different from the point of maximum crop yield. It might also be quite different from the point of maximum net revenue.

Figure 1. Depicting the water productivity of applied water in a typical crop water production function.

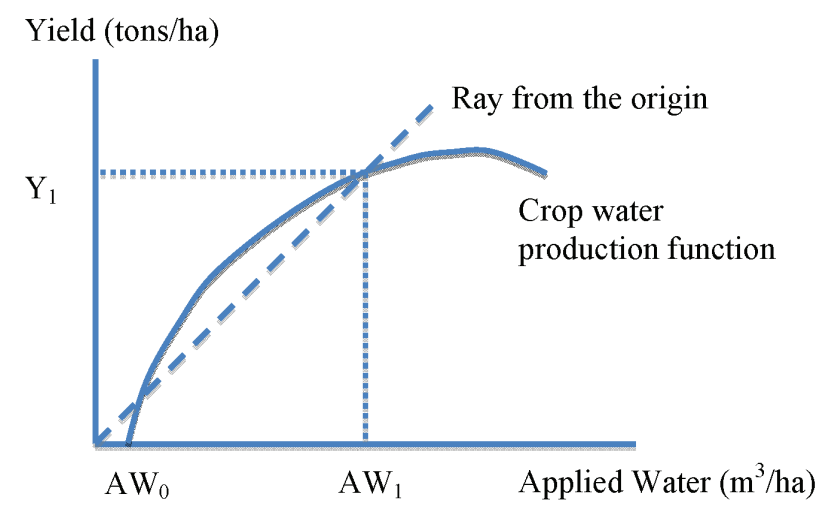


Figure 2. Depicting the maximum value of the water productivity of applied water.

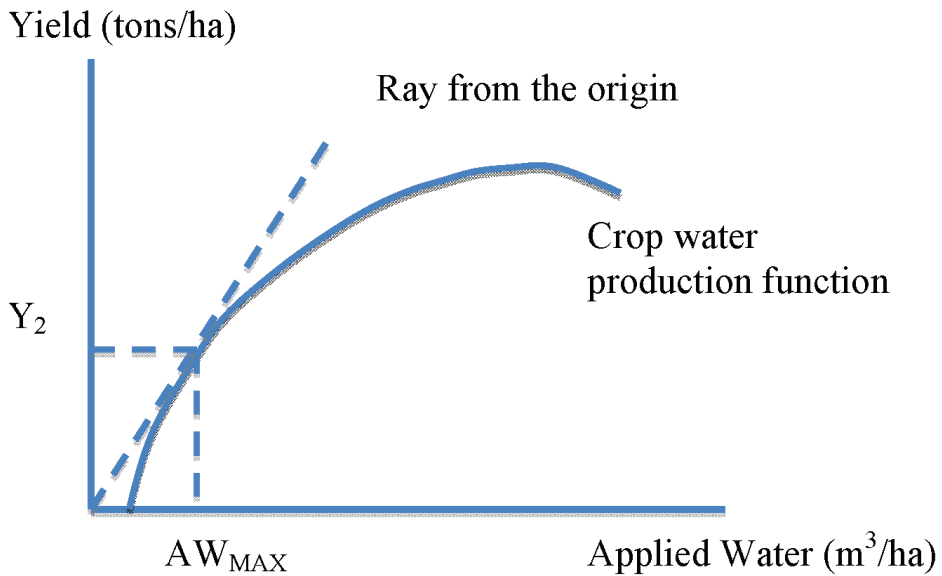

The profit-maximizing amount of applied water, $A W_{N R}$, is found where marginal revenue is equal to marginal cost. To determine this amount, we first transform the crop water production function into a crop revenue function by multiplying by crop price. The shape of the crop revenue function will be the same as the crop water production function. We can depict the total cost of water as a straight line from the origin, provided that the unit price of water is constant. As shown in Figure 3, the profit-maximizing amount of applied water is larger than the volume that would maximize water productivity, and yet smaller than the volume that would maximize crop yield. This will be the case for many crops in a range of settings. Indeed, there is no particular importance attached to the water volume that maximizes water productivity, or equivalently, the average productivity of water.

It is also worth noting that for a crop water production function that arises from the origin or has a positive intercept on the vertical axis, water productivity will decline throughout the entire range of volumes of applied water. In that case, it is easy to determine that maximizing water productivity would not be the appropriate optimizing criterion, as it would generate the recommendation of using zero applied water. Such a production function would pertain in cases in which rainfall is sufficient to generate some yield, but farmers apply supplemental irrigation water to enhance crop production. The water productivity of the applied irrigation water would decline throughout the range of applied water volumes.

Figure 3. Depicting the profit-maximizing amount of applied water.

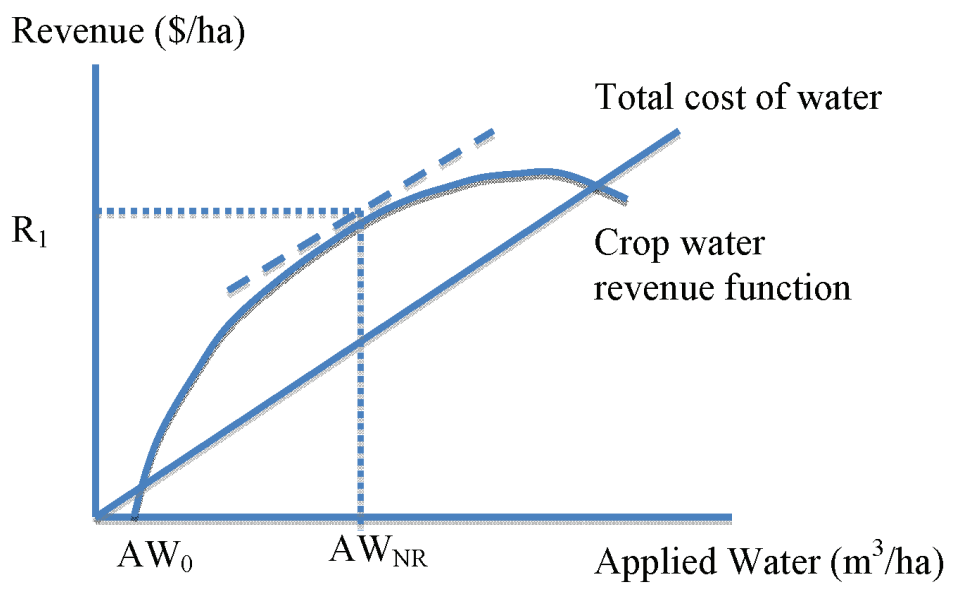




\section{Empirical Examples}

Several authors provide empirical examples of production functions that are useful in demonstrating the difference in outcomes when maximizing water productivity or maximizing crop yield or net revenue. Igbadun et al. [25] examined onion production in Nigeria. They presented the following estimated crop water production function in which the yield of onion bulbs is expressed as a function of seasonal applied water:

$$
\text { Yield (tons } / \text { ha) }=-14.88+0.131 \mathrm{AW}-0.0001 \mathrm{AW}^{2}
$$

The applied water variable, AW, is expressed in mm.

Given this empirical production function, farmers could maximize water productivity by applying $390 \mathrm{~mm}$ of irrigation water. The yield of onion bulbs would be 21 tons per ha and the water productivity would be $54 \mathrm{~kg}$ of onion bulbs per mm of applied water (Table 1). As noted above, this is equivalent to the average productivity of applied water.

Farmers could achieve the maximum yield of 28 tons per ha by applying $660 \mathrm{~mm}$ of irrigation water. The crop water productivity would decline to $42 \mathrm{~kg}$ per $\mathrm{mm}$ at maximum yield, but the farmers would be producing an additional 7 tons of onion bulbs per ha. Lacking a cost function, it is not possible to determine the profit-maximizing volume of applied water. However, we can expect that if onion production is profitable, the optimal volume of applied water will be between $390 \mathrm{~mm}$, where crop water productivity is maximum, and $660 \mathrm{~mm}$, where yield is maximum and the marginal productivity of water is zero.

Zhang and Oweis [26] examine durum wheat production in Syria, where farmers rely partly on rainfall and partly on supplemental irrigation. Their estimated production is the following:

$$
\text { Yield }(\text { tons } / \text { ha })=-5.8556+0.0329(\mathrm{AW}+\mathrm{P})-0.00002164(\mathrm{AW}+\mathrm{P})^{2}
$$

Both the supplemental irrigation (AW) and precipitation $(\mathrm{P})$ are expressed in $\mathrm{mm}$.

We determine the volumes of water that will maximize crop water productivity, yield, and net revenue, after choosing a seasonal precipitation level of $250 \mathrm{~mm}$. In such a season, farmers can maximize crop water productivity by applying an additional $270 \mathrm{~mm}$ of irrigation water (Table 1). The yield would be 5.4 tons of wheat per ha, and the crop water productivity would be $2.00 \mathrm{~kg}$ of wheat per $\mathrm{m}^{3}$ of applied water. The maximum wheat yield of 6.65 tons per ha can be achieved with supplemental irrigation of $510 \mathrm{~mm}$. Crop water productivity would decline to $1.30 \mathrm{~kg}$ per $\mathrm{m}^{3}$, but farmers would be producing an additional 1.25 tons of wheat per ha. 
Table 1. Examples of water levels that maximize water productivity, net revenue, and yields, from empirical crop water production functions.

\begin{tabular}{|c|c|c|c|c|c|}
\hline Citation & $\begin{array}{l}\text { Crop and } \\
\text { Location }\end{array}$ & $\begin{array}{c}\text { Applied Water } \\
(\mathbf{m m})\end{array}$ & $\begin{array}{l}\text { Yield } \\
\text { (t/ha) }\end{array}$ & $\begin{array}{c}\text { CWP } \\
\left(\mathrm{kg} / \mathrm{m}^{3}\right)\end{array}$ & $\begin{array}{c}\text { Net Rev. } \\
\text { (\$/ha) }\end{array}$ \\
\hline \multirow[t]{4}{*}{ Igbadun et al., 2012 [25] } & Onions, Nigeria & \multicolumn{4}{|c|}{$\mathrm{Y}=-14.88+0.131 \mathrm{AW}-0.0001 \mathrm{AW}^{2}$} \\
\hline & Max. CWP & 390 & 21.0 & 5.38 & 1709 \\
\hline & Max. Net Rev & $\mathrm{n} / \mathrm{a}$ & $\mathrm{n} / \mathrm{a}$ & $\mathrm{n} / \mathrm{a}$ & $\mathrm{n} / \mathrm{a}$ \\
\hline & Max. Yield & 660 & 28.0 & 4.24 & 2141 \\
\hline \multirow[t]{4}{*}{ Zhang and Oweis, 1999 [26] } & Wheat, Syria & \multicolumn{4}{|c|}{$\mathrm{Y}=-5.8556+0.0329(\mathrm{AW}+\mathrm{P})-0.00002164(\mathrm{AW}+\mathrm{P})^{2}$} \\
\hline & Max. CWP & 270 & 5.40 & 2.00 & 866 \\
\hline & Max. Net Rev & 454 & 6.58 & 1.45 & 1048 \\
\hline & Max. Yield & 510 & 6.65 & 1.30 & 1032 \\
\hline \multirow[t]{4}{*}{ Zhang et al., 1999 [27] } & Wheat, Syria & \multicolumn{4}{|c|}{$\mathrm{Y}=307+1.839 \mathrm{AW}-0.00402 \mathrm{AW}^{2}$} \\
\hline & Max. CWP & 0 & 3.07 & $\mathrm{n} / \mathrm{a}$ & 491 \\
\hline & Max. Net Rev & 195 & 5.13 & 2.63 & 737 \\
\hline & Max. Yield & 230 & 5.17 & 2.25 & 729 \\
\hline
\end{tabular}

Notes: CWP refers to crop water productivity, which is defined as yield divided by applied water, and expressed in $\mathrm{kg} \mathrm{per}^{3}$. In the example of Zhang and Oweis (1999) [27], we assume seasonal rainfall of $250 \mathrm{~mm}$.

Zhang and Oweis [26] provide cost information that enables us to determine the profit-maximizing amount of supplemental irrigation. In a season with $250 \mathrm{~mm}$ of rainfall and a wheat price of $\$ 0.25$ per $\mathrm{kg}$, farmers would maximize profit by applying $454 \mathrm{~mm}$ or supplemental irrigation, generating a wheat yield of 6.58 tons per ha. Crop water productivity would be $1.45 \mathrm{~kg}$ per $\mathrm{m}^{3}$. As expected, this profit-maximizing result lies between the volumes of water that maximize water productivity and crop yield. The difference in profit between the water applications that maximize crop water productivity and net revenue is $\$ 182$ per ha.

Zhang et al. [27] provide an empirical production function for winter wheat in China, which has a positive intercept on the yield axis. Given this characteristic, as noted above, crop water productivity will decline throughout all values of applied water. The estimated production is the following:

$$
\text { Yield }\left(\mathrm{g} / \mathrm{m}^{2}\right)=307+1.839 \mathrm{AW}-0.00402 \mathrm{AW}^{2}
$$

Farmers wishing to maximize crop water productivity would abstain from irrigating, thus obtaining a yield of $307 \mathrm{~g}$ per $\mathrm{m}^{2}$, or 3.07 tons per ha. Crop water productivity is not defined at the value of zero $\mathrm{mm}$ of irrigation water. Yet the pertinent point is that water productivity declines for any positive value of applied water. Farmers could achieve the maximum yield of 5.2 tons per ha by applying $230 \mathrm{~mm}$ of irrigation water (Table 1). Farmers wishing to maximize net revenue would apply $195 \mathrm{~mm}$ of irrigation water, thus generating a yield of 5.1 tons per ha and obtaining a profit of $\$ 737$ per ha. Here again, the profit-maximizing volume of applied water lies between the volumes that maximize water productivity and crop yield. 


\section{A Special Case}

The above examples demonstrate empirically that farmers applying irrigation water would not have an interest in maximizing water productivity, as that strategy would not maximize yields or net revenue. Yet there is a special case in which the goal of maximizing net revenue generates a strategy that involves maximizing the average productivity of water. In particular, when water is limiting, relative to land, the profit maximizing solution will be the same as that which maximizes water productivity.

We can demonstrate this result using the empirical production function for maize, presented by Zand-Parsa and Sepaskhah [28], in which maize yield is a function of nitrogen and irrigation water:

$$
\begin{gathered}
\text { Yield (tons/ha) }=\mathrm{a}_{0}+\mathrm{a}_{1} \times \mathrm{W}+\mathrm{a}_{2} \times \mathrm{W}^{2}+\mathrm{a}_{3} \times\left(\mathrm{N}+\mathrm{N}_{\mathrm{r}}\right)+\mathrm{a}_{4} \times\left(\mathrm{N}+\mathrm{N}_{\mathrm{r}}\right)^{2}+\mathrm{a}_{5} \times(\mathrm{W})(\mathrm{N}+ \\
\left.\mathrm{N}_{\mathrm{r}}\right)+\mathrm{a}_{6} \times(\mathrm{W})\left(\mathrm{N}+\mathrm{N}_{\mathrm{r}}\right)^{2}+\mathrm{a}_{7} \times\left(\mathrm{W}^{2}\right)\left(\mathrm{N}+\mathrm{N}_{\mathrm{r}}\right)+\mathrm{a}_{8} \times\left(\mathrm{W}^{2}\right)\left(\mathrm{N}+\mathrm{N}_{\mathrm{r}}\right)^{2}
\end{gathered}
$$

In this equation, $\mathrm{W}$ represents the depth of irrigation water applied $(\mathrm{m}), \mathrm{N}$ is nitrogen applied ( $\mathrm{kg}$ per ha), and $\mathrm{N}_{\mathrm{r}}$ is residual nitrogen in the soil before planting ( $\mathrm{kg}$ per ha). The empirical values of the coefficients a0 through as are $-1.862,6.0386,-3.580,-0.178,0.0005,0.5733,-0.00148$, -0.3021 , and 0.000806 . The assumed value of $\mathrm{N}_{\mathrm{r}}$ is $54.6 \mathrm{~kg}$ per ha. The prices in the original analysis of Zand-Parsa and Sepaskhah [28] for output, water, and nitrogen are \$200 per ton, \$31 per m $\left(\$ 0.003\right.$ per $\mathrm{m}^{3}$ ), and $\$ 0.13$ per $\mathrm{kg}$, respectively.

In the standard case, in which water is plentiful, but the farmer's land is limited, the profit maximizing levels of water and nitrogen are $990 \mathrm{~mm}$ and $212 \mathrm{~kg}$ per ha (Table 2). As expected, the net revenue of $\$ 2,556$ per ha is larger than the net revenue that would be achieved if the farmer chose to maximize water productivity. Given that goal, the farmer would apply $723 \mathrm{~mm}$ of irrigation water and $207 \mathrm{~kg}$ per ha of nitrogen, while earning net revenue of \$2,152 per ha.

Table 2. Optimizing water and nitrogen applications for maize, when either land or water

\begin{tabular}{|c|c|c|c|c|c|c|}
\hline Citation & $\begin{array}{l}\text { Crop and } \\
\text { Location }\end{array}$ & $\begin{array}{l}\text { Applied Water } \\
(\mathbf{m m})\end{array}$ & Applied N (kg/ha) & Yield (t/ha) & $\begin{array}{c}\text { CWP } \\
\text { (tons/m) }\end{array}$ & $\begin{array}{l}\text { Net Rev. } \\
\text { (\$/ha) }\end{array}$ \\
\hline [28] & Maize, Iran & \multicolumn{5}{|c|}{$\begin{aligned} \text { Yield }(\mathrm{t} / \mathrm{ha})= & \mathrm{a}_{0}+\mathrm{a}_{1} \times \mathrm{W}+\mathrm{a}_{2} \times \mathrm{W}^{2}+\mathrm{a}_{3} \times\left(\mathrm{N}+\mathrm{N}_{\mathrm{r}}\right)+\mathrm{a}_{4} \times\left(\mathrm{N}+\mathrm{N}_{\mathrm{r}}\right)^{2}+\mathrm{a}_{5} \times(\mathrm{W})\left(\mathrm{N}+\mathrm{N}_{\mathrm{r}}\right)+ \\
& \mathrm{a}_{6} \times(\mathrm{W})\left(\mathrm{N}+\mathrm{N}_{\mathrm{r}}\right)^{2}+\mathrm{a}_{7} \times\left(\mathrm{W}^{2}\right)\left(\mathrm{N}+\mathrm{N}_{\mathrm{r}}\right)+\mathrm{a}_{8} \times\left(\mathrm{W}^{2}\right)\left(\mathrm{N}+\mathrm{N}_{\mathrm{r}}\right)^{2}\end{aligned}$} \\
\hline \multirow{3}{*}{$\begin{array}{l}\text { Land is } \\
\text { limiting }\end{array}$} & Max. CWP: & 723 & 207 & 11.0 & 15.2 & 2,152 \\
\hline & Max. Net Rev: & 990 & 212 & 13.1 & 13.2 & 2,556 \\
\hline & Max. Yield: & 1,000 & 212 & 13.1 & 13.1 & 2,555 \\
\hline \multirow{3}{*}{$\begin{array}{l}\text { Water is } \\
\text { limiting }\end{array}$} & Max. CWP: & 723 & 207 & 11.0 & 15.2 & 2,152 \\
\hline & Max. Net Rev: & 723 & 207 & 11.0 & 15.2 & 2,152 \\
\hline & Uniform water: & 567 & 254 & 8.2 & 14.5 & 1,588 \\
\hline
\end{tabular}
is the limiting input.

Notes: CWP refers to crop water productivity, which is defined as yield divided by applied water, and expressed in tons per $\mathrm{m}^{3}$. CWP refers to crop water productivity, which is defined as yield divided by applied water, and expressed in tons per $\mathrm{m}^{3}$. In the uniform water example, we assume the famer has the equivalent of $1.7 \mathrm{~m}$ of irrigation water available and 3.0 ha of land that are available for cultivation. The optimal amount of land to plant and irrigate is $2.35 \mathrm{ha}$, while the optimal amounts of applied water and nitrogen are those shown in the table. 
When water is limiting, relative to land, the amount of irrigation water that maximizes profit is the same as that which maximizes water productivity. Thus, the farmer would choose to apply $723 \mathrm{~mm}$ of irrigation water, while leaving some land idle. For example, suppose a farmer has 3.0 ha of land available, but only the equivalent of $1.7 \mathrm{~m}$ of irrigation water available. The farmer could plant all 3 ha in maize and apply $567 \mathrm{~mm}$ of irrigation water on those planted hectares. If the farmer also applies $254 \mathrm{~kg} / \mathrm{ha}$ of nitrogen, he or she will achieve a yield of 8.2 tons/ha, while generating a net revenue of $\$ 1,588$ per ha, or $\$ 4,764$ per season for the farm (Table 2). By contrast, if the farmer plants only 2.35 ha in maize and applies $723 \mathrm{~mm}$ of water and $207 \mathrm{~kg} / \mathrm{ha}$ of nitrogen on those hectares, he or she will generate a net revenue of $\$ 2,152$ per cultivated ha, or $\$ 5,057$ for the farm.

This empirical example applies to situations in which water is limiting, relative to land. In such cases, the profit maximizing amount of land in cultivation can be determined by dividing the amount of water available by the amount of water per hectare that maximizes average productivity. In this example, the area of 2.35 ha can be determined by dividing the $1.7 \mathrm{~m}$ available by the $0.723 \mathrm{~m}$ at which water productivity is maximized. Thus, the strategy of maximizing water productivity in this instance is a special case result of the broader economic objective of maximizing profit.

\section{The Productivity of Water Evapotranspired}

The production functions examined above depict the empirical relationship between crop yield and applied water. The curvature of each function reflects the diminishing and eventually negative incremental returns to applied water, as some of the water is not used productively by the plants. Functions describing crop yield or biomass as an outcome of evapotranspiration (ET) are essentially linear, for a given production setting [24,29,30]. Thus, additional evapotranspiration generates additional yield at a rate that is essentially constant. Despite this constant rate of transformation, estimated values of water productivity can increase, decline, or remain the same, as the volume of water evapotranspired increases.

Linear segments depicting crop yield as a function of evapotranspiration cannot intercept the vertical axis, as it is not possible to achieve a positive yield with no ET. Yet one can project where the vertical axis intercept would occur, if the linear segment were extended to the axis. Such an exercise is helpful in determining whether water productivity will increase or decrease at higher levels of ET for a given crop-ET relationship.

For example, if the linear segment depicting crop yield as a function of ET projects a positive vertical axis intercept, the empirical value of crop water productivity will decline as ET increases. This can be verified by noting that the slope of a ray from the origin through a point on the production function diminishes at higher levels of ET (Figure 4). By analogy, if the linear segment depicting crop yield as a function of ET projects a negative vertical axis intercept, the empirical value of crop water productivity will increase as ET increases (Figure 5). If the linear segment happens to be coincident with a 45-degree ray from the origin, the value of crop water productivity will be the same for all amounts of evapotranspiration.

Given that water productivity can increase or decrease monotonically along the linear segment depicting crop yield as a function of ET, it is not clear that the objective of increasing or maximizing water productivity, with respect to ET, is pertinent. If the empirical relationship between yield and 
ET resembles the one in Figure 4, water productivity will be maximized at the smallest amount of ET. Yet that level would also generate the smallest yield. By contrast, if the empirical relationship resembles Figure 5, there is no apparent upper bound to the value of water productivity. Higher measures of water productivity can be achieved at ever higher levels of ET. Such a relationship is not helpful in determining the optimal amount of evapotranspiration at the farm level.

Figure 4. Depicting crop water productivity of evapotranspired (ET) water, when the linear segment projects a positive vertical axis intercept.

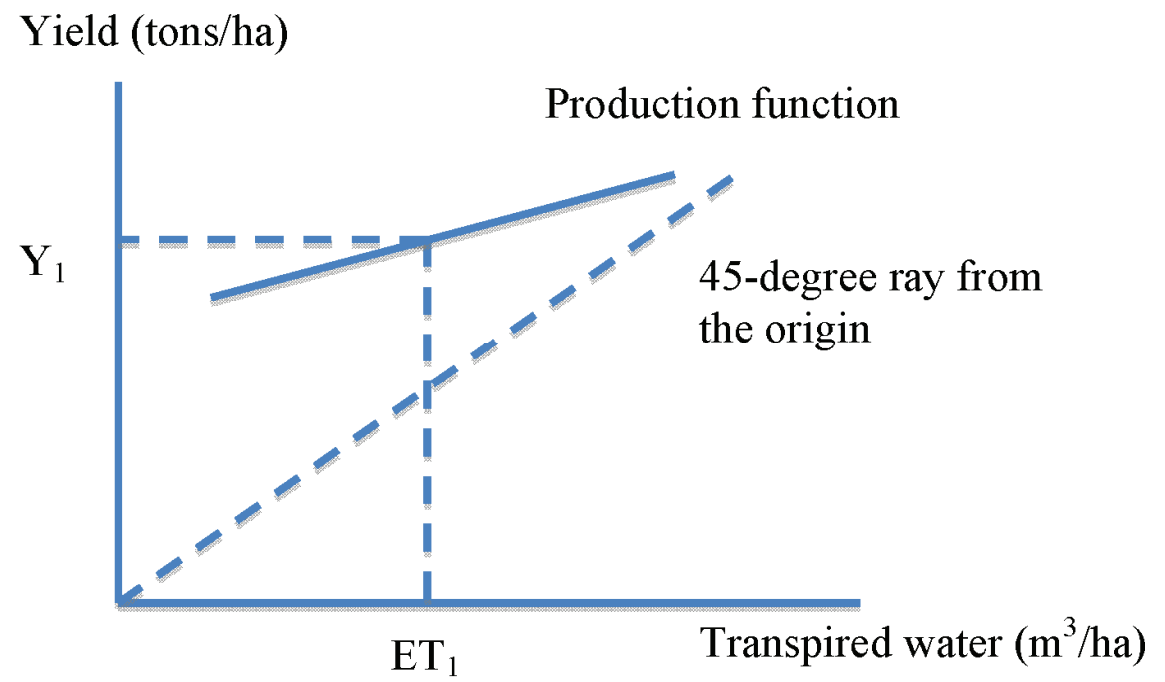

Figure 5. Depicting crop water productivity of evapotranspired water, when the linear segment projects a negative vertical axis intercept.

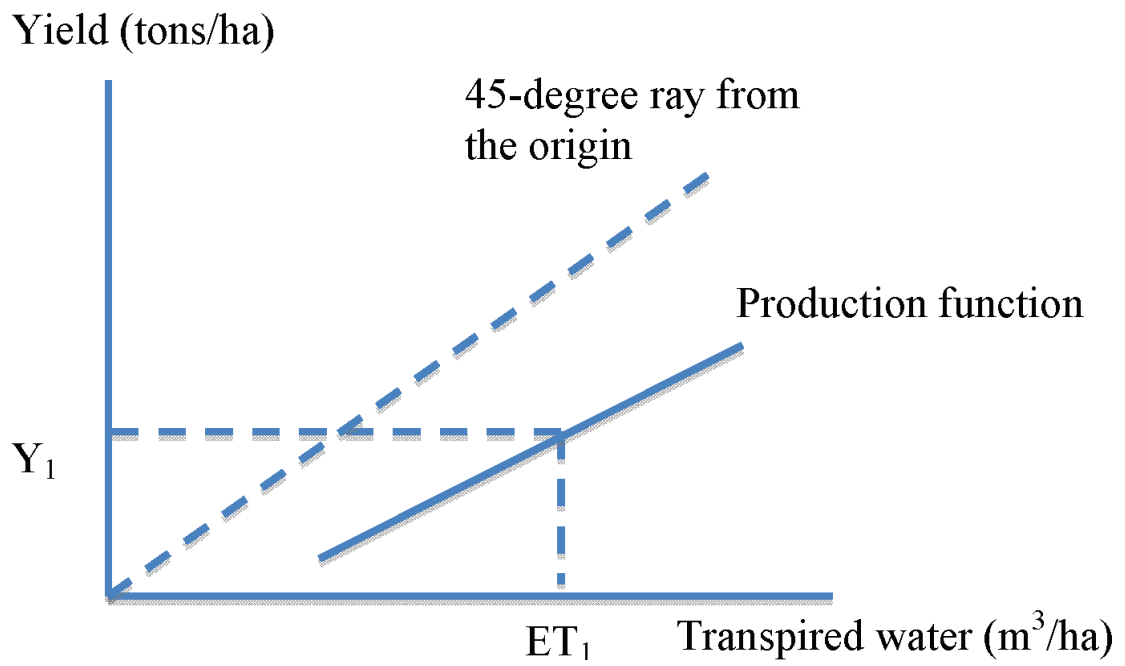

Empirical examples of linear relationships involving crop yield and ET are presented in Table 3. Three of these examples project a negative vertical intercept, while one projects a positive intercept. The $\mathrm{R}^{2}$ values for these estimated relationships are higher than some others that appear in the literature, in part because the equations are estimated using relatively small numbers of observations. In larger scale studies, the scatter of observations is substantial, such that the measures of $\mathrm{R}^{2}$ are much smaller. Depictions of linear yield-ET relationships for wheat, rice, cotton, and maize in Zwart and 
Bastiaanssen [24] carry $\mathrm{R}^{2}$ values ranging from 0.09 to 0.39 . Those authors acknowledge that the empirical description of crop yield and ET in any setting is determined by "many factors that influence the soil-plant-water relationship."

Table 3. Examples of linear crop production functions expressing yield as a function of evapotranspiration (ET).

\begin{tabular}{ccc}
\hline Citation & Crop and Location & Estimated Production Function and R \\
\hline Zhang and Oweis, 1999 [26] & Bread wheat, Syria & $\begin{array}{c}\mathrm{Y}=-2.4969+0.016 \mathrm{ET} \mathrm{R}^{2}=0.68 \\
\text { Yield is in tons per ha, ET is in mm. }\end{array}$ \\
\hline Zhang and Oweis, 1999 [26] & Durum wheat, Syria & $\begin{array}{c}\mathrm{Y}=-0.1093+0.116 \mathrm{ET} \mathrm{R} \mathrm{R}^{2}=0.68 \\
\text { Yield is in tons per ha, ET is in mm. }\end{array}$ \\
\hline Karam et al., 2009 [31] & Wheat, Lebanon & $\begin{array}{c}\mathrm{Y}=1364.6+5.0601 \mathrm{ET} \mathrm{R}^{2}=0.60 \\
\text { Yield is in kg per ha, ET is in mm. }\end{array}$ \\
\hline Igbadun et al., 2012 [25] & Onions, Nigeria & $\begin{array}{c}\mathrm{Y}=-0.4956+0.052 \mathrm{ET} \mathrm{R}^{2}=0.87 \\
\text { Yield is in tons per ha, ET is in mm. }\end{array}$ \\
\hline
\end{tabular}

Notes: Estimates of crop water productivity will diminish with increasing values of ET for the estimated functions that project a positive intercept. Measures of crop water productivity will increase with increasing values of ET for the estimated functions that project a negative intercept.

\section{Estimates of Water Productivity are Random Variables}

Crop yield is a random variable in both rainfed and irrigated settings. So too is soil moisture, at any point in time, or as measured cumulatively throughout a season. Thus, the ratio representing water productivity, whether defined as biomass, crop yield, or revenue per unit of water applied or consumed, is essentially a ratio involving two random variables. Farmers certainly can influence the yields they achieve each season through their choices and timing of crop inputs, such as water, nutrients, pesticides, and labor, but the yields they obtain are random draws from a probability distribution. The same is true for soil moisture.

Farmers with access to irrigation can modify soil moisture to some degree, but they cannot determine with certainty the amount of moisture available to a plant or the amount of moisture the plant takes up. Nonetheless, farmers with irrigation can notably influence plant growth and crop yield. Farmers lacking irrigation can manage soil moisture through their choices of crops and varieties, soil preparation, planting dates, plant densities, and cultural practices [32-35], but they generally cannot supplement soil moisture autonomously. For both groups of farmers, the amount of soil moisture available at any point in time, and the uptake of soil moisture by plants, are random draws from probability distributions.

Given that measures of water productivity are ratios of two random variables, it is not clear how much influence farmers can exert on the empirical values observed on farms or computed across agricultural areas. Thus, the seemingly compelling goal of increasing water productivity might have limited relevance in most agricultural settings. Rather than attempting to increase water productivity, farmers might endeavor instead to reduce the variance in crop yields and soil moisture, while also increasing the mean values of crop yields, over time, in part by gaining greater influence over the seasonal pattern of soil moisture. Many farmers, particularly those in rainfed settings, likely already 
adopt such a management objective, either explicitly or implicitly. It is not possible to farm successfully in rainfed settings without paying close attention to soil moisture conditions, and managing accordingly.

Farmers in rainfed and partially irrigated settings can reduce the variance and increase the mean of their crop yields by investing in measures that modify soil moisture availability [36,37]. Farmers who capture rainwater in a small pond for irrigation, or pump groundwater from a shallow aquifer, can manage the amount of soil moisture available during crop growth and reproductive stages. They have the options of stimulating rapid growth of the plant canopy early in the season to reduce evaporation, and applying supplemental water during particularly dry stretches of a crop production cycle [38].

The actions taken by farmers to modify soil moisture might cause the observed value of water productivity to increase or decrease, depending on the final measured values of crop yields and water applied or consumed. Given the random nature of both outcomes, and interactions with other inputs, it is not possible to know in advance the eventual measure of water productivity. Yet the farmers will have made better use of the water within their control, by modifying the pattern of soil moisture to match crop water demands, and by striving to maximize transpiration while minimizing nonbeneficial evaporation.

\section{Comparing Estimates of Water Productivity}

Many authors compare estimates of water productivity, over time or in selected locations. Examples include the comprehensive review by Zwart and Bastiaanssen [24] and smaller, regional reviews by Hussain et al. [39] and Yan and $\mathrm{Wu}$ [40]. One goal of such studies is to highlight differences in crop water productivities that might provide insight regarding policy measures or technological interventions that might improve water management and thus lead to greater output per unit of water used in agriculture. This goal is compelling, yet it is not clear if the comparisons provide sufficient information to enhance understanding of the underlying issues that generate the observed values of water productivity.

Recalling the framework presented above, we can depict observations of water productivity in coordinate space defined either by crop yields and applied water, or by crop yields and ET, or water consumed. Choosing the first of these, suppose we observe three estimates of water productivity, perhaps in three locations or on three farms. We can represent these observations as points A, B, and $\mathrm{C}$ in Figure 6. Recalling that the slope of a ray from the origin, through each point, depicts the water productivity for each, we can readily observe that the water productivity for observation A is greater than that for observation B, which is greater than that for observation C. A strict preference for points reflecting higher water productivity would result in the choice of Point $\mathrm{A}$ as most desirable. Yet that choice might be inappropriate. Observing the points, alone, does not provide information regarding the underlying production functions. It is possible that any of the points represents an inefficient use of water, or that all points represent efficient use. We need to know more about the production setting to determine which point or points might be desirable.

Suppose the underlying production functions are those depicted in Figure 7. It would appear that the production situation at Point A is least desirable, as Point A lies to the right of the point of 
maximum yield. Thus, the same amount of yield could be generated with less applied water. Point B might also be inefficient, as it appears production is very close to the point of maximum yield. If there is a positive opportunity cost of the applied water, it is likely that the incremental cost exceeds the incremental again at Point $\mathrm{B}$. It is therefore possible that Point $\mathrm{C}$ is the most desirable point of those depicted in Figure 7, even though the estimated water productivity at that point is the smallest.

Figure 6. Comparing observations of water productivity, with respect to applied water.

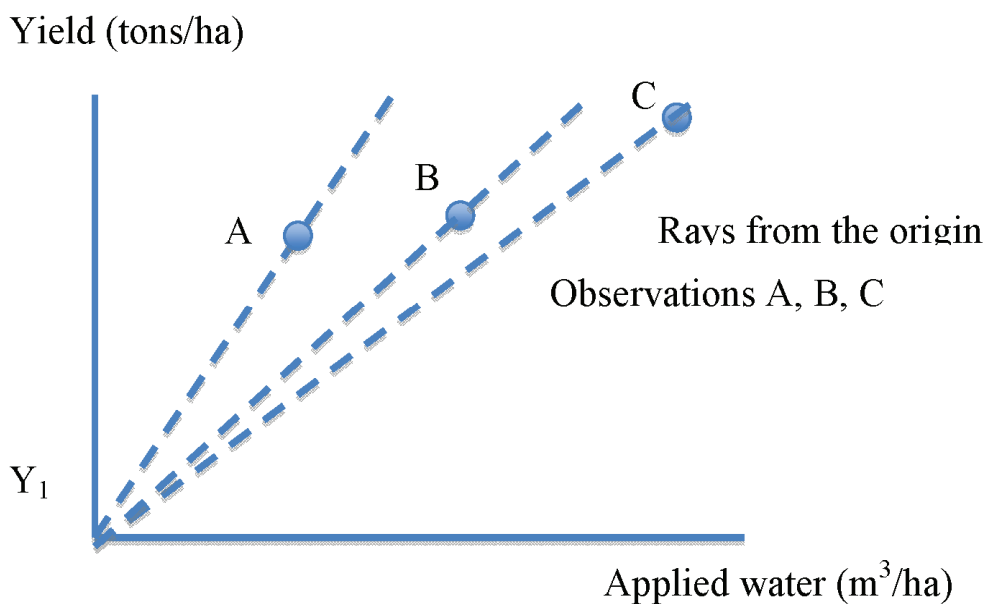

Figure 7. Considering the underlying production functions.

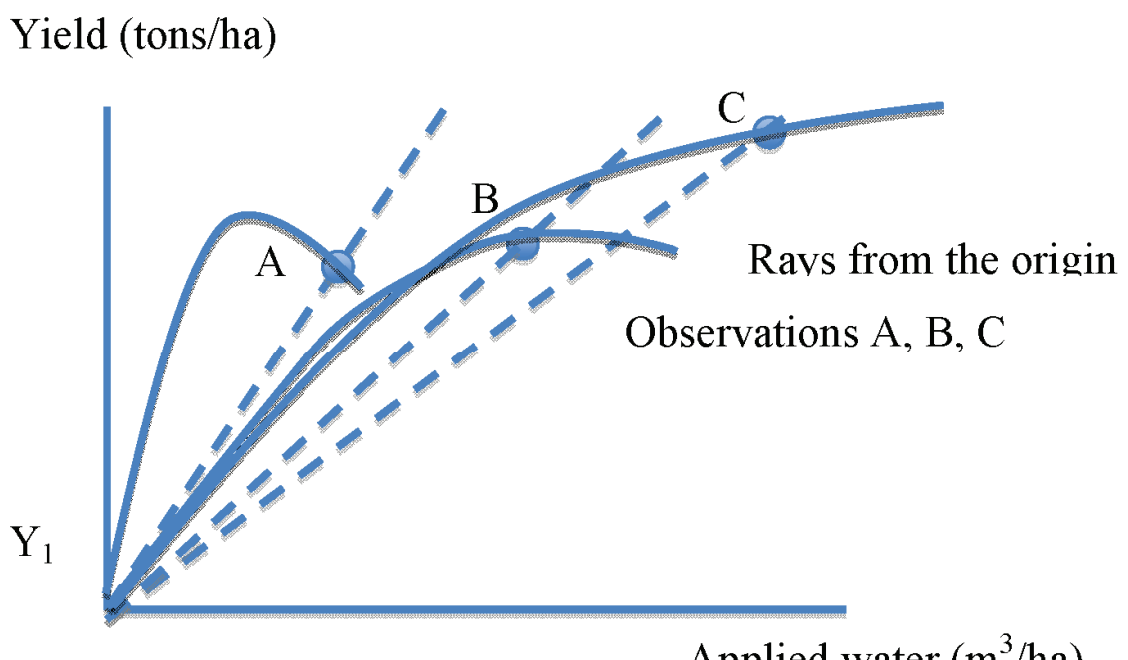

Applied water $\left(\mathrm{m}^{3} / \mathrm{ha}\right)$

This is just one of many possible depictions of the underlying production functions that might generate the observations represented by Points A, B, and C. Differences in climate, soils, irrigation systems, and human capital can generate an array of empirical production functions within a given region. Observed values of crop yields might lie on the same function, or they might all lie on different functions, as depicted in Figure 7. In any event, it is not possible to evaluate the desirability of Points A, B, and C using only the measure of water productivity. This perspective can be demonstrated also in yield-ET space.

Suppose we observe three production situations, depicted as Points A, B, and C in Figure 8. We can see by inspection that Point A has the highest measure of water productivity, followed by 
Point B, and then Point C. Yet we could not conclude that Point A is preferable, without knowing the incremental costs and benefits of moving from Point A to Point B. If the incremental cost of providing the additional ET is less than the incremental gain, Point B would be preferred to Point A. The same analysis pertains to the potential move from Point $\mathrm{B}$ to Point $\mathrm{C}$. The information provided by the estimated water productivity is not sufficient for determining which of these points is best from either the farm-level or societal perspective.

It is quite possible also that we observe situations in which farmers are operating on different production functions, due to differences in the amount or quality of the other, non-water inputs available to them. For example, farmers with better access to high-quality seeds, fertilizer, and pesticides will have the ability to generate higher yields per unit of transpired water. Their production functions will lie above those pertaining to farmers with limited access or with less financial ability to purchase and apply complementary inputs in a timely fashion. This information, while pertinent to discussions of agricultural policy and livelihoods, will not be reflected in estimates of water productivity.

Figure 8. Comparing observations of water productivity, with respect to ET.

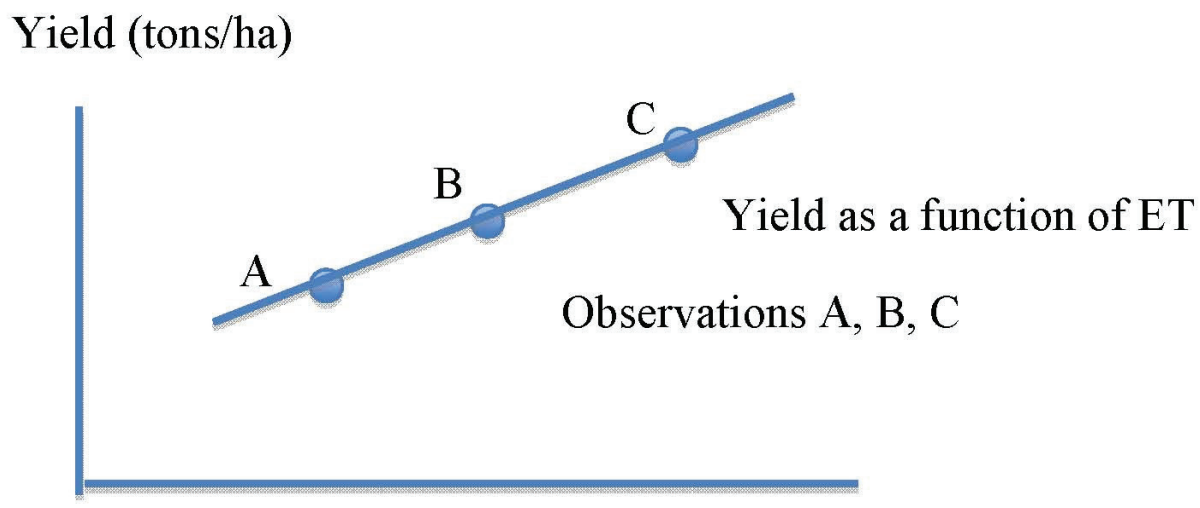

\section{Evapotranspired water $\left(\mathrm{m}^{3} / \mathrm{ha}\right)$}

We might observe points such as those depicted in Figure 8, yet they might lie along different production functions, as depicted in Figure 9. The policy challenges implied by these depictions are different. In the case of Figure 8, the challenge is to determine whether or not additional transpiration is desirable, and then how to motivate greater use of water per hectare. The challenge implied by Figure 9 is that of determining how to motivate farm-level shifts in the yield-ET function. Investments in efforts to provide farmers with more affordable access to complementary inputs might be among the pertinent policy actions. 
Figure 9. Comparing observations of water productivity, with respect to ET.

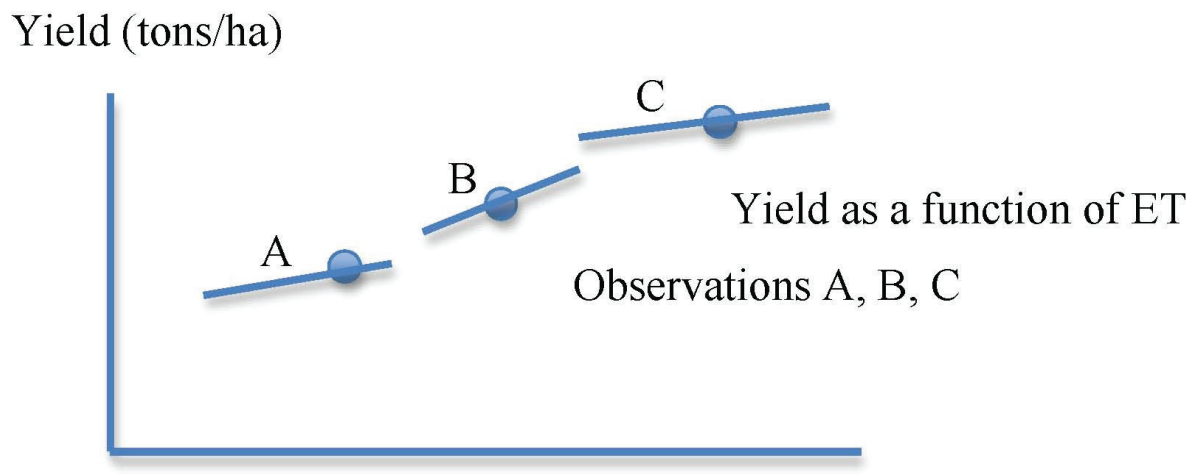

Evapotranspired water $\left(\mathrm{m}^{3} / \mathrm{ha}\right)$

The situation depicted in Figure 9 suggests also that estimates of water productivity from different points in time must be interpreted with care. Over time, with improvements in agricultural technology and human capital, we expect to see crop water production functions shift upward. As this occurs, it is likely that transpiration rates per hectare also will increase, coincident with higher crop yields. Observations such as Point $\mathrm{C}$ in Figure 9 likely will replace observations such as Points A and B. As depicted in Figure 9, the higher output per hectare comes at the cost of greater evapotranspiration per hectare, such that the measure of water productivity is smaller. Yet the value of the additional output might exceed the opportunity cost of the additional water evapotranspired. In the future, we might aspire to observe yield-ET combinations that lie above and to the left of Point B, if advances in plant genetics enable the production of higher yields with less evapotranspiration.

\section{An Empirical Example}

Li and Barker [41] describe the higher crop yields and improvements in water management made possible by the alternate wetting and drying method of rice irrigation (AWD), in which the soil is allowed to dry between irrigation events. The authors suggest that water deliveries and losses to percolation and seepage are reduced when using the alternate wetting and drying method. They provide estimates of crop water productivity for traditional and AWD irrigation in four provinces of China. Those data are helpful in depicting the difficulty in gaining insight when comparing estimates of crop water productivity over time, locations, and crop types.

The data in Table 4 were compiled originally by authors other than Li and Barker [41]. Thus, it is not possible to know the numbers of observations that generate each value in Table 4 or to know the characteristics of the underlying distributions. Yet, taken on face value, the data reflect several interesting comparisons, within and across provinces, and over time. For example, in Hubei, the yield of traditional, middle-season rice in 1998 was higher than the yield of traditional, early-season rice in 1997, and yet the estimated water productivity is higher in 1997. Similarly, in Zhejiang, the yield of traditional, late-season rice is higher than the yield of traditional, early-season rice in 1998, yet the estimated water productivity is higher for the early-season rice. These are certainly plausible observations. The question is whether or not the estimates of water productivity are helpful in determining which production setting is better, or which should be preferred over the other. 
Table 4. Rice yields and estimates of farm-level water productivity for rice, irrigated with traditional methods and using alternate wetting and drying. Source: This table is reproduced from the paper by Li and Barker (2004) [41].

\begin{tabular}{ccccccc}
\hline \multirow{2}{*}{ Province } & \multirow{2}{*}{ Year } & Rice Type & \multicolumn{2}{c}{ Yield (kg/ha) } & \multicolumn{2}{c}{$\mathbf{C W P}\left(\mathbf{k g} / \mathbf{m}^{\mathbf{3}}\right)$} \\
\cline { 3 - 7 } & & (season) & Traditional & AWD & Traditional & AWD \\
\hline \multirow{2}{*}{ Hubei } & 1997 & Early & 5,438 & 6,393 & 0.889 & 1.183 \\
& 1998 & Middle & 7,767 & 8,790 & 0.856 & 1.122 \\
\hline \multirow{2}{*}{ Guangxi } & 1980 & Early & 6,975 & 7,518 & 1.333 & 1.688 \\
& 1980 & Early & 6,876 & 7,242 & 1.217 & 1.519 \\
\hline \multirow{2}{*}{ Shandong } & 1986 & Middle & 8,799 & 9,954 & 1.006 & 1.419 \\
& 1989 & Middle & 8,242 & 10,359 & 0.853 & 1.858 \\
\hline \multirow{2}{*}{ Zhejiang } & 1998 & Early & 6,075 & 6,746 & 1.168 & 1.775 \\
& 1998 & Late & 6,363 & 6,746 & 0.994 & 1.599 \\
\hline
\end{tabular}

Notes: AWD refers to the alternate wetting and drying method of irrigating rice, in which the soil is allowed to dry between irrigations. Crop water productivity in this table, as described by the original authors, pertains to ET plus percolation. AWD can reduce percolation substantially.

Looking across provinces, the yields of traditional rice are higher in Shandong than in Guangxi, yet the estimates of water productivity are higher for Guangxi. Lacking information regarding the opportunity cost of water in the two provinces and the costs of other, complementary inputs, it is not possible to determine if the higher values of water productivity in Guangxi are meaningful from a policy perspective. Similarly, the yields of AWD rice in Zhejiang are smaller than in Guangxi, yet the estimates of water productivity are higher for Zhejiang.

The yields and water productivities for AWD rice generally are higher than the yields and productivities for traditionally irrigated rice (Table 4). Yet without information describing the incremental costs and benefits associated with the change in water management, it is not possible to know if the higher yields and water productivities are desirable. For example, if weeding costs are higher or more pesticides are needed when using alternate wetting and drying, the incremental cost of achieving higher yields might negate the value of the incremental gain. In any event, it is not possible to derive helpful conclusions from the limited information presented in Table 4. Much more is needed, regarding the opportunity costs of key inputs and the stochastic nature of crop yields, rainfall, percolation, ET, and the resulting estimates of water productivity.

\section{Summing Up}

The motivation for increasing water productivity is well-stated and compelling. With increasing competition for freshwater resources, farmers, researchers, and public officials must continuously pursue opportunities to improve agricultural productivity, while promoting also the wise use of renewable and non-renewable resources. Estimates of water productivity seem pertinent, particularly in water scarce areas. It is indeed compelling to think about increasing the returns per unit of water consumed in agriculture. Yet estimates of water productivity, by themselves, do not provide the information needed to fully understand the production opportunities, constraints, and livelihood 
considerations that determine farm input choices and the resulting probabilistic distributions of crop and livestock output.

Many authors compare estimates of water productivity across locations and over time. Yet the estimates are point observations, calculated by dividing some measure of crop or livestock production by some measure of water applied or consumed. It is not possible to derive helpful insight from such comparisons, without knowing much more about the production settings, the availability of complementary inputs, the distribution of rainfall, and the risk and uncertainty farmers face when making decisions regarding crop choices, input levels, and markets. We need also to know more about the incremental costs and gains of water use in each setting, rather than simply comparing measures of average productivity.

In summary, estimates of water productivity do not enhance understanding of farm-level water management in rainfed and irrigated settings in a manner that would guide researchers or policy makers toward wise interventions and investments. Water interacts with many other inputs in crop and livestock production. Thus, to ensure sufficient food production in future we must analyze production settings in greater detail, measuring interactions involving water and other inputs, and evaluating strategies that acknowledge those interactions, just as farmers must do each season. We must also invest greater effort in understanding risk and uncertainty, particularly from the perspective of smallholder farmers, who have little freeboard for accommodating crop failures or recovering from mistakes in input allocation. We can develop more useful guidance for smallholders if we enhance our analysis in ways that look beyond point estimates of water productivity.

\section{Acknowledgments}

I appreciate the helpful comments of two reviewers, who encouraged me to enhance the clarity of discussion in several sections of the paper.

\section{Conflicts of Interest}

The author declares no conflict of interest.

\section{References}

1. Rockström, J.; Barron, J. Water productivity in rainfed systems: Overview of challenges and analysis of opportunities in water scarcity prone savannahs. Irrig. Sci. 2007, 25, 299-311.

2. Molden, D.; Oweis, T.; Steduto, P.; Bindraban, P.; Hanjra, M.A.; Kijne, J. Improving agricultural water productivity: Between optimism and caution. Agric. Water Manag. 2010, 97, $528-553$.

3. Cai, X.; Molden, D.; Mainuddin, M.; Sharma, B.; Ahmad, M.-U.-D.; Karimi, P. Producing more food with less water in a changing world: Assessment of water productivity in 10 major river basins. Water Int. 2011, 36, 42-62.

4. Jia, S.; Ge, Z.; Fang, X. Less water, more grain in dry Hebei Province, China. Water Int. 2011, $36,861-872$. 
5. Brauman, K.A.; Siebert, S.; Foley, J.A. Improvements in crop water productivity increase water sustainability and food security-A global analysis. Environ. Res. Lett. 2013, 8, doi:10.1088/ 1748-9326/8/2/024030.

6. Kijne, J.; Barker, R.; Molden, D. Water Productivity in Agriculture: Limits and Opportunities for Improvement; CABI Publishing: Wallingford, UK, 2003.

7. Liu, J.; Williams, J.R.; Zehnder, A.J.B.; Yang, H. GEPIC-Modelling wheat yield and crop water productivity with high resolution on a global scale. Agric. Syst. 2007, 94, 478-493.

8. Vince, G. Getting more drops to the crops. Science 2010, 327, 800.

9. Monaghan, J.M.; Daccache, A.; Vickers, L.H.; Hess, T.M.; Weatherhead, E.K.; Grove, I.G.; Knox, J.W. More 'crop per drop': Constraints and opportunities for precision irrigation in European agriculture. J. Sci. Food Agric. 2013, 93, 977-980.

10. Borlaug, N.E. Feeding a hungry world. Science 2007, 318, 359.

11. De Fraiture, C.; Wichelns, D. Satisfying future water demands for agriculture. Agric. Water Manag. 2010, 97, 502-511.

12. Fedoroff, N.V.; Battisti, D.S.; Beachy, R.N.; Cooper, P.J.M.; Fischhoff, D.A.; Hodges, C.N.; Knauf, V.C.; Lobell, D.; Mazur, B.J.; Molden, D.; et al. Radically rethinking agriculture for the 21st century. Science 2010, 327, 833-834.

13. Turral, H.; Svendsen, M.; Faures, J.M. Investing in irrigation: Reviewing the past and looking to the future. Agric. Water Manag. 2010, 97, 551-560.

14. You, L.; Ringler, C.; Wood-Sichra, U.; Robertson, R.; Wood, S.; Zhu, T.; Nelson, G.; Guo, Z.; Sun, Y. What is the irrigation potential for Africa? A combined biophysical and socioeconomic approach. Food Policy 2011, 36, 770-782.

15. Wichelns, D. Investing in small, private irrigation to increase production and enhance livelihoods. Agric. Water Manag. 2014, 131, 163-166.

16. Passioura, J. Increasing crop productivity when water is scarce: From breeding to field management. Agric. Water Manag. 2006, 80, 176-196.

17. Zoebl, D. Is water productivity a useful concept in agricultural water management? Agric. Water Manag. 2006, 84, 265-273.

18. Zwart, S.J.; Bastiaanssen, W.G.M.; de Fraiture, C.; Molden, D.J. A global benchmark map of water productivity for rainfed and irrigated wheat. Agric. Water Manag. 2010, 97, 1617-1627.

19. Rockström, J.; Karlberg, L.; Wani, S.P.; Barron, J.; Hatibu, N.; Oweis, T.; Bruggeman, A.; Farahani, J.; Qiang, J. Managing water in rainfed agriculture: The need for a paradigm shift. Agric. Water Manag. 2010, 97, 543-550.

20. Araya, A.; Stroosnijder, L. Assessing drought risk and irrigation need in northern Ethiopia. Agric. For. Meteorol. 2011, 151, 425-436.

21. Burney, J.A.; Naylor, R.L. Smallholder irrigation as a poverty alleviation tool in sub-Saharan Africa. World Dev. 2012, 40, 110-123.

22. Burney, J.A.; Naylor, R.L.; Postel, S.L. The case for distributed irrigation as a development priority in sub-Saharan Africa. Proc. Natl. Acad. Sci. USA 2013, 110, 12512-12517.

23. De Fraiture, C.; Giordano, M. Small private irrigation: A thriving but overlooked sector. Agric. Water Manag. 2014, 131, 167-174. 
24. Zwart, S.J.; Bastiaanssen, W.G.M. Review of measured crop water productivity values for irrigated wheat, rice, cotton and maize. Agric. Water Manag. 2004, 69, 115-133.

25. Igbadun, H.E.; Ramalan, A.A.; Oiganji, E. Effects of regulated deficit irrigation and mulch on yield, water use and crop water productivity of onion in Samaru, Nigeria. Agric. Water Manag. 2012, 109, 162-169.

26. Zhang, H.; Oweis, T. Water-yield relations and optimal irrigation scheduling of wheat in the Mediterranean region. Agric. Water Manag. 1999, 38, 195-211.

27. Zhang, H.; Wang, X.; You, M.; Liu, C. Water-yield relations and water-use efficiency of winter wheat in the North China Plain. Irrig. Sci. 1999, 19, 37-45.

28. Zand-Parsa, S.; Sepaskhah, A.R. Optimal applied water and nitrogen for corn. Agric. Water Manag. 2001, 52, 73-85.

29. Tolk, J.A.; Howell, T.A. Field water supply: Yield relationships of grain sorghum grown in three USA Southern Great Plains soils. Agric. Water Manag. 2008, 95, 1303-1313.

30. Steduto, P.; Hsiao, T.C.; Raes, D.; Fereres, E. AquaCrop-The FAO crop model to simulate yield response to water: I. Concepts and underlying principles. Agron. J. 2009, 101, 426-437.

31. Karam, F.; Kabalan, R.; Breidi, J.; Rouphael, Y.; Oweis, T. Yield and water-production functions of two durum wheat cultivars grown under different irrigation and nitrogen regimes. Agric. Water Manag. 2009, 96, 603-615.

32. Sadras, V.; Roget, D.; Krause, M. Dynamic cropping strategies for risk management in dry-land farming systems. Agric. Syst. 2003, 76, 929-948.

33. Blum, A. Drought resistance, water-use efficiency, and yield potential: Are they compatible, dissonant, or mutually exclusive? Aust. J. Agric. Res. 2005, 56, 1159-1168.

34. Kirkegaard, J.A.; Hunt, J.R. Increasing productivity by matching farming system management and genotype in water-limited environments. J. Exp. Bot. 2010, 61, 4129-4143.

35. Biazin, B.; Sterk, G.; Melesse Temesgen, M.; Abdulkedir, A.; Stroosnijder, L. Rainwater harvesting and management in rainfed agricultural systems in sub-Saharan Africa: A review. Phys. Chem. Earth 2012, 47-48, 139-151.

36. Torkamani, J.; Shajari, S. Adoption of new irrigation technology under production risk. Water Resour. Manag. 2008, 22, 229-237.

37. Takeshima, H.; Yamauchi, F. Risks and farmers' investment in productive assets in Nigeria. Agric. Econ. 2012, 43, 143-153.

38. Rockström, J.; Barron, J.; Fox, P. Rainwater management for increased productivity among small-holder farmers in drought prone environments. Phys. Chem. Earth 2002, 27, 949-959.

39. Hussain, I.; Sakthivadivel, R.; Amarasinghe, U. Land and water productivity of wheat in the western Indo-Gangetic Plains of India and Pakistan: A comparative analysis. In Water Productivity in Agriculture: Limits and Opportunities for Improvement; Kijne, J., Barker, R., Molden, D., Eds.; CABI Publishing: Wallingford, UK, 2003.

40. Yan, N.; Wu, B. Integrated spatial-temporal analysis of crop water productivity of winter wheat in Hai Basin. Agric. Water Manag. 2014, 133, 24-33.

41. Li, Y.; Barker, R. Increasing water productivity for paddy irrigation in China. Paddy Water Environ. 2004, 2, 187-193. 


\title{
An Input-Output Assessment of Water Productivity in the Castile and León Region (Spain)
}

\section{Carlos Dionisio Pérez Blanco and Thomas Thaler}

\begin{abstract}
The failure in the past to acknowledge the limits of water supply and to decouple economic development from water demand has resulted in a water dependent growth model currently threatened by increasing scarcity and droughts. Consequently, there is now an urgent need to use sparse water resources in a more sustainable and efficient way. This demands a comprehensive understanding of water productivity and the linkages among economic sectors to illustrate the tradeoffs in water reallocations from productive sectors to priority uses (household and urban uses). This paper develops a methodology based on the Hypothetical Extraction Method to estimate inter-temporal direct and indirect water productivity. The method is applied to the Spanish region of Castile and León. Results confirm the existence of a relevant water productivity gap between the agriculture (the largest water consumer) and that of the other sectors, which are nonetheless largely dependent on the agricultural output (and thus, on agricultural water demand). Results also show that Gross Domestic Product (GDP) growth, say about 1\%, results in an increase of indirect water productivity in the manufacturing blocks $(0.49 \%$ and $0.38 \%)$, energy and water $(0.39 \%)$ and service blocks $(0.41 \%)$, providing evidence of the existence of a Verdoorn's Law for water.
\end{abstract}

Reprinted from Water. Cite as: Blanco, C.D.P.; Thaler, T. An Input-Output Assessment of Water Productivity in the Castile and León Region (Spain). Water 2014, 6, 929-944.

\section{Introduction}

Water is a scarce input necessary for the production of many valuable goods and services and should be managed accordingly. However, water policy in European Union (EU) countries up to this date has failed to consider water as an economic good and has focused instead on guaranteeing the supply of this resource at subsidized prices. Under this paradigm, population growth and the improvement of living standards brought about by development have driven water demand up and the pressures over water resources have escalated. Consequently, water is now overexploited in many areas across the globe [1]. As water has become scarcer, policy making has been reactive and incremental, and conventional supply policies, instead of being replaced, have been reinforced. Surprise and crisis are now more regular occurrences and there is an increasing need worldwide to manage water resources "better" [2,3].

Alternative policies, comprising command-and-control instruments (e.g., Drought Management Plans), technical alternatives (e.g., Irrigation Modernization Plans) and economic instruments (e.g., water pricing, water markets, insurance, buyback of agricultural water use rights) have been explored to address this challenge [4-8]. Ultimately, all these policies aim towards the attainment of a strategic reallocation of water resources that achieves the collectively agreed goals of water policy without impairing, or alternatively minimizing, the impact on the output of the productive activities that rely upon this input. Therefore, what is crucial in their design is to identify the productive 
activities in which potential water use restrictions may have a lower impact on the economy, in the short (e.g., Drought Management Plans) and in the medium-long term (e.g., Irrigation Modernization Plans). This demands a comprehensive understanding of Water Productivity (WP) dynamics that integrates the relevant linkages among productive sectors. The objective of this paper is to improve this understanding in order to better inform policy makers in the development of new water policies.

We can safely define WP as the output of a given activity (in economic terms, if possible) divided by a measure of water input [9]. There is a vast array of techniques and methodologies available to estimate WP, ranging from intrasectoral to intersectoral analyses. In the following lines, we present some relevant studies to illustrate the advances in this field and we show how our model may contribute to fill in a gap in the literature through the development of an intersectoral and inter-temporal Input-Output (IO) model.

As irrigation is by and large the main water consumer worldwide, most of the studies available refer to WP in agriculture either from an agronomic, economic or hydrologic perspective, or a combination of them (intrasectoral models). A very fruitful research field relies on the water balance concept considering different spatial boundaries [10-14]. More recently, the rise of geo-referenced systems and remote sensing has permitted the development of a new series of studies based on spatial models [15-19]. Although rare, there is also research on WP in the secondary and tertiary sectors [20,21]. All this research allows a detailed understanding of the water use within a particular sector, but it only offers an intrasectoral assessment of WP (apparent/direct WP) that excludes the analysis of forward and backward linkages among sectors and therefore is insufficient to assess the potential for intersectoral water reallocations.

The problem of how to better allocate the scant water resources available in an economy among competing uses requires an intersectoral assessment of WP. IO models have the potential to address this issue. IO models have been traditionally used to assess direct (observed) and indirect water uses (induced) in different EU regions [22-24]. More recently, these models have been adapted to assess the economic impact of alternative water policies [25-27].

This body of literature offers an insightful approach to WP assessment for all the sectors in the economy considering different scenarios. In addition, it makes possible the estimation and comparison of both apparent/direct WP (which is measured in the intrasectoral models above) and indirect WP (missing in the intrasectoral models). Direct WP is obtained as the ratio of the economic output to the observed water use in the sector, while indirect WP is obtained as the ratio of the economic output to the amount of water consumption induced by the sector. That is to say, the latter includes in the denominator the water that would not be used in the economy if that sector was to be removed from the economy. This information is of great importance to assess the actual impact on the economy of policies constraining water use over specific productive sectors.

Although WP assessments have become increasingly complex over time, from intrasectoral to intersectoral studies, simultaneous intersectoral and inter-temporal IO models are not available yet. IO models are static and do not assess WP dynamics. This is largely owed to the lack of continuous data series [28]. Nonetheless, this has changed recently as environmental satellite accounts (including water accounting) and IO tables have become regularly available in some regions, such as the Castile and León Region in Spain. New statistical data now makes possible not only an intersectoral but also 
an inter-temporal assessment of WP. This is useful for comparing the performance of different sectors of the economy over time.

This paper aims to shed light over the inter-temporal problem of how to efficiently assign scarce water resources among productive sectors. The study applies the Hypothetical Extraction Method (HEM) $[29,30]$ to the particular case of water resources and obtains annual indirect and direct WP in the Spanish region of Castile and León (CL) for a seven-year period (2000-2006) [31]. HEM has been used previously in the literature to measure the intersectoral linkages of inputs such as energy (see for example [32]). The paper is structured as follows: Section 2 introduces the Case Study area, the Castile and León Region in Spain; Section 3 describes the HEM applied to water; Section 4 presents the results, including direct and indirect WP values for urban and irrigation water and the Verdoorn's Law for water; Section 5 discusses the implications of the findings for current policy making and concludes the paper.

\section{The Case Study Area: The Castile and León Region (Spain)}

$\mathrm{CL}$ is at the same time the largest region in Spain $\left(94,223 \mathrm{~km}^{2}, 18.7 \%\right.$ of the Spanish territory) and one of the most depopulated regions in Europe (26.6 people per $\mathrm{km}^{2}$ ) [33]. The structure of the CL's economy is similar to that of the Spanish economy as a whole. Industry, construction and the tertiary sector have a similar composition in CL and in Spain and their weights over regional and national GDP, although slightly smaller in the case of CL, have also showed a similar evolution during the last decades. However, CL has been traditionally and is still today an agrarian region with classic agrarian periphery socio-economic problems, namely, depopulation and low income.

In 2006, agriculture represented $6.6 \%$ of the GDP and $10.2 \%$ of total employment in CL, more than doubling the Spanish shares $(2.7 \%$ of the GDP and $4.4 \%$ of the employment) and well above the EU-28 shares (1.7\% and 5.7\%). More than half (52\%) of CL surface is devoted to agricultural uses (Spain: 52\%; EU-27: 43\%). Prevailing agro-ecosystems in CL are cereal landscapes and irrigated areas that produce relatively low agrarian incomes [34,35]. Irrigation is the main water user and represents $92 \%$ of total consumption in the region or $98 \%$ excluding non-consumptive uses [36].

Eighty-two percent of the CL Region is located inside the Duero River Basin (DRB) boundaries. Since the 1990s, the DRB has experienced the most intense, widespread and lasting droughts in a century [36]. Moreover, average water availability has fallen and this trend is expected to continue [36,37], thus threatening all water uses including priority environmental and household supply [36]. Authorities have reacted to these challenges in two ways. First, the regional authority has regulated drought response through a Drought Management Plan that decreases water availability for productive uses under drought events [36]. Unlike other Drought Management Plans that clearly specify the water restrictions to be applied for every sector under each drought threshold, the DRB Drought Management Plan offers a considerable degree of flexibility [36]. Therefore, this new regulation may have a different impact on regional GDP depending on the sectors affected by water restrictions [25]. Second, regarding water scarcity, the recently approved Duero River Basin Management Plan established a set of guidelines (potentially including economic instruments, command-and-control policies and technical alternatives) to restore environmental services that will likely demand a permanent restriction in water use in some productive activities [34]. 
Although with a different time scope (short run in the case of the Drought Management Plan and medium-long run in the case of the River Basin Management Plan), both regulations determine a reallocation of water resources from productive activities to priority uses, which include environmental uses, household demand and under particular junctures industrial uses and energy production [34,36]. This demands a profound understanding of the impacts of permanent and temporary reallocation policies over productive activities, and thus of WP dynamics and the linkages among economic sectors.

\section{Data and Methods}

This study uses the Hypothetical Extraction Method (HEM) to combine Water Satellite Accounts (WSA) with IO symmetric tables in order to estimate intersectoral water flows and from here their corresponding direct and indirect WPs $[29,30,32,38]$. We repeat the process for each one of the seven years of the period considered.

This paper starts from an IO model where the production of an economy comprising $n$ sectors is described as follows $[29,30,38]$ :

$$
x=\mathrm{A} x+y=\left(\begin{array}{cc}
\mathrm{A}_{s, s} & \mathrm{~A}_{s,-s} \\
\mathrm{~A}_{-s, s} & \mathrm{~A}_{-s,-s}
\end{array}\right)\left(\begin{array}{c}
x_{s} \\
x_{-s}
\end{array}\right)+\left(\begin{array}{c}
y_{\mathrm{s}} \\
y_{-s}
\end{array}\right)
$$

Being $x=x_{i}$ the production vector or total output, $y=y_{i}$ the vector of final demands (i.e., the final output of the economy [39]) and $\mathrm{A}=\mathrm{A}_{i j}$ the matrix of technical coefficients. The economy can be split into blocks comprising one or more sectors. The subscript $s$ refers to a specific block, and the subscript $-S$ to the remaining blocks of the economy. Alternatively, Equation (1) can be formulated as follows $[29,30,38]$ :

$$
\begin{gathered}
x=(\mathrm{I}-\mathrm{A})^{-1} y=\left(\begin{array}{cc}
\Delta_{s, s} & \Delta_{s,-s} \\
\Delta_{-s, s} & \Delta_{-s,-s}
\end{array}\right)\left(\begin{array}{c}
\mathrm{y}_{s} \\
\mathrm{y}_{-s}
\end{array}\right) \\
\text { where: }\left(\begin{array}{cc}
\Delta_{s, s} & \Delta_{s,-s} \\
\Delta_{-s, S} & \Delta_{-s,-s}
\end{array}\right)=\left(\begin{array}{cc}
\left(\mathrm{I}-\mathrm{A}_{s, S}\right)^{-1} & \left(\mathrm{I}-\mathrm{A}_{s,-s}\right)^{-1} \\
\left(\mathrm{I}-\mathrm{A}_{-s, s}\right)^{-1} & \left(\mathrm{I}-\mathrm{A}_{-s,-s}\right)^{-1}
\end{array}\right)
\end{gathered}
$$

Being $(\mathrm{I}-\mathrm{A})^{-1}$ the Leontief inverse. The HEM measures the impact of every block (namely, $s$ ) by comparing the production vector of that economy with $(\mathrm{X} x)$ and without $\left(x^{*}\right)$ that block, which are a function of the technical coefficients with (AA) and without $\left(\mathrm{A}^{*}\right)$ that block and the final demands with (Yy) and without $\left(y^{*}\right)$ that block, respectively. The production of the economy in which a given block $(s)$ is extracted is described as follows [29,30,38]:

$$
x^{*}=\left(\mathrm{I}-\mathrm{A}^{*}\right)^{-1} y^{*}=\left(\begin{array}{cc}
\left(\mathrm{I}-\mathrm{A}_{s, s}\right)^{-1} & 0 \\
0 & \left(\mathrm{I}-\mathrm{A}_{-s,-s}\right)^{-1}
\end{array}\right)\left(\begin{array}{c}
y_{s} \\
y_{-s}
\end{array}\right)
$$

The change in production is obtained as the difference between $\mathrm{X} x$ (Equation (2)) and $x^{*}$ (Equation (4)) and shows the effect of the block $s$ over the remaining blocks of the economy $[29,30,38]$ :

$$
x-x^{*}=\left(\begin{array}{cc}
\mathrm{C}_{s, s} & \mathrm{C}_{s,-s} \\
\mathrm{C}_{-s, s} & \mathrm{C}_{-s,-s}
\end{array}\right)\left(\begin{array}{c}
y_{s} \\
y_{-s}
\end{array}\right)
$$

Every block has four separate effects over the economy: an internal effect, a mixed effect, an external or net backward linkage and an external or net forward linkage. The internal effect of the 
block $s\left(I E_{S}\right)$ represents the effect of the goods produced, sold and purchased inside the sector $s$ to obtain its final demand $y_{s}$. The mixed effect $\left(M E_{S}\right)$ measures the impact of the products sold by the block $s$ to other blocks and later re-purchased to produce $y_{s}$. The net backward linkage $\left(N B L_{s}\right)$ represents the direct and indirect requirements of the sector $s$ from the rest of the economy to obtain $y_{s}$, namely the "imports" of the sectors. Finally, the net forward linkage $\left(N F L_{S}\right)$ represents the direct and indirect requirements of the rest of the economy from the sector $s$ to obtain $y_{-s}$, namely the "exports" of the sectors [30]:

$$
\begin{gathered}
I E_{s}=c^{\prime}\left(\mathrm{I}-\mathrm{A}_{s, s}\right)^{-1} \mathrm{y}_{s} \\
M E_{s}=c^{\prime}\left[\Delta_{s, s}-\left(\mathrm{I}-\mathrm{A}_{s, s}\right)^{-1}\right] y_{s} \\
N B L_{s}=c \Delta_{-s, s} y_{s} \\
N F L_{s}=c^{\prime} \Delta_{s,-s} y_{-s}
\end{gathered}
$$

where $c^{\prime}$ denotes the vector $(1, \ldots, 1)$.

Vector $c^{\prime}$ is now replaced by a vector of unitary inputs of water $\left(w^{\prime}\right)$ calculated as the quotient of water use in every sector $s$ (available in the WSA) to its final demand $y_{s}$ (or final output, available in the IO symmetric tables) [22,32]. With this information it is possible to obtain the four effects over the economy of the block $s$, but this time referred to the amount of water embodied in the part of the production process that the different effects represent. Now the internal effect $\left(I E w_{S}\right)$ is the water consumed exclusively inside the block $s$; the mixed effect $\left(M E w_{S}\right)$ is the water consumed in the block $s$, then used as an input in other block/s and again used as an input in the block $s$; the net backward linkage $\left(N B L w_{s}\right)$ is the water originally used in other blocks than $s$ and then "imported" and used in $s$ to generate the final demand; and the net forward linkage $\left(N F L w_{S}\right)$ is the water originally used in the block $s$ and then "exported" and used in other block/s to generate their final demand:

$$
\begin{gathered}
I E w_{s}=w^{\prime}\left(\mathrm{I}-\mathrm{A}_{s, s}\right)^{-1} y_{s} \\
M E w_{s}=w^{\prime}\left[\Delta_{s, s}-\left(\mathrm{I}-\mathrm{A}_{s, s}\right)^{-1}\right] y_{s} \\
N B L w_{s}=w \Delta_{-s, s} y_{s} \\
N F L w_{s}=w^{\prime} \Delta_{s,-s} y_{-s}
\end{gathered}
$$

These effects are subsequently added into two groups in order to obtain the vertically integrated effect and the direct effect. The direct effect $\left(D E_{S}\right)$ stems from direct consumption and is the result of the aggregation of the mixed effect, internal effect and net forward linkages of the block $s$ (i.e., the water directly consumed by the block). The ratio between the final demand $\left(y_{s}\right)$ and the direct effect $\left(D E_{s}\right)$ of that block is its direct water productivity $(D W P)$, namely, the quotient of final demand to observed water uses (equivalent to apparent productivity) [29]:

$$
\begin{gathered}
D E_{s}=I E w_{s}+M E w_{s}+N F L w_{s} \\
D W P=\frac{y_{s}}{D E_{s}}
\end{gathered}
$$

The vertically integrated effect $\left(V I E_{s}\right)$ stems from indirect consumption and is the result of the aggregation of the internal effect, mixed effect and the net backward linkages (i.e., the water that would not be consumed in the economy if blocks was to be removed from the economy, or 
alternatively the water consumption induced by blocks). The ratio between the final demand $\left(y_{s}\right)$ and the vertically integrated effect $\left(V I E_{S}\right)$ of a given block is its indirect water productivity $(I W P)$, namely, the quotient of final demand to water use induced by this block [30].

$$
\begin{gathered}
V I E_{s}=I E w_{s}+M E w_{s}+N B L w_{s} \\
I W P=\frac{y_{s}}{V I E_{s}}
\end{gathered}
$$

For the assessment of $W P$, this study uses data from the WSA and the IO symmetric tables (product-by-product, constant prices) for CL. WSA are a statistical source yearly available in Spain since 1997 that provide information on the amount of water used by every economic sector [40]. On other hand, symmetric tables are offered intermittently by national and regional institutes of statistics; however, CL Institute of Statistics has been yearly supplying symmetric IO tables since 2000 [41]. As a result, both symmetric tables and WSA have been available simultaneously for every year during the period 2000-2006.

Table 1. Block configuration and water demand ${ }^{1}$ by block in the Castile and León Region,

\begin{tabular}{|c|c|c|c|c|c|c|c|c|}
\hline \multirow{2}{*}{ Block } & \multirow{2}{*}{ Economic sector } & \multicolumn{7}{|c|}{ Direct water consumption (thousand $\mathrm{m}^{3} /$ year) } \\
\hline & & 2000 & 2001 & 2002 & 2003 & 2004 & 2005 & 2006 \\
\hline $\begin{array}{l}\text { Block } \\
1(\mathrm{~B} 1)\end{array}$ & $\begin{array}{l}\text { Agriculture, livestock, hunting, } \\
\text { forestry and fishing }\end{array}$ & $2,079,842$ & $1,917,250$ & $2,101,940$ & $2,235,375$ & $2,356,046$ & $2,317,267$ & $2,171,866$ \\
\hline $\begin{array}{l}\text { Block } \\
2(\mathrm{~B} 2)\end{array}$ & $\begin{array}{l}\text { Extraction of energy products, } \\
\text { extraction of other mineral products, } \\
\text { oil refining and nuclear fuels, water } \\
\text { collection, purification and } \\
\text { distribution and energy, gas and } \\
\text { water production and distribution }\end{array}$ & 7,451 & 7,060 & 7,139 & 8,312 & 6,794 & 6,460 & 4,622 \\
\hline $\begin{array}{l}\text { Block } \\
3 \text { (B3) }\end{array}$ & Food, drinks and tobacco & 3,693 & 3,586 & 3,939 & 4,543 & 3,954 & 5,206 & 4,701 \\
\hline $\begin{array}{l}\text { Block } \\
4 \text { (B4) }\end{array}$ & $\begin{array}{l}\text { Textile and clothing, leather and } \\
\text { footwear, timber and cork, paper and } \\
\text { publishing and other non-metallic } \\
\text { mineral products industries }\end{array}$ & 1,338 & 1,359 & 1,391 & 1,946 & 1,533 & 1,443 & 970 \\
\hline $\begin{array}{l}\text { Block } \\
5(\mathrm{~B} 5)\end{array}$ & $\begin{array}{l}\text { Chemicals, rubber and plastic } \\
\text { materials transformation, metallurgy } \\
\text { and manufacture of metal products, } \\
\text { machinery and mechanical } \\
\text { equipment, electric and electronic } \\
\text { material, transport material and } \\
\text { diverse manufacturing industries }\end{array}$ & 7,979 & 7,909 & 8,779 & 9,920 & 8,557 & 8,012 & 5,538 \\
\hline $\begin{array}{l}\text { Block } \\
6 \text { (B6) }\end{array}$ & Construction & 1,309 & 1,453 & 1,538 & 1,627 & 1,395 & 1,550 & 1,109 \\
\hline $\begin{array}{l}\text { Block } \\
7 \text { (B7) }\end{array}$ & $\begin{array}{l}\text { Public sanitation, public } \\
\text { Administration and other service } \\
\text { sector activities }\end{array}$ & 24,017 & 25,288 & 25,634 & 27,653 & 21,232 & 22,459 & 16,840 \\
\hline $\begin{array}{c}\text { All } \\
\text { blocks }\end{array}$ & All economic sectors & $2,125,628$ & $1,963,904$ & $2,150,360$ & $2,289,376$ & $2,399,510$ & $2,362,397$ & $2,214,380$ \\
\hline
\end{tabular}
2000-2006. 
WSA offer information on water use disaggregated in 24 productive sectors for different types of water. This paper distinguishes between irrigation (92\% of total water demand, $98 \%$ excluding non-consumptive uses such as hydropower and power plant cooling water demand) and the sum of drinkable and non-drinkable water (to which this paper will refer as urban water, representing the remaining $8 \%$ of the total water demand and $2 \%$ excluding non-consumptive uses). Therefore, the vector $w^{\prime}$ (the quotient of water use in every sector $s$ to its final demand $y_{s}$ ) is obtained for both irrigation and urban water, and accordingly DWP and IWP are obtained for irrigation and urban water separately. On the other hand, the IO symmetric tables for CL offer economic information disaggregated in 58 sectors. In this paper, all the different sectors in the WSA and IO tables are put into the seven homogeneous blocks described in Table $1[22,38]$.

\section{Results}

We obtain IWP (Tables 2 and 3) and DWP (Tables 4 and 5) for every single block and year during the period 2000-2006, for both urban and irrigation water. All WP values are shown in constant prices (real WP).

Table 2. Indirect Water Productivity (IWP) in the Castile and León Region, 2000-2006 $\left(€ / \mathrm{m}^{3}\right.$, constant prices), irrigation water.

\begin{tabular}{cccccccc}
\hline Block/year & $\mathbf{2 0 0 0}$ & $\mathbf{2 0 0 1}$ & $\mathbf{2 0 0 2}$ & $\mathbf{2 0 0 3}$ & $\mathbf{2 0 0 4}$ & $\mathbf{2 0 0 5}$ & $\mathbf{2 0 0 6}$ \\
\hline B1 & 1.81 & 1.81 & 1.72 & 1.58 & 1.67 & 1.46 & 1.92 \\
B2 & 186.46 & 193.91 & 172.6 & 172.62 & 179.45 & 141.38 & 145.42 \\
B3 & 4.06 & 4.27 & 3.98 & 3.74 & 3.99 & 3.35 & 3.73 \\
B4 & 26.84 & 29.1 & 26.09 & 24.97 & 29.04 & 22.98 & 24.32 \\
B5 & 103.19 & 104.41 & 95.38 & 93.53 & 99.6 & 81.11 & 91.55 \\
B6 & 77.24 & 82.07 & 72.92 & 67.79 & 72.21 & 55.29 & 57.73 \\
B7 & 63.72 & 66.82 & 60.42 & 56.34 & 59.81 & 50.07 & 55.79 \\
\hline \multicolumn{7}{c}{ Note: Authors' elaboration from $[40,41]}$.
\end{tabular}

Table 3. Indirect Water Productivity (IWP) in the Castile and León Region, 2000-2006

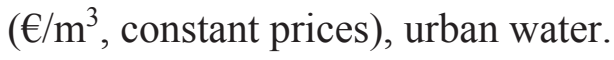

\begin{tabular}{cccccccc}
\hline Block/year & $\mathbf{2 0 0 0}$ & $\mathbf{2 0 0 1}$ & $\mathbf{2 0 0 2}$ & $\mathbf{2 0 0 3}$ & $\mathbf{2 0 0 4}$ & $\mathbf{2 0 0 5}$ & $\mathbf{2 0 0 6}$ \\
\hline B1 & 169.06 & 148.15 & 129.08 & 112.51 & 137.32 & 124.15 & 168.72 \\
B2 & 250.75 & 269.39 & 272.46 & 237.76 & 295.46 & 292.79 & 458.47 \\
B3 & 265.84 & 252.38 & 220.72 & 199.14 & 243.78 & 213.27 & 247.31 \\
B4 & 557.77 & 585.93 & 557.41 & 471.81 & 615.26 & 598.05 & 802.64 \\
B5 & 531.68 & 526.79 & 501.64 & 459.93 & 562.00 & 570.78 & 822.52 \\
B6 & 869.88 & 869.99 & 826.12 & 732.37 & 878.23 & 807.52 & 1088.99 \\
B7 & 701.30 & 685.85 & 671.72 & 623.25 & 810.61 & 788.63 & 1065.41 \\
\hline
\end{tabular}

Note: Authors' elaboration from [40,41].

IWP values (Table 2) in the year 2006 are inflated as a result of the extreme drought that suffered Spain and particularly the DRB since mid-2005, the most intense ever recorded in the basin [34]. Water supply restrictions significantly increased water efficiency and IWP. The opposite can be said for the relatively water abundant period 2002-2003. In any case and in spite of these anomalies, a 
clear trend for IWP in every block and water type (irrigation, urban) can be inferred for the period analyzed.

Irrigation water (Table 2) is directly demanded by agriculture. The remaining blocks demand irrigation water only indirectly through the significant backward linkages that they have with agriculture. The observed IWP in the CL Region is low and lower than the values available for other Spanish regions [22-24]. Moreover, IWP in the agricultural sector shows a negative trend, thus dragging IWP in the other sectors of the economy. This means that most of the water being used in the economy is employed with a low and decreasing efficiency. This happens in spite of the large investments in irrigation modernization in the area as part of the National Irrigation Modernization Plan that started in 2002. In fact, although the National Irrigation Modernization Plan put into practice the existing resource saving technical alternatives, water governance and institutional capacity were not improved accordingly. As a result, the potential for water saving through the development of more efficient irrigation devices was largely used to increase the irrigated area [42], thus showing no positive impact on IWP (nor in DWP).

In the case of urban water (Table 3), there are two clearly differentiated trends. In the primary sector (B1) and in the food industry (B3), IWP is low and shows a negative trend. IWP low value in $\mathrm{B} 3$ is a consequence of its dependency on B1, which results in a high indirect demand (high net backward linkage) from low productive B1. The construction sector (B6) shows a constant trend for IWP [43] (until the 2005-2006 drought).

On other hand, the tertiary sector (B7), manufacturing industry (B4 and B5) and the energy and water block (B2) show a significant and continued increase of IWP along the period: IWP increases by $15.5 \%$ in $\mathrm{B} 2,6.8 \%$ in $\mathrm{B} 4,7.1 \%$ in $\mathrm{B} 5$ and $11.7 \%$ in B7 in the period $2000-2005$. At the same time, GDP also shows significant growth rates for these sectors $(31.6 \%, 17.9 \%, 18.2 \%$ and $28.5 \%$ ) [33]. This empirical result may be regarded as a Verdoorn's Law for water: faster growth in output increases productivity due to increasing returns in certain blocks of the economy prone to technological improvements and efficiency gains (such as the manufacturing industry). To the best of our knowledge, this is the first time that the Verdoorn's Law for Water is assessed in the literature. Original research based on labor productivity [44,45] estimated that changes in the volume of production, say about $1 \%$, tend to be associated with an average increase in input productivity (in those cases, labor) between $0.45 \%$ and $0.484 \%$, with extreme values of 0.41 in the UK and 0.57 in the US. Subsequent estimations of the law found figures close to this value. In our case, a $1 \%$ increase in the volume of production results in an average increase of IWP in the selected blocks of $0.49 \%$ (B2), $0.38 \%$ (B4), $0.39 \%$ (B5) and $0.41 \%$ (B7) in the period 2000-2005. Longer series are needed to obtain concluding evidence; nonetheless, these results suggest the existence of a Verdoorn's law for water in these economic sectors.

DWP values largely differ from IWP. In the case of irrigation water (Table 4), DWP method does not consider the water indirectly demanded by other blocks and consumed in agriculture. As a result, DWP underestimates WP in agriculture as compared to the preferred IWP method by $26 \%-31 \%$. DWP in the rest of the blocks of the economy equals 0 , since backward linkages are not considered in this method. 
Table 4. Direct/apparent Water Productivity (DWP) in the Castile and León Region, 2000-2006 (€/m³ , constant prices), irrigation water.

\begin{tabular}{cccccccc}
\hline Block/year & $\mathbf{2 0 0 0}$ & $\mathbf{2 0 0 1}$ & $\mathbf{2 0 0 2}$ & $\mathbf{2 0 0 3}$ & $\mathbf{2 0 0 4}$ & $\mathbf{2 0 0 5}$ & $\mathbf{2 0 0 6}$ \\
\hline B1 & 0.56 & 0.55 & 0.52 & 0.47 & 0.51 & 0.4 & 0.51 \\
B2 & 0 & 0 & 0 & 0 & 0 & 0 & 0 \\
B3 & 0 & 0 & 0 & 0 & 0 & 0 & 0 \\
B4 & 0 & 0 & 0 & 0 & 0 & 0 & 0 \\
B5 & 0 & 0 & 0 & 0 & 0 & 0 & 0 \\
B6 & 0 & 0 & 0 & 0 & 0 & 0 & 0 \\
B7 & 0 & 0 & 0 & 0 & 0 & 0 & 0 \\
\hline
\end{tabular}

Note: Authors' elaboration from [40,41].

In the case of urban water demand (Table 5), DWP method largely overestimates WP in the water-importing blocks (B3, B4, B5, B6 and B7) and underestimates it in the water-exporting blocks (B1 and B2) as compared to IWP. DWP method supports the existence of increasing returns in water for blocks B2, B4, B5 and B7, but also for B6. In this case, the construction sector (B6) shows this positive relationship as the negative effect of its net backward linkages with low WP blocks is replaced by the positive effect of its net forward linkages with high WP blocks.

Table 5. Direct/apparent Water Productivity (DWP) in the Castile and León Region, 2000-2006 (€/ $\mathrm{m}^{3}$, constant prices $)$, urban water.

\begin{tabular}{cccccccc}
\hline Block/year & $\mathbf{2 0 0 0}$ & $\mathbf{2 0 0 1}$ & $\mathbf{2 0 0 2}$ & $\mathbf{2 0 0 3}$ & $\mathbf{2 0 0 4}$ & $\mathbf{2 0 0 5}$ & $\mathbf{2 0 0 6}$ \\
\hline B1 & 57.86 & 55.48 & 46.20 & 42.25 & 54.81 & 43.21 & 49.07 \\
B2 & 144.80 & 145.56 & 156.37 & 142.80 & 174.41 & 185.96 & 338.47 \\
B3 & 1030.70 & 921.67 & 860.56 & 952.85 & 982.45 & 832.67 & 952.22 \\
B4 & 1044.29 & 1506.13 & 1539.60 & 843.55 & 1374.38 & 1701.20 & 2727.97 \\
B5 & 677.72 & 734.66 & 695.81 & 604.52 & 808.37 & 855.78 & 1295.45 \\
B6 & 3421.15 & 2635.68 & 2733.49 & 3679.54 & 3846.88 & 4012.62 & 6525.80 \\
B7 & 639.89 & 650.63 & 704.48 & 693.59 & 955.72 & 978.06 & 1418.25 \\
\hline
\end{tabular}

Note: Authors' elaboration from [40,41].

\section{Discussion and Conclusions}

This paper uses the HEM applied for water to estimate WP in the production of goods and services in the CL Region during the period 2000-2006. Using the internal effect, the mixed effect, the net forward linkage and the net backward linkage values and the concepts of vertically integrated and direct consumption this paper assesses direct and indirect WP in the different sectors of the economy for irrigation water and drinkable and non-drinkable water (urban water). It is argued that apparent/direct WP is not the appropriate measure to obtain WP, as it misses the relevant links that exist among sectors and that explain observed water demand. To the best of our knowledge, the model presented in this paper constitutes the first IO analysis on WP combining intersectoral and inter-temporal data. The results obtained with this methodology may be used to draw relevant conclusions for policy making in increasingly water stressed and drought exposed regions. 
Water saving policies need to have a strong focus on irrigation. Agriculture is the main water consumer worldwide, and in the CL Region it shows a low and decreasing WP that drags the remaining sectors of the economy (see Table 2) [22-24]. With only a few exceptions in small agricultural areas where water availability is very low and agricultural income is very high [46], it would be unrealistic to expect that agricultural water use may reach a WP level comparable to those of other economic sectors. Therefore, a large potential for water saving may be found here and several proposals to limit water demand in agriculture have been advanced. This is the case of command-and-control policies such as Drought Management Plans, which establish temporary irrigation restrictions during drought events and are a key element of the EU strategy against droughts [4]. However, Drought Management Plans have been often criticized because they do not address the incentives behind increasing water demand [46]. Also, technical alternatives such as the National Irrigation Modernization Plan have been explored and implemented in the CL Region, although with disappointing results: in this case, the opportunity to save water from the enhanced technical efficiency was largely used to increase the irrigated surface $[42,47]$. This is coherent with the findings obtained elsewhere by $[8,48,49]$. This is not to say that technical improvements should be disregarded: there is still significant leeway for further savings if best available technologies are used. However, converting higher technical efficiency (i.e., the effectiveness with which inputs are used to produce an output) into higher allocative efficiency (i.e., a more efficient allocation of resources within markets) is not straightforward.

In this context, water policy should focus on taking the advantage of regulatory instruments and technical efficiency gains to achieve collectively agreed goals through a better governance of water resources, for example through the use of economic instruments that allow an internalization of the costs of the resource and encourage a higher technical and allocative efficiency and WP (e.g., water pricing, water trading) [50-52].

In any case, any water saving policy needs to consider that most of the water that is directly demanded by agriculture is used to produce goods that supply other sectors of the economy. This paper contributes to shed light upon this relevant issue and estimates the indirect productivity of irrigation water. In the case of CL, the net backward linkages ("imports") of the remaining blocks from the agricultural block (B1) represent between $69 \%$ and $73.5 \%$ of irrigation water demand along the period 2000-2006. Therefore, any policy to reduce the volume of water used by agriculture, even in the less water productive areas, may significantly affect other sectors of the economy (such as the food industry or the service sector, both essential in the CL economy). For example, during the 2005-2006 drought event in CL, water restrictions reduced agricultural GDP by $6.2 \%$ and as a result production in the food industry fell by more than 3\% [33]. If the new Drought Management Plan had been applied, restrictions over irrigation water supply would have been presumably larger and thus would have had a more negative impact on both sectors, which together represent $14 \%$ of the employment and $20.1 \%$ of the GVA in the region $[33,36]$.

Consequently, although a reduction in water use in the agricultural sector would result in an overall WP increase, it would have also adverse effects over production and employment in the rest of the economy in the short run (e.g., through restrictions during drought events as considered in Drought Management Plans). In the case of medium to long run irrigation restrictions, such as 
permanent water reallocations through the public buyback of agricultural water use rights as in the Murray-Darling Basin Plan in Australia [50], the dependence of some sectors on the agricultural output would likely result in either a reduction of exports (the most likely case in the CL Region, a net exporter of agricultural products) or a substitution of local products by imports (noteworthy, this may increase the costs and in some sectors such as the agro industry this substitution may not be possible due to high transportation costs) [33]. Thus, the water scarcity problem would be transformed into a balance of payments problem.

In addition, agriculture still has a fundamental and strategic role in terms of food supply independence, habitat and landscape protection, soil conservation, carbon dioxide sequestration, biodiversity conservation and food security [53]. Moreover, the transaction costs of implementing these policies may be prohibitive $[54,55]$. These spin-offs are outside our financial analysis but are undoubtedly a relevant factor to understand agricultural policies in the EU and worldwide and may result in a reluctance to implement significant water restrictions in this sector.

Because of the negative impact on the economy (estimated in this paper) and due to the high transaction costs and the strategic role of agriculture, policy makers have been traditionally unwilling to reduce and even to limit agricultural water use. However, unless current water demand trends are reverted, this situation will ultimately become unsustainable as a result of the river basin closure, the anthropogenic process that is manifested when water supply cannot meet the commitments to fulfil demand in terms of water quality and quantity within the basin during a given period of time. Experience shows that eventually the opportunity costs of inaction will be perceived as prohibitive, and water restrictions and reallocations will be necessary. In this context, our analysis may provide relevant insights for policy makers. Moreover, if transaction costs may be successfully addressed by institutions, these results may serve to guide a smooth transition towards a sustainable water use, which is more economically efficient than abrupt reactions [54,55].

In the meantime, though, an alternative solution has been the implementation of water restrictions in the urban sector during droughts $[34,36]$, even if the potential for water saving here is marginal and the impact on markets is larger as compared to irrigation. In any case, this paper also shows that relevant increases in WP of urban water (drinkable and non-drinkable water) can be obtained along with GDP growth, thus creating an opportunity to stabilize urban water use without impairing GDP growth. Evidence of the existence of a Verdoorn's Law for water has been found in CL for the energy and water block (B2), manufacturing (B4 and B5) and the service sector (B7), which together represent $76 \%-78 \%$ of CL's GDP in the period considered and a decreasing share of indirect urban water consumption (from $66.7 \%$ in 2000 to $56.1 \%$ in 2006). Although urban water means a minor fraction of total water demand ( $8 \%$ in $\mathrm{CL}$ ), this result shows that economic growth is not necessarily positively correlated with higher water use. However, it should be noted that higher WP stemming from GDP growth is only an opportunity to decouple economic growth and water use that may be lost if water authorities fail to acknowledge the limits of water supply. If this is the case, higher economic output in sectors like agriculture might indeed result in higher water use [56].

In conclusion, the necessary increases in WP in the economy in order to preserve water resources without impairing GDP growth can be obtained in two different ways. In the face of a river basin closure, it is necessary to implement the necessary reforms to limit and even reduce water use in 
agriculture, the main water consumer worldwide and the sector with a lowest WP, avoiding a negative cascade effect over production. This goal may be attained, for example, through the progressive implementation of demand side policies that allow an internalization of the costs of the resource and encourage a higher technical and allocative efficiency and WP (e.g., water pricing, water trading). This paper contributes to this objective through the estimation of the market impact that could be expected from irrigation water restrictions (Table 2). Second, relevant GDP growth in urban areas may be attained without further additional water use as a result of the increase in WP inherent to economic growth in some sectors (B2, B4, B5 and B7). This paper obtains the relationship between GDP growth and WP. These results need to be refined when longer data series are made available, if possible identifying the impact of total factor productivity at a sectoral level, particularly in manufacturing blocks.

\section{Acknowledgments}

The research leading to these results has received funding from the EU Seventh Framework Program (FP7/2007-2013) under Grant Agreements 265213 (EPI-WATER_Evaluating Economic Policy Instruments for Sustainable Water Management in Europe) and 308438 (ENHANCE_Enhancing risk management partnerships for catastrophic natural disasters in Europe) and from the Middlesex University. The authors acknowledge valuable discussion and comments from the participants at the 20th International Input-Output Conference in Bratislava in 2012, the Workshop New Directions in the Economic Analysis of Water in Lisbon in 2013 and the Envecon-Applied Environmental Economics Conference in London in 2013.

\section{Author Contributions}

Carlos Dionisio Pérez-Blanco and Thomas Thaler designed the methodology during the stay of the former in the Flood Hazard Research Centre of the Middlesex University (UK) in 2012. Carlos Dionisio Pérez-Blanco gathered the data and conducted the literature review and Thomas Thaler applied the methodology. The paper was written with contributions from both authors.

\section{Conflicts of Interest}

The authors declare no conflict of interest.

\section{References and Notes}

1. Massarutto, A. Water pricing and irrigation water demand: Economic efficiency versus environmental sustainability. Environ. Policy Gov. 2003, 13, 100-119.

2. Molden, D.; Sakthivadivel, R. Water accounting to assess use and productivity of water. Water Resour. Dev. 1999, 15, 55-71.

3. Anderies, J.; Ryan, P.; Walker, B. Loss of resilience, crisis, and institutional change: Lessons from an intensive agricultural system in southeastern australia. Ecosystems 2006, 9, 865-878. 
4. European Commission (EC). Drought Management Plan Report, Technical Report-2008-023. Available online: http://ec.europa.eu/environment/water/quantity/pdf/dmp_report.pdf(accessed on 25 February 2013).

5. Interviews, E.; Dworak, T.; Goerlach, B.; Best, A. WFD and Agriculture Linkages at the EU Level; Final Report about Incentive Water Pricing and Cost Recovery in the WFD; Elements for linking EU Agricultural and Water Policies: Berlin, Germany, 2006.

6. Albiac, J.; Playan, E.; Martinez, Y. Instruments for water quantity and quality management in the agriculture of Aragon. Int. J. Water Resour. Dev. 2007, 23, 147-164.

7. Veettil, P.C.; Speelman, S.; van Huylenbroeck, G. Estimating the impact of water pricing on water use efficiency in semi-arid cropping system: An application of probabilistically constrained nonparametric efficiency analysis. Water Resour. Manag. 2013, 27, 55-73.

8. Pfeiffer, L.; Lin, C.-Y.C. Does efficient irrigation technology lead to reduced groundwater extraction? J. Environ. Econ. Manag. 2014, 67, 189-208.

9. Playan, E.; Mateos, L. Modernization and optimization of irrigation systems to increase water productivity. Agric. Water Manag. 2006, 80, 100-116.

10. Mishra, H.S.; Rathore, T.R.; Tomar, V.S. Water use efficiency of irrigated wheat in the Tarai Region of India. Irrig. Sci. 1995, 16, 75-80.

11. Rathore, A.L.; Pal, A.R.; Sahu, R.K.; Chaudhary, J.L. On-farm rainwater and crop management for improving productivity of rain fed areas. Agric. Water Manag. 1996, 31, 253-267.

12. Bhuyian, S.I.; Sattar, M.A.; Khan, M.A.K. Improving water use efficiency in rice irrigation through wet seeding. Irrig. Sci. 1995, 16, 1-8.

13. Tuong, T.P.; Cabangon, R.J.; Wopereis, M.C.S. Quantifying flow processes during land soaking of cracked rice soils. Soil Sci. Soc. Am. J. 1996, 60, 872-879.

14. Molden, D. Accounting for Water Use and Productivity; International Irrigation Management Institute: Colombo, Sri Lanka, 1997.

15. Van Dam, J.C.; Singh, R.; Bessembinder, J.J.E.; Leffelaar, P.A.; Bastiaanssen, W.G.M.; Jhorar, R.K.; Kroes, J.G.; Droogers, P. Assessing options to increase water productivity in irrigated river basins using remote sensing and modelling tools. Int. J. Water Resour. Dev. 2006, $22,115-133$.

16. Wesseling, J.G.; Feddes, R.A. Assessing crop water productivity from field to regional scale. Agric. Water Manag. 2006, 86, 30-39.

17. Zwart, S.J.; Bastiaanssen, W.G.M. SEBAL for detecting spatial variation of water productivity and scope for improvement in eight irrigated wheat systems. Agric. Water Manag. 2007, 89, 287-296.

18. Vazifedoust, M.; van Dam, J.C.; Feddes, R.A.; Feizi, M. Increasing water productivity of irrigated crops under limited water supply at field scale. Agric. Water Manag. 2008, 95, 89-102.

19. Cai, X.; de Fraiture, C.; Hejazi, M.I. Retrieve irrigated and rain fed crop data using general maximum entropy approach. Irrig. Sci. 2007, 25, 325-338.

20. Perez, C.D.; Gomez, C.M.; Yserte, R. Structural change and water: Scarcity, dependence and impacts on the economy. The case of andalusia. Estud. Econ. Apl. 2010, 28, 423-446. 
21. Maestu, J.; Gomez, C.M.; Gutierrez, C. Los Usos del Agua en la economia Espanola: Situacion y Perspectivas; Ministerio de Medio Ambiente Medio Rural y Marino: Madrid, Spain, 2008. (in Spanish)

22. Duarte, R.; Sanchez-Choliz, J.; Bielsa, J. Water use in the spanish economy: An input-output approach. Ecol. Econ. 2002, 43, 71-85.

23. Velazquez, E. An input-output model of water consumption: Analysingintersectoral water relationships in Andalusia. Ecol. Econ. 2006, 56, 226-240.

24. Perez, C.D.; Gomez, C.M.; Del Villar, A. Water Uncertainty in Agriculture: An Application to Guadalquivir and Segura River Basins. Estud. Econ. Apl. 2011, 29, 333-358. (in Spanish)

25. Gonzalez, J.F. Assessing the macroeconomic impact of water supply restrictions through an input-output analysis. Water Resour. Manag. 2011, 25, 2335-2347.

26. Tirado, D.; Gomez, C.M.; Lozano, J. Un modelo de equilibrio general aplicado a Baleares: Análisis económico de la reasignación del agua para uso agrícola. Rev. Esp. Estudios Agrosoc. Pesq. 2006, 209, 75-109. (in Spanish)

27. Llop, M. Economic impact of alternative water policy scenarios in the Spanish production system: An input-output analysis. Ecol. Econ. 2008, 68, 288-294.

28. Lenzen, M. Aggregation versus disaggregation in input-output analysis of the environment. Econ. Syst. Res. 2011, 23, 73-89.

29. Strasser, G. Zur Bestimmung strategischer Sektoren mit Hilfe von Input-Output-Modellen. Jahrb. Natl. Stat. 1968, 182, 211-215.

30. Cella, G. The input-output measurement of interindustry linkages. Oxford B Econ. Stat. 1984, $46,73-84$.

31. IO tables in are usually made available with a with a 4-5 years delay (the last year for the CL Region is 2008). Environmental accounting such as the Water Satellite Accounts may experience even larger delays (the last year available is 2006).

32. Guerra, A.-I.; Sancho, F. Measuring energy linkages with the hypothetical extraction method: An application to Spain. Energy Econ. 2010, 32, 831-837.

33. Eurostat. Eurostat: Regional Statistics; European Commission: Bruxelles, Belgium, 2011. Available online: http://epp.eurostat.ec.europa.eu/portal/page/portal/region_cities/ regional_statistics (accessed on 25 February 2013).

34. Duero River Basin Authority (DRBA). Proyecto de Plan Hidrológico de Cuenca; Duero River Basin Authority: Valladolid, Spain, 2012. (in Spanish)

35. Instituto Nacional de Estadistica (INE). Agrarian Census 2009; Instituto Nacional de Estadistica: Madrid, Spain, 2011. (in Spanish)

36. Duero River Basin Authority (DRBA). Plan Especial de Actuación en Situaciones de Alerta y Eventual Sequía; Duero River Basin Authority: Valladolid, Spain, 2007. (in Spanish)

37. Intergovernmental Panel on Climate Change (IPCC). Climate Change 2007: Impacts, Adaptation and Vulnerability. IPCC Fourth Assessment Report (AR 4); Contribution of Working Group II to the Fourth Assessment Report of the Intergovernmental Panel on Climate Change; Cambridge University Press: Cambridge, UK, 2007. 
38. Hirschman, A.O. The Strategy of Economic Development (A Western Encore Edition); Yale University Press: New Haven, CT, USA, 1988.

39. The total output of each sector in the vector $x x$ equals the intermediate output (Ax) plus final demand (or alternatively, the final output, $y y$ ).

40. Instituto Nacional de Estadistica (INE). Water Satellite Accounts, Series 2000-2006. Available online: $\mathrm{http}: / \mathrm{www}$. ine.es/jaxi/menu.do? $\mathrm{L}=0 \&$ type $=$ pcaxis \&path $=\% 2 \mathrm{Ft} 26 \%$ 2Fp067\&file=inebase (accessed on 25 February 2013).

41. Junta de Castilla y Leon (JCYL). Tablas Input Output de Castilla y León. Available online: http://www.jcyl.es/web/jcyl/Estadistica/es/Plantilla100/1164898806585/1246989275272/__ (accessed on 25 February 2013). (in Spanish)

42. Lopez-Gunn, E.; Zorrilla, P.; Prieto, F.; Llamas, M.R. Lost in translation? Water efficiency in spanish agriculture. Agric. Water Manag. 2012, 108, 83-95.

43. This model uses constant prices and therefore avoids the effect of inflated prices in this sector.

44. Verdoorn, P.J. Fattori che regolano lo sviluppo della produtività del lavoro. L'industria 1949, 1, 3-10. (in Italian)

45. Kaldor, N. Causes of the Low Rate of Economic Growth of the UK: An Inaugural Lecture; Cambridge University Press: Cambridge, UK, 1966.

46. Gomez, C.M.; Perez, C.D. Do drought management plans reduce drought risk? A risk assessment model for a Mediterranean river basin. Ecol. Econ. 2012, 76, 42-48.

47. Ministerio de Agricultura, Alimentación y Medio Ambiente (MAGRAMA). Plan Nacional de Regadios. Available online: http://www.magrama.gob.es/es/agua/temas/gestion-sostenible-deregadios/plan-nacional-de-regadios/texto-completo/ (accessed on 30 September 2013). (in Spanish)

48. Ward, F.A.; Pulido-Velazquez, M. Water conservation in irrigation can increase water use. PNAS 2008,105, 18215-18220.

49. Adamson, D.; Loch, A. Possible negative feedbacks from "gold-plating" irrigation infrastructure. Agric. Water Manag. 2014, in press.

50. Quiggin, J. Why the guide to the proposed basin plan failed, and what can be done to fix it. In Water Policy Reform; Edward Elgar Publishing: Cheltenham, Australia, 2012; pp. 37-48.

51. Crase, L. Water markets, property rights and managing environmental water reserves. In Water Policy Reform; Edward Elgar Publishing: Cheltenham, Australia, 2012; pp. 49-62.

52. Gómez, C.M.; Delacámara, G.; Pérez-Blanco, C.D.; Ibáñez, E.; Rodríguez, M. Droughts and Water Scarcity-Tagus (Central Spain \& Portugal) and Segura (SE Spain) Interconnected River Basins (Deliverable No. 4.3); Work Package 4-Ex-Ante Case Studies. 7th Framework Contract Project EPI-Water Project (GA 265213); European Commission: Brussels, Belguim, 2013.

53. Organisation for Economic Co-operation and Development (OECD). Water Security for Better Lives. OECD: Paris, France, 2013.

54. McCann, L. Transaction costs and environmental policy design. Ecol. Econ. 2013, 88, 253-262. 
55. Pannell, D.J.; Roberts, A.M.; Park, G.; Alexander, J. Improving environmental decisions: A transaction-costs story. Ecol. Econ. 2013, 88, 244-252.

56. Calzadilla, A.; Rehdanz, K.; Tol, R.S.J. The economic impact of more sustainable water use in agriculture: A computable general equilibrium analysis. J. Hydrol. 2010, 384, 292-305. 


\title{
2. Institutional Framework and Mechanisms
}

\section{Water Trading: Locational Water Rights, Economic Efficiency, and Third-Party Effect}

\author{
Ming-Feng Hung, Daigee Shaw and Bin-Tzong Chie
}

Abstract: Rivers flow downstream and unidirectionally. However, this fact has not yet been utilized in the institutional design for water trading. By utilizing this characteristic, we first designed a water trading system of "locational water rights." This new system is able to mitigate the return flowrelated and instream flow-related third-party effects of volumetric reliability from water transfers. We provided mathematical proof of its economic efficiency. We then applied this water trading system to the case of the Choushui River basin in Taiwan. In this area, agriculture is highly developed while domestic and industrial water demands have increased rapidly. Using an agent-based model simulation, we estimated the potential economic benefits of implementing the system of locational water rights in the Choushui River basin.

Reprinted from Water. Cite as: Hung, M.; Shaw, D.; Chie, B.-T. Water Trading: Locational Water Rights, Economic Efficiency, and Third-Party Effect. Water 2014, 6, 723-744.

\section{Introduction}

Associated with population growth and economic activities, difficulties in developing new water supplies, as well as increasing uncertainties regarding hydrology and water disasters due to climate change, water has become increasingly scarce and more essential than ever in almost every country. Several countries, such as the United States (western part), Australia, Chile, and South Africa, have adopted the water market as an alternative to various methods of water allocation (see e.g., the review of Hadjigeorgalis [1]).

Water trading has great potential to increase the efficiency of water use and help water users to cope with a drier and more unstable climate (see e.g., [1-4]). Successful water trading needs the following three conditions: (i) a monitorable and enforceable quantity cap that is placed on the market that limits the amount of resource used in a defined area; (ii) entitlements are defined and distributed among the users; and (iii) a market is created to enable trading of entitlements [2]. However, even when these conditions are met, they are not sufficient to achieve social optimality. Other factors such as increasing uncertainties from climate change and institutional constraints may make water trading perform unexpectedly. Most importantly, water trading usually fails to take into account third-party effects, that is, the effects of water transfers on parties that are not directly involved in the transaction (also called externalities) (see e.g., p. 2 in Hartman and Seastone [5] and p.5 in Scheierling [6]). There are several kinds of third-party effects that result from water trade such as volumetric reliability, delivery reliability, timeliness of delivery, water quality, and rural development effects $[7,8]$. Based on the water reform experiences in Australia's Murray-Darling Basin and Chilean water 
markets, some recent papers examine the social, economic, environmental, and institutional limitations and externalities that restrict the success of water trading (see e.g., $[2,3,9,10]$ ).

The first purpose of this article is to reduce the third-party effects associated with water transfers by designing a system of "locational water rights" for a spot water market. This trading system exploits the specific characteristic that water flows downstream unidirectionally. Among the various externalities, we focus on the third-party effects of volumetric reliability related to return flow and instream flow $[11,12]$. For example, water transferred from downstream to upstream users might reduce intermediate instream flows and flows to intermediate users. The changes in return flows might also result in insufficient water for diversion to downstream users. To internalize the externalities that affect other water users, most studies propose that the water rights should be defined on the basis of consumptive use (see e.g., [13-15]). When flow constraints are not binding, this type of water rights implements the optimal solution. When flow constraints are binding, however, a two-party upstream transfer can result in impairment even when consumptive use is the measure of water right $[13,16]$. Moreover, consumptive use transfers may not prevent damage to instream flows [17]. Therefore, requiring a review and approval of transactions by a public agency and/or establishing a fund to compensate third parties for damages incurred in trading are the usual methods used to deal with the externalities [18]. However, a court system might result in a litigious environment and increase transaction costs substantially [19].

For the system of locational water rights proposed in this article, the initial cap of consumption rights allowed for each location is calculated from upstream to downstream with consideration of the requirement of minimum instream flows. Each consumption right is labeled by location and defined as a locational water right. This special design aims to be consistent with the characteristic of water, namely, it always flows downstream unidirectionally, and also meets the requirement of minimum instream flows. To our knowledge, it is the first time this characteristic of water has been used in designing water rights (for effluent trading, this characteristic has been applied in Hung and Shaw [20]). By so doing the system can ensure no third-party effects will be caused on the instream flows since the caps of locational water rights meet the requirements. It should be noted that the locational water rights can be distributed suitably to water users in other locations so that there is no conflict with the existing water using institution. In combination with the traditional trading of consumption and return-flow rights, the system of locational water rights can achieve economic efficiency even when flow constraints are binding. In addition, by restricting only downstream transfers of locational water rights, no negative externalities will result to other water users. Transfers can be made bilaterally and are not restricted to being simultaneous, adjacent or approved ex ante (regardless of the import/export of water or non-adjacent transfers). Transaction costs can therefore be largely reduced. Theoretically, this locational water right system improves the way in which the third-party effects of volumetric reliability related to return flow and instream flow are handled [21].

The second purpose of this article is to apply the system of locational water rights to study the economic efficiency of a potential water market for the case of the Choushui River basin in Taiwan. In this area, agriculture is highly developed and the local irrigation associations own most of the registered water rights. However, because the water demand of industrial and domestic uses increase rapidly and the uncertainty and unevenness of water supply rise, conflicts and problems among water 
users have been increasing. Agricultural irrigation water is arbitrated by the government for regular reallocation to industrial and domestic uses. The existing water transfers do not adequately address the third-party effects, return flows, and ecological and environmental problems, however. It is therefore very important to deal with the third-party effects to water users and the environment and to improve the economic efficiency of water usage by a well-designed water market in this area $[22,23]$. By using an agent-based model, we have simulated the water trading scenarios in this area with the proposed trading system of locational water rights.

The remainder of this article is organized as follows. In Section 2, the basic environment of a river system is first described. We introduce the system of locational water rights and prove that water transfers under this institutional design can achieve economic efficiency. We also propose a simple example to illustrate the third-party effect with and without the design of locational water rights. In Section 3, the system of locational water rights is applied to the Choushui River basin in Taiwan. In this area, the promotion of water use efficiency is very important and imperative. The last section offers a conclusion.

\section{Locational Water Rights, Economic Efficiency, and Third-Party Effect}

In this section, we first describe the basic environment of a river system where there are no branches feeding into the system. The return flow of a diversion returns back to the river before the next diversion point (see Table 1). This is a common scenario setting in the literature (see e.g., $[13,24,25])$. The simplified river system facilitates the analysis but is not necessary, however [26]. We then introduce the design of locational water rights and its advantages. A simple illustration follows to explain the differences between the system of locational water rights and other water right systems and to discuss the third-party effect. Lastly, the economic efficiency of water transfers under the system of locational water rights is proved.

Table 1. Schematic diagram of a simplified river system.

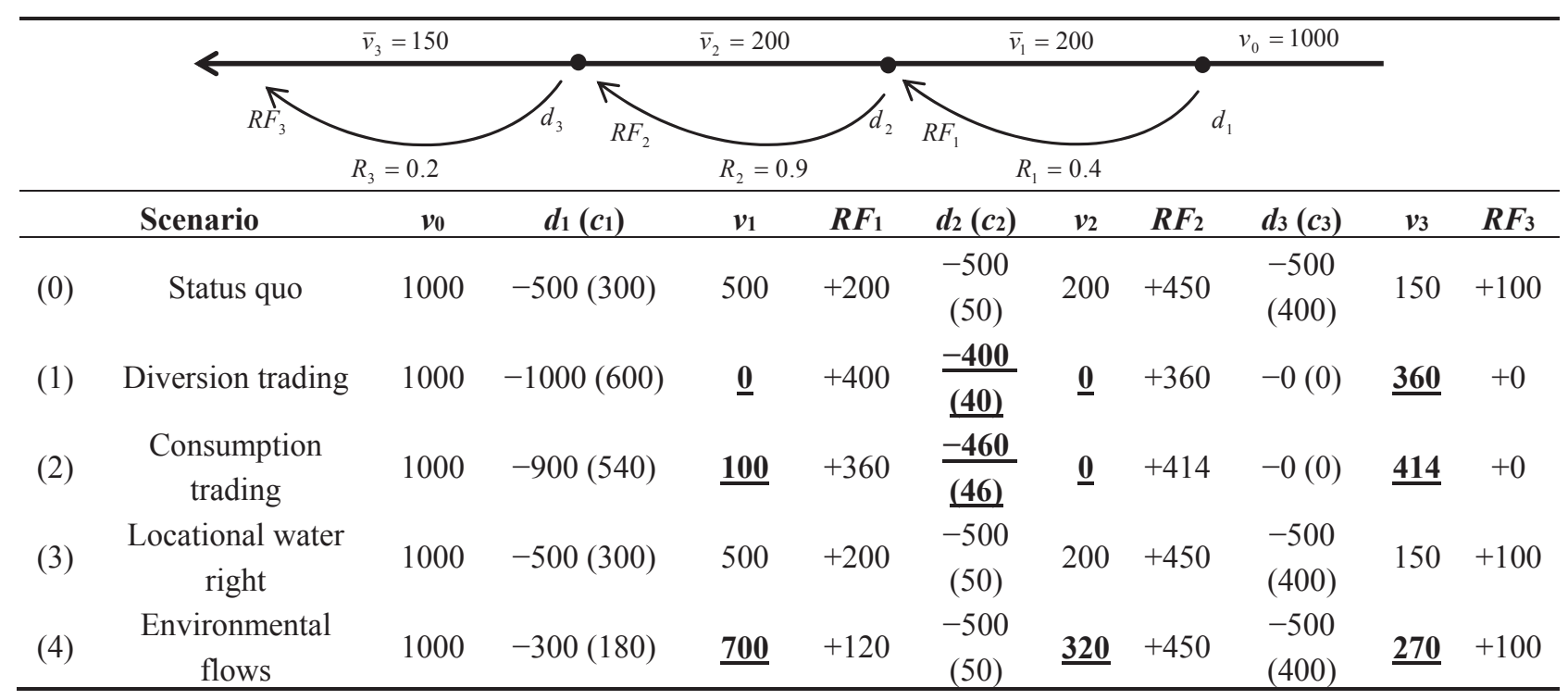

Notes: ${ }^{1}$ In the table, $v_{i}$ represents streamflow in section $i, R F$ is return flow, and minus (plus) sign indicates the reduction (increase) of streamflow; ${ }^{2}$ Row (3) indicates the allocation of locational water rights to water users according to the status quo distribution. 


\subsection{Basic River System and Optimal Water Allocation}

Suppose that there is a set of water users located along a river and numbered as $i=1, \ldots, n$ from upstream to downstream. Water flow at the source is denoted by $v_{0}$. The requirement of minimum instream flow at location $i$ is denoted by $\bar{v}_{i}$. A minimum flow which aims to provide a certain level of protection for the aquatic environment describes the amount of water flow required to preserve aquatic life, habitat, water quality, navigation, recreation, or aesthetic beauty (see e.g., [27-29]). If we designate user $i$ 's diversion and consumption of water by $d_{i}$ and $c_{i}$, respectively, then

$$
c_{i}=\left(1-R_{i}\right) d_{i}
$$

In this equation, $R_{i}(\geq 0)$ is a net return flow parameter which indicates the percentage of diversion water returning to the river after a specific water use of user $i$. The evaporation, seepage, and infiltration have been deducted. This parameter is usually assumed exogenous in the literature because water use habits, irrigation technologies, land uses, or natural conditions do not change in the short run. In the long run, the introduction of water trade would create incentives for water users to modify their practices of water use so as to maximize the benefits of both consumptive use and return flows. The authority could update the return flow parameters periodically. In addition, because the calculation of this parameter case-by-case is complicated in practice, $R_{i}$ is often determined by the particular water uses (e.g., agricultural, domestic, or industrial use) and geographic conditions.

To satisfy the requirement of minimum instream flows, the following constraints for diversions must be satisfied:

$$
v_{0}-\left(\sum_{j=1}^{i-1}\left(1-R_{j}\right) d_{j}+d_{i}\right) \geq \bar{v}_{i}, \quad i=1, \ldots, n
$$

Equivalently,

$$
\sum_{j=1}^{i-1}\left(1-R_{j}\right) d_{j}+d_{i} \leq v_{0}-\bar{v}_{i}, \quad i=1, \ldots, n
$$

That is, at a particular location, the total amount of water consumed upstream and the immediate diversion must be less than the total available amount of water. According to Equation (1), the above constraints for diversions can be rearranged as constraints for water consumption:

$$
\left(1-R_{i}\right) \sum_{j=1}^{i-1} c_{j}+c_{i} \leq\left(1-R_{i}\right)\left(v_{0}-\bar{v}_{i}\right), \quad i=1, \ldots, n
$$

Assuming that water user $i$ 's benefit depends only on the amount of water he consumes, his benefit function can be written as $B_{i}=B_{i}\left(c_{i}\right)$, where $B_{c}>0$ and $B_{c c}<0$. The regulator maximizes the total benefits by solving the optimization problem

$$
\begin{gathered}
\operatorname{Max}_{c_{i}} \sum_{i=1}^{n} B_{i}\left(c_{i}\right) \\
\text { s.t. } \quad\left(1-R_{i}\right) \sum_{j=1}^{i-1} c_{j}+c_{i} \leq\left(1-R_{i}\right)\left(v_{0}-\bar{v}_{i}\right), \quad i=1, \ldots, n
\end{gathered}
$$




$$
\mathbf{c}=\left(c_{1}, \ldots, c_{n}\right) \geq 0
$$

The necessary condition for an interior solution with strictly positive consumption is

$$
B_{i}^{\prime}=\lambda_{i}+\sum_{j=i+1}^{n}\left(1-R_{j}\right) \lambda_{j}, \quad i=1, \ldots, n
$$

where $B_{i}^{\prime}$ is the marginal benefit of water user $i$ and $\lambda$ is the shadow price of water consumption.

\subsection{Locational Water Right}

One of the very specific characteristics of water is that it always flows downstream unidirectionally. By using this important feature, we propose an institutional design of locational water right which allocates the initial cap of consumption rights for each location from upstream to downstream subject to the requirement of minimum instream flows. Note that the locational water right is defined on the basis of consumptive use. Mathematically, this allocation design is represented as:

$$
T_{i}^{0}=\left(1-R_{i}\right)\left(v_{0}-\bar{v}_{i}\right)-\left(1-R_{i}\right) \sum_{j=1}^{i-1} T_{j}^{0}, i=1, \cdots, n
$$

where $T^{0}$ is the initial amount of water rights for each location [30]. Water users can freely trade these water rights. Owning one unit of local locational water rights, a water user can increase one unit of water consumption. Owning one unit of upstream (downstream) water rights, a water user can increase one (no) unit of water diversion.

It should be noted that the above analysis is based on a scenario with certainty. In regions with high hydroclimatic variability or areas that are susceptible to major shifts in water availability, it is very difficult to robustly quantify the amount of minimum instream flows [2]. Under such uncertainty, the government or organizations can buy water rights for the environment to protect instream uses; other consumptive water users can also react to changes through water trading. In addition, due to increasing variable environment in the world, e.g., the prolonged "Big Dry" in Australia from 1997 to 2009 , there might be not enough water in the system to meet the requirement of minimum instream flows. In this kind of extreme case, the protection level of environmental flows might need to be traded off with other consumptive uses. However, the market mechanism for water transfers can help improve water use efficiency especially when water is such a scarce resource. NWC [31], which studied Australia's prolonged drought, demonstrated that water markets and trading made a major contribution to the achievement of optimizing the economic, social, and environmental value of water.

The advantages derived from the locational water rights are as follows. First, the allocation Equation (9) is essentially derived from the constraints of the minimum instream flows (Equation (4)) by substituting $T^{0}$ for $c$. This water consumption cap, $T^{0}$, for each location will therefore protect the minimum instream flows not being violated due to water transfers. Second, this upstream to downstream allocation method "exploits all the available water allowed by the instream constraint" for each location "from upstream to downstream." In one aspect, because return flows can be used downstream, this upstream to downstream allocation can assure the possibility of water being used most efficiently to achieve economic efficiency. In the other aspect, since all available and allowed water has been allocated to the upstream locations, only downstream transfers of 
locational water rights will be needed subsequently. If, however, locational water rights are transferred upstream, more water (higher than the allowed quantity of water) will be used upstream and reduce intermediate instream flows and flows to intermediate users. Conversely, downstream transfers of locational water rights will keep water in the river until it is consumed downstream. These kind of transfers will therefore not result in negative externalities to other users and instream uses. The authority does not need to review and approve every trade in advance. Transaction costs are largely reduced.

It should be noted that the locational water rights are defined by location, not by water users. The rights of location $i$ are not necessarily distributed to water users located at $i$. They can be allocated to users at other places at the beginning to meet the existent status of water right distribution. In the next subsection, a simple example is used to illustrate the differences between the system of locational water rights and other water right systems under different scenarios.

\subsection{A Simple Illustration}

Suppose there are three water users $(i=1,2,3)$ located along a river from upstream to downstream as shown in Table 1. Water flow at the source $\left(v_{0}\right)$ is 1000 acre-feet (af hereafter). The requirement of minimum instream flow $\left(\bar{v}_{i}\right)$ after diversion at Sections 1 and 2 are both 200 af and 150 af for Section 3. The return flow parameters $R_{1}, R_{2}$, and $R_{3}$ are $0.4,0.9$, and 0.2 , respectively. The status quo is that water users 1-3 all have rights to divert 500 af of water (see Row (0) in Table 1). Note that the flow constraints are binding at the status quo because the water quantity allowed by the requirements of minimum instream flow is all consumed.

Let us consider some trading scenarios. First, if the water rights are defined on the basis of diversions, negative externalities might occur after trading. See Row (1) in Table 1. When user 3 sells 500 af to user 1, the instream flow requirement at Section 1 is violated where the streamflow $v_{1}=0<\bar{v}_{1}=200$. Meanwhile, user 2 is affected by this trade. The available water for user 2 to divert is now only 400 af which is less than the amount of water allowed by his diversion rights (500 af). The instream flow requirement at Section 2 is also violated $\left(v_{2}=0<\bar{v}_{2}=200\right)$. Second, suppose that water rights are defined on the basis of consumptive use as suggested by some literature to avoid negative externalities. If user 3 sells consumption rights of 400 af (a corresponding reduction in diversion of 500 af) to user 1 and lets user 1 increase his diversion of 400 af, the instream flow requirement at Section 1 is still violated (see Row (2), $v_{1}=100<\bar{v}_{1}=200$ ). User 2 is affected and has only 460 af of water to divert. The instream flow requirement at Section 2 is again violated $\left(v_{2}=0<\bar{v}_{2}=200\right)$. In addition, the flow constraint at Section 3 in both cases is not binding. This implies that water can be used more efficiently to increase benefits. In sum, the possible negative externalities resulting from the transfers of water diversion or consumption make trades should be reviewed and approved ex ante. The derived substantial transaction costs will defer the development of the water market.

Third, when the design of locational water rights is applied, the initial allocations of water rights for locations 1-3 are 480, 32, and 270.4 af, respectively, according to Equation (9). Note that this 
initial allocation is consistent with the instream requirements and the unidirection flow characteristic of rivers. Therefore, none of the instream requirements will be violated.

These locational water rights can be distributed to water users to be consistent with the existent situation of water right distribution at the beginning. In this case, the government distributes 300 and 180 af of location 1's water rights to users 1 and 2, respectively. By so doing, initially, all users can divert their water at the status quo levels (see Row (3)). That is, $d_{1}^{0}=(480-180) /(1-0.4)=500$; $d_{2}^{0}=180+32 /(1-0.9)=500$; and $d_{3}^{0}=(180 \times 0.9)+(270.4 /(1-0.2))=500$ (the first parenthesis in $d_{3}^{0}$ is the derived return flow from the transfer of location 1's water rights to user 2).

Now, if the marginal benefit from water consumption of user 1 is higher than that of user 2, user 1 can buy location 1's water rights from user 2 to improve economic efficiency. It should be noted that the downstream transfer is a constraint to locational water rights. It does not mean that the upstream water user cannot buy upstream locational water rights from downstream water users. Since the amount of locational water rights at each location is a constant cap consistent with the instream flow requirement and there are only downstream transfers of locational water rights, no negative externalities of_volumetric reliability related to return flow or instream flow will occur after trades. Thus no ex ante reviews by the government are needed.

In addition, the government or environmental parties can participate in the market and purchase water for environmental benefit. For example (following the scenario of locational water rights meeting the status quo), the government can purchase 120 af of location 1's water rights from user 1 (a corresponding reduction in a diversion of $200(=120 /(1-0.4))$ af to increase instream flows for all downstream sections (see Row (4)). Or, if the government just wants to increase the instream flows at Section 1, it can sell the rights to user 2.

\subsection{Market Equilibrium and Efficiency}

As shown above, due to the design of locational water rights and downstream transfers of rights, no third-party effect will be caused on in-stream flows or other water users. However, to achieve economic efficiency of water uses, return flows derived from water transfers should be used. It is therefore in addition to locational water rights, that a right of return flows should be considered as well. The return-flow rights, $S_{i}$, are generated when the water rights bought by water user $i$ are used and new return flows occur. A downstream water user can buy the upstream return-flow rights to increase his diversion. One unit of the return-flow right bought can be used to increase the diversion of the buyer by one unit.

We assume that the market is perfectly competitive so that there is no strategic behavior among water users. Faced with choosing a non-negative level of water consumption and quantity of rights transferred, the objective of a water user is to maximize his net benefit which is composed of the benefit from water consumption and net revenue from water rights. Water user $i$ 's problem can be characterized as:

$$
\underset{c_{i}, T_{i j}, T_{j i}, S_{i j}, S_{j i}}{\operatorname{Max}} B_{i}\left(c_{i}\right)+P_{i} \sum_{j=i+1}^{n}\left(T_{i j}+S_{i j}\right)-\sum_{j=1}^{i-1} P_{j}\left(T_{j i}+S_{j i}\right)
$$




$$
\begin{gathered}
\text { s.t. } \quad c_{i}+\sum_{j=i+1}^{n} T_{i j}-\left(1-R_{i}\right)\left[\sum_{j=1}^{i-1} T_{j i}+\sum_{j=2}^{i-1} S_{j i}\right] \leq T_{i}^{0} \\
\sum_{j=i+1}^{n} S_{i j} \leq R_{i}\left[\sum_{j=1}^{i-1} T_{j i}+\sum_{j=2}^{i-1} S_{j i}\right]
\end{gathered}
$$

where Equation (10) is the objective function, $P_{i}$ is the price of the water rights that prevails at location $i, T_{i j}$ and $S_{i j}$ are location $i$ 's water rights and return-flow rights that user $i$ sells, and $T_{j i}$ and $S_{j i}$ are the location $j$ 's water rights and return-flow rights that user $i$ buys.

Equations (11) and (12) are the transfer constraints under the institution design of locational water right system. Equation (11) means that, for water user $i$, his actual consumption of water must not be greater than the total effective amount of water rights he owns. On the left-hand side, the first term is water user $i$ 's actual water consumption, the second term is the location $i$ 's water rights that user $i$ sold, and the third term, $\left(1-R_{i}\right)\left[\sum_{j=1}^{i-1} T_{j i}+\sum_{j=2}^{i-1} S_{j i}\right]$, refers to the increasable amount of water consumption by the rights user $i$ bought. The term on the right-hand side is the initial amount of location $i$ 's water rights that user $i$ owns. Equation (12) requires that the amount of return-flow rights user $i$ sells must not be greater than the amount of return-flow rights he owns.

The necessary conditions for interior solutions with strictly positive water consumption and right transfers are

$$
\begin{gathered}
B_{i}^{\prime}=P_{i}, i=1, \ldots, n-1 \\
P_{1}=P_{2}=\ldots=P_{n-1}=\left(1-R_{n}\right) B_{n}^{\prime}
\end{gathered}
$$

Equation (13) means that, in equilibrium, the marginal benefit of water consumption should equal the price of the water right. Equation (14) indicates that the prices of the water rights at each location (except the most downstream location) are the same in equilibrium. This is because locational water rights can be traded and used across locations. If different prices exist for different locational rights, the supply (demand) of the higher-priced locational rights will increase (decrease), which forces the price to decrease. Conversely, the supply (demand) of the lower-priced locational rights will decrease (increase), which forces the price to increase. Finally, the prices of different locational water rights will be the same in equilibrium. The shadow price for the water rights of the most downstream location is equal to $B_{n}^{\prime}$. Because the buying of one unit of an upstream water right by user $n$ can increase water consumption by $\left(1-R_{n}\right)$ units, $P_{i}=\left(1-R_{n}\right) B_{n}^{\prime}(i<n)$.

In the following, we take two steps to prove that the above market equilibrium can achieve the efficiency of water use. First, we prove that if a social planner who maximizes the total benefits by applying the trading rule of Equations (11) and (12), the social planner will implement the optimal solution to Equations (5)-(7). Then, we use this result to prove that the market equilibrium solution is socially optimal. Since the mathematical proof is complex and lengthy, we present it in the appendix. 
Proposition 1. The market equilibrium solution under the system of locational water rights is socially optimal.

Proof. See Appendix 1.

\section{Case Study: Water Transfers in the Choushui River Basin}

In this section, we apply the design of locational water rights to the southern part of the Choushui River basin located in central-western Taiwan. We first introduce the basic environment and water using situation in this area and then use an agent-based model to simulate various scenarios of water trading.

\subsection{Background and Existing Registered Water Rights}

The Choushui River is $187 \mathrm{~km}$ in length and is the longest river in Taiwan. The rainfall pattern here is seasonal. Over 70\% rainfall in a year happens in the wet season (from June to October). In the southern part of the Choushui River basin, there are different water uses including irrigative, domestic, and industrial water demands. Agriculture in the Choushui River basin is highly developed and the irrigation associations own most of the registered water rights. Paddy rice is the primary crop and is irrigated mainly by surface water with a flooding method. However, the water demands for industrial and domestic uses have increased rapidly. The shortage of water and loose enforcement of a water right system create the very common problem of an illegal overdraft of groundwater which has resulted in serious ecological damage and environmental problems of seawater intrusion and land subsidence. Facing the problems of water shortages and environmental damage, the government constructed the Chichi Diversion Weir in 2001 to integrate water uses.

The schematic diagram of the Choushui River basin is illustrated in Figure 1. We focus on its southern part in the simulation. Along the Choushui River, the main water users are: the Linnei water treatment plant (for domestic water demand, indexed by 1), Douliou Canal (for agricultural irrigation, indexed by 2), Yunlin Offshore Industrial Park (for industrial water demand, indexed by 3), Chou Main Canal (for agricultural irrigation, indexed by 4), Yinsi Canal (for agricultural irrigation, indexed by 5), and the Dayilun Canal (for agricultural irrigation, indexed by 6). Although the Yunlin Offshore Industrial Park is located farthest downstream, its water demand is diverted from a more upstream point and transported through a specific pipe for industrial water use only. In addition, the No. 6 Naphtha Cracking Project (No. 6 NCP) of the Formosa Petrochemical Corporation (FPC) is the major industrial water user in this industrial area. It should be mentioned that in the simulation, the complex geography and water using situation practically is largely simplified; therefore, not all water users are included.

The registered rights to divert water for different water uses are promulgated in the "Directions on Chichi Diversion Weir Operation" (Directions hereafter). The amounts vary among months and users. In particular, the amounts of registered water rights for industrial use are zero in the dry season (from February to May). Since the climatic conditions differ largely between the dry and the wet seasons, these two seasons should be defined as two distinct trading periods. In this case study, we consider the period of the dry season. It is also the period when the first crop grows. According to the Directions, existing water rights for different water users in the dry season are calculated as 12 , 
$16,0,96,38$, and 36 million cubic meters (mcm hereafter) for water users 1 to 6 , respectively. Note that the agricultural water rights belong to the Yunlin Irrigation Association. We calculate existing water rights for different canals by their individual share of the total irrigated area. In addition, the requirement of minimum instream flow is $3.1 \mathrm{~cm}$ anywhere to maintain the downstream ecology of the river based on the Water Resources Agency [32].

Figure 1. Schematic diagram of the Choushui River basin.

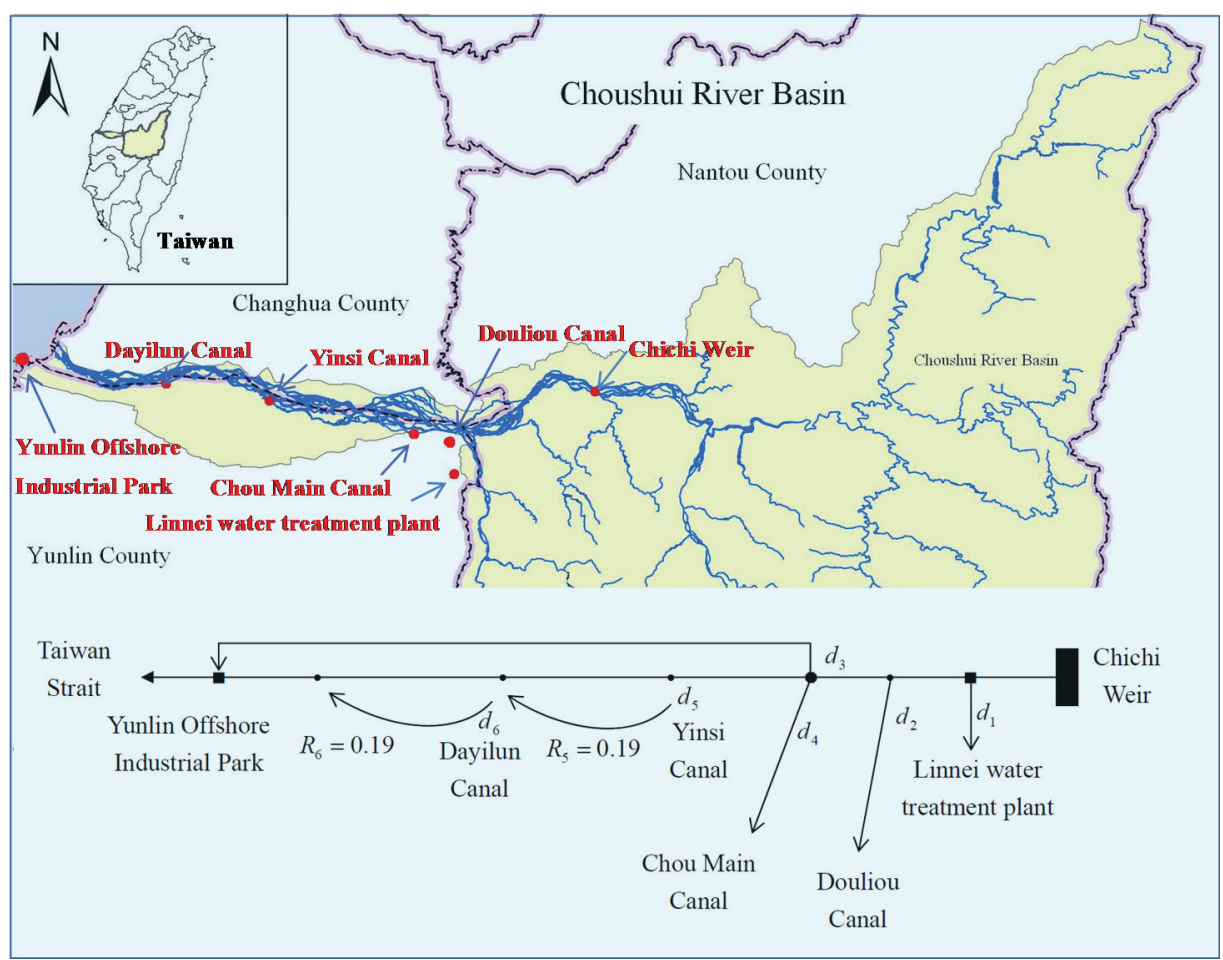

The return flow parameter of agricultural use for the first crop is 0.19 in the studied area according to the Water Resources Agency [33]. The return flows of agricultural water users 2 and 4, however, do not go back to the Choushui River. In general, the agricultural return flows can be reused by the downstream farms and industry (at least as water for cooling). The return flows derived from industrial and domestic uses are specified as zero. This is because the Yunlin Offshore Industrial Park is located farthest downstream and there is no well-constructed infrastructure for domestic water reclamation in this area. All effluent should meet the water quality requirement promulgated by the government. In sum, the parameter vector of return flows for users $1-6$ is $R=(0,0,0,0,0.19,0.19)$. Currently, the return flows in the Choushui River basin are not used. However, because of the high water demand in this area, central and local governments and scholars have begun to bring attention to this issue and give a value to return flows.

The total amount of source water of the Chichi Weir deducted from the minimum instream flows is assumed to be equal to the summation of existing registered water diversions because the water in this area is not abundant. It is $198 \mathrm{mcm}$. Empirical benefit functions specifically estimated for water uses in the Choushui River basin are not available. The benefit transfer method is thus applied. The inverse water demand functions for individual water user are obtained from Hung and Chie [34], Chiueh and Chen [35], and $\mathrm{Wu}[36]$ and are listed as follows: 
Domestic water user 1: $p=37002550 /(c-11844426)$

Agricultural water user 2: $p=28.593453-0.00000208 c$

Industrial water user 3: $\ln p=18.36231-0.93406 \ln c$

Agricultural water user 4: $p=28.746093-0.000000348 c$

Agricultural water user 5: $p=28.916009-0.000000885 c$

Agricultural water user 6: $p=28.568181-0.000000992 c$

In Equations (15)-(20), $p$ is the price of water (unit: NT $\$ \mathrm{~m}^{3}$; the average exchange rate for the year 2013 is 29.77 NT\$ $=1$ U.S. dollar according to the Central Bank of Taiwan) and $c$ is the water consumption (unit: $\mathrm{m}^{3}$ ) [37].

\subsection{Application of the System of Locational Water Rights}

If the system of locational water rights is applied, the initial allocations of locational water rights are consistent with the instream flow constraints. For the case of the Choushui River basin, they are $198 \mathrm{mcm}$ for location one, and 0 for other locations according to Equation (9) (note that the minimum instream flows have been deducted as mentioned in the background description). There are two important things that should be noted again. First, the locational water rights are defined by "location," not by water users. The rights of location $i$ are not necessarily distributed to water users located at $i$. They can be allocated to users at other places at the beginning to meet the existent status of water right distribution. In this case study, the government should initially distribute location 1's water rights to every user except for user 3 to meet the status quo. That is, user $1-6$ has $12,16,0,96,38$, and 36 units of location 1's water rights to divert water, respectively (here we assume that one unit water right is equal to one mcm water; note also that at the status quo, return flows are not considered). The corresponding quantities of consumption are 12, 16, 0, 96, 30.78, and $29.16 \mathrm{mcm}$ for user $1-6$, respectively.

Second, the downstream transfer is a constraint to locational water rights rather than to users. This means that the upstream water users can buy upstream locational water rights from downstream water users. For example, if the marginal benefit from water consumption of user 1 is higher than that of user 4 , user 1 can pay money to buy location 1's water rights from user 4 to increase water consumption; user 4 sells location 1's water rights and earns money.

\subsection{Simulation and Discussion}

In this section, we use an agent-based model to simulate the implementation of status quo water consumption and water trading based on the system of locational water rights (a simple explanation for the agent-based water rights trading is provided in Appendix 2). We define a water user as an agent. The above-mentioned water demand functions (Equations (15)-(20)) are used to calibrate the behavior of individual agents. Theoretically, locational water rights and return-flow rights are traded with perfect information in a market. In practice, information is limited. We therefore separate the market into two parts. First the locational water rights are traded; thereafter the return-flow rights are 
traded. It is expected that the equilibrium price of the return-flow rights will be lower than that for locational water rights because the qualified buyers of return-flow rights are more restricted and the willingness to pay for additional water is decreasing.

The first simulation scenario is the present situation in the Choushui River basin. The return flows are not considered. As mentioned above, $d_{i}=12,16,0,96,38$, and $36 \mathrm{mcm}$ for water users 1-6, respectively, according to the Directions. Their corresponding quantities of consumption are 12, 16, $0,96,30.78$, and $29.16 \mathrm{mcm}$, respectively. For this status quo, the total benefit (the summation of the areas under the individual demand function corresponding to its water consumption) is NT\$2,664,532,902 [38]. Table 2 lists all the individual water consumptions and the corresponding total benefit under different scenarios.

Table 2. Individual water consumption and total benefit.

\begin{tabular}{ccccc}
\hline Water user $\boldsymbol{i}$ & $\begin{array}{c}\text { Status quo } \\
\text { Diversion (mcm) }\end{array}$ & $\begin{array}{c}\text { Status quo } \\
\text { consumption (mcm) }\end{array}$ & $\begin{array}{c}\text { LWR_NORFa }^{\text {L }} \\
\text { consumption (mcm) }\end{array}$ & $\begin{array}{c}\text { LWR_RF }^{\mathbf{a}} \\
\text { consumption (mcm) }\end{array}$ \\
\hline 1 & 12 & 12 & 18.2 & 18.2 \\
2 & 16 & 16 & 11 & 11 \\
3 & 0 & 0 & 52.1 & $61.2(+9.1)^{\mathrm{b}}$ \\
4 & 96 & 96 & 65.9 & 65.9 \\
5 & 38 & 29.78 & 21.1 & 21.1 \\
6 & 36 & $2,664,532,902$ & 20 & $20.5(+0.5)^{\mathrm{b}}$ \\
Total benefit (NT\$) & & $3,439,845,867$ & $3,491,961,946$ \\
\hline
\end{tabular}

Notes: ${ }^{a}$ LWR_NORF and LWR_RF indicate the scenarios applying the system of locational water rights without and with considering return flows, respectively; ${ }^{\mathrm{b}}$ Figures in parentheses are the consumption increases resulting from the quantities of return-flow rights bought.

The second simulation scenario is the application of the system of locational water rights which meets the status quo. Under this scenario, the government distributes location 1's water rights to every user except for user 3 to reconcile the status quo at the beginning. In addition, return flows are not considered. After trading, the final consumptions are listed in column LWR_NORF. It is shown that the domestic and industrial water users 1 and 3 increase their water consumptions by paying money to buy location 1's water rights from agricultural water users (users 2, 4, 5, and 6). Agricultural water users sell location 1's water rights and earn money. The industrial user 3 in particular sees a large increases in water consumption. The total benefit is NT $\$ 3,439,845,867$ which is higher than that under the status quo.

The equilibrium price of water rights is $5.84 \mathrm{NT} \$ / \mathrm{m}^{3}$ and the quantity transferred to the industrial user is $52.1 \mathrm{mcm}$. These figures are higher than the present compensation and quantity of water transfers from agricultural to industrial uses. According to the news report regarding contracts signed among the irrigation associations, the No. $6 \mathrm{NCP}$, and the Industrial Development Bureau, the annual compensation to irrigation associations is NT\$240 million if the water transfer is around $300,000 \mathrm{~m}^{3}$ per day $\left(2.1918 \mathrm{NT} \$ / \mathrm{m}^{3}\right.$ on average) and the No. $6 \mathrm{NCP}$ should pay 5.6467 (4.1559) $\mathrm{NT} \$ / \mathrm{m}^{3}$ if the water transfer is larger (not larger) than $300,000 \mathrm{~m}^{3}$ per day. The quantity of water transfer is around $300,000-350,000 \mathrm{~m}^{3}$ per day. The higher equilibrium price indicates that the present water price might be under-priced and does not reveal the true value of water in this area. 
The higher equilibrium quantity indicates that the marginal benefit of industrial water using is far higher than that from agriculture and industry might like to buy more water if the quantity was not capped. Presently, the market mechanism for water transfers does not work. On the one hand, because the industry does not have any registered water rights in the dry season, the large regular transfer of water is controversial and has been considered a possible cause of the problem of land subsidence since it reduces the available water for agricultural and domestic uses and thus results in the overdraft of groundwater. On the other hand, the government is criticized for favoring industry at the expense of agriculture. Farmers do not receive sufficient compensation. In our simulation of the water market, industrial and domestic water users can buy more water and agriculture obtains a higher compensation, which might be a win-win solution and increases the economic efficiency of water use.

The third simulation scenario is the application of the system of locational water rights which takes return flows into account (see column LWR_RF in Table 2). Since a downstream water user can buy the upstream return-flow rights to increase water diversion, the simulated results show that the industry user 3 (located at the most downstream) buys the return flows from users 5 and 6; and user 6 from user 5. The equilibrium price of return-flow right is NT\$ 5.02 and the increase in total benefit resulting from the use of return flows is NT\$52,116,079.

There are very few studies in Taiwan which focus on the demand-side management for water use in comparison to the abundant research for the supply side. To the best of our knowledge, this article is the first simulation for a potential water market for the case of Taiwan. There are three caveats to this simulation that should be noted. First, because of the unavailability of the water demand functions specifically estimated for the Choushui River basin, a benefit transfer method is applied. Since related studies are rare in Taiwan, the water demand functions for agricultural and industrial users are old and the raw water demand for the domestic user is substituted by the demand for higher quality tap water. To obtain a precise estimation, demand functions should be estimated specifically for the studied area. Second, we take only six main water users among others in the Choushui River basin to simulate water trading. The complicated situations regarding return flows and infrastructures are also simplified. More thorough consideration of water users involved and rigorous design of a topographic map should be studied in the future. It is expected that the more users participating in the market, the higher the total benefit will be achieved. Third, for such a potential water trading market to work in practice, property rights should be well-defined and enforced. Related water laws would therefore need to be amended or stipulated. This will cause substantial transaction costs preventing the application of a free market. However, as the well-known Demsetz hypothesis indicated, property rights develop to internalize externalities as the gains of internalization become larger than the cost of internalization [39]. Therefore, when the problems of water shortage, land subsidence, and ecological damage become even worse, the possibility of obtaining additional water by constructing new dams or reservoirs becomes less, negative externalities to third parties of water users and instream flows are addressed, and the economic efficiency of water use is promoted, then the water trading market will be a promising mechanism for demand-side management. 


\section{Conclusions}

By exploiting the characteristic that water flows downstream unidirectionally, this article proposes a system of locational water rights. Under this system, the initial cap of water rights at each location is calculated from upstream to downstream according to the requirement of minimum instream flows in order to protect the instream uses and to efficiently use all available water. These locational water rights could then be distributed to water users to meet the status quo of water use. Based on its trading rules, economic efficiency of water use can be achieved and no third-party effects of volumetric reliability related to return flow and instream flow arise. To be practical, however, it is of course the case that information and experience are very important. A procedure of learning by doing is inevitable. Measures such as a transparent and real-time information system, separating the trading period into marketing and implementation stages, and testing the system of locational water rights by means of laboratory experiments, etc., could help the application of this system in practice. In addition, under an uncertain environment, the requirement of minimum instream flows might not be met. Buying water for environmental flows may be an effective way to protect instream uses.

For the simulation of a potential water trading market in the Choushui River basin, the higher equilibrium price indicates that the present water price does not reveal the true value of water. In fact, an under-priced situation has resulted in the status quo of water shortage, stress among water users, overdraft of groundwater, as well as ecological and environmental damage in this area. The simulation shows a substantial economic benefit from water trading. The industrial and domestic water users are the buyers while the agricultural water users are the sellers of the water rights. In addition, the equilibrium price of return-flow right provides a reference for the value of return flows which has not yet been used in this area.

As previously mentioned, there are several kinds of third-party effects from water trade such as volumetric reliability, delivery reliability, timeliness of delivery, water quality, and rural development effects, which will result in market failure. A lot of methods like taxation, compensation, or the one proposed in this paper have been studied to cope with some of the effects. However, there is still room for improvement and further research is needed. In particular, the impacts on social and environmental aspects have been examined less than the economic aspect. Kiem [2] indicated water trading reallocates a resource to high-value users who may be high greenhouse gas emitters. These kinds of trades will worsen the environment. Therefore, not only should the externalities in the water market per se be internalized, other external costs like pollution should also be internalized (this makes the polluters pay and reduce the artificial high-value uses ) to ensure resource allocation is efficient and fair. Finally, a complete design of a water transfer system for conjunctive use of surface water and groundwater is important. The usage and concerns regarding the return flow parameters under the locational water right system might be expanded to consider the complicated hydrological conditions of groundwater and surface water. In addition, derivatives such as forwards, options, and futures should be developed for water users to hedge under an increasingly stochastic environment associated with climate change. 


\section{Acknowledgments}

We thank three anonymous reviewers for helpful comments on an earlier draft. We also like to extend our special appreciation to Yih-Chi Tan and Ya-Wen Chiueh for their consultations and contribution.

\section{Appendix 1. Proof of Proposition 1}

Step 1. Prove that a social planner who maximizes the total benefits by applying the trading rule of Equations (11) and (12) (that is, the following Equations (A2) and (A3)) will implement the solution to Equations (5)-(7).

The optimization problem of the social planner is as follows:

$$
\begin{gathered}
\operatorname{Max}_{c, T, S} \sum_{i=1}^{n} B_{i}\left(c_{i}\right) \\
\text { s.t. } c_{i}+\sum_{j=i+1}^{n} T_{i j}-\left(1-R_{i}\right)\left[\sum_{j=1}^{i-1} T_{j i}+\sum_{j=2}^{i-1} S_{j i}\right] \leq T_{i}^{0}, i=1, \ldots, n \\
\sum_{j=i+1}^{n} S_{i j} \leq R_{i}\left[\sum_{j=1}^{i-1} T_{j i}+\sum_{j=2}^{i-1} S_{j i}\right], i=2, \ldots, n \\
T_{i j} \geq 0, i, j=1, \ldots, n, i<j \\
S_{i j} \geq 0, i, j=2, \ldots, n, i<j \\
\mathbf{c}=\left(c_{1}, \ldots, c_{n}\right) \geq 0
\end{gathered}
$$

Let us denote the set of water consumptions that satisfies the constraints of Equations (A2)-(A6) as $\Omega^{L W R}$, and the set of water consumptions that satisfies the constraints of Equations (6) and (7) as $\Omega$.

Step 1.1: Prove $\Omega^{L W R} \subseteq \Omega$

Here we first show that constraints (A2)-(A5) imply that constraint (6) is satisfied.

For any $\mathbf{c} \in \Omega^{L W R}, c_{i}+\sum_{j=i+1}^{n} T_{i j}-\left(1-R_{i}\right)\left[\sum_{j=1}^{i-1} T_{j i}+\sum_{j=2}^{i-1} S_{j i}\right] \leq T_{i}^{0}, i=1, \ldots, n$. (Equation (A2)).

By using the initial allocation rule (Equation (9)), the above equation can be rearranged as:

$$
c_{i}+\sum_{j=i+1}^{n} T_{i j}+\left(1-R_{i}\right)\left[\sum_{j=1}^{i-1} T_{j}^{0}-\sum_{j=1}^{i-1} T_{j i}-\sum_{j=2}^{i-1} S_{j i}\right] \leq\left(1-R_{i}\right)\left(v_{0}-\bar{v}_{i}\right), i=1, \ldots, n .
$$

Because $\sum_{j=i+1}^{n} T_{i j} \geq 0$ and $c_{j}+\sum_{k=j+1}^{n} T_{j k}-\left(1-R_{j}\right)\left[\sum_{k=1}^{j-1} T_{k j}+\sum_{k=2}^{j-1} S_{k j}\right] \leq T_{j}^{0}$ (by Equation (A2)), we have: $c_{i}+\left(1-R_{i}\right)\left\{\sum_{j=1}^{i-1}\left[c_{j}+\sum_{k=j+1}^{n} T_{j k}-\left(1-R_{j}\right)\left[\sum_{k=1}^{j-1} T_{k j}+\sum_{k=2}^{j-1} S_{k j}\right]\right]-\sum_{j=1}^{i-1} T_{j i}-\sum_{j=2}^{i-1} S_{j i}\right\} \leq\left(1-R_{i}\right)\left(v_{0}-\bar{v}_{i}\right)$

Equivalently, 


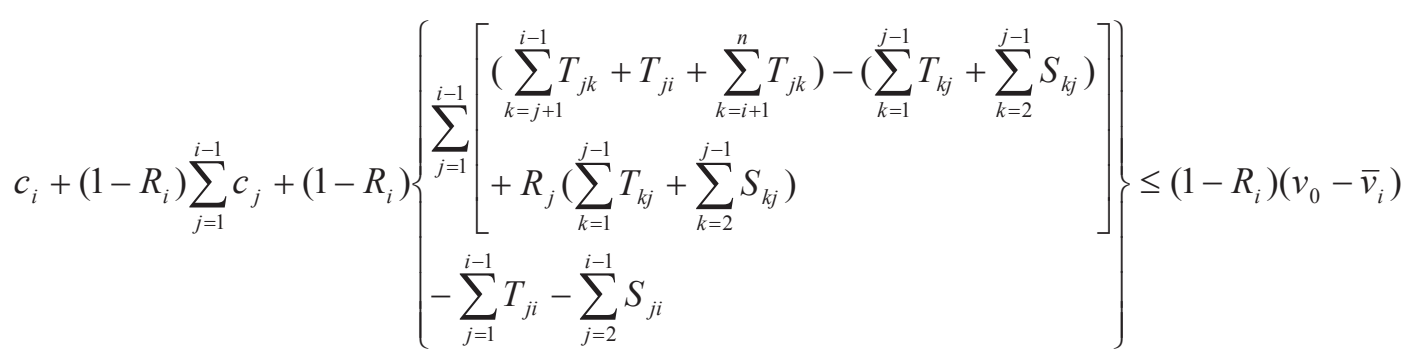

That is,

$$
c_{i}+\left(1-R_{i}\right) \sum_{j=1}^{i-1} c_{j}+\left(1-R_{i}\right) \sum_{j=1}^{i-1} \sum_{k=i+1}^{n} T_{j k}+\left(1-R_{i}\right)\left\{\sum_{j=1}^{i-1} R_{j}\left(\sum_{k=1}^{j-1} T_{k j}+\sum_{k=2}^{j-1} S_{k j}\right)-\left(\sum_{j=1}^{i-1} \sum_{k=2}^{j-1} S_{k j}+\sum_{j=2}^{i-1} S_{j i}\right)\right\} \leq\left(1-R_{i}\right)\left(v_{0}-\bar{v}_{i}\right)
$$

Let us define the terms in the above brace as $W$.

Based on the constraint (A3), we have $\sum_{j=1}^{i-1}\left(\sum_{k=j+1}^{n} S_{j k}\right) \leq \sum_{j=1}^{i-1} R_{j}\left[\sum_{k=1}^{j-1} T_{k j}+\sum_{k=2}^{j-1} S_{k j}\right]$.

Because

$\sum_{j=1}^{i-1}\left(\sum_{k=j+1}^{i} S_{j k}\right) \leq \sum_{j=1}^{i-1}\left(\sum_{k=j+1}^{n} S_{j k}\right)$

we

have

$\sum_{j=1}^{i-1}\left(\sum_{k=j+1}^{i} S_{j k}\right)=\sum_{j=1}^{i-1}\left(\sum_{k=j+1}^{i-1} S_{j k}+S_{j i}\right) \leq \sum_{j=1}^{i-1} R_{j}\left[\sum_{k=1}^{j-1} T_{k j}+\sum_{k=2}^{j-1} S_{k j}\right]$.

Then:

$$
\sum_{j=1}^{i-1} R_{j}\left[\sum_{k=1}^{j-1} T_{k j}+\sum_{k=2}^{j-1} S_{k j}\right]-\sum_{j=1}^{i-1}\left(\sum_{k=j+1}^{i-1} S_{j k}+S_{j i}\right) \geq 0
$$

The left-hand side of Equation (A8) is just the terms in the brace $(W)$ in Equation (A7).

Now because $\sum_{j=1}^{i-1} \sum_{k=i+1}^{n} T_{j k} \geq 0$ and $W \geq 0$, by Equation (A7),

$$
c_{i}+\left(1-R_{i}\right) \sum_{j=1}^{i-1} c_{j} \leq\left(1-R_{i}\right)\left(v_{0}-\bar{v}_{i}\right), i=1, \ldots, n
$$

This equation is exactly the requirement of minimum instream flows (Equation (6)). In addition, constraint (A6) is the same as constraint (7). Therefore, for any $\mathbf{c} \in \Omega^{L W R}$, we have $\mathbf{c} \in \Omega$. We have shown that $\Omega^{L W R} \subseteq \Omega$.

Step 1.2: Prove $\Omega \subseteq \Omega^{L W R}$

Here we show that, given constraint (6), we can find at least a set of $\boldsymbol{T}$ and $\boldsymbol{S}$ satisfying constraints (A3)-(A5) that imply that constraint (A2) is satisfied.

For any $\mathbf{c} \in \Omega,\left(1-R_{i}\right) \sum_{j=1}^{i-1} c_{j}+c_{i} \leq\left(1-R_{i}\right)\left(v_{0}-\bar{v}_{i}\right), i=1, \ldots, n$. (Equation (6))

There exists a set of $\boldsymbol{T}$ and $\boldsymbol{S}$ :

$$
\begin{gathered}
T_{i(i+1)} \equiv\left(1-R_{i}\right)\left(v_{0}-\bar{v}_{i}\right)-\left(1-R_{i}\right) \sum_{j=1}^{i-1} c_{j}-c_{i} \geq 0, i=1, \ldots, n \quad \text { (by Equation (6)) } \\
T_{n(n+1)} \equiv 0 \geq 0
\end{gathered}
$$




$$
\begin{gathered}
\left.T_{i j}\right|_{j=i+2, \ldots, n} \equiv 0 \geq 0, i=1, \ldots, n \\
\left.S_{i j}\right|_{j=i+2, \ldots, n} \equiv 0 \geq 0, i=2, \ldots, n \\
S_{i(i+1)} \equiv R_{i}\left(\sum_{j=1}^{i-1} T_{j i}+\sum_{j=2}^{i-1} S_{j i}\right) \quad R_{i}\left(\sum_{j=1}^{i-1} T_{j i}+\sum_{j=2}^{i-1} S_{j i}\right) \\
\geq 0, i=2, \ldots, n \text { (by equations (A10-A13)) }
\end{gathered}
$$

such that constraints (A3)-(A5) are satisfied and Equation (6) becomes

$$
\left(1-R_{i}\right) \sum_{j=1}^{i-1} c_{j}+c_{i}+T_{i(i+1)}=\left(1-R_{i}\right)\left(v_{0}-\bar{v}_{i}\right) \leq\left(1-R_{i}\right)\left(v_{0}-\bar{v}_{i}\right), i=1, \ldots, n
$$

Because $\left(1-R_{i}\right)\left(v_{0}-\bar{v}_{i}\right)=T_{i}^{0}+\left(1-R_{i}\right) \sum_{j=1}^{i-1} T_{j}^{0}$ (by Equation (9)), we rearrange Equation (A15) as

$$
c_{i}+T_{i(i+1)}-\left(1-R_{i}\right) \sum_{j=1}^{i-1}\left(T_{j}^{0}-c_{j}\right) \leq T_{i}^{0}, i=1, \ldots, n
$$

Expand $T_{j}^{0}$ by using Equation (9) and adding $\left(-\left(1-R_{j}\right) \sum_{k=1}^{j-1} c_{k}+\left(1-R_{j}\right) \sum_{k=1}^{j-1} c_{k}\right)$ in the following brackets, we have: $c_{i}+T_{i(i+1)}-\left(1-R_{i}\right) \sum_{j=1}^{i-1}\left[\left(1-R_{j}\right)\left(v_{0}-\bar{v}_{j}\right)-\left(1-R_{j}\right) \sum_{k=1}^{j-1} T_{k}^{0}-c_{j}-\left(1-R_{j}\right) \sum_{k=1}^{j-1} c_{k}+\left(1-R_{j}\right) \sum_{k=1}^{j-1} c_{k}\right] \leq T_{i}^{0}$. Therefore, $c_{i}+T_{i(i+1)}-\left(1-R_{i}\right) \sum_{j=1}^{i-1}\left[T_{j(j+1)}-\left(1-R_{j}\right) \sum_{k=1}^{j-1}\left(T_{k}^{0}-c_{k}\right)\right] \leq T_{i}^{0}$.

By continuing to expand $T^{0}$ on the LHS and performing the same rearrangement procedure as in the previous equation, we have

$$
c_{i}+T_{i(i+1)}-\left(1-R_{i}\right) \sum_{j=1}^{i-1}\left[T_{j(j+1)}-\left(1-R_{j}\right)\left[\sum_{k=1}^{j-1}\left(T_{k(k+1)}-\left(1-R_{k}\right)\left[\sum_{m=1}^{k-1} T_{m(m+1)}-\cdots-\left(1-R_{2}\right)\left[T_{1}^{0}-c_{1}\right]\right]\right]\right] \leq T_{i}^{0}\right.
$$

Equivalently,

$$
c_{i}+T_{i(i+1)}-\left(1-R_{i}\right)\left[T_{(i-1) i}+R_{i-1}\left[T_{(i-2)(i-1)}+R_{i-2}\left[T_{(i-3)(i-2)}+\cdots+R_{3}\left[T_{23}+R_{2}\left(T_{12}\right)\right]\right] \| T_{i}^{0}\right.\right.
$$

By using Equations (A12)-(A14), we can rearrange Equation (A18) as $c_{i}+T_{i(i+1)}-\left(1-R_{i}\right)\left[T_{(i-1) i}+S_{(i-1) i}\right] \leq T_{i}^{0}$.

By adding $\sum_{j=i+2}^{n} T_{i j}=0, \sum_{j=1}^{i-2} T_{j i}=0$, and $\sum_{j=2}^{i-2} S_{j i}=0$ to the LHS of the above equation, we have:

$c_{i}+T_{i(i+1)}+\sum_{j=i+2}^{n} T_{i j}-\left(1-R_{i}\right)\left[T_{(i-1) i}+\sum_{j=1}^{i-2} T_{j i}+S_{(i-1) i}+\sum_{j=2}^{i-2} S_{j i}\right] \leq T_{i}^{0}$.

That is,

$$
c_{i}+\sum_{j=i+1}^{n} T_{i j}-\left(1-R_{i}\right)\left[\sum_{j=1}^{i-1} T_{j i}+\sum_{j=2}^{i-1} S_{j i}\right] \leq T_{i}^{0} \quad(i=1, \ldots, n)
$$


This equation is the exact constraint on water right transfers (Equation (A2)). In addition, constraint (7) is the same as constraint (A6). Thus, for any $\mathbf{c} \in \Omega$, we have $\mathbf{c} \in \Omega^{L W R}$. We have shown that $\Omega \subseteq \Omega^{L W R}$.

Since $\Omega^{L W R} \subseteq \Omega\left(\right.$ Step 1.1) and $\Omega \subseteq \Omega^{L W R}$ (Step 1.2), we have $\Omega^{L W R}=\Omega$.

Because the objective functions and constraints of Equations (A1)-(A6) and Equations (5)-(7) are the same, the solution under the scenario of the social planner who applies the locational water right system, $\mathbf{c}^{S P}$, is the same as the solution to Equations (5)-(7), $\mathbf{c}^{*}$.

Step 2. Prove that the market equilibrium solution is socially optimal.

Based on Step 1, $\mathbf{c}^{\boldsymbol{S P}}$ is the same as $\mathbf{c}^{*}$. Then, if the market equilibrium solution, $\mathbf{c}^{\boldsymbol{M E}}$, is $\mathbf{c}^{\boldsymbol{S P}}$, the market equilibrium solution is efficient.

Both $\mathbf{c}^{M E}$ and $\mathbf{c}^{S P}$ are feasible under the locational water right system. Supposing that $\mathbf{c}^{M E} \neq \mathbf{c}^{S P}$, then $\sum_{i=1}^{n} B_{i}\left(c_{i}^{M E}\right)<\sum_{i=1}^{n} B_{i}\left(c_{i}^{S P}\right)$.

Because ( $\left.\mathrm{c}^{M E}, \boldsymbol{T}^{M E}, \boldsymbol{S}^{M E}, \boldsymbol{P}\right)$ is the market equilibrium,

$B_{i}\left(c_{i}^{M E}\right)+P_{i} \sum_{j=i+1}^{n}\left(T_{i j}^{M E}+S_{i j}^{M E}\right)-\sum_{j=1}^{i-1} P_{j}\left(T_{j i}^{M E}+S_{j i}^{M E}\right)>B_{i}\left(c_{i}^{S P}\right)+P_{i} \sum_{j=i+1}^{n}\left(T_{i j}^{S P}+S_{i j}^{S P}\right)-\sum_{j=1}^{i-1} P_{j}\left(T_{j i}^{S P}+S_{j i}^{S P}\right)$

for $i=1, \ldots, n$. Summing over $i=1, \ldots, n$, we have $\sum_{i=1}^{n} B_{i}\left(c_{i}^{M E}\right)>\sum_{i=1}^{n} B_{i}\left(c_{i}^{S P}\right)$, which is a contradiction. Therefore, $\mathbf{c}^{M E}=\mathbf{c}^{S P}=\mathbf{c}^{*}$, i.e., the market equilibrium solution is efficient. Q.E.D.

\section{Appendix 2. The Agent-based Water Rights Trading}

We define a water user as an agent. The water demand functions (Equations (15)-(20)) are used to calibrate the behavior of individual agents. Assume that agent $i$ 's willingness to pay (WTP) for an additional unit of water rights is represented by:

$$
\operatorname{BID}_{i}\left(q_{0}+1\right)=D_{i}^{-1}\left(q_{0}+1\right)
$$

where $B I D_{i}$ is the "bid price" function of agent $i, q_{0}$ is the status-quo water rights, and $D_{i}^{-1}$ is the inverse water demand function. In the same manner, agent $i$ 's willingness to accept (WTA) for giving up one unit of water rights is:

$$
\operatorname{ASK}_{i}\left(q_{0}\right)=D_{i}^{-1}\left(q_{0}\right)
$$

where $A S K_{i}$ is agent $i$ 's "asking price" function.

The trading mechanism follows Chicago Board of Trade (CBOT) matching rule. A locational water right is like a financial asset (e.g., stock). In the water right market, only orders from qualified traders are accepted. That is, a water user can just buy non-downstream locational water rights to increase water diversion. The orders are taken on a continuous basis. The matching is based on the principle of first come first served. However, if more than one buy or sell orders are received for the same locational water right at the same time, the order with a better price will be matched as a priority, resembling current bids and offers of a stock market. A transaction is made when one of the following criteria is met, (i) the bid price is higher than the outstanding (lowest) asking price or (ii) the asking 
price is lower than the outstanding (highest) bid price. Under the CBOT mechanism, the transaction price for location $l$ 's water right $(P l)$ will be carried out by the mean of its bid price and asking price, which can be represented by

$$
P_{l}=\left(A S K_{i}+B I D_{j}\right) / 2
$$

where $i \neq j$.

Traders will submit their orders to the locational water rights with the best affordable offer. For a potential buyer (seller), the best offer will be his or her reachable lowest asking (highest bid) price for a locational water right. Let's give a simple illustration in Table A1. Suppose there are two agents ( $k$ and $m$ ) located at location 3, both own some location 3's water rights, and $R_{k}=R_{m}=0$. Currently, agent $k$ 's WTA is $A S K_{k}=30.7$ and WTP is $B I D_{k}=30.5$. Since Agent $k$ 's WTA is higher than the outstanding asking price for location 3's water right, he will not place an order for selling water right. On the other hand, he is a qualified buyer for water rights of locations 1 to 3. Then, his best choice is to place a buy order for location 1's water right, where the outstanding asking price is the lowest. Column "Location 1" shows the current market status after taking agent $k$ 's buy order. The latest transaction price of location 1 will be updated to $(30.5+9.0) / 2=19.8$. For agent $m$, his WTP is $B I D_{m}$ $=4.7$ and WTA is $A S K_{m}=8.2$. Since Agent $m$ 's WTP is lower than the outstanding bid prices for location 1 to 3's water rights, he will not place an order for buying a water right. On the other hand, his WTA is lower than outstanding asking price for location 3's water rights, he will place a sell order there. Column "Location 3" shows the current market status after taking agent $m$ 's sell order. The latest transaction price of Location 3's water right is then updated to $(12.2+8.2) / 2=10.2$. The market clearing will be achieved until no agent has a motive to submit orders to the market.

Table A1. Illustration of market transaction.

\begin{tabular}{|c|c|c|c|c|c|c|c|c|c|c|}
\hline \multirow{2}{*}{ Water right } & \multicolumn{2}{|c|}{ Location 1} & \multicolumn{2}{|c|}{ Location 2} & \multicolumn{2}{|c|}{ Location 3} & \multicolumn{2}{|c|}{ Location 4} & \multicolumn{2}{|c|}{ Location 5} \\
\hline & bid & ask & bid & ask & bid & ask & bid & ask & bid & Ask \\
\hline \multicolumn{11}{|c|}{ Current market status } \\
\hline Outstanding & 5.3 & 9.0 & 10.1 & 10.5 & 12.2 & 13.5 & 11.2 & 13.3 & 6.3 & 7.1 \\
\hline Next & 5.2 & 9.1 & 10.0 & 10.6 & 12.1 & 13.6 & 11.1 & 13.4 & 6.2 & 7.2 \\
\hline Transaction price & \multicolumn{2}{|c|}{8.5} & \multicolumn{2}{|c|}{10.4} & \multicolumn{2}{|c|}{12.6} & \multicolumn{2}{|c|}{12.0} & \multicolumn{2}{|c|}{6.9} \\
\hline \multicolumn{11}{|c|}{ Current market status after taking agent $k$ 's and agent $m$ 's orders } \\
\hline Outstanding & $\underline{30.5}$ & 9.0 & 10.1 & 10.5 & 12.2 & $\underline{8.2}$ & 11.2 & 13.3 & 6.3 & 7.1 \\
\hline Next & 5.3 & 9.1 & 10.0 & 10.6 & 12.1 & 13.5 & 11.1 & 13.4 & 6.2 & 7.2 \\
\hline Transaction price & \multicolumn{2}{|c|}{8.5} & \multicolumn{2}{|c|}{10.4} & \multicolumn{2}{|c|}{12.6} & \multicolumn{2}{|c|}{12.0} & \multicolumn{2}{|c|}{6.9} \\
\hline \multicolumn{11}{|c|}{ Current market status after matching agent $k$ 's and agent $m$ 's orders } \\
\hline Outstanding & 5.3 & 9.1 & 10.1 & 10.5 & 12.1 & 13.5 & 11.2 & 13.3 & 6.3 & 7.1 \\
\hline Next & 5.2 & 9.2 & 10.0 & 10.6 & 12.0 & 13.6 & 11.1 & 13.4 & 6.2 & 7.2 \\
\hline Transaction price & \multicolumn{2}{|c|}{19.8} & \multicolumn{2}{|c|}{10.4} & \multicolumn{2}{|c|}{10.2} & \multicolumn{2}{|c|}{12.0} & \multicolumn{2}{|c|}{6.9} \\
\hline
\end{tabular}

\section{Conflicts of Interest}

The authors declare no conflict of interest. 


\section{References and Notes}

1. Hadjigeorgalis, E. A place for water markets: Performance and challenges. Rev. Agric. Econ. 2009, 31, 50-67.

2. Kiem, A.S. Drought and water policy in Australia: Challenges for the future illustrated by the issues associated with water trading and climate change adaptation in the Murray-Darling Basin. Glob. Environ. Change 2013, 23, 1615-1626.

3. Wei, Y.; Langford, J.; Willett, I.R.; Barlow, S.; Lyle, C. Is irrigated agriculture in the Murray Darling Basin well prepared to deal with reductions in water availability? Glob. Environ. Change 2011, 21, 906-916.

4. Ashton, D.; Hooper, S.; Oliver, M. An Economic Survey of Irrigation Farms in the MurrayDarling Basin: Industry Overview and Region Profiles 2007-08; Australian Bureau of Agricultural and Resource Economics: Canberra, Australia, 2009.

5. Hartman, L.M.; Seastone, D. Water Transfers: Economic Efficiency and Alternative Institutions; Johns Hopkins Press: Baltimore, MD, USA, 1970.

6. Scheierling, S.M. Assessing the Direct Economic Effects of Reallocating Irrigation Water to Alternative Uses: Concepts and an Application; Policy Research Working Paper Series 5797; The World Bank: Washington, DC, USA, 2011.

7. Etchells, T.; Malano, H.M.; McMahon, T.A. Overcoming third party effects from water trading in the Murray-Darling Basin. Water Policy 2006, 8, 69-80.

8. Heaney, A.; Dwyer, G.; Beare, S.; Peterson, D.; Pechey, L. Third-party effects of water trading and potential policy responses. Aust. J. Agric. Resour. Econ. 2006, 50, 277-293.

9. Connell, D.; Grafton, R.Q. Water reform in the Murray-Darling Basin. Water Resour. Res. 2011, 47, doi:10.1029/2010WR009820.

10. Bauer, C.J. Results of Chilean water markets: Empirical research since 1990. Water Resour. Res. 2004, 40, doi:10.1029/2003WR002838.

11. Griffin, R.C.; Boadu, F.O. Water marketing in Texas: Opportunities for reform. Nat. Resour. J. 1992, 32, 265-288.

12. Lee, T.R.; Jouravlev, A.S. Prices, Property and Markets in Water Allocation, Economic Commission for Latin America and the Caribbean; United Nations: Santiago, Chile, 1998.

13. Johnson, R.N.; Gisser, M.; Werner, M. The definition of a surface water right and transferability. J. Law Econ. 1981, 24, 273-288.

14. Lee, T.R. Water Management in the 21st Century: The Allocation Imperative; Edward Elgar: Cheltenham, UK, 1999.

15. Donohew, Z. Property rights and western United States water markets. Aust. J Agric. Resour. Econ. 2009, 53, 85-103.

16. Smith, H. Governing water: The semicommons of fluid property rights. Ariz. Law Rev. 2008, $50,445-478$.

17. Livingston, M.L.; Miller, T.A. A framework for analyzing the impact of western instream water rights on choice domains: Transferability, externalities, and consumptive use. Land Econ. 1986, 62, 269-277. 
18. Easter, K.W.; Rosegrant, M.W.; Dinar, A. Formal and informal markets for water: Institutions, performance, and constraints. World Bank Res. Obs. 1999, 14, 99-116.

19. Howe, C.W. Property rights, water rights and the changing scene in western water. In Water Institutions: Policies, Performance and Prospects; Gopalakrishnan, C., Tortajada, C., Biswas, A.K., Eds.; Springer-Verlag: Berlin, Germany, 2005; pp. 175-185.

20. Hung, M.F.; Shaw, D. A trading-ratio system for trading water pollution discharge permits. J. Environ. Econ. Manag. 2005, 49, 83-102.

21. Etchells et al. [7] have done a good job of assessing the advantages and disadvantages of five existing strategies in response to third-party effects. The five strategies are restricting trade to smaller areas to limit third-party effects, third parties seek compensation for effects, fees to compensate affected parties, actions to mitigate impacts, and exchange rates to adjust traded entitlement. See Table 1 in Etchells et al. [7]. The system of locational water rights developed in this paper can be categorized as the strategy of "exchange rates to adjust traded entitlements" among the five strategies.

22. Huang, C.C.; Tsai, M.H.; Lin, W.T.; Ho, Y.F.; Tan, C.H.; Sung, Y.L. Experiences of water transfer from the agricultural to the non-agricultural sector in Taiwan. Paddy Water Environ. 2007, 5, 271-277.

23. Levine, G.; Barker, R.; Huang, C.C. Water transfer from agriculture to urban uses: Lessons learned, with policy considerations. Paddy Water Environ. 2007, 5, 213-222.

24. Anderson, R.L.; Johnson, R.N. The problem of instream flows. Econ. Inq. 1986, 24, 535-554.

25. Weber, M.L. Markets for water rights under environmental constraints. J. Environ. Econ. Manag. 2001, 42, 53-64.

26. A mathematical simulation of how the system of locational water rights is applied in a more general river environment where a river system has branches, cross-location and multiple-point return flows can be made available for those who are interested.

27. Jowett, I.G. Instream flow methods: A comparison of approaches. Regul. Rivers Res. Manag. 1997, 13, 115-127.

28. Tharme, R.E. A global perspective on environmental flow assessment: Emerging trends in the development and application of environmental flow methodologies for rivers. River Res. Appl. 2003, 19, 397-441.

29. State Environmental Resource Center Homepage. Available online: http://www.serconline.org/ streamflow/faq.html (accessed on 3 March 2014).

30. Note that if $T_{i}^{0}<0$ according to Equation (9), location $i$ is called a critical location. $\bar{v}_{i}$ then becomes the binding constraint for its immediate upstream location, i.e., the regulator should set $T_{i}^{0}=0$ and reset $T_{i-1}^{0}=\left(v_{0}-\bar{v}_{i}\right)-\sum_{j=1}^{i-2} T_{j}^{0}$ by expanding and rearranging Equation (9).

31. National Water Commission (NWC). The Impacts of Water Trading in the Southern Murray-Darling Basin: An Economic, Social and Environmental Assessment; National Water Commission: Canberra, Australia, 2010. 
32. Water Resources Agency. Chi-Chi Weir Operation in Yr. 2005 Aquatic Ecology and Water Quality Monitoring Report; Water Resources Agency, Ministry of Economic Affairs, Taiwan: Taichung, Taiwan, 2006 (in Chinese).

33. Water Resources Agency. Study on Investigation, Assessment and Operation Management of the Reuse of Agriculture Return Water in Taiwan (1/2); Water Resources Agency, Ministry of Economic Affairs, Taiwan: Taichung, Taiwan, 2008 (in Chinese).

34. Hung, M.F.; Chie, B.T. Residential water use: Efficiency, affordability, and price elasticity. Water Resour. Manag. 2013, 27, 275-291.

35. Chiueh, Y.W.; Chen, M.C. Establishment of regional water transfer mechanism-Theoretical and empirical model of water bank. J. Agric. Econ. 2005, 77, 171-202 (in Chinese).

36. Wu, H.R. An empirical study on the industrial water demand in Taiwan. Taiwan Bank Q. 1996, 47, 253-275 (in Chinese).

37. In fact, there is very little research studying demand functions of water consumption in Taiwan which might be due to the regulation and small variation of water price. After considering the compatibility with this simulation, we applied demand functions estimated for other cases in Taiwan. First, the domestic water demand function was drawn from Hung and Chie [34] who studied the case of Taipei City. We adjusted the function by using the 2011 household data in the Choushui River basin for variables in the equation; Second, the agricultural water demand function was obtained from Chiueh and Chen [35] who studied the case of water demand for the first crop in the Kaohsiung area. We adjusted the function according to the coverage of irrigated area in 2011 for each canal in our case; Third, the industrial water demand function is acquired from $\mathrm{Wu}$ [36] who studied the water demand of the chemical materials industry. Because the No. 6 NCP of FPC is the dominant and largest user in the Yunlin Offshore Industrial Park, we applied the water demand of the chemical materials industry with the adjustment of using 2011 data of the No. 6 NCP for variables in the equation. Finally, the time span of water demand for all these demand functions was transformed to four months to be consistent with the length of dry season.

38. It should be mentioned that the inverse demand functions for agricultural users are linear, while those for domestic and industrial users are nonlinear. As the water consumption approaches zero, the marginal benefits of agricultural water are no larger than $29 \mathrm{NT} \$ / \mathrm{m}^{3}$ while the marginal benefits for domestic and agricultural water approach infinity. This will result in an unrealistic high value of the estimated total benefit for water using. Because the agricultural user will sell water if the bid for water is higher than $29 \mathrm{NT} \$ / \mathrm{m}^{3}$, we assume that the maximal WTP for water of domestic and industrial users is $30 \mathrm{NT} \$ / \mathrm{m}^{3}$ (a little higher than $29 \mathrm{NT} \$ / \mathrm{m}^{3}$ ) to calculate the total benefit.

39. Demsetz, H. Toward a theory of property rights. Am. Econ. Rev. 1967, 57, 347-359. 


\title{
Inexact Mathematical Modeling for the Identification of Water Trading Policy under Uncertainty
}

\section{Xueting Zeng, Yongping Li, Guohe Huang and Liyang Yu}

\begin{abstract}
In this study, a two-stage inexact credibility-constrained programming (TICP) method is developed for identifying the efficiency of water trading under multiple uncertainties. TICP can tackle uncertainties expressed as probabilistic distributions, discrete intervals and fuzzy sets. It can also provide an effective linkage between the benefits to the system and the associated economic penalties attributed to the violation of the predefined policies for water resource allocation. The developed TICP method is applied to a real case of water resource allocation management and planning in the Kaidu-kongque River Basin, which is a typical arid region in Northwest China. Different water resource allocation policies based on changes to the water permit and trading ratio levels are examined. The results indicate that the efficiencies of water trading are sensitive to the degrees of satisfaction (i.e., interval credibility levels), which correspond to different water resource management policies. Furthermore, the comparison of benefits and shortages between trading and non-trading schemes implies that trading is more optimal and effective than non-trading. The results are helpful for making decisions about water allocation in an efficient way and for gaining insight into the tradeoffs between water trading and economic objectives.
\end{abstract}

Reprinted from Water. Cite as: Zeng, X.; Li, Y.; Huang, G.; Yu, L. Inexact Mathematical Modeling for the Identification of Water Trading Policy under Uncertainty. Water 2014, 6, 229-252.

\section{Introduction}

In the past few decades, the pressures of human population and patterns of economic development have led to the shrinking of available water resources worldwide, while water shortage has become a critical factor in the global water crisis. It is a challenge for water resource managers and planners to maintain sustainable development under situations of increasing population, developing economies and changing climate. Particularly in many semiarid and arid regions, water shortage and an unreliable water supply have been regarded as one major obstacle to regional sustainable development for watershed systems [1-4]. Water trading is useful for allocating water resources optimally, which increases the economic productivity of water by encouraging its movement from low to high valued use. Under the situation of limited water resources, markets can also provide incentives to adopt water saving policies [5]. Water trading can balance limited water resources between the allocation for human use and the streamflow, especially in semi-arid and arid regions, such that several water trading programs have been established and are under development throughout the world [6-8]. However, the uncertainties existing in practical water trading programs are often related to errors in the acquired data, variations in spatial and temporal units and the incompleteness or impreciseness of the observed information, which leads to difficulties in planning water trading scientifically [9]. Consequently, the effective planning of water resource management 
under such uncertainties and complexities is important for facilitating sustainable socio-economic development for watershed systems [10].

Two-stage stochastic programming (TSP) is effective in dealing with problems for which an analysis of policy scenarios is desired and the uncertainties can be expressed as probabilistic distributions [11,12]. In TSP, an initial decision must be made before the realization of random variables (first-stage decision), and then, a corrective action can be taken after random events have taken place (second-stage decision) [13]. This implies that a second-stage decision can be used to minimize "penalties" that may appear, due to some infeasibility [14]. TSP has been widely used for water resource management and planning over the past few decades. For example, Maqsood et al. [15] developed an interval-fuzzy two-stage stochastic programming method for planning water resource management systems associated with multiple uncertainties, in which interval fuzzy programming methods were introduced into a TSP framework. Kenneth et al. [16] developed a TSP method for tackling uncertainties expressed as probability density functions for water availability. Li et al. [17] proposed an interval-parameter two-stage stochastic nonlinear programming method for supporting decisions about water-resource allocation within a multi-reservoir system, where uncertainties expressed as both probability distributions and discrete intervals were reflected. Vidoli [18] evaluated water resource services by integrating conditional, robust, nonparametric frontier and multivariate adaptive regression splines into a TSP framework. In general, TSP can provide an effective linkage between policies and the economic penalties, which has the advantages of reflecting the complexities of system uncertainties, as well as analyzing policy scenarios when the pre-regulated targets are violated. However, the major problem of TSP is that the increased data requirement for specifying the probability distributions of coefficients may affect their practical applicability [19]. One potential approach to better account for more complex uncertainties is to introduce an interval-parameter programming (IPP) technique into the TSP framework. IPP is an alternative for handling uncertainties in the model's left- and/or right-hand sides, as well as those that cannot be quantified as membership or distribution functions, since interval numbers are acceptable as its uncertain inputs. Moreover, in practical water resource management problems, uncertainties may be related to errors in the acquired data, variations in spatial and temporal units and the incompleteness or impreciseness of the observed information in water resource management $[10,20]$. Fuzzy programming (FP) is effective in handling ambiguous coefficients of objective functions and constraints caused by imprecision and vagueness, when the quality and quantity of uncertain information is often not satisfactory enough to be presented as a probabilistic distribution. Previously, a number of FP techniques, such as the fuzzy-stochastic [21,22], interactive fuzzy [23] and robust methods [24,25], were developed to deal with uncertainties in decision making problems. Fuzzy credibility-constrained programming (FCP) is effective in reflecting the fuzziness inherited with parameters associated with subjective considerations, which would be useful in the presence of weaker sources of information. FCP can measure the confidence levels in a fuzzy water system to tackle uncertainties expressed as fuzzy sets, when detailed information is not able to be presented by interval or stochastic numbers [26-29]. However, few studies have been reported on the application of FCP techniques to water resource management and planning [30-32]. Therefore, one potential approach to better account for multiple 
uncertainties and economic penalties is to introduce the IPP and FCP concepts into the TSP framework; this will lead to a two-stage inexact credibility-constrained programming (TICP) method.

The aim of this study is to develop such a TICP method for identifying a cost-effective water trading policy under multiple uncertainties. The TICP is an integrated optimization technique for tackling uncertainties expressed as discrete intervals, probability distributions and fuzzy sets. The TICP method will be applied to a real case study of water resource management in the Kaidu-kongque River Basin, which is one of the aridest regions in Northwest China. The degrees of satisfaction for the given constraints will be represented using interval credibility levels, which can provide scientific support for large-scale regional water-resource management under uncertainty conditions at the watershed level. A number of policy scenarios that are associated with different decreasing levels of the water permit and trading ratio will be analyzed, which can help in gaining insight into the tradeoff between water trading and economic objectives.

\section{Methodology}

When uncertainties of the right-hand side of the model are expressed as probability density functions (pdfs) and decisions need to be made periodically over time, the problem can be formulated as a two-stage stochastic programming (TSP) model [33]. A general TSP linear model can be formulated as follows:

$$
\operatorname{Max} f=c^{T} x-\sum_{h=1}^{H} p_{h} Q\left(y, \omega_{h}\right)
$$

subject to:

$$
\begin{gathered}
A x \leq b \\
T\left(\omega_{h}\right) x+W\left(\omega_{h}\right)=g\left(\omega_{h}\right), \quad \forall h=1,2, \ldots, H \\
x \geq 0 \\
\mathrm{y}\left(\omega_{h}\right) \geq 0
\end{gathered}
$$

where $x$ is the vector of the first-stage decision variables, $c^{T} x$ is the first-stage benefits, $\omega$ is the random events after the first-stage decisions are made, $p_{h}$ is the probability of an event, $\omega_{h}, Q\left(y, \omega_{h}\right)$ is the recourse at the second-stage under the occurrence of the event, $\omega h$, and $\sum_{h=1}^{H} p_{h} Q\left(y, \omega_{h}\right)$ is the expected value of the second-stage penalties [12]. However, the parameter of a model may fluctuate within a certain interval, and it is difficult to state a meaningful probability distribution for this variation. Interval-parameter programming (IPP) can deal with uncertainties in objective function and system constraints, which can be expressed as intervals without distribution information. An interval number, $x^{ \pm}$, can be defined as an interval with a known lower-bound and upper-bound, but unknown distribution information $[34,35]$. It can be expressed as $\left[x^{-}, x^{+}\right]$, representing a number (or an interval), which can have a minimum value of $x^{-}$and a maximum one of $x^{+}$.

$$
x^{ \pm}=\left[x^{-}, x^{+}\right]=\left\{a \in x \mid x^{-} \leq a \leq x^{+}\right\}
$$


where $x^{-}$and $x^{+}$are the lower and upper bounds of $x^{ \pm}$, respectively. When $x^{-}=x^{+}, x^{+}$becomes a deterministic number. When uncertainties presented as probabilities and intervals exist in water resource management systems, based on IPP and TSP techniques, an inexact TSP (ITSP) model can be formulated as follows [17]:

$$
\operatorname{Max} f^{ \pm}=c^{ \pm} x^{ \pm}-\sum_{h=1}^{H} p_{h} Q\left(y^{ \pm}, \omega_{h}^{ \pm}\right)
$$

subject to:

$$
\begin{gathered}
A^{ \pm} x^{ \pm} \leq b^{ \pm} \\
T\left(\omega_{h}^{ \pm}\right) x^{ \pm}+W\left(\omega_{h}^{ \pm}\right)=g\left(\omega_{h}^{ \pm}\right), \quad \forall h=1,2, \ldots, H \\
x^{ \pm} \geq 0 \\
y\left(\omega_{h}^{ \pm}\right) \geq 0
\end{gathered}
$$

Let $\tilde{b}$ be a fuzzy set of imprecise right-hand sides with possibility distributions. The triangular fuzzy membership function is the most popular possibility distribution, and it is adopted in this study, due to its computational efficiency. Accordingly, the credibility of the constraint $A x \leq \tilde{b}$ could be defined as follows [32]:

$$
\operatorname{Cr}(A x \leq \tilde{b})=\left\{\begin{array}{l}
1 \text { if } \mathrm{A} x \leq b, \\
\frac{2 b-\underline{b}-A x}{2(b-b)} \quad \text { if } \quad \underline{b} \leq A x \leq b, \\
\frac{b-r}{2(\bar{b}-b)} \text { if } \quad b \leq \mathrm{A} x \leq \bar{b}, \\
0 \text { if } \mathrm{A} x \leq \bar{b}
\end{array}\right\}
$$

Thereby, a general credibility constrained problem can be formulated as follows:

$$
\operatorname{Max} f=c^{T} X
$$

subject to:

$$
\begin{gathered}
C r\{A x \leq \tilde{b}\} \geq \lambda \\
x \geq 0
\end{gathered}
$$

where $\lambda$ is the credibility level. In the optimization process for management and planning, it is usually assumed that the credibility level should be no less than 0.5 [32]. Thus, Equation (5b) can be rewritten as:

$$
\operatorname{Cr}\{A x \leq \tilde{b}\}=\frac{2 b-\underline{b}-A x}{2(b-\underline{b})} \geq \lambda
$$

where it can be transformed into a deterministic constraint as follows:

$$
A x \leq b+(1-2 \lambda)(b-\underline{b})
$$


Therefore, by incorporating the creditability constraints equation into the ITSP framework, a two-stage inexact credibility-constrained programming (TICP) model can be formulated as follows:

$$
\operatorname{Max} f^{ \pm}=c^{ \pm} x^{ \pm}-\sum_{h=1}^{H} p_{h} Q\left(y^{ \pm}, \omega_{h}^{ \pm}\right)
$$

subject to:

$$
\begin{gathered}
\operatorname{Cr}\left\{A^{ \pm} x^{ \pm} \leq \tilde{b}^{ \pm}\right\} \geq \lambda \\
T\left(\omega_{h}^{ \pm}\right) x^{ \pm}+W\left(\omega_{h}^{ \pm}\right)=g\left(\omega_{h}^{ \pm}\right), \quad \forall h=1,2, \ldots, H \\
x^{ \pm} \geq 0 \\
\mathrm{y}\left(\omega_{h}^{ \pm}\right) \geq 0
\end{gathered}
$$

Then, an interactive two-step solution algorithm is proposed for solving the TICP model, which is different from normal interval analysis and best/worst-case analysis [12,34,35]. The TICP model can be transformed into two sets of deterministic submodels, which correspond to the lower and upper bounds of the desired objective function value. The resulting solutions can provide intervals for the objective function and decision variables with different levels of risk in violating the constraints. When the objective is $f^{+}$, which corresponds to the upper bound of the objective function value, it can be formulated as follows:

$$
\operatorname{Max} f^{+}=\sum_{j=1}^{q_{1}} c_{j}^{+} x_{j}^{+}+\sum_{j=q_{1}+1}^{n} c_{j}^{+} x_{j}^{-}-\sum_{h=1}^{H} \sum_{k=1}^{q_{2}} p_{h} d_{k}^{-} y_{k}^{-}-\sum_{h=1}^{H} \sum_{k=q_{2}+1}^{m} p_{h} d_{k}^{+} y_{k}^{+}
$$

subject to:

$$
\begin{gathered}
\sum_{j=1}^{q_{1}}\left|a_{i j}^{ \pm}\right|^{-} \operatorname{sign}\left(a_{i j}^{ \pm}\right) x_{j}^{+}+\sum_{j=q_{1}+1}^{n}\left|a_{i j}^{ \pm}\right|^{+} \operatorname{sign}\left(a_{i j}^{ \pm}\right) x_{j}^{-} \leq b_{i}+\left(1-2 \lambda_{i}^{-}\right)\left(b_{i}-\underline{b}_{i}\right), \quad \forall i=1,2, \ldots, M \\
\sum_{j=1}^{q_{1}} T\left(\omega_{h}\right) x_{j}^{+}+\sum_{j=q_{1}+1}^{n} T\left(\omega_{h}\right) x_{j}^{-}+\sum_{k=1}^{q_{2}} W\left(\omega_{h}\right) y_{k}^{-}+\sum_{k=q_{2}+1}^{m} W\left(\omega_{h}\right) y_{k}^{+}=g\left(\omega_{h}\right), \quad \forall h=1,2, \ldots, H \\
x_{j}^{+} \geq 0, \quad j=1,2, \ldots, q_{1} \\
x_{j}^{-} \geq 0, \quad j=q_{1}+1, \ldots, n \\
y_{k}^{+} \geq 0, \quad k=1,2, \ldots, q_{2} \\
y_{j}^{-} \geq 0, \quad j=q_{2}+1, \ldots, m \\
\sum_{h=1}^{H} p_{h}=1
\end{gathered}
$$

where $c_{j}^{+}\left(j=1,2, \ldots, q_{1}\right)>0 ; c_{j}^{+}\left(j=q_{1}+1, q_{1}+2, \ldots, n\right)<0 ; d_{k}^{+}\left(j=1,2, \ldots, q_{2}\right)>0 ; d_{k}^{+}\left(j=q_{2}+1, q_{2}\right.$ $+2, \ldots, m)<0 ; \operatorname{sign}\left(a_{j}^{ \pm}\right)=-1$ when $a_{j}^{ \pm}<0, \operatorname{sign}\left(a_{j}^{ \pm}\right)=1$ when $a_{j}^{ \pm}>0$ and $\lambda^{-}=$the lower bound of the credibility level value. 
The optimal solution of Model (9), including $x_{\text {jopt }}^{+}$for $j=1$ to $q_{1}, x_{j o p t}^{-}$for $j=q_{1}+1$ to $n, y_{k o p t}^{+}$ for $k=1$ to $q_{2}$ and $y_{k o p t}^{-}$for $k=q_{2}+1$ to $m$, can be obtained. Accordingly, the second submodel corresponding to the lower bound of the objective function value can be formulated as:

$$
\operatorname{Max} f^{-}=\sum_{j=1}^{q_{1}} c_{j}^{-} x_{j}^{-}+\sum_{j=q_{1}+1}^{n} c_{j}^{-} x_{j}^{+}-\sum_{h=1}^{H} \sum_{k=1}^{q_{2}} p_{h} d_{k}^{+} y_{k}^{+}-\sum_{h=1}^{H} \sum_{k=q_{2}+1}^{m} p_{h} d_{k}^{-} y_{k}^{-}
$$

subject to:

$$
\begin{gathered}
\sum_{j=1}^{q_{1}}\left|a_{i j}^{ \pm}\right|^{+} \operatorname{sign}\left(a_{i j}^{ \pm}\right) x_{j}^{-}+\sum_{j=q_{1}+1}^{n}\left|a_{i j}^{ \pm}\right|^{-} \operatorname{sign}\left(a_{i j}^{ \pm}\right) x_{j}^{+} \leq b_{i}+\left(1-2 \lambda_{i}^{+}\right)\left(b_{i}-\underline{b_{i}}\right), \quad \forall i=1,2, \ldots, M \\
\sum_{j=1}^{q_{1}} T\left(\omega_{h}\right) x_{j}^{-}+\sum_{j=q_{1}+1}^{n} T\left(\omega_{h}\right) x_{j}^{+}+\sum_{k=1}^{q_{2}} W\left(\omega_{h}\right) y_{k}^{+}+\sum_{k=q_{2}+1}^{m} W\left(\omega_{h}\right) y_{k}^{-}=g\left(\omega_{h}\right), \quad \forall h=1,2, \ldots, H \\
0<x_{j}^{+} \leq x_{j o p t}^{+}, \quad j=1,2, \ldots, q_{1} \\
0<x_{j}^{-} \leq x_{j o p t}^{-}, \quad j=q_{1}+1, q_{1}+1, \ldots, n \\
0<y_{j}^{+} \leq y_{j o p t}^{+}, \quad j=1,2, \ldots, q_{2} \\
0<y_{j}^{-} \leq y_{j o p t}^{-}, \quad j=q_{2}+1, q_{2}+1, \ldots, n \\
\sum_{h=1}^{H} p_{h}=1
\end{gathered}
$$

Thereby, optimal solutions of Model (10) can be gained, including $x_{j o p t}^{-}$for $j=1$ to $q_{1}, x_{j o p t}^{+}$for $j=q_{1}+1$ to $n, y_{k o p t}^{-}$for $k=1$ to $q_{2}$ and $y_{k o p t}^{+}$for $k=q_{2}+1$ to $\mathrm{m}$. Therefore, by integrating the solutions of the two submodels, the solution of the TICP model can be generated.

The solution process of TICP can be summarized as follows:

- Step 1: Formulate the TICP model.

- Step 2: Transform the TICP model into two submodels, where the submodel corresponding to $f^{+}$is desired first, since the objective is to maximize $f^{ \pm}$.

- Step 3: Obtain the optimal solutions by solving the $f^{+}$submodel under each $\lambda$.

- Step 4: Formulate and solve the $f^{-}$submodel by importing optimal solutions from the $f^{+}$ submodel into the $f^{-}$submodel under each $\lambda$.

- Step 5: Obtain the optimal solution interval value under each $\lambda$.

\section{Case Study}

The Kaidu River and the Kongque River are the branches of the Tarim River formed from the middle of mountain Tian to Lake Bositeng and are about $610 \mathrm{~km}$ - and $785 \mathrm{~km}$-long, respectively. The Kaidu-kongque River Basin is located in the middle reach of the Tarim River Basin, which is approximately $62 \times 10^{3} \mathrm{~km}^{2}$ [36] (as shown in Figure 1). It is a typical arid region, due to an extremely dry climate and a low and uneven distribution of rainfall. For example, the climate in the basin is 
extremely dry, with the average rainfall being about $273 \mathrm{~mm} / \mathrm{year}$, which is more than $80 \%$ of the total annual precipitation fall from May to September and less than $20 \%$ of the total fall from November to the following April [37]. The basin includes six counties (i.e., Kuerle, Yanqi, Hejing, Heshuo, Bohu and Yuli) and has a population of more than one million [36]. It is suitable for the growth of crops, such as wheat, corn, sugar beet, tomato and fruit, which have provided high-speed growth in agricultural product processing and manufacturing. Moreover, the rich mineral and oil resources of the basin form an industrial structure dominated by mining, the chemical industry and the fossil oil industry, while textiles, electric power, papermaking and transportation are keeping pace with the development of the mainstay industries. The water demands of four users (e.g., municipal, agricultural, industrial and ecological) in six districts rely on the river's streamflow, which is mainly derived from upstream flow, snow melt and rainfall. Due to the dry climate, low-rainfall and high evaporation, the water supply capacity of the river is quite low, which presents difficulties in satisfying the water demands from the six counties. Particularly in recent years, the demand for water has reached the limits of what the natural system can provide, so that water shortage could become a major obstacle to social and economic development for this region. Unfortunately, in the study of the basin, there is a lack of effective tools for facilitating efficient, equitable and sustainable water resource management. Therefore, population growth, the food security challenge, industrial sector development and the potential threat of climate change elevate the attention given to efficient and sustainable water management [38].

Figure 1. The study area.

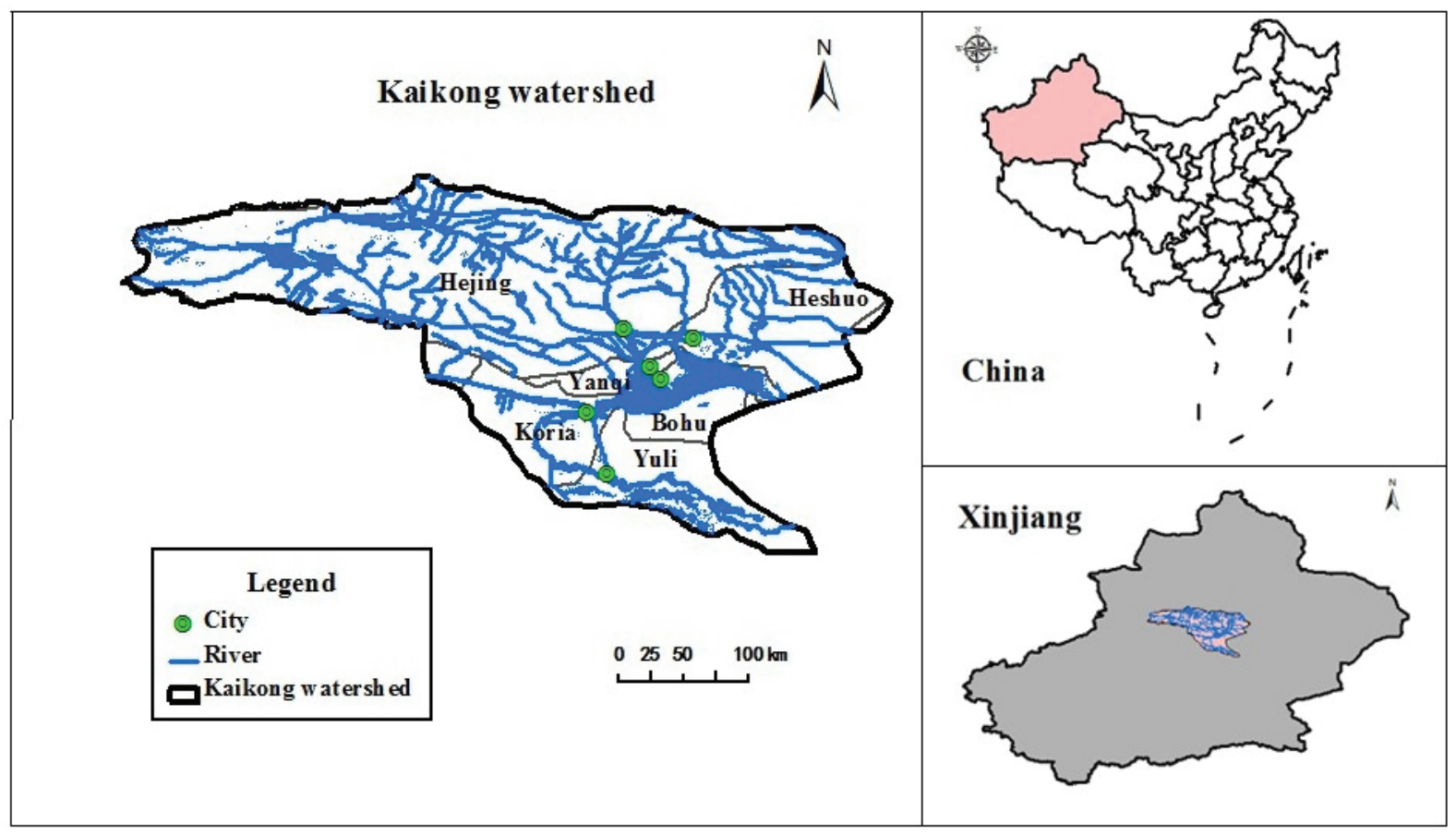

Water trading can solve conflicts caused by water shortage $[39,40]$, not only improving the net benefit for the system, but also saving water, while respecting hydrological, environmental, food security, economic development, population growth and institutional constraints. Under an allocated water permit, trading can release surplus water to remedy the losses from water deficiency, achieving 
a higher profitability. However, a number of variations caused by factitious factors and natural factors exist in the trading system, which bring more complexities and uncertainties to the water trading system. For example, less observation and insufficient data create uncertainties in data inputting, and natural uncertainties generate many stochastic factors in the trading system, such as streamflow water, demand and water-allocation targets; fluctuations can be associated with the net benefit for the system. These complexities could become further compounded by not only interactions among the uncertain parameters, but also their economic implications [2]. Therefore, the proposed TICP model can be used in water trading for optimally allocating limited water resources to facilitate regional sustainability with a maximized benefit for the system.

A manager (e.g., a valley authority or water resources bureau) is responsible for allocating water resources to multiple users (e.g., residential, industrial, agricultural and ecological) in the Kaidukongque River Basin and aims to create a plan to effectively allocate the uncertain supply of water to every user in order to satisfy the users' demand and to maximize the overall benefit for the system. In order to recover the ecological system of the lower reach of the watershed, the manager has obligated water to maintain the water level of the river first. Water permits have been allocated to each user by a manager in the beginning of this year, which are based on the water utilization of last year. Nevertheless, allocations are made once per year, which will be adjusted by the water manager next year. When variations emerge in this year, system disruption risk attributable to the uncertainties may influence the benefits for the system and water supplies tremendously. This leads to a problem of recourse for planning water resource allocation with a maximized economic benefit and a minimized system failure risk.

On the basis of the local management policy, water availability is allocated to users for consumption by the percentage of the water permits, which leads to water surpluses and water shortages, but not to trading, when water is not tradable. The benefits for the system denote the profit of the economic production in proportion to the pre-regulated economic targets, while the system's recourse penalties denote the loss for a shortage. With the purpose of obtaining a more effective water allocation, a water trading program can be established, in which water permits being traded at a higher value substitute for the allocation to each user proportionally. When water is tradable, water permits being allocated to users by cubic meters, water shortages and surpluses emerge, due to the difference between water targets, permits and availability. Therefore, retributions for water permits would be acquired, with which water shortages and surpluses could join in the water market for trading based on the law of value. Since the water market can provide an equal and effective manner of allocating water, water shortages and surpluses reallocated by water trading led to water permits being reattributed. Under such a situation, the manager can reduce the water permits to release appropriate water permits for trade in the water market according to the actual water requirements, which achieves a maximized benefit for the system, while considering the trading costs (the trading cost is smaller than the loss of the shortage). Moreover, multiple uncertainties may exist in water allocation and trading processes (e.g., uncertain data and the probability distribution of water availability), which affect water resource management planning. Thus, the manager will formulate a TICP model for water trading to maximize the entire benefit for the system, which can satisfy the 
goal of water use reduction and allow for reflection on complex uncertainties. When water is tradable, the TICP model can be formulated as follows:

$$
\operatorname{Max} f_{1}^{ \pm}=\sum_{i=1}^{I} \sum_{j=1}^{J} B_{i j}^{ \pm} W_{i j}^{ \pm}-\sum_{i=1}^{I} \sum_{j=1}^{J} \sum_{h=1}^{H} P_{h} C_{i j}^{ \pm} Y_{i j h}^{ \pm}+\sum_{i=1}^{I} \sum_{j=1}^{J} B_{i j}^{ \pm} L_{i j h}^{ \pm}-\sum_{i=1}^{I} \sum_{j=1}^{J}\left(F C_{i j}^{ \pm}+V C_{i j}^{ \pm}\right) L_{i j h}^{ \pm}
$$

Subject to the:

(1) Constraints of water permit:

$$
\sum_{i=1}^{I} \sum_{j=1}^{J} M_{i j}^{ \pm} \leq(1-d) * \sum_{i=1}^{I} \sum_{j=1}^{J} T_{i j}^{ \pm}, \quad \forall i, j
$$

(2) Constraints of water shortage:

$$
\sum_{i=1}^{I} \sum_{j=1}^{J}\left(W_{i j}^{ \pm}-Y_{i j h}^{ \pm}\right) \leq \widetilde{Q_{j i h}}, \quad \forall i, j, h
$$

(3) Constraints of water surplus:

$$
\sum_{i=1}^{I} \sum_{j=1}^{J}\left(M_{i j}^{ \pm}+N_{i j h}^{ \pm}\right) \geq \widetilde{Q_{j i h}}, \quad \forall i, j, h
$$

(4) Constraints of water trading:

$$
\begin{gathered}
L_{i j h}^{ \pm} \leq \frac{t_{i j h}^{\prime}}{t_{i j h}}\left(Y_{i j h}^{ \pm}-N_{i j h}^{ \pm}\right) \quad \forall i, j, h \\
F C_{i j}^{ \pm}+V C_{i j}^{ \pm} \leq C_{i j}^{ \pm}, \quad \forall i, j
\end{gathered}
$$

(5) Constraints of technical:

$$
\begin{gathered}
0 \leq Y_{i j h}^{ \pm} \leq W_{i j}^{ \pm}, \quad \forall i, j \\
M_{i j}^{ \pm} \geq 0, \quad \forall i, j \\
W_{i j}^{ \pm} \geq 0, \quad \forall i, j
\end{gathered}
$$

where $i$ denotes the type of user $(i=1,2,3,4), j$ denotes name of the district $(j=1,2, \ldots, 6), h$ denotes the probability level of random water availability $(h=1,2,3), f_{1}^{ \pm}$presents the net benefit of the entire system with trading (US\$), $B_{i j}^{ \pm}$is net benefit to user $i$ in district $j$ per volume of water being delivered (US\$ $\left.\$ 10^{3} \mathrm{~m}^{3}\right), W_{i j}^{ \pm}$is the water demand target for user $i$ in district $j\left(10^{6} \mathrm{~m}^{3}\right), Q_{i j h}^{ \pm}$is the total water availability of the entire system under probability $P_{h}\left(10^{6} \mathrm{~m}^{3}\right), P_{h}$ denotes the probability of random water availability $Q_{i j}^{ \pm}$under level h (\%), $C_{i j}^{ \pm}$is the economic loss to user $i$ in district $j$ per volume of water not being delivered (US\$ $\left.\$ 10^{3} \mathrm{~m}^{3}\right), Y_{i j h}^{ \pm}$is the water deficiency for user $i$ in district $j$ when demand $W_{i j}^{ \pm}$is not met $\left(10^{6} \mathrm{~m}^{3}\right), T_{i j}^{ \pm}$is the allocated allowable water permit to user $i$ in district $j\left(10^{6} \mathrm{~m}^{3}\right), \lambda$ is the credibility level, which measures the degrees of satisfaction of the constraints, $d$ is the percentage of the reduced total allowable water allocation, $\mathrm{N}_{i j h}^{ \pm}$is the water released to user $i$ in district $j$ when the total water availability exceeds the allowable water reallocation with trading 
scheme $\left(10^{6} \mathrm{~m}^{3}\right), F C_{i j}^{ \pm}$is the trading fixed cost to user $i$ in district $j$ with trading scheme (US\$ $/ 10^{3}$ $\left.\mathrm{m}^{3}\right), V C_{i j}^{ \pm}$is the variable trading cost to user $i$ in district $j$ with trading scheme (US\$ $\left.\$ 10^{3} \mathrm{~m}^{3}\right), L_{i j h}^{ \pm}$ is the amount of water trading from other water sources to user $i$ in district $j$ with trading scheme $\left(10^{6}\right.$ $\mathrm{m}^{3}$ ) and $t_{i j h}^{\prime} / t_{i j h}$ is the ratio of water trading from other water sources to user $i$ in $\operatorname{district} j$ with the trading scheme.

Table 1 shows basic economic data and trading costs, which are estimated indirectly based on the statistical yearbook of the Xinjiang Uygur Autonomous Region in the Uygur Autonomous Region, 2005-2010, and the water price for the Xinjiang Autonomous Region. Values of $B_{i j}^{ \pm}$and $C_{i j}^{ \pm}$are estimated according to different users' gross national product in different counties indirectly, the upper bound values of which are estimated as the highest from the yearbook (2005-2010) and the lower bound values of which are the opposite. For example, the net benefit $\left(B_{i j}^{ \pm}\right)$for the agricultural user in Hejing County is estimated by the gross amount of crops (i.e., wheat, corn, tomato, cotton and fruit) and the total water demand (net benefit = gross amount of crops/total water demand). From 2005 to 2010, the highest net benefit was $1860 \mathrm{US} \$ 10^{3} \mathrm{~m}^{3}$ in 2008 , which was estimated by the gross amount of crops (i.e., wheat $=45.1 \times 10^{6} \mathrm{US} \$$; oil plant $=11.3 \times 10^{6} \mathrm{US} \$$; tomato $=15.93 \times 10^{6} \mathrm{US} \$$; cotton $t=44.02 \times 10^{6} \mathrm{US} \$$ and other crops $=47.33 \times 10^{6} \mathrm{US} \$$ ) and the water demand (i.e., wheat $=24.1 \times 10^{6} \mathrm{~m}^{3}$; oil plant $=2.91 \times 10^{6} \mathrm{~m}^{3}$; tomato $=3.41 \times 10^{6} \mathrm{~m}^{3}$; cotton $=29.4 \times 10^{6} \mathrm{~m}^{3}$ and other crops $=28.18 \times 10^{6} \mathrm{~m}^{3}$ ). Meanwhile, the lowest net benefit was $1530 \mathrm{US} \$ / 10^{3} \mathrm{~m}^{3}$ in 2005 . Therefore, the interval value of the net benefit is acquired as $[1530,1860]$ $\mathrm{US} \$ 10^{3} \mathrm{~m}^{3}$, which is on the basis of the highest and lowest value of the net benefit. The method calculated for the net benefit of the agricultural user in Hejing County can be applied to other users, districts and even other economic data. $F C_{i j}^{ \pm}$is a basic form of trading cost, which is estimated by the actual price of water exceed water permit in Kaidu-kongque Basin. $V C_{i j}^{ \pm}$is estimated according to the opportunity cost of water, which is affected by a number of factors, such as the scarcity of water resources, the relationship between supply and demand and the status of socio-economic development. Table 2 shows policy data $T_{i j}^{ \pm}$, which are acquired from the water permits of the water authority of Uygur Autonomous Region from 2005 to 2010 directly. Additionally, water target $W_{i j}^{ \pm}$ is estimated by the users' actual water usage in recent years, which takes the situation of economic development into consideration. The value of $Q_{i j h}^{ \pm}$should be derived by conducting statistical analyses with the results of the annual streamflow of the Kaidu-kongque River (2005-2010). Due to the rainy seasons in the Kaidu-kongque River Basin, more than $80 \%$ of the total annual precipitation falls from May to September, and less than $20 \%$ of the total falls from November to the following April [37]. Therefore, the total water availability can be converted to several levels. Table 3 shows the total water availability of the Kaidu-kongque River Basin under several level probabilities. 
Table 1. Economic data and trading costs.

\begin{tabular}{|c|c|c|c|c|}
\hline \multirow{3}{*}{ District } & \multicolumn{4}{|c|}{ User } \\
\hline & $i=1$ & $i=\mathbf{2}$ & $i=\mathbf{3}$ & $i=4$ \\
\hline & Municipality & Agriculture & Industry & Ecology \\
\hline \multicolumn{5}{|c|}{ Net benefits (unit: US $\$ / 10^{3} \mathrm{~m}^{3}$ ) } \\
\hline$j=1$ Kuerle county & {$[6030,6670]$} & {$[2320,2520]$} & {$[4530,4670]$} & {$[1960,2120]$} \\
\hline$j=2$ Yanqi county & {$[5500,6040]$} & {$[1420,1560]$} & {$[2600,2930]$} & {$[1680,1930]$} \\
\hline$j=3$ Hejing county & {$[4670,4800]$} & {$[1530,1860]$} & {$[3730,3810]$} & {$[1540,1780]$} \\
\hline$j=4$ Heshuo county & {$[5300,5530]$} & {$[2010,2340]$} & {$[3440,3620]$} & {$[1660,1940]$} \\
\hline$j=5$ Bohu county & {$[4910,5100]$} & {$[1780,2010]$} & {$[3620,3740]$} & {$[1530,1840]$} \\
\hline$j=6$ Yuli county & {$[4600,5260]$} & {$[2230,2460]$} & {$[3220,3440]$} & {$[1690,1990]$} \\
\hline \multicolumn{5}{|c|}{ Penalties (unit: US $\$ / 10^{3} \mathrm{~m}^{3}$ ) } \\
\hline$j=1$ Kuerle county & {$[9045,10005]$} & {$[3480,3765]$} & {$[6795,7005]$} & {$[2940,3180]$} \\
\hline$j=2$ Yanqi county & {$[8250,9060]$} & {$[2130,2340]$} & {$[3900,4395]$} & {$[2520,2895]$} \\
\hline$j=3$ Hejing county & {$[7005,7200]$} & {$[2295,2790]$} & {$[5595,5725]$} & {$[2310,2670]$} \\
\hline$j=4$ Heshuo county & {$[7950,8295]$} & {$[3015,3510]$} & {$[5160,5430]$} & {$[2190,2490]$} \\
\hline$j=5$ Bohu county & {$[7365,7650]$} & {$[2670,3015]$} & {$[5430,5610]$} & {$[2295,2760]$} \\
\hline$j=6$ Yuli county & {$[6900,7890]$} & {$[3345,3690]$} & {$[4830,5160]$} & {$[2535,2985]$} \\
\hline \multicolumn{5}{|c|}{ Trading fix cost (unit: US $\$ 110^{3} \mathrm{~m}^{3}$ ) } \\
\hline$j=1$ to 6 & {$[3050,3150]$} & {$[550,650]$} & {$[2400,2600]$} & {$[280,350]$} \\
\hline \multicolumn{5}{|c|}{ Trading variable cost (unit: US $\$ 110^{3} \mathrm{~m}^{3}$ ) } \\
\hline$j=1$ to 6 & {$[1200,1350]$} & {$[700,800]$} & {$[150,200]$} & {$[100,150]$} \\
\hline
\end{tabular}

Since linguistic terms are encountered in the practical process of data acquisition associated with human subjective judgment, scales of linguistic terms have been established [41]. Semantic scales are used to present the credibility levels of decision makers (i.e., quite, very, almost and practical degree of satisfaction corresponding to $\lambda=0.6$ to 0.9 ) and violated constraints (i.e., quite, very, almost and practical violation risk level corresponding to $\lambda=0.4$ to 0.1$)$. There is a strong negative correlation between credibility levels and violated levels (i.e., credibility levels + violated levels $=1$ ), in which is manifest the relationship between the degree of satisfaction and the violation risk level. For example, the quite satisfied constraint $(\lambda=0.6)$ corresponds to the quite violated constraint $(r=0.4)$, which indicates a high satisfaction degree corresponding to a low violation risk. By setting the acceptable semantic terms of decision makers, acceptable interval credibility levels can then be generated. In order to ensure that the constraints would be practically satisfied and not violated in the study system, the credibility level, $\lambda$, in this model is set as [0.6, 0.9] [32]. In this study, two cases were examined based on different water resource management policies. Case 1 was based on a policy for a $5 \%$ decrease in the water permit and a 100\% trading ratio. Case 2 was based on a policy for a $10 \%$ decrease in the water permit and a $90 \%$ trading ratio. Since the credibility level, $\lambda$, in this model is set as $[0.6,0.9]$, different violation risk levels of water availability and water resource constraints are considered in two cases, which can help in analyzing different water resource management policies under the credibility levels. 
Table 2. Water targets and water permits.

\begin{tabular}{|c|c|c|c|c|}
\hline \multirow{3}{*}{ District } & \multicolumn{4}{|c|}{ User } \\
\hline & $i=1$ & $i=2$ & $i=\mathbf{3}$ & $i=4$ \\
\hline & Municipality & Agriculture & Industry & Ecology \\
\hline \multicolumn{5}{|c|}{ Water target (unit: $10^{6} \mathrm{~m}^{3}$ ) } \\
\hline$j=1$ Kuerle County & {$[8.80,14.00]$} & {$[258.00,275.00]$} & {$[53.30,620.00]$} & {$[56.00,76.00]$} \\
\hline$j=2$ Yanqi County & {$[6.00,8.20]$} & {$[158.00,165.00]$} & {$[28.00,39.00]$} & {$[31.00,47.00]$} \\
\hline$j=3$ Hejing County & {$[2.40,4.30]$} & {$[81.00,88.00]$} & {$[16.00,20.10]$} & {$[14.70,23.00]$} \\
\hline$j=4$ Heshuo County & {$[0.24,0.50]$} & {$[9.70,10.10]$} & {$[1.78,2.25]$} & {$[1.28,2.60]$} \\
\hline$j=5$ Bohu County & {$[2.20,4.30]$} & {$[75.00,85.00]$} & {$[15.60,19.00]$} & {$[13.70,23.00]$} \\
\hline$j=6$ Yuli County & {$[4.60,6.00]$} & {$[110.00,120.00]$} & {$[21.60,27.00]$} & {$[24.00,33.00]$} \\
\hline \multicolumn{5}{|c|}{ Allocated allowable water permit (unit: $10^{6} \mathrm{~m}^{3}$ ) } \\
\hline$j=1$ Kuerle County & {$[9.72,13.75]$} & {$[261.60,275.08]$} & {$[55.44,61.89]$} & {$[59.56,75.65]$} \\
\hline$j=2$ Yanqi County & {$[[6.64,8.14]$} & {$[158.33,162.87]$} & {$[30.31,36.65]$} & {$[32.26,44.79]$} \\
\hline$j=3$ Hejing County & {$[2.89,4.23]$} & {$[82.22,84.50]$} & {$[15.70,19.01]$} & {$[17.08,23.24]$} \\
\hline$j=4$ Heshuo County & {$[0.36,0.53]$} & {$[9.11,9.38]$} & {$[1.89,2.11]$} & {$[1.69,2.70]$} \\
\hline$j=5$ Bohu County & {$[2.56,4.09]$} & {$[78.89,81.84]$} & {$[15.78,18.41]$} & {$[15.58,22.58]$} \\
\hline$j=6$ Yuli County & {$[4.94,5.87]$} & {$[110.56,117.41]$} & {$[22.33,26.42]$} & {$[25.56,32.29]$} \\
\hline
\end{tabular}

\section{Result Analysis}

\subsection{Results under Different Credibility Levels}

Figure 2 shows the results of optimal water allocations for municipal, agricultural, industrial and ecological users in the six counties of the study basin under Case 1 when $\lambda=0.6$ and 0.9 . Results indicate that a shortage in the water supply would be generated if the pre-regulated target could not be satisfied (i.e., shortage $=$ targeted value - available inflow). Under such a situation, the actual water allocation would be the difference between the pre-regulated target and the probabilistic shortage (i.e., allocation $=$ target - shortage). Each allocated water flow is the difference between the promised target and the probabilistic shortage under a given stream condition with an associated probability level, which indicates that different violation levels would result in varied water-allocation patterns. For example, under Case $1(\lambda=0.6)$, the optimized targets of municipal, agricultural, industrial and ecological users (in Bohu County, $j=5$ ) would be $4.95 \times 10^{6} \mathrm{~m}^{3}$, $97.75 \times 10^{6} \mathrm{~m}^{3}, 21.85 \times 10^{6} \mathrm{~m}^{3}$ and $28.75 \times 10^{6} \mathrm{~m}^{3}$, respectively. When inflow is high, shortages would be $[0.19,1.28] \times 10^{6} \mathrm{~m}^{3},[3.82,12.11] \times 10^{6} \mathrm{~m}^{3},[2.55,2.55] \times 10^{6} \mathrm{~m}^{3}$ and $[6.59,7.06] \times 10^{6} \mathrm{~m}^{3}$; correspondingly, the actual allocations would be $[3.66,4.75] \times 10^{6} \mathrm{~m}^{3},[85.65,93.93] \times 10^{6} \mathrm{~m}^{3}$, $[19.30,19.30] \times 10^{6} \mathrm{~m}^{3}$ and $[18.81,19.29] \times 10^{6} \mathrm{~m}^{3}$. The total amount of allocated water to Bohu County would be from $127.42 \times 10^{6} \mathrm{~m}^{3}$ to $137.27 \times 10^{6} \mathrm{~m}^{3}$; however, its total water demand would be $153.3 \times 10^{6} \mathrm{~m}^{3}$, indicating that there would be a shortage, even though the inflow is high. Due to more than $80 \%$ of the total annual precipitation falls from May to September in the study region, falls in other months were much less. Therefore, when inflows are medium or low, the shortage would be strengthened, whereas each user would have to obtain water from other sources to satisfy its essential demands. 


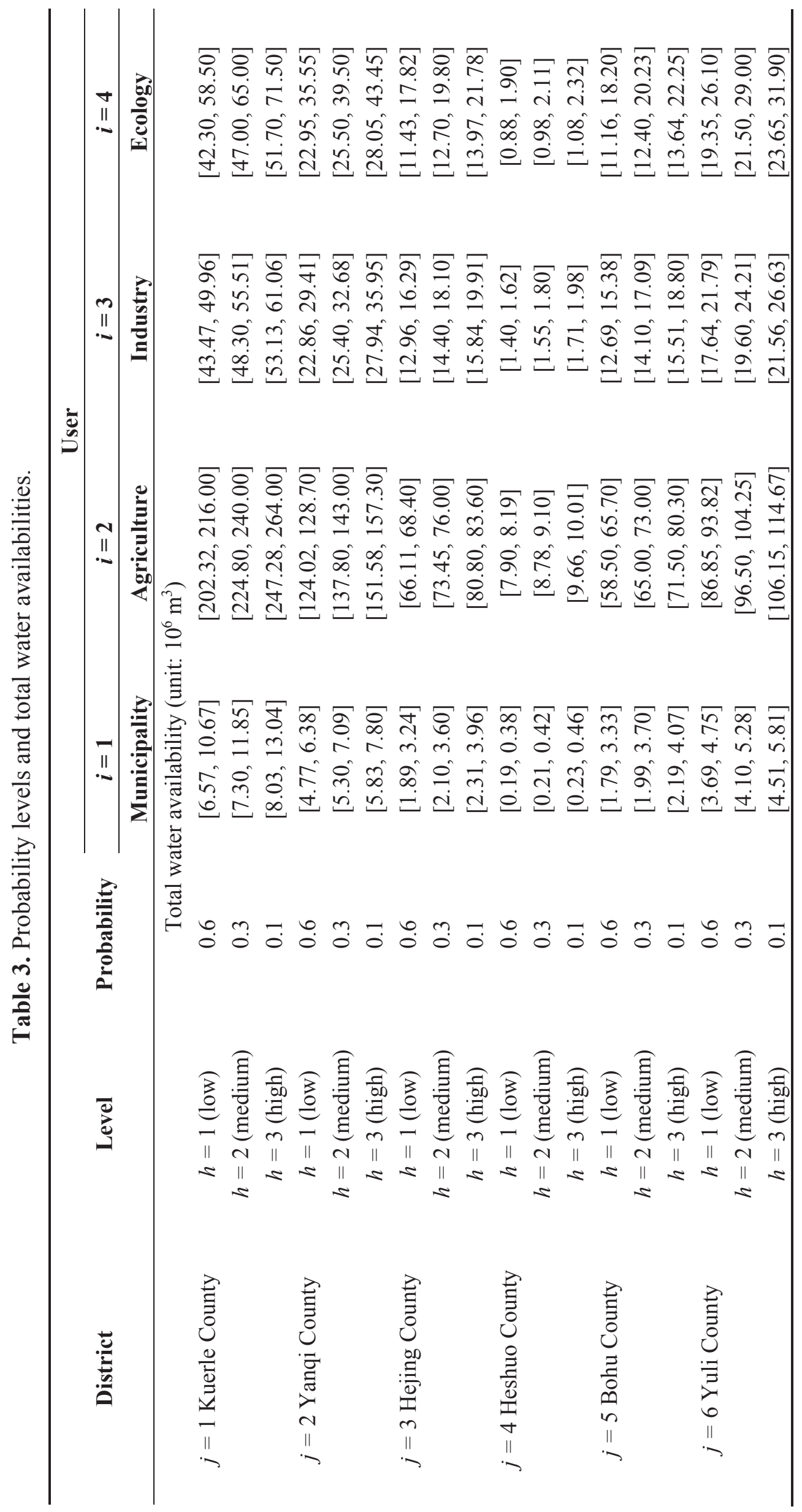


Figure 2. Solutions for water allocation under Case $1(\lambda=0.6$ and 0.9$)$.
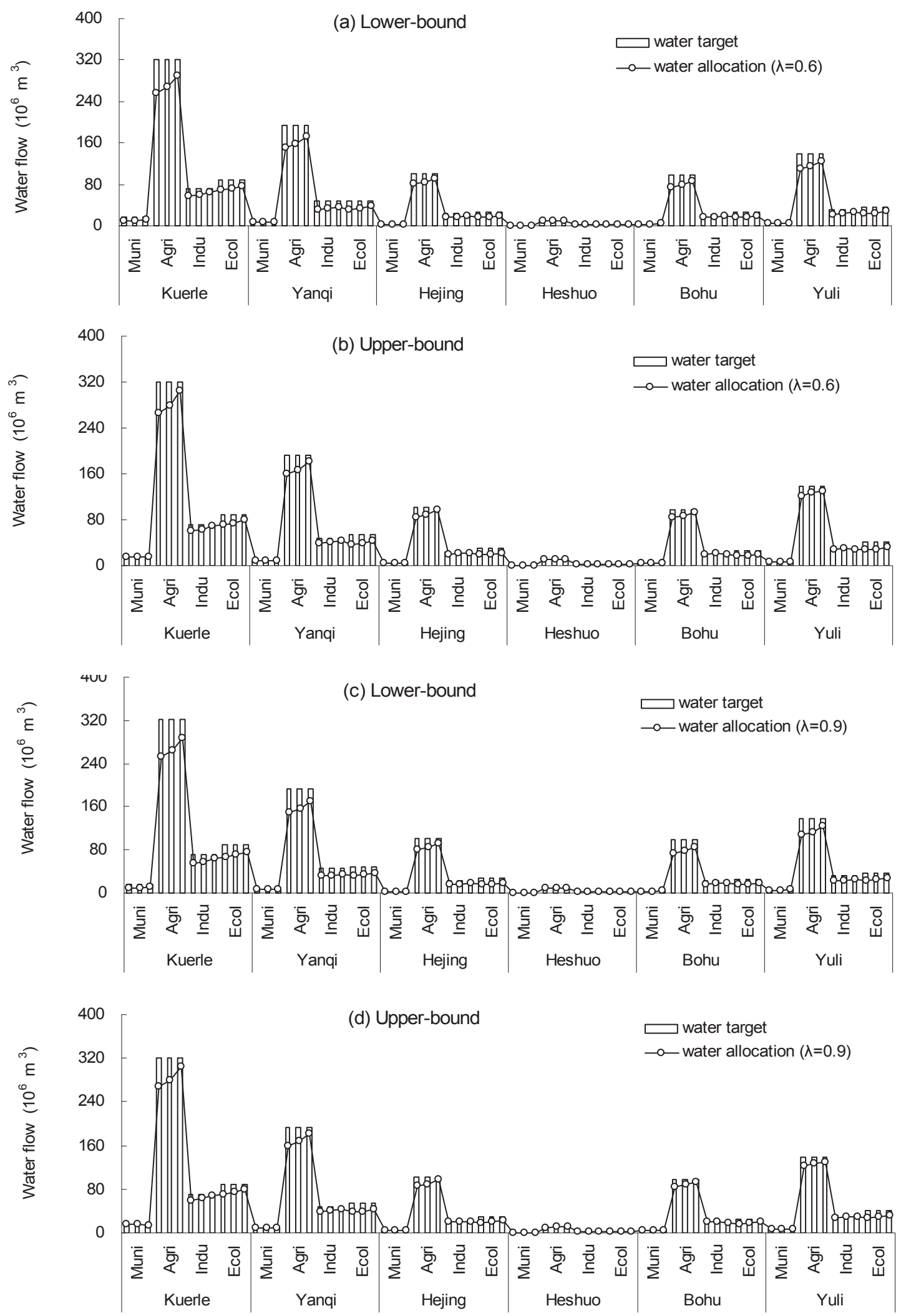

Meanwhile, several $\lambda$ levels were examined by different combinations of the fuzzy sets, which achieved different water availabilities, water targets and varied water-allocations under Case 1 . When $\lambda=0.6$, higher water availability corresponding to the lower credibility satisfaction levels would lead 
to lower water deficiency, which produced a higher water allocation. While $\lambda=0.9$, lower water availability corresponding to the higher credibility satisfaction levels would produce the opposite result. Therefore, as shown in Figure 2, the amount of water allocation when $\lambda=0.6$ is greater than that when $\lambda=0.9$, implying that a low credibility level could result in a high water allocation level in the trading program. For example, when $\lambda=0.6$, optimized target of municipal users in Bohu County $(j=5)$ was $4.95 \times 10^{6} \mathrm{~m}^{3}$. When inflow is high, shortages would be $[0.19,1.28] \times 10^{6} \mathrm{~m}^{3}$; correspondingly, the actual allocations would be $[3.66,4.75] \times 10^{6} \mathrm{~m}^{3}$. Meanwhile, when $\lambda=0.9$, a lower water resource permit and water availability would correspond to the higher credibility satisfaction levels. The optimized municipal target for Bohu County $(j=5)$ was $4.95 \times 10^{6} \mathrm{~m}^{3}$. When inflow is high, shortages would be $[0.21,1.32] \times 10^{6} \mathrm{~m}^{3}$; correspondingly, the actual allocations would be $[1.32,4.75] \times 10^{6} \mathrm{~m}^{3}$. This implies that different $\lambda$ levels lead to different credibility satisfaction levels and violation risks in the water planning system, corresponding to different water availabilities, which lead to different shortages and allocations.

Meanwhile, several $\lambda$ levels were examined by different combinations of the fuzzy sets, which achieved different water availabilities, water targets, and varied water allocations under Case 1. When $\lambda=0.6$, higher water availability corresponding to the lower credibility satisfaction levels would lead to lower water deficiency, which produced a higher water allocation. While $\lambda=0.9$, lower water availability corresponding to the higher credibility satisfaction levels would produce the opposite result. Therefore, as shown in Figure 2, the amount of water allocation when $\lambda=0.6$ is greater than that when $\lambda=0.9$, implying that a low credibility level could result in a high water allocation level in the trading program. For example, when $\lambda=0.6$, the optimized target for municipal users in Bohu County $(j=5)$ was $4.95 \times 10^{6} \mathrm{~m}^{3}$. When inflow is high, shortages would be $[0.19,1.28]$ $\times 10^{6} \mathrm{~m}^{3}$; correspondingly, the actual allocations would be $[3.66,4.75] \times 10^{6} \mathrm{~m}^{3}$. Meanwhile $\lambda=0.9$, lower water resource permit and water availability would correspond to the higher credibility satisfaction levels. Optimized targets of municipal in Bohu County $(j=5)$ was $4.95 \times 10^{6} \mathrm{~m}^{3}$. When inflow is high, shortages would be $[0.21,1.32] \times 10^{6} \mathrm{~m}^{3}$; correspondingly, the actual allocations would be $[1.32,4.75] \times 10^{6} \mathrm{~m}^{3}$. It replied that different $\lambda$ levels led to different credibility satisfactions and violation risks in water planning system, corresponding to different water availabilities, which lead to different shortages, and allocations.

Different policies in water resources planning would result in varied shortages, targets, allocations and trading amounts. Figure 3 presents water shortages under the two cases $(\lambda=0.9)$, which indicated that water shortages changed by decreasing the water permits. Water shortages would occur if the available water resource could not meet the regulated targets, which indicated that the shortages were associated with water targets and water availability. In the study basin, water targets are often determined before total water inflows are known, which generates a problem of recourse for water allocation caused by variations between targets and water availabilities. Due to water deficiency in the study region, water permits have been allocated in advance, so as to save more water or to obtain higher benefits. By decreasing water permits, less water would be allowanced, but more water would be released to trade, which leads to much more shortage under Case 2 than under Case 1. For example, water shortages of municipal users in Kuerle County $(j=1)$ would be $[1.31,6.29] \times 10^{6} \mathrm{~m}^{3}$ at the low level, $[0.62,5.86] \times 10^{6} \mathrm{~m}^{3}$ at the medium level and $[0.66,4.99] \times 10^{6} \mathrm{~m}^{3}$ at the high level under 
Case $1(\lambda=0.6)$, while it would be $[1.31,6.39] \times 10^{6} \mathrm{~m}^{3}$ at the low level, $[0.62,5.96] \times 10^{6} \mathrm{~m}^{3}$ at the medium level and $[1.54,5.11] \times 10^{6} \mathrm{~m}^{3}$ at the high level under Case $2(\lambda=0.6)$. Moreover, shortages are affected by the randomness of water availabilities. Due to a special climate situation, when the flow is high in the wet season, the shortages may be relatively low under advantageous conditions and would be increased when the flow is low in the dry season.

Figure 4 presents the results for water allocations under the two cases $(\lambda=0.6)$, which indicated that the allocated water changed by decreasing the water permits. Results demonstrated that higher water permits lead to a lower shortage, resulting in a lower allocation. Meanwhile, lower water permits generate the opposite result. For example, the water allocation of municipal users in Yuli County $(j=6)$ would be $[5.12,6.34] \times 10^{6} \mathrm{~m}^{3}$ at the low level, $[5.35,6.64] \times 10^{6} \mathrm{~m}^{3}$ at the medium level and $[5.82,6.22] \times 10^{6} \mathrm{~m}^{3}$ at the high level under case $1(\lambda=0.6)$, while it would be $[5.12,6.20] \times 10^{6} \mathrm{~m}^{3}$ at the low level, $[5.35,6.50] \times 10^{6} \mathrm{~m}^{3}$ at the medium level and $[5.82,5.91] \times 10^{6} \mathrm{~m}^{3}$ at the high level under Case $2(\lambda=0.6)$. The results of water allocations under the two cases indicated that different water allocations would be achieved, due to different shortages, based on different policies. It is implied that water allocations were sensitive to water permitting, since different water permits led to different shortages, resulting in different water allocations. Figure 5 presents the amount of water trading under different water permit and trading ratios. In the study region, due to the extremely dry climate, low rainfall and high evaporation rate, the losses from a water shortage are serious. Thus, trading was introduced to reduce the losses from, shortages and to obtain greater benefits. When the losses from water shortages are generated, each user would need to obtain water from released water and other sources to satisfy its essential demands. For example, the amount of water trading for agricultural users in Heshuo County $(j=4)$ would be $[1.48,1.62] \times 10^{6} \mathrm{~m}^{3}$ at the low level, $[0.70,1.16] \times 10^{6} \mathrm{~m}^{3}$ at the medium level and $[0,1.36] \times 10^{6} \mathrm{~m}^{3}$ at the high level under Case 1 $(\lambda=0.9)$, while it would be $[1.05,1.46] \times 10^{6} \mathrm{~m}^{3}$ at the low level, $[0.25,0.65] \times 10^{6} \mathrm{~m}^{3}$ at the medium level and $[0,0] \times 10^{6} \mathrm{~m}^{3}$ at the high level under Case $2(\lambda=0.9)$. The solutions indicated that the amount of trading based on shortages was relatively low under advantageous conditions and rose in the dry season. Meanwhile, by decreasing the water permit and trading ratios, the more the water surplus remedies the water shortage, the less is the amount of water trading from other sources. Moreover, the amount of water trading is sensitive to trading cost, particular in assuming different water polices. Under the situation of water permit and trading ratio change, the amount of water trading changes dissimilarly, due to the law of value. More released water permits lead to a greater difference in the amount of water trading, while a smaller trading ratio obtains a tremendous change in water trading. For example, in Figure 5, the amount of water trading for agricultural users in Yanqi County $(j=2)$ would be $[7.54,7.54] \times 10^{6} \mathrm{~m}^{3}$ at the low level under Case $1(\lambda=0.9)$, while it would be $[0,6.65] \times 10^{6} \mathrm{~m}^{3}$ at the low level under Case $2(\lambda=0.9)$. The difference of water trading between Case 1 and Case 2 was caused by the lowest trading cost and limited trading resources. 
Figure 3. Solutions for water shortage under case 1 and case $2(\lambda=0.6)$.
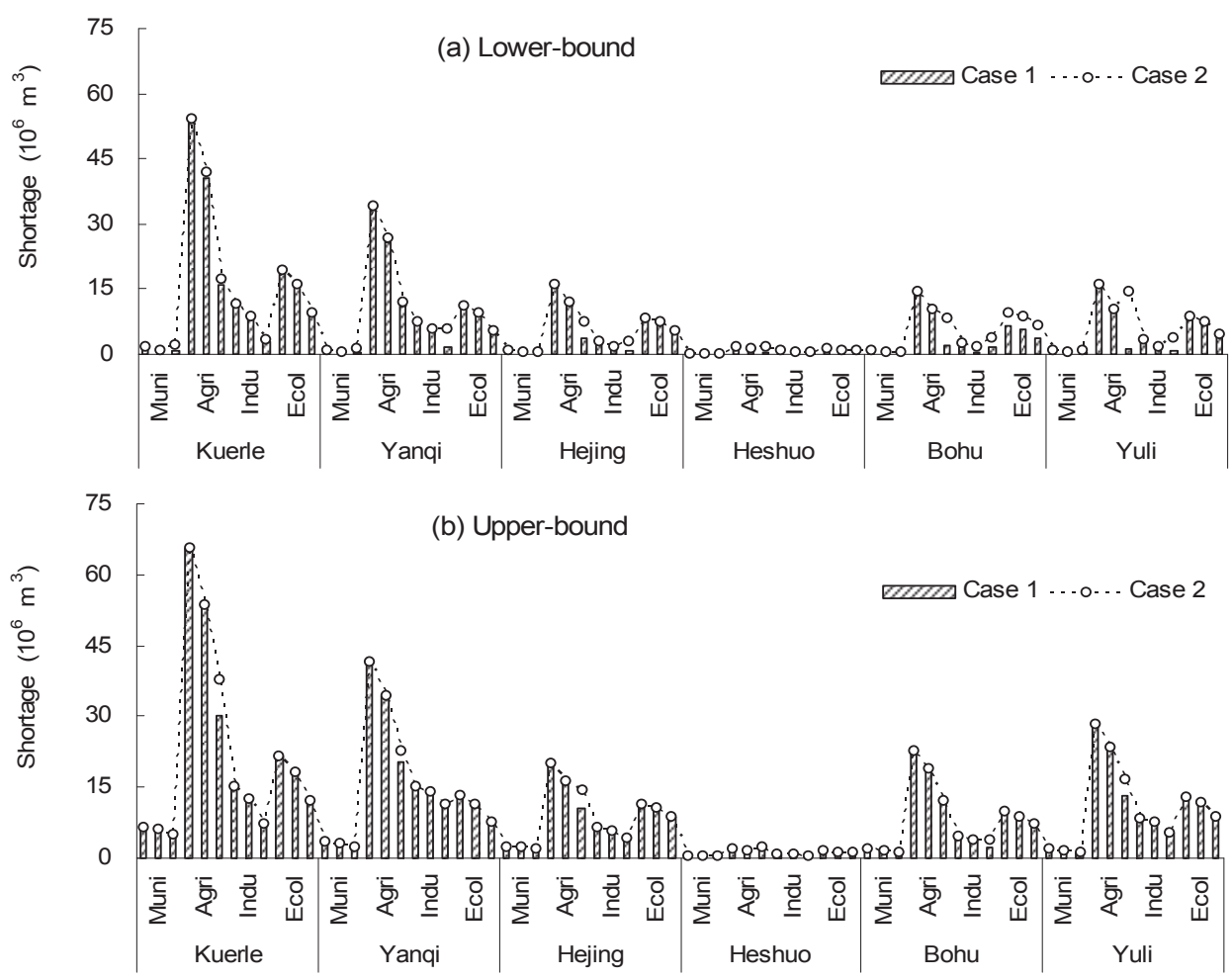

Figure 4. Solutions for water allocation under Case 1 and Case $2(\lambda=0.9)$.
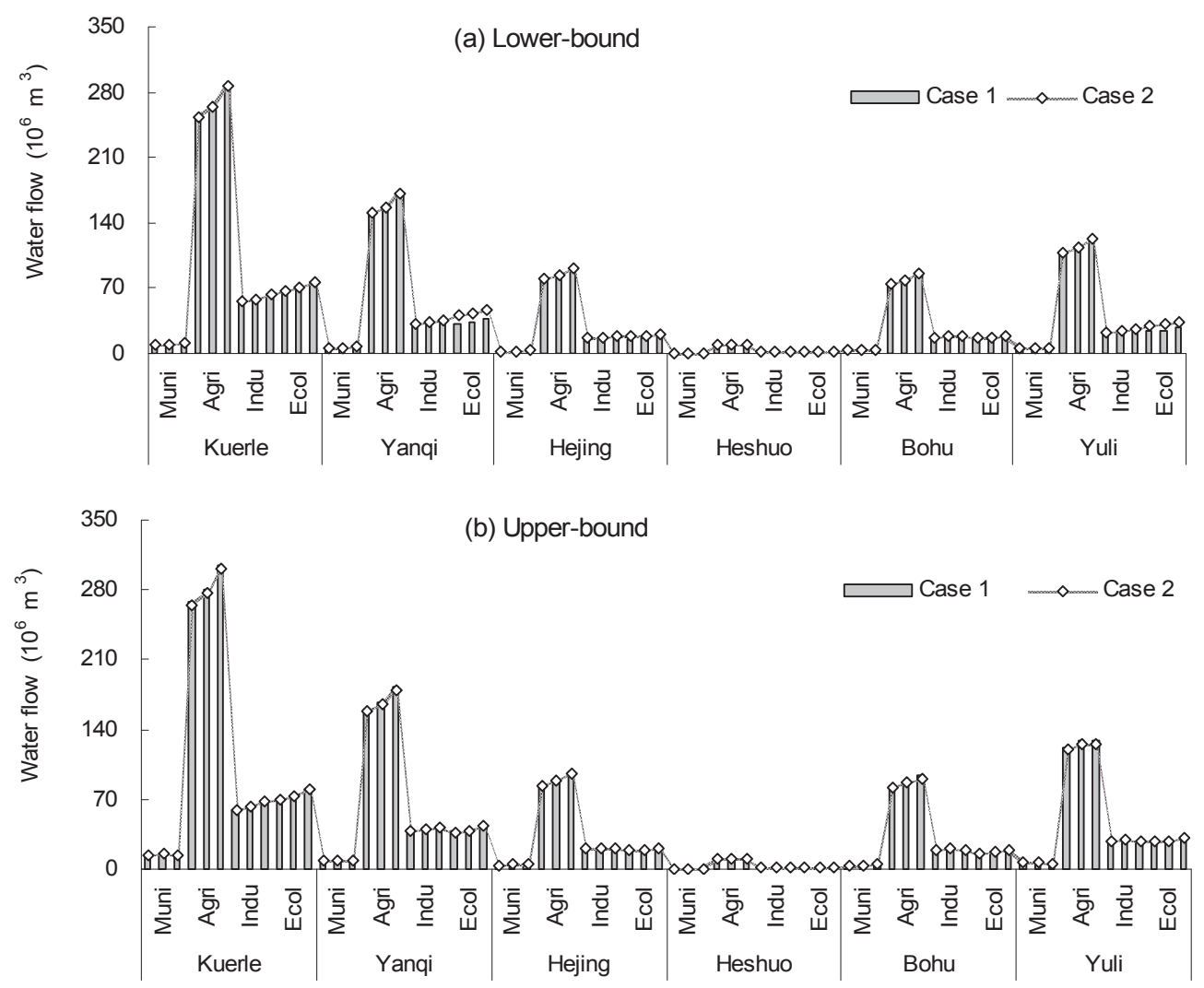
Figure 5. Solutions for water trading under Case 1 and Case $2(\lambda=0.6)$.
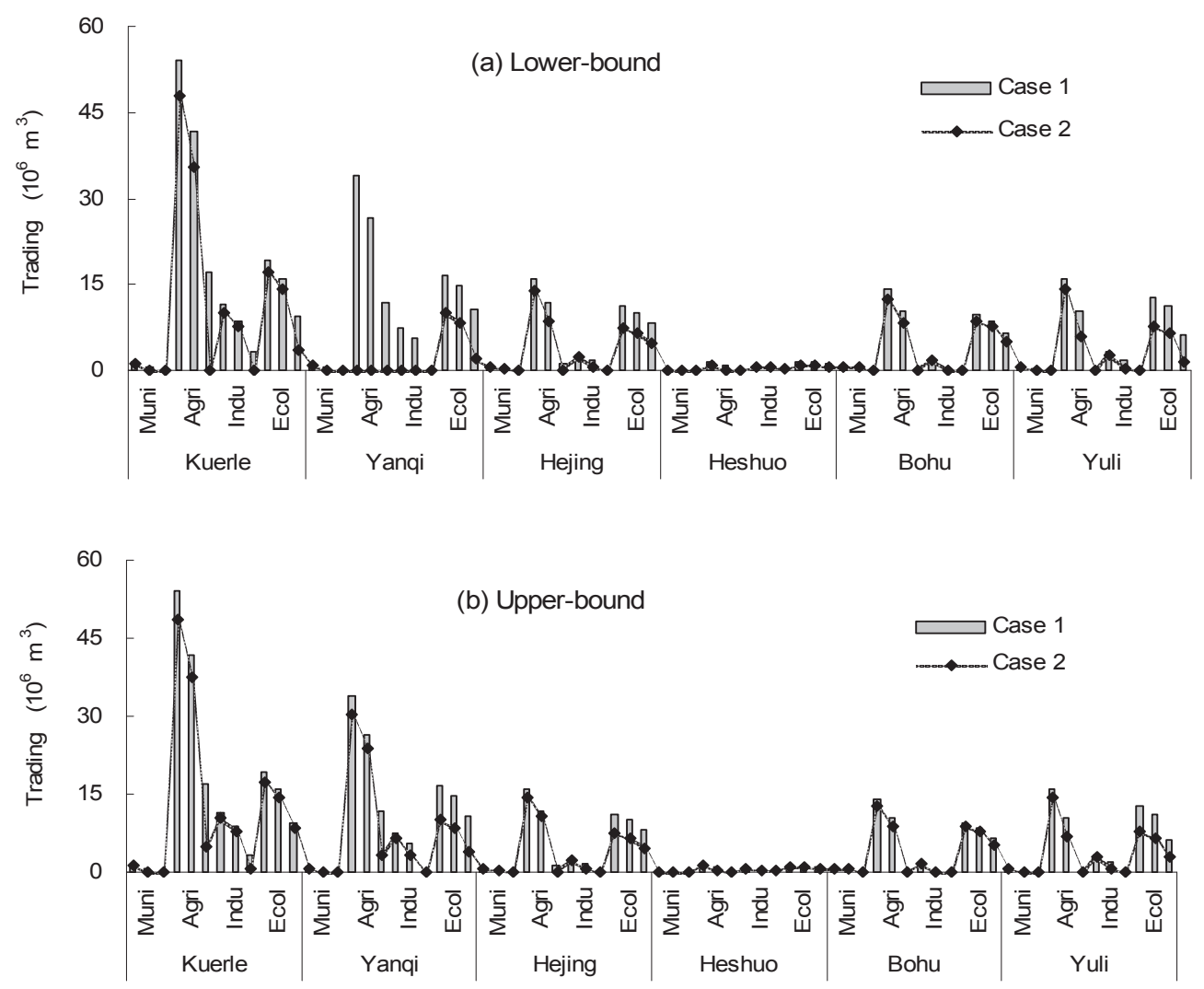

\subsection{Comparison of Trading and Non-Trading Schemes}

Figure 6 shows the solutions for the optimized net benefit for the system obtained from the TICP model with trading and non-trading schemes, which are the sum of the first-stage benefit from the water allocation and the second-stage random losses of water deficiency. The lower-bound benefits for the system could result in a lower risk of violating the allowable water permit. Conversely, a higher benefit would lead to a higher probability of violating the allowance. Consequently, there is a tradeoff between the net benefit for the system and the water permit violation risk. In Figure 6, the net benefit for the system would be achieved as $[0.77,2.28] \times 10^{9}$ US $\$(\lambda=0.6)$ and $[0.68,2.20] \times 10^{9}$ US $\$(\lambda=0.9)$ under Case 1 . By decreasing the water permit, the benefits for the system would be $[0.51,1.89] \times 10^{9} \operatorname{US} \$(\lambda=0.6)$ and $[0.47,1.82] \times 10^{9} \operatorname{US} \$(\lambda=0.9)$ under Case 2, which indicates that the net benefit for the system would decrease by decreasing the water permit and trading ratio. However, the net benefit for the system under the two cases with the trading scheme was much higher than that with the non-trading scheme (i.e., $[0.47,1.81] \times 10^{9}$ US\$ when $\lambda=0.6$ and $[0.31,1.77] \times 10^{9}$ US $\$$ when $\left.\lambda=0.9\right)$. Comparing the net benefit for the system under trading and that under non-trading, the efficiency of trading and non-trading would be acquired. This implies that trading through water markets is likely to increase and improve economic efficiency overall. 
Figure 6. Benefits for the system under Case 1 and Case $2(\lambda=0.6$ to 0.9$)$ with the trading scheme and non-trading scheme.

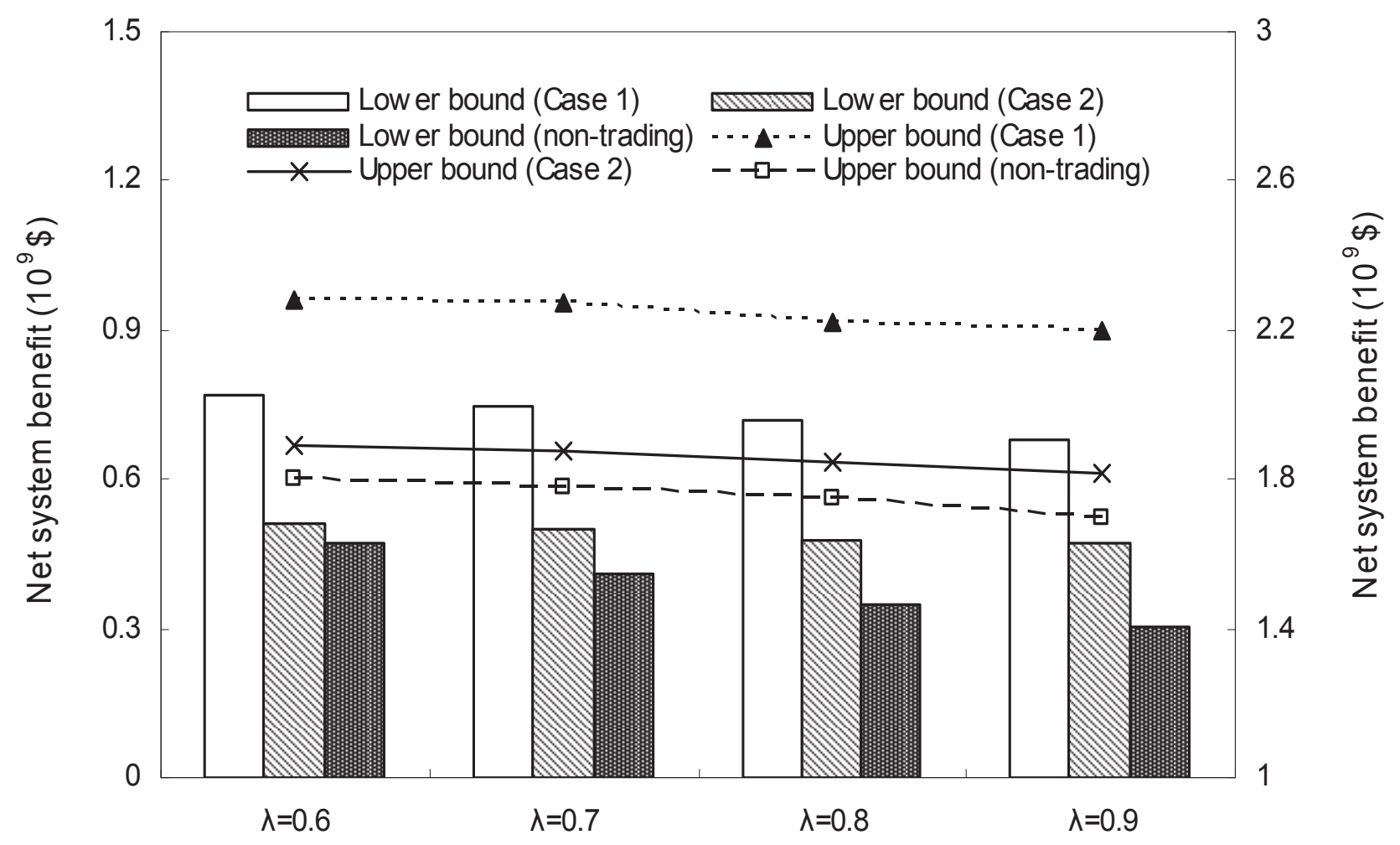

Meanwhile, water shortages would reduce through water trading, by releasing more water surplus and obtaining other sources of water to remedy water deficiencies. Figure 7 shows the solutions for water shortage under Case $1(\lambda=0.6)$ with the trading scheme and non-trading scheme, which indicated that water shortages with the trading scheme were much smaller than with the non-trading scheme. For example, water shortages for industrial users in Hejing County $(j=3)$ with the trading scheme would be $[0,4.24] \times 10^{6} \mathrm{~m}^{3}$ at the low level, $[1.78,5.74] \times 10^{6} \mathrm{~m}^{3}$ at the medium level and $[2.73,6.50] \times 10^{6} \mathrm{~m}^{3}$ at the high level under Case $1(\lambda=0.6)$, while with the non-trading scheme, they would be $[1.96,6.55] \times 10^{6} \mathrm{~m}^{3}$ at the low level, $[1.78,8.05] \times 10^{6} \mathrm{~m}^{3}$ at the medium level and $[2.73,8.81] \times 10^{6} \mathrm{~m}^{3}$ at the high level. This implies that markets can provide incentives for adopting water saving practices, since market prices make the opportunity cost of water explicit to users. Therefore, water trading was considered as an effective way for not only reducing the shortages of water systems, but also for gaining a higher net benefit for the system in an arid region. 
Figure 7. Solutions shortages under Case $1(\lambda=0.6)$ with the trading scheme and non-trading scheme.
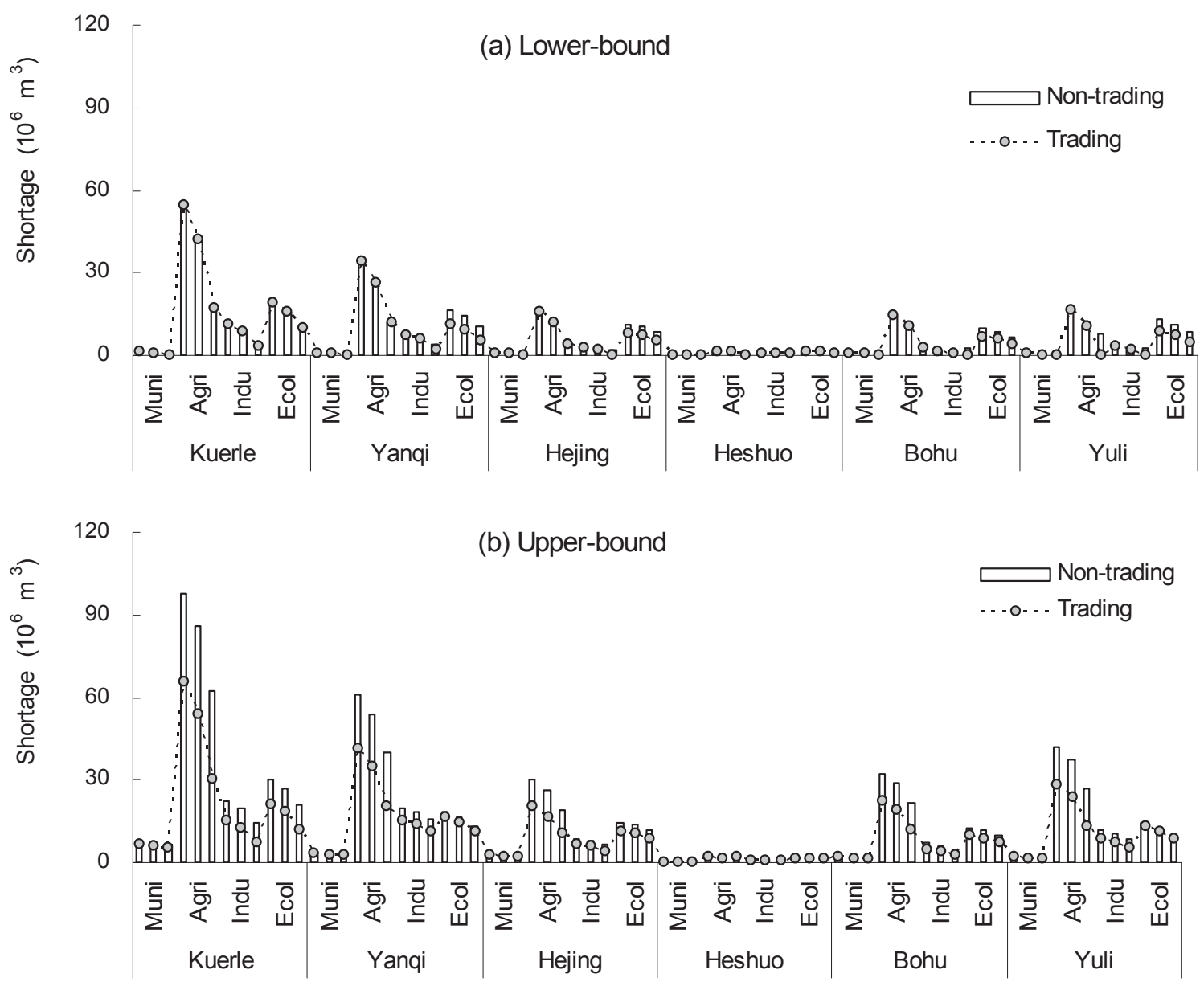

\section{Conclusions}

In this study, a two-stage inexact credibility-constrained programming (TICP) method has been developed for identifying the efficiency of water trading policy under multiple uncertainties. The TICP can incorporate uncertainties presented as intervals, probability distributions and fuzzy sets within its modeling framework. It can quantify the effectiveness of water trading, which can deal with system uncertainties between the allocation policy and violation risk. In the proposed model, the credibility constrained programming method, which is derived from fuzzy possibility theory, was incorporated to account for the imprecision associated with the goals of water trading and to make full use of the available information. Fuzzy membership functions were used to encode the possibilistic distribution of the parameters, and credibility was proposed to measure the satisfaction level of the fuzzy constraints. It can deal with water resource allocation problems resulting from randomness in the total water supply and uncertainties represented as interval credibility constrained programming in the water trading system. The significant advantage of the TICP model is that it can reflect the tradeoffs between the predefined economic targets and the associated water shortage penalties, as well as the fuzziness of the water availability. 
The developed method has been applied to the Kaidu-kongque River Basin for water trading under uncertainties of water supply and demand. The study region is a typical arid region, in which water shortage and unreliable water supply impede the sustainable development of the regional economy and society in watershed systems. The TICP can facilitate reducing the risks of establishing a water trading program, and the developed method will support decision makers in allocating water resources effectively. Based on the regional situation of water resources, a number of different policy cases based on arid characteristics were listed for comparison. The resulting analysis shows that trading is much more effective than non-trading under some designated situations, which not only increases the economic benefits according to the law of value, but also provides incentives for adopting water saving policies. Water shortage can be remedied by water trading, resulting in loss reduction and improving the benefits for the system. Therefore, trading is an efficient way for allocating water resources optimally, which should be considered in water resource management to remedy the limitation of polices. The results of the case study indicate that the effectiveness of a trading program is sensitive to the water permit and trading ratio; thus the water permit and trading ratio should be considered as a primary factor for policy formulations in water resource management. Therefore, a manager of water resources in the Kaidu-kongque River Basin should adjust the water policies based on regional development, to release appropriate water permits for water trading, which cannot only remedy the losses of water deficiency, but also improve the efficiency of the water resource system. Meanwhile, the policies of the trading ratio should be formulated by the relationships between water availability and regional sustainable development (e.g., economic development, social progress and ecological protection), since fallacious policies of the trading ratio would lead to water trading failure in response to the trading cost and other opportunity costs.

\section{Acknowledgments}

This research was supported by the National Natural Science Foundation for Distinguished Young Scholars (grant no. 51225904), the Natural Sciences Foundation of China (grant nos. 51379075 and 51190095), the 111 Project (B14008), and the Program for Innovative Research Team in University (IRT1127).The authors are grateful to the editors and the anonymous reviewers for their insightful comments and helpful suggestions.

\section{Conflicts of Interest}

The authors declare no conflict of interest. 


\section{References}

1. Bates, B.C.; Kundzewicz, Z.W.; Wu, S.; Palutikof, J.P. Climate Change and Water. In Technical Paper of the Intergovernmental Panel on Climate Change; IPCC Secretariat: Geneva, Switzerland, 2008.

2. Huang, Y.; Li, Y.P.; Chen, X.; Ma, Y.G. Optimization of irrigation water resources for agricultural sustainability in Tarim River Basin, China. Agric. Water Manag. 2012, 107, 74-85.

3. Hassan, Q.K.; Sekhon, N.S.; Magai, R.; McEachern, P. Reconstruction of snow water equivalent and snow depth using remote sensing data. J. Environ. Inform. 2012, 20, 67-74.

4. Su, L.Y.; Christensen, P.; Liu, J.L. Comparative study of water resource management and policies for ecosystems in China and Denmark. J. Environ. Inform. 2013, 21, 72-83.

5. Calatrava, J.; Garrido, A. Spot water markets and risk in water supply. Agric. Econ. 2005, 33, 131-143.

6. Zaman, A.M.; Malano, H.M.; Davidson, B. An integrated water trading-allocation model, applied to a water market in Australia. Agric. Water Manag. 2009, 96, 149-159.

7. Youkhana, E.; Laube, W. Virtual water trade: A realistic policy option for the countries of the Volta Basin in West Africa? Water Policy 2009, 11, 569-581.

8. Luo, B.; Maqsood, I.; Gong, Y.Z. Modeling climate change impacts on water trading. Sci. Total Environ. 2010, 408, 2034-2041.

9. Dominguez, D.; Truffer, B.; Gujer, W. Tackling uncertainties in infrastructure sectors through strategic planning: The contribution of discursive approaches in the urban water sector. Water Policy 2010, 13, 299-316.

10. Li, Y.P.; Huang, G.H.; Chen, X. Multistage scenario-based interval-stochastic programming for planning water resources allocation. Stoch. Environ. Res. Risk Assess. 2009, 23, 781-792.

11. Ahmed, S.; Tawarmalani, M.; Sahinidis, N.V. A finite branch-and-bound algorithm for two-stage stochastic integer programs. Math. Program. 2004, 100, 355-377.

12. Li, Z.; Huang, G.; Zhang, Y.; Li, Y. Inexact two-stage stochastic credibility constrained programming for water quality management. Resourc. Conserv. Recycl. 2013, 73, 122-132.

13. Lu, H.W.; Huang, G.H.; Zeng, G.M.; Maqsood, I.; He, L. An inexact two-stage fuzzy-stochastic programming model for water resource management. Water Resour. Manag. 2008, 22, 991-1016.

14. Birge, J.R.; Louveaux, F.V. Introduction to Stochastic Programming; Springer-Verlag: New York, NY, USA, 1997.

15. Maqsood, I.; Huang, G.H.; Huang, Y. ITOM: An interval-parameter two-stage optimization model for stochastic planning of water resources systems. Stoch. Environ. Res. Risk Assess. 2005, 19, 125-133.

16. Kenneth, W.H. Two-stage decision-making under uncertainty and stochasticity: Bayesian Programming. Adv. Water Resour. 2007, 30, 641-664.

17. Li, Y.P.; Huang, G.H. Interval-parameter two-stage stochastic nonlinear programming for water resource management under uncertainty. Water Resour. Manag. 2008, 22, 681-698. 
18. Vidoli, F. Evaluating the water sector in Italy through a two stage method using the conditional robust nonparametric frontier and multivariate adaptive regression splines. Eur. J. Oper. Res. 2011, 3, 584-595.

19. Li, Y.P.; Huang, G.H. Two-stage planning for sustainable water-quality management under uncertainty. J. Environ. Manag. 2009, 90, 2402-2413.

20. Freeze, R.A.; Massmann, J.; Smith, L.; Sperling, T.; James, B. Hydrogeological decision analysis: 1. A framework. Ground Water 1990, 28, 738-766.

21. Li, Y.P.; Huang, G.H. Fuzzy-stochastic-based violation analysis method for planning water resource management systems with uncertain information. Inf. Sci. 2009, 179, 4261-4276.

22. Nazemi, A.R.; Akbarzadeh, M.R.; Hosseini, S.M. Fuzzy-stochastic linear programming in water resources engineering. Stoch. Environ. Res. Risk Assess. 2002, 2, 167-174.

23. Lee, C.S.; Chang, S.P. Interactive fuzzy optimization for an economic and environmental balance in a river system. Water Res. 2005, 39, 221-231.

24. Bertsimas, D.; Sim, M. The price of robustness. Oper. Res. 2004, 52, 35-53.

25. Doolse, G.; Kingwell, R. Robust mathematical programming for natural resource modeling under parametric uncertainty. Nat. Resourc. Modell. 2010, 23, 283-302.

26. Liu, S.S.; Papageorgiou, L.G.; Gikas, P. Integrated management of nonconventional water resources in anhydrous islands. Water Resourc. Manag. 2012, 26, 359-375.

27. Vylder, F.D.; Sundt, B. Constrained credibility estimators in the regression model. Scand. Actuar. J. 1982, 1, 27-31.

28. Liu, B.; Liu, Y.K. Expected value of fuzzy variable and fuzzy expected value models. IEEE Trans. Fuzzy Syst. 2002, 10, 45-50.

29. Punyangarm, V.; Yanpirat, P.; Charnsethikul, P.; Lertworasirikul, S. A Credibility Approach for Fuzzy Stochastic Data Envelopment Analysis (FSDEA). In Proceedings of the 7th Asia Pacific Industrial Engineering and Management Systems Conference, Bangkok, Thailand, 17-20 December, 2006.

30. Luo, S.X.; Li, F.C.; Qiu, J.Q.; Li, L.X. Credibility-Based General Hartley Measure and Its Application on Fuzzy Programming. In Proceedings of the IEEE 2004 International Conference on Machine Learning and Cybernetics, Shanghai, China, 26-29 August, 2004.

31. Rong A.; Lahdelma, R. Fuzzy chance constrained linear programming model for optimizing the scrap charge in steel production. Eur. J. Oper. Res. 2008, 186, 53-64.

32. Zhang, Y.M.; Huang, G.H. Inexact credibility constrained programming for environmental system management. Resour.Conserv. Recycl. 2011, 55, 1-7.

33. Li, Y.P.; Huang, G.H.; Nie, S.L. An interval-parameter multistage stochastic programming model for water resource management under uncertainty. Adv. Water Resour. 2006, 29, 776-1377.

34. Huang, G.H. A hybrid inexact-stochastic water management model. Eur. J. Oper. Res. 1998, 107, 137-158.

35. Fan, R.; Huang, G.H. A robust two-step method for solving interval linear programming problems within an environmental management context. J. Environ. Inform. 2012, 19, 1-12. 
36. Xinjiang Uygur Autonomous Bureau of statistics. The statistical yearbook of Xinjiang Uygur Autonomous Region in Uygur Autonomous Region 2005-2011; Xinjiang Uygur Autonomous Bureau of statistics: Uruemqi, China, 2012, in Chinese.

37. Huang, Y.; Li, Y.P.; Chen, X.; Bao, A.M.; Zhou, M. Simulation-based optimization method for water resource management in Tarim River Basin, China. Sci. Direct 2010, 2, 1451-1460.

38. Abdelaziz, A.G.; Frank A.W. Gains from expanded irrigation water trading in Egypt: An integrate basin approach. Ecol. Econ. 2010, 69, 2535-2548.

39. Richard, A.; Wildman, J.; Noelani, A.F. Management of water shortage in the colorado river basin: Evaluating current policy and the viability of interstate water trading. J. Am. Water Resourc. Assoc. 2012, 48, 411-422.

40. Luo, B.; Huang, G.H.; Zou, Y.; Yin Y.Y. Toward quantifying the effectiveness of water trading under uncertainty. Environ. Manag. 2007, 83, 181-190.

41. Jiménez, M; Arenas, M.; Bilbao, A. Linear programming with fuzzy parameters: An interactive method resolution. Eur. J. Oper. Res. 2007, 177, 1599-1609. 


\title{
Pricing Policies in Managing Water Resources in Agriculture: An Application of Contract Theory to Unmetered Water
}

\author{
Francesco Galioto, Meri Raggi and Davide Viaggi
}

\begin{abstract}
The paper explores how agricultural water pricing could contribute to lowering water demand when uses are unobserved (asymmetric information). The topic of the paper is justified by the fact that most water authorities worldwide do not control water uses at the farm scale. The study draws inspiration from the pricing policies of a Reclamation and Irrigation Board in Northern Italy. It analyses the optimal design of current tariff strategies with respect both to the actual regulator's goals and the cost recovery objective of an ideal regulator driven by European Water Framework Directive principles and having full information. The analysis is based on the logic of a Principal-Agent model implemented as a mathematical non-linear programming model. Given the current pricing structure and assuming zero transaction costs, the results show a relevant increase in net benefits for the ideal scenario with respect to the actual one as water use costs increase. Benefits differences between the two scenarios mark a limit in value below which mechanisms able to solve the existing asymmetries between the principal and the agents are economically desirable. The study concludes by showing that the current regulator's discriminatory strategy (pricing structure) would be better justified with higher levels of cost for water use. However, the existence of non-zero transaction costs related to the control of water uses points to the need for further research in order to analyze incentive mechanisms in the absence of water metering.
\end{abstract}

Reprinted from Water. Cite as: Galioto, F.; Raggi, M.; Viaggi, D. Pricing Policies in Managing Water Resources in Agriculture: An Application of Contract Theory to Unmetered Water. Water 2014, 6, $1502-1516$.

\section{Introduction}

The European Union, Russia and South Africa have recently reformed their water policies in order to address new water-related challenges, including population growth and climate change [1]. These water reforms have in common a transition from an approach focused on increasing water supply to one that focuses on the management of water demand. These reforms were partly devoted to identify an institutional body able to ensure a suitable management of water uses. As a result of this process, watersheds are mostly recognized to be the most effective and sustainable institutions for water governance. Another strand of action concerns the identification of policy instruments to efficiently impact the behavior of water users. In spite of the increasing attention being paid to economic instruments, this issue is not suitable for generalized solutions, since pricing schemes should take into account local and regional circumstances regarding water uses, water availability, farm size and crops grown. However, economic instruments remain explicitly promoted by the European Union (EU) through its Water Framework Directive (WFD). The WFD includes three economic concepts: 
(1) Full Cost Recovery (FCR) which covers the recovery of the costs related to water services, the potential negative environmental effects of socio-economic activities and the foregone opportunities of alternative water uses (resource costs);

(2) The Polluter Pays Principle (PPP) that looks at the adequacy of contributions to compensate for the cost of environmental damage generated by users;

(3) Incentive Pricing (IP) that deals with the way in which water use is paid for and whether the right signals are transmitted to the water users.

These concepts underscore the dual purpose of charging for water use, namely financial and economic. From a financial perspective, the tariff allows the regulator to recover all or part of the capital and current costs. From an economic perspective, the tariff enables the regulator to conserve water and raise water productivity [2]. The main assumption underlying the regulator's ability to achieve one or more of the above policy objectives by way of tariffs relies on direct or indirect knowledge of the amount of water used by individual sectors or agents. Hence, water metering is a key step in allowing local authorities to develop pricing policies that adhere to EU WFD principles [3-11]. However, the most common pricing systems for irrigation water in the world [12] and in Europe $[12,13]$ rely on area-based charges, disconnected from actual use. Indeed, water metering is extremely controversial in agriculture and greatly constrains the adoption of efficient water pricing for irrigation [2]. The result is the inability of tariffs to contribute to more efficient water use, with, in addition, the fact that higher tariffs (potentially needed in order to achieve cost recovery) hurt the less water intensive crops. This also undermines the EU WFD objective of using pricing-based incentive mechanisms to mitigate water scarcity.

From an economic point of view, the lack of water metering can be interpreted in the framework of information asymmetries between management authorities and farmers. This situation has prompted some researchers to study the problem of tariff design when water uses are unobserved. Unmetered water is usually priced on a per area basis [14,15] but may also be priced, at least theoretically, by charging per unit fees on observable outputs or inputs $[12,16]$.

If the entire water supply cost is borne by the water users, then it makes no difference if water inputs are unobservable. A problem arises, however, when the cost of water includes public good components due to scarcity or extraction cost externalities [12]. In this case, farmers would likely decide to use more water than they would use in a situation characterized by a socially optimal allocation, and hence some kind of regulatory intervention may be desirable. Available information, such as the total harvested area, could constitute inaccurate proxies for water uses and, hence, indirect water fees may even increase inefficiencies. The pricing problem is also exacerbated when individual farmers' production technologies are unknown to the water authorities (adverse selection) [17,18] and regulation entails transaction costs associated with administration, monitoring and enforcing activities [12].

This paper aims to verify whether existing area-based tariff strategies are efficient economic instruments for water policy and to what extent alternative design in the direction of irrigated area-based instruments can help in better complying with European water policy principles.

The case study focuses on a Reclamation and Irrigation Board (RIB). This type of institution, the main provider of irrigation water in Italy, is a user-based allocation mechanism similar to others in 
place in some Southern EU Member States [13], and is recognized as being an appropriate institution to allow for the analysis of different kinds of tariff policies [19,20]. This institution provides water for users in keeping with the relevant Italian legislation and imposes a payment based on a portion of the RIB's costs, shared among users on the basis of an estimation of their expected benefits [21]. RIB pricing policies are not necessarily focused on promoting sustainable water uses. Pricing strategies are limited to the recovery of current financial costs and do not account for other financial costs, opportunity costs or costs associated with environmental externalities.

In the case of a revision of the RIB's contribution system in accordance with the FCR principles defined in the WFD, a significant restructuring of RIB water pricing systems could occur. As specified above, tariff strategies should be tailored to the specific types of distribution systems. The inability to meter water consumption requires various tools of price discrimination aimed at improving the control of water uses [22]. Specifically, the RIB in the case study offers farmers the possibility to choose between a tariff based on the total farm area and a tariff based on the irrigated area. These optional contracts generate information for the RIB about the actual production technology (which allows for a more efficient incentive system), based on the contract chosen by each farm, as well as transaction costs due to the need to monitor irrigated farmland.

Given the water demand function and the profit function of different farm types estimated in a recent research study carried out in the RIB's area [23], and assuming that farmers are profit maximizers and that the regulator seeks to meet the new requirements imposed by the Directive, we examine the contribution of improved contract design through a contract theory approach starting from the current RIB pricing strategies. The results show that benefit differences, arising from the ability to manage farmers' tariff choices, vary with increasing water use costs. Within a certain range of water scarcity, surplus differences may justify the transaction cost required to solve information asymmetries.

The paper is divided into four sections. Section 2 describes the current pricing policies in the Case Study area. Section 3 sets out the methodology; formalizing the producer's behavior; the section identifies two different potential scenarios for the regulator's pricing strategies. Section 4 presents a numerical analysis of the identified pricing strategies based on available information about irrigation in the area, under different scenarios of cost recovery obligations and information asymmetry. Section 5 provides a discussion on how contract theory could help to define strategies able to integrate the WFD principles in actual pricing policies based on the experience carried out in this study, followed by some concluding remarks.

\section{The Case Study}

The RIB is an association of persons who own property (land and buildings) in its jurisdiction. Landowners who are associates of the RIB are required, according to the subsidiarity principle, to contribute directly to the pursuit of the general interest.

The RIB undertakes institutional (collection of contributions), operational (management) and proactive (planning) functions. With regard to the institutional functions, contributions for reclamation are enforced on all agricultural and non-agricultural assets in its jurisdiction. RIBs are also major providers of irrigation water. Pricing strategies arising from the use of irrigation water are currently designed autonomously by the RIB and vary with respect to the type of distribution system. 
In any case, by statute, cost allocations among associates are performed on the basis of the degree of benefit. In fact, this principle is not always rigorously met, especially when irrigation water is unmetered.

Italian RIBs have historically dealt with the recovery of operating costs. They rely on State funding for the coverage of infrastructural investments and hence are not in charge of recovering the related (capital) costs.

According to the FCR principle, with the implementation of the WFD, State intervention should drive the local population towards the self-management of water resources. Accordingly, Basin Districts [24] should lead the various economic sectors using water, including those served by the RIBs, to take responsibility of the full costs required to ensure a good hydrological status of the area under their jurisdiction. Lack of metering conditions hinders the application of cost sharing between farmers on the basis of water use. In this respect, options allowing some price discrimination are expected to favor a greater ability to control resources, ensuring a better allocative efficiency and a more rational use of water for irrigation.

The case study focuses on the RIB of Western Romagna (Consorzio di Bonifica della Romagna Occidentale-CBRO). The consortium covers an area of 195,000 ha of which 70,000 ha are plains. Fruit and wine grapes are the main crops grown in the area. Therefore, irrigation is both frequent and abundant. The study area is particularly attractive for the investigation of different water management instruments: Part of it is served by pressure pipes and part receives water via open canals. As a result, different pricing systems are also in place, including volumetric pricing in areas served by pressure pipes and area-based tariffs in the remaining parts of the RIB.

For some of the areas served by surface water, the RIB uses a pricing regime that provides the choice between two tariff options.

The first option is a per area based tariff imposed on the entire farmland area, i.e., it does not account directly for the distinction between irrigated and non-irrigated land in individual farms. However, it takes into account the general greater share of irrigated area for smaller farms, by setting a per hectare tariff, $T^{a}\left(x_{i}\right)$, that decreases with the increase in farm size, $x_{i}$ up to a certain threshold of land size, $x^{s}$, after which it stabilizes to a flat rate per hectare. For farmers exceeding $x^{s}$, the tariff per hectare is traceable to the following formula: Here, $K$ is the tariff corresponding to the total paid for amount of land equal to $x^{s}$ and equals the integral of $T^{a}\left(x_{i}\right)$ from 0 hectares to $x^{s}$; $t^{a}$ is the tariff per hectare over the remaining harvested area. Thus, if $x_{i}$ equals $x^{s}$ the average per hectare tariff would be equal to $K / x^{s}$. For larger farms, $t^{a} \times\left(x_{i}-x^{s}\right)$ will play a greater role in influencing the entire value paid by the farm, while the average (per hectare) tariff will tend to the marginal value $\left(t^{a}\right)$ as $x_{i}$ tends to $+\infty$. We define this pricing scheme as a "no incentive tariff" since it is not capable of affecting water uses.

The second option, unlike the first one, is based on a per hectare tariff proportional to the quota of irrigated farmland, $x_{i}^{i r r}$, such that: $T^{b}\left(x^{i r r}{ }_{i}\right)=t^{b} \times x_{i}{ }_{i r r}$. We refer to this pricing scheme as "incentive tariff" since it is able to affect water uses. Here, farmers are required to declare the size of the irrigated area. This practice, based on self-reporting by farmers, and hence requiring controls by the RIB, generates specific monitoring costs that are charged by way of the water tariffs themselves. 
Figure 1 describes the evolution of the per hectare tariff under the two pricing schemes as farm size $\left(x_{i}\right)$, and, respectively, irrigated land $\left(x_{i}^{i r r}\right)$, increases.

As $x_{i}$ increases, the average fee under the first pricing option (blue line) decreases from $72 € /$ ha, for farms size under 1.5 ha, to $27 € /$ ha, for huge farms. In contrast, the second pricing option (red line) is not affected by farm size and its average value is constant (187 €/ha of irrigated farmland).

This double tariff scheme is implemented for the main purpose to ensure a more equitable allocation of costs among beneficiaries, since the share of irrigated crops tend to decrease with increasing farm size. Under such circumstances an irrigation-related tariff proportional to the total farmland area would be too unbalanced for large farms.

In addition, the RIB offers the option of choosing the incentive tariff, $T^{b}\left(x_{i}^{i r r}\right)$ only to farms that are larger than 15 ha. This limit is set since the incentive tariff requires the farmer to self-report the quota of irrigated farmland, forcing the RIB to organize controls in order to verify compliance. Costs arising by direct monitoring are charged by way of the water tariffs themselves. These costs increase with the farmer's choice of the incentive tariff scheme limiting the regulator's ability to check for uses. This explains the regulator's decision to limit the choice of this tariff scheme only to large farms (that are also less numerous).

In a recent research five different clusters of farms were identified in the RIB's region [23]. Under the current policy, only two of them have the opportunity to choose between the discussed tariff schemes. The first type represents $3 \%$ of RIB farms and is characterized by an average farm size of 33.85 ha, $37 \%$ of which is covered by orchards; the second, represents $1 \%$ of RIB farms and is characterized by an average farmland area of $75.07 \mathrm{ha}, 16 \%$ of which is devoted to orchards. The two farm types represent $21 \%$ of the area managed by the RIB. As these farm types are the only ones that can choose between the two tariff options, they are also the only ones considered in this study.

Figure 1. Average tariff trends with increasing total and irrigated farmland for the two tariff options.

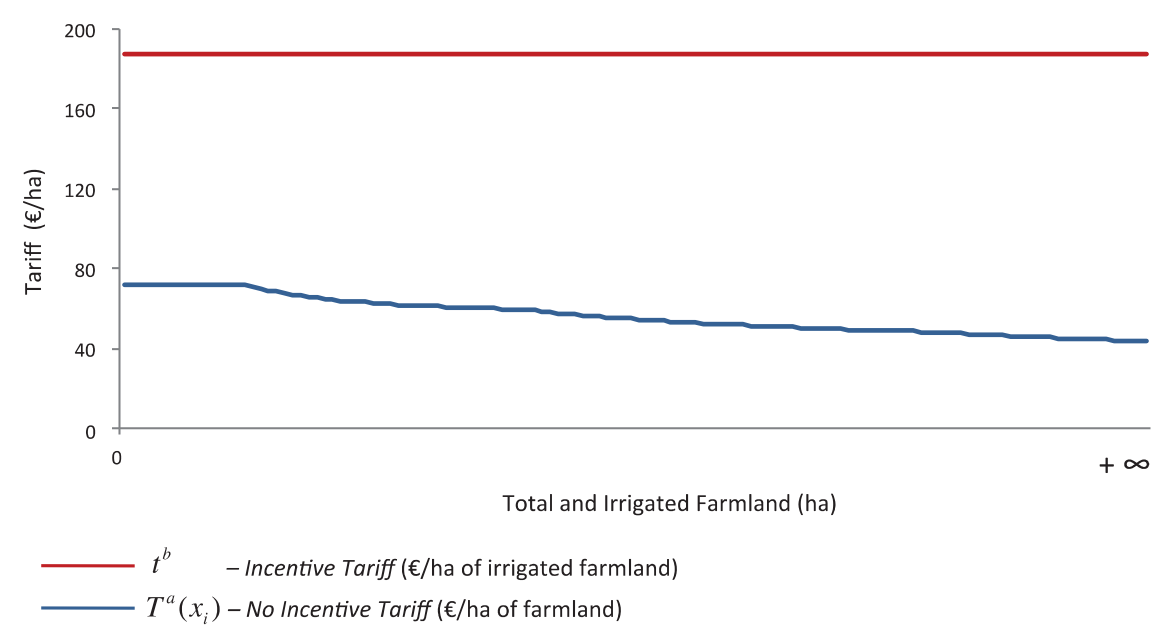

\section{Methodology}

The present section begins first by analyzing how the producers behave given the two tariff alternatives previously described and assuming that the farmer maximizes his/her profits. Then, the 
methodology shifts from the users to the regulator's perspective. The tariff is no longer exogenously given, as in the producers' problem, but is rather endogenous to the regulator's problem. The key parameter driving the decision is the cost of water. Once the public problem is defined we consider two scenarios. The first scenario reflects the present situation. Here, the water use cost is assumed to be perceived directly by the regulator but the tariff instrument is used only to recover operational costs. The second scenario assumes the commitment to FCR and perfect information by the regulator regarding farmer types (technology). It reflects the theoretical situation in which the water use cost is entirely transferred to the producers by the tariff instrument, while maintaining the current tariff structure.

In the producer problem, given the RIB's pricing options, and assuming that the farmer maximizes his/her profit and that the share of irrigated area has already been established, the choice of the tariff option by the farmer, $T_{i}^{k^{*}}$, may be expected to be directed towards the less costly option:

$$
T_{i}^{k^{*}}=\min \left[T^{a}\left(x_{i}\right), T^{b}\left(x_{i}^{i r r}\right)\right] \quad \forall i, \text { with } k=\{a, b\}
$$

where $a$ and $b$ reflect the two tariff options and $k^{*}$ is the one chosen. If $T^{a}\left(x_{i}\right) \leq t^{b} \times x_{i}^{i r r}$, then $T^{a}\left(x_{i}\right)$ will be preferred over $T^{b}\left(x_{i}^{i r r}\right)$. That is, as long as $x_{i}^{i r r} \geq T^{a}\left(x_{i}\right) / t^{b}$ the farmer is induced to opt for the no incentive tariff. Otherwise, the farmer is induced to opt for the incentive tariff.

Thus, the ratio between the average value of the no incentive tariff and the marginal value of the incentive tariff, which decreases as farmland increases, provides a threshold, $\operatorname{Tr}_{i}$, such that $\operatorname{Tr}_{i}=T^{a}\left(x_{i}\right) / t^{b}=x_{i}^{i r r}$. This threshold, on the basis of the actual quota of irrigated farmland, marks the transition from preferring one tariff to preferring the other.

The previous model can be reformulated by removing the hypothesis that the share of irrigated area has already been established by the farmer, thus conditioning the choice of the tariff to the choice of the optimal share of irrigated farmland. The problem can, therefore, be modeled as a choice between the two pricing options, jointly considering the optimal irrigated area, according to the criterion of profit maximization. Assuming that the per hectare profit function, $\pi_{i}(\cdot)$, is concave and increases as the quota of irrigated farmland increases, with $\pi_{i}^{\prime}\left(x_{i}^{i r r}\right)>0 e \pi_{i}^{\prime \prime}\left(x_{i}^{i r r}\right) \leq 0$, the farmer compares the profit that can be obtained under each tariff option:

$$
\Pi_{i}^{k}\left(x_{i}^{i r r^{*}}\right)=\max \left[\pi_{i}\left(x_{i}^{i r r^{*}}\right)-T^{a}\left(x_{i}\right), \quad \pi_{i}\left(x_{i}^{i r r^{*}}\right)-T^{b}\left(x_{i}^{i r r^{*} b}\right)\right]
$$

$\prod_{i}^{k}\left(x_{i}^{i r r^{*}}\right)$ is the maximum profit that can be obtained as a result of both the choice of tariff type and share of irrigated area; $x_{i}^{i r r^{*}{ }_{a}}, x_{i}^{i r r^{*}{ }_{b}}$ are respectively the optimal quota of irrigated areas in each tariff option (resulting from the relevant first derivative of the difference between profits and the optional tariffs); accordingly, $x_{i}^{i r r^{*}}$ is the optimal share of irrigated farmland resulting from the higher value of the net profit options.

The tariff choice, $T_{i}{ }^{k^{*}}$, does not necessarily match the minimum value of the two tariff options as given in Equation (1). Here, when the first option of Equation (2) is greater than the second, $\pi_{i}\left(x_{i}^{i r *_{a}}\right)-T^{a}\left(x_{i}\right) \geq \pi_{i}\left(x_{i}^{i r *_{b}}\right)-t^{b} \times x_{i}^{i r r *_{b}}$, then the farmer will opt for the no incentive tariff, $T_{i}^{k^{*}}=T^{a}\left(x_{i}\right)$. That is, as long as $x_{i}^{i r r_{b}} \geq T^{a}\left(x_{i}\right) / t^{b}-\left[\pi_{i}\left(x_{i}^{i r r^{*}{ }_{a}}\right)-\pi_{i}\left(x_{i}^{i r r_{b}}\right)\right] / t^{b}$ the farmer is induced to opt for the no incentive tariff. Otherwise, the farmer is induced to opt for the incentive tariff. 
The tariff option threshold, $\operatorname{Tr}_{i}$, is no longer compared with a given share of irrigated farmland, but rather with the optimal share of irrigated farmland resulting from the choice of the incentive tariffs, $x_{i}^{i r r_{b}}$, plus the ratio between the differences in gross profits and the incentive tariff, $\left[\pi_{i}\left(x_{i}^{i r r_{a}}\right)-\pi_{i}\left(x_{i}^{i r r^{*} b}\right)\right] / t^{b}$, and such that: $\operatorname{Tr}_{i}=T^{a}\left(x_{i}\right) / t^{b}=x_{i}^{i r r}+\left[\pi_{i}\left(x_{i}^{i r *_{a}^{*}}\right)-\pi_{i}\left(x_{i}^{i r r_{b}}\right)\right] / t^{b}$. The value of this last argument is always positive as $x_{i}^{i r *_{b}} \leq x_{i}^{i r r^{*}{ }_{a}}$ [25]. As a result, the threshold tends to be higher than the ones obtained in Equation (1). This is consistent with the fact that this second modeling option allows for more flexibility in farm adaptation, which is, by the way, closer to reality.

In brief, the choice threshold is conditioned both by the public pricing policies and the intrinsic characteristics of each farm type. Both the relative values of the price schemes $\left(T^{a}\left(x_{i}\right) / t^{b}\right)$ and the absolute values of the incentive tariff $\left(t^{b}\right)$ play a key role in conditioning private choices with different results, depending on how farm types differ.

Assuming that the regulator is acting in compliance with the FCR principle, the cost of water use ( $v$, in $€ / \mathrm{m}^{3}$ ) does not depend solely on the current operating costs, but is rather tied to other costs, including environmental and opportunity costs. These costs should be charged to the recipients on the basis of the respective degree of responsibility. Environmental externalities are related to pollution and to an excessive use of water. In the present study it is assumed that the unit cost of water usage, $v$, is proportional to irrigation water use and that the amount of water use per hectare of irrigated land varies across farms. Hence, the total per hectare water use cost is directly connected to water uses, $W_{i}\left(x_{i}^{i r r^{*}}\right)$, that differ as both farm types, $i$, and irrigated farmland, $x_{i}^{i r r^{*}}$, differ, and such that: $C W_{i}\left(x_{i}^{i r r *}\right)=V \times W_{i}\left(X_{i}^{i r r *}\right)$.

The public regulator is assumed to act in the interests of the community by regulating the choices of individuals in order to seek an optimal use of the resources. Formalizing the problem we have:

$$
\begin{gathered}
\max Z\left(x_{i}^{i r r^{*}}\right)=\gamma_{i} \times\left[\sum_{i=1}^{n} \pi_{i}\left(x_{i}^{i r r^{*}}\right)-C W_{i}\left(x_{i}^{i r r^{*}}\right)\right] \\
\text { s.t.: } \\
\text { where } x_{i}^{i r r^{* *}}=C W_{i}\left(x_{i}^{i r r^{*}}\right)
\end{gathered}
$$

$Z\left(x^{i r r^{*}}\right)$ is the objective variable and represents the per hectare net social benefit, of a regulator that acts in the interests of the society as a whole; this is an often used assumption in environmental-economic modeling. This is given by summing the weighted differences between the per hectare profits (excluding water tariffs) of each type of user under the regulator's jurisdiction (here, farmers) and the corresponding costs associated to water uses, considered to be borne by society. The weighting term, $\gamma_{i}$, is the share of each farm type, given by the ratio between the total agricultural area related to each farm type and the overall agricultural area under the regulator's jurisdiction. Farmers do not directly perceive water use costs as water is managed collectively and costs are transferred to users via tariffs. Thus, tariffs are not costs per se, but rather constitute transfers and do not enter into the objective function of the regulator (while they remain costs from the farmers' point of view).

FCR is the constraint of full cost recovery for water use. According to the full cost recovery principles, it requires tariffs that are able to recover the cost of water uses and according to the 
polluter pays principle it imposes tariffs that are at least equal to the water use costs borne by each type of farm. Note that this interpretation is stricter than the one actually given in the implementation of the WFD, which applies to entire sectors and not to individual users.

$x_{i}^{i r r^{*}}=f\left(T_{i}^{k^{\prime}}\right)$ derives from the private problem and is the reaction function of the irrigated farmland for each farm type that varies as the RIB's pricing policy changes. An additional condition is $x_{i}^{i r r^{*}} \geq 0$.

The cost function associated with the use of irrigation water $\left[C W_{i}\left(x_{i}^{i r r^{*}}\right)\right]$ is primarily faced by the RIB as a result of users' decisions (farmers). Currently, as previously stated, the RIB ascribes only a part of the cost recovery to the recipients. The FCR constraint is activated if the regulator acts in compliance with the WFD. Hence, costs are directly shifted to producers by way of the tariff. Under such circumstances, the awareness of farm types allows the RIB to identify the optimal mix of tariff levels that minimize the impact of water use costs on farm profits. If the regulator does not comply with the WFD, the effort to optimize tariff strategies is not justified as most of the social cost of water uses is borne by society and not directly by farmers.

We test the model above using two scenarios and for increasing values of water use costs, which is expected to be one of the major drivers of the actual social desirability of more complex pricing solutions. The current water use costs corresponding to the full cost are currently unknown in the area, so a parametrization in a reasonable range was carried out for financial capital, environmental and resource costs to be considered in addition to operational costs.

Specifically, in a first scenario it is assumed that, regardless of the cost of water use, the RIB ignores the requirements imposed by the WFD (FCR constraint) without changing its pricing policies, hence keeping constant the marginal values of the tariff options $\left(\bar{T}_{i}^{k^{*}}\right)$. This is the present situation that considers only the recovery of the operational costs. Additional costs are implicitly left to be borne by society.

In a second scenario it is assumed that the RIB knows the profits and water use functions of its members. Under these conditions, the regulator is able to predict producers' reactions to a tariff variation and, hence, to act appropriately on tariff variations in order to optimize the collective benefit.

\section{Results}

The methodology was implemented in the case study using a recent estimation of the per hectare profit and water use function of two farm types in the RIB's region [15].

Figure 2 shows the marginal profit functions of the farm types and the marginal functions of the tariff options offered by the RIB. The slope of the profit functions depends on the crops grown by each farm types. Profit functions cross the $x$-axis to a point corresponding with the optimal quota of irrigated farmland under the no incentive tariff regimes, $x_{i}^{i r{ }^{i} *}$ (respectively point A and B in Figure 2). The horizontal line represents the marginal value of the incentive tariff, $t^{b}$. The projection on the $x$-axis of the crossing point between the marginal tariffs and the profit function of the two farm types (respectively points A and D in Figure 2) is the optimal quota of irrigated farmland under the incentive tariff regimes for each type, $x_{i}^{i r r_{b}^{*}}$ (respectively points $\mathrm{C}$ and $\mathrm{F}$ in Figure 2). 
The dotted vertical lines in Figure 2 show the tariff thresholds obtained in Equation (4) for each farm type. The thresholds cross the $x$-axis to a point the value of which is given by adding to the optimal quota of irrigated farmland under the incentive tariff regimes, $x_{i}^{i r r^{*}{ }_{b}}$, the ratio between the gross profit differences with the two tariff options and the incentive tariff, $\left[\pi_{i}\left(x_{i}^{i r r^{*}{ }^{a}}\right)-\pi_{i}\left(x_{i}^{i r r_{b}^{*}}\right)\right] / t^{b}$. The gross profit differences correspond to the triangular areas $\mathrm{ABC}$ and DEF in Figure 2 respectively for the two farm types. The height of those areas matches the level of the incentive tariff. Thus the threshold can be rewritten as follows: $\operatorname{Tr}_{i}=x_{i}^{i r r_{b}{ }_{b}}+\left(x_{i}^{i r r^{*}{ }_{a}}-x_{i}^{i r r_{b}^{*}}\right) / 2$.

For a tariff ratio equal to the threshold farmers are indifferent to both tariff regimes. Hence, the discriminatory power of the optional tariffs is null. If the relative ratio between the tariffs is higher than the threshold, farmers will opt for the incentive tariff $\left[T^{b}\left(x_{i}^{i r_{b}}\right)\right]$. As a result, the irrigated farmland decreases by a quota corresponding to the difference between the intersection of the marginal profit function with the $x$-axis and the projection of the intersection of the marginal profit function with the incentive tariff level. Currently the tariff ratio, $T^{a}\left(x_{i}\right) / t^{b}$, is lower than the threshold for both farm types. However, few farms, only partially represented by the type associated to their characteristics, currently opt for the incentive tariff. Hence, because of the present tariff option levels most of the farmers agree with the no incentive tariff, $T^{a}\left(x_{i}\right)$ [26].

The private problem helps to understand how the public decision-maker should direct its pricing strategies in light of the new challenges imposed by the WFD.

Figure 3 shows the collective benefit of the two scenarios described in the methodology. In the first scenario, tariff choice conditions are constant and reflect the repayment of the delivery costs borne by the water authority. Producers do not pay any additional costs that are assumed to be charged to society.

In the second scenario it is assumed that the regulator is aware of the users' production and irrigation schemes and the costs associated with the use of irrigation water are entirely transferred to the producers. With respect to the other scenarios, the regulator is induced to minimize the impact on users' benefits by setting the optional tariff.

Figure 2. Profit and tariff functions with increasing quotas of irrigated farmland.

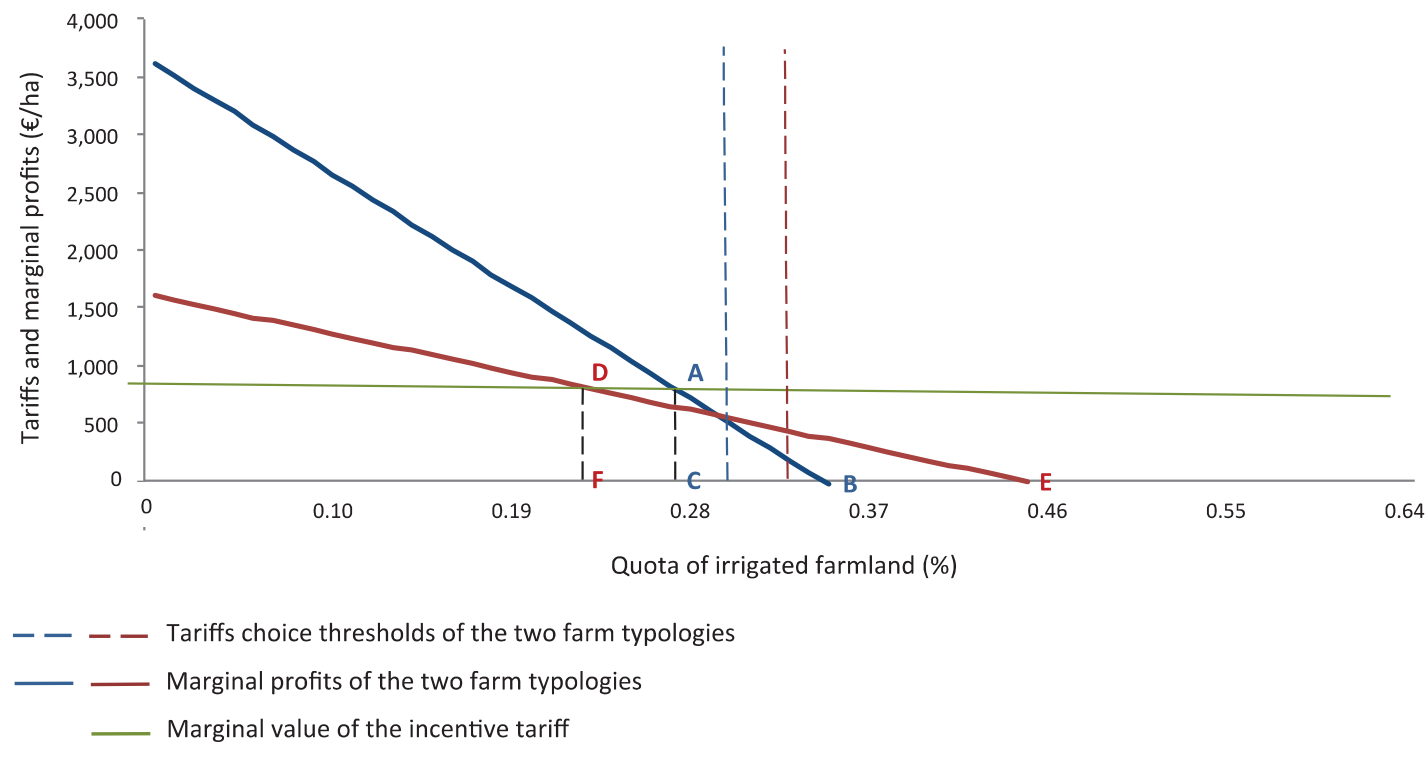


Figure 3. Benefit trends with increasing irrigation costs for the two scenarios.

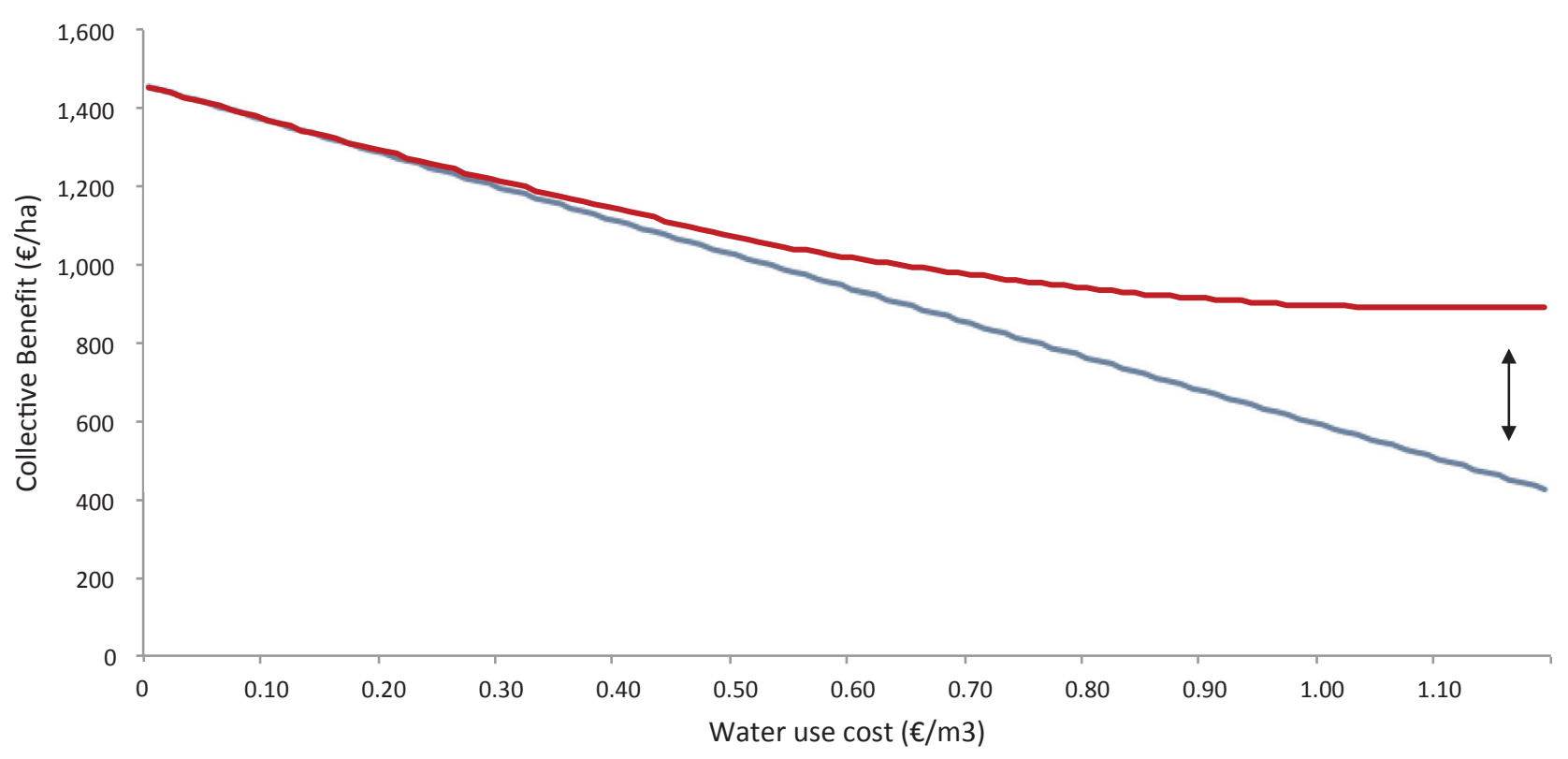

\footnotetext{
- $1^{\circ}$ Scenario - implementation of costant charges on operational costs

— $\quad 2^{\circ}$ scenario - implementation of the tariff's options schemes on full costs

Range of benefit variation between scenarios
}

Benefit differences between the two scenarios mark the acceptable limit of the transaction costs that would arise with the adoption of the incentive tariffs in the second scenario. Up to a water use cost of $0.30 € / \mathrm{m}^{3}$ differences in benefits between the two scenarios are not significant: In between $0.30 € / \mathrm{m}^{3}$ and $1.00 € / \mathrm{m}^{3}$ differences in benefit increase from about $0 € /$ ha to $30 € /$ ha. From a water use cost of $1.00 € / \mathrm{m}^{3}$ the trend in benefits in the second scenario remains constant, while in the first scenario it still decreases. This is due to the fact that in the second scenario for increasing levels of water use costs the regulator tends to set tariff options in such a way as to induce an increasing number of farmers to choose the incentive tariff up until a value at which all farm types cease to irrigate. Currently, farmers served by pressure pipes in the region under the case study jurisdiction pay volumetric tariffs equal to $0.12 € / \mathrm{m}^{3}$. The level of the current tariffs is much lower than the value at which it is possible to ascertain appreciable differences in benefits between the two scenarios. This fact helps justify why the RIB is limiting the enforcement of tariff options to a few farms.

Figure 4 shows the trend of the quota of irrigated farmland with increasing water use costs for the different scenarios. For the first and second scenarios water use costs do not condition farmers' water uses. In the first scenario, this is due to the absence of a tariff policy that endogenizes any externalities associated with the use of water for irrigation purposes. In the second scenario, a tariff disconnected from water uses is the explanation of farmers' indifference to increasing water use costs. 
Figure 4. Quota of irrigated farmland trends with increasing irrigation costs for the two scenarios.

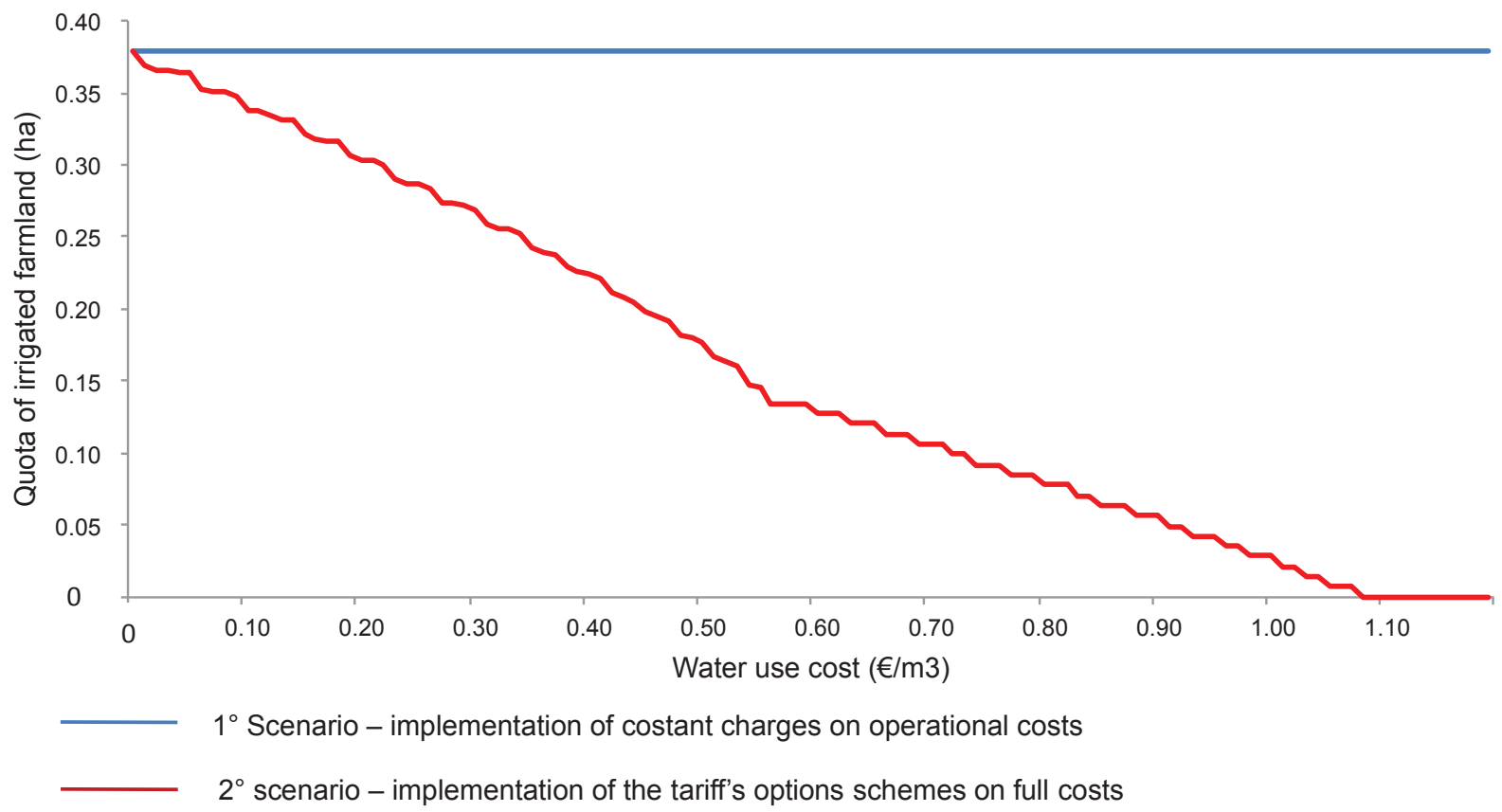

Even if indirectly, only the second scenario shows the existence of a relation between water use costs and water uses. The relation between the water use cost level and the quota of irrigated farmland in the second scenario is explained by the fact that at least one of the two farm types considered in this paper opts for the incentive tariff. The change in slope of the red line in Figure 4 results from a variation in tariff choices. This variation occurs in favor of the incentive tariff as the quota of irrigated farmland continues to decrease with increasing water use costs to a level at which all farms cease to irrigate.

For a cost of water equal to $0.12 € / \mathrm{m}^{3}$, corresponding to the current value for volumetric tariffs in the case study region, the second scenario shows a 5\% reduction in the irrigated land share. A $400 \%$ increase in the cost of water with respect to the current value bring to a $50 \%$ reduction in the irrigated land share, while an $800 \%$ increase in the cost of water induces farmers to cease irrigation.

\section{Discussion and Conclusions}

The aim of this study was to verify whether the existing tariff strategies for irrigation water are efficient economic instruments for water policy and to what extent alternative designs could help in better managing water demand in the absence of water metering.

Specifically, the paper discusses the design of a pricing strategy presently applied in the case study area that, with the addition of reasonable monitoring costs, allows for the implementation of an incentive tariff which approximates a volumetric pricing scheme by coupling tariffs to the irrigated area.

According to the scenarios proposed, the implementation of the WFD principles should enable the regulator to recover the full cost needed to provide services. The modification of the existing tariff policies, presently based on an area-based flat rate system, is justified if transaction costs, due to the need to monitor at least irrigated areas under no metering conditions, are lower than the 
difference in benefit between the two scenarios. From this perspective, the RIB should adjust the tariffs for irrigation water uses according to the type of priority (funding and/or environmental protection) and in compliance with the criterion of cost sharing (equity). As noted in the results, this may, at least partially, resolve the problem of asymmetric information. Indeed, even if farmers' profit and water use functions are unknown, the tariff options, if properly calibrated, would lead some farmers to choose the incentive tariffs, hence revealing their water profitability. This would lead to an intermediate situation between the two extreme scenarios that includes, on the one hand, the absence of any volume-related pricing policy and, on the other, a meticulous tariff plan modulated on the marginal productivity of each farm type.

Although using quite different premises from those in our study, other recent studies have analyzed the implementation of alternative water pricing policies for irrigation [10,11]. Specifically, the analysis of Veettil et al. [10] in the Krishna River basin, India, demonstrated that farms served in the absence of water metering tend to opt for incentive tariff schemes mostly for high levels of water use costs. This is also consistent with our study in which the current low level of cost recovery does not justify the adoption of the alternative tariff by any of the farm types served by the RIB. Moreover, Fragoso and Marques [11], in a study carried out in the Alentejo region of Portugal, identified volumetric block tariffs as the most efficient incentive strategy. This is due to the fact that farmers mostly used to have a demand elasticity for irrigation water that increases with increasing water use cost. In the absence of water metering this would probably result in the identification of fixed charge quotas as being the best incentive strategy. However, beyond comparing the tariff schemes, the main purpose of the present study was to analyze the regulator's behavior under different policy scenarios, given a discriminatory strategy that consists of the implementation of two tariff options. This is very relevant in the case study areas as it allows for the identification of incentives to lower water demand without major changes to the existing pricing structure and without water metering.

Thus, the study describes a discriminatory strategy that enables the regulator to partially control water use in surface water delivery systems serving a large number of farms (specifically the RIBs of Western Romagna). Under such circumstances, incentive strategies are considered prohibitively expensive [2]. That is why the regulator is currently limiting the implementation of the tariff option schemes to only a few farms.

An important limitation of the research is found in the simplified description of the two scenarios. Compliance or not with WFD principles on water pricing is the principal difference between the two scenarios. However, we only analyzed the effects related to the implementation of the incentive pricing principles. The other two principles appear as assumptions of the regulator's maximization problem and are implicit in the FCR constraint. The polluter pays principle is also implicit in the regulator's tariff policies. Moreover, the FCR constraint at the farm level is an exacerbation of current regulatory guidance. Charging full costs to individual farmers is in fact beyond the prescriptions of the WFD, which recommends implementing its principles for the agricultural sector as a whole, and at the river basin district level, but not at the level of each individual water service user [27].

Another significant limitation arises from the assumption of perfect information under the scenario in which compliance with the WFD principles is assumed. In the absence of water metering, the regulator would not be able to determine the technology used (farm types) nor control water use 
(irrigated land). This condition implicitly poses the two main problems of asymmetric information: adverse selection and moral hazard. Smith and Tsur [12] were the first to tackle both problems theoretically, but only adverse selection has actually been tested [15]. The ability to deal with adverse selection allowed Viaggi et al. [15] to distinguish tariffs according to farmers' water use attitudes; hence substantially increasing performances with respect to there being no discrimination. The discriminatory strategy described in this paper in addition to tariff options would probably further improve the discriminatory power of the regulator, strengthen its ability to minimize the impact of water tariffs on farm profits, while providing more adequate incentives.

Currently there are no studies, including this one, which directly tackle the issues of moral hazard. This is the main limiting factor of the present study as moral hazard conditions the extent to which monitoring activities enables the regulator to implement incentive strategies in the absence of water metering. In this study, the differences in performance between the two scenarios limit the monitoring costs due to the need to control irrigated land that would arise with the adoption of the incentive tariff. As a result, by adjusting tariff option levels, the regulator would be able to foresee how many farms will opt for the incentive tariff and hence control both water uses and monitoring costs. Thus, the discrimination strategy described in this paper could be considered as a starting point for the analysis of moral hazard in the absence of water. Specifically, the main question with respect to water pricing in the absence of metering is to recognize the most cost effective monitoring strategies that would enable the regulator to overcome moral hazard arising from false reporting. This last consideration suggests a new direction for further research.

\section{Acknowledgments}

The authors wish to thank the anonymous referees for the fruitful suggestions and David Cuming for English editing. Responsibility for the contents of the study lies solely with the authors.

\section{Conflicts of Interest}

The authors declare no conflict of interest.

\section{References and Notes}

1. Christian, J.S.; Gleick, P.H.; Cooley, H. US Water policy reform. In The World's Water: The Biennial Report on Freshwater Resources; Gleick, P.H., Ed.; Island Press: Washington, DC, USA, 2011.

2. Molle, F.; Berkoff, J. Water pricing in irrigation: Mapping the debate in the light of experience. In Irrigation Water Pricing: The Gap between Theory and Practice; Molle, F., Berkoff, J., Eds.; CAB International: Wallingford, UK, 2007; pp. 21-93.

3. Moore, M.; Gollehon, N.; Carey, M. Multicroop production decisions in western irrigated agriculture: The role of water price. Am. J. Agric. Econ. 1994, 76, 859-874.

4. Gardner, B.D. Some implications of federal grazing, timber, irrigation, and recreation subsidies. Choices 1997, 12, 9-14. 
5. Schaible, G.D. Water conservation policy analysis: An interregional, multi-output, primal-dual optimization approach. Am. J. Agric. Econ. 1997, 79, 163-177.

6. Iglesias, E.; Garrido, A.; Sumpsi, J.; Varela-Ortega, C. Water demand elasticity: implications for water management and water pricing policies. In Proceedings of the World Congress of Environmental and Resource Economists, Venice, Italy, 26-29 June 1998; pp. 1-16.

7. Varela-Ortega, C.; Sumpsi, J.M.; Garrido, A.; Blanco, M.; Iglesias, E. Water pricing policies, public decision making and farmers' response: Implications for water policy. Agric. Econ. 1998, 19, 193-202.

8. Berbel, J.; Gomez-Limon, J.A. The impact of water-pricing policy in Spain: An analysis of three irrigated areas. Agric. Water Manag. 2007, 43, 219-238.

9. Yang, H.; Zhang, X.; Zehnder, A.J.B. Water scarcity, pricing mechanism and institutional reform in northern China irrigated agriculture. Agric. Water Manag. 2003, 61, 143-161.

10. Veettil, C.P.; Speelman, S.; Frija, A.; Buysse, J.; Mondelaers, K.; van Huylenbroeck, G. Price sensitivity of farmer preferences for irrigation water-Pricing method: Evidence from a choice model analysis in Krishna River Basin, India. J. Water Resour. Plan. Manag. 2011, 137, 205-214.

11. Fragoso, R.; Marques, C. The Economic Impact of Alternative Water Pricing Policies in the Alentejan Region; CEFAGE-UE Working Paper; University of Evora: Evora, Portugal, 2013.

12. Smith, R.B.W.; Tsur, Y. Asymmetric information and the pricing of natural resources: Understanding the case of unmetered water. Land Econ. 1997, 73, 392-403.

13. Bogaert, S. The Role of Water Pricing and Water Allocation in Agriculture in Delivering Sustainable Water Use in Europe; European Commission: Brussels, Belgium, 2012.

14. Bazzani, G.M.; di Pasquale, S.; Gallerani, V.; Viaggi, D. Irrigated agriculture in Italy and water regulation under the European Union Water Framework Directive. Water Resour. Res. 2004, 40, $1-8$.

15. Viaggi, D.; Raggi, M.; Bartolini, F.; Gallerani, V. Designing contracts for irrigation water under asymmetric information: Are simple pricing mechanisms enough? Agric. Water Manag. 2010, 97, 1326-1332.

16. Bowen, R.; Young, R. Allocative impacts on alternative methods of charging for irrigation water in Egypt. In Irrigation Investments, Technology and Management Strategies for Development; Ester, K.W., Ed.; West View Press: Boulder, CO, USA, 1986.

17. Besanko, D.; Sappington, D. Designing Regulatory Policy with Limited Information; Harwood Academic Publisher: Newark, NJ, USA, 1987.

18. Smith, R.B.W. The conservation reserved program as a least-cost land retirement mechanism. Am. J. Agric. Econ. 1995, 77, 93-105.

19. Schlagler, E.; Ostrom, E. Property rights regimes and natural resources: A conceptual analysis. Land Econ. 1992, 68, 249-262.

20. Coletta, A. Pricing strategies for commons: The case of water users association for irrigation. Riv. Econ. Agrar. 2010, 4, 619-635. 
21. Testo unico delle disposizioni di legge sulle acque e impianti elettrici. Avaliable online: http://www.google.com.hk/url?sa=t\&rct=j\&q=\&esrc=s\&source=web\&cd=1\&ved=0CCoQFjA A\&url=http $\% 3 \mathrm{~A} \% 2 \mathrm{~F} \% 2 \mathrm{Fwww}$. sportelloenergia.info $\% 2$ Findex.php $\% 3$ Faction $\% 3$ Ddownload resource $\% 26 \mathrm{id} \% 3 \mathrm{D} 112 \% 26$ module $\% 3$ Dresourcesmodule $\% 26 \mathrm{src} \% 3 \mathrm{D} \% 2540$ random $4 \mathrm{a} 647 \mathrm{f} 4 \mathrm{e}$ 18d8e\&ei=UMA-U1DEyq0Ble6A4As\&usg=AFQjCNE8hhWniPxcHbTlErxLOZeshmpmWw (accessed on 12 March 2013).

22. Carlton, D.W.; Perloff, J.M. Modern Industrial Organization, 3rd ed.; Pearson-Addison Wesley: New York, NY, USA, 2005; pp. 32-55.

23. Gallerani, V.; la Via, G.; Zanni, G. Water and Agriculture in Italy: Decision Rules and Scenario Analysis, 1st ed.; Franco Angeli: Milano, Italy, 2009; pp. 62-84.

24. The Basin District consists in one or more watersheds (territorial unit where all surface water flow into the sea in a single estuary (article 2 [27] paragraph 13, WFD) defined as the main territorial unit for river basin management (article 2 [27] paragraph 15, WFD).

25. Indeed, by deriving the differences between the gross profit function and the relative tariffs with respect to the irrigated area for each farm type the optimal solution is reached at the equality between marginal profits and marginal tariffs:

$$
\begin{aligned}
& \partial \Pi_{i}^{k} / \partial x_{i}^{i r r}=\pi_{i}^{\prime}\left(x_{i}^{i r r}\right)-T_{i}^{k^{\prime}}\left(x_{i}^{i r r}\right)=0 \\
& \text { if } k=a, \pi_{i}^{\prime}\left(x_{i}^{i r r}\right)=0 ; \quad \text { if } \quad k=b, \pi_{i}^{\prime}\left(x_{i}^{i r r}\right)=T^{b}
\end{aligned}
$$

The value of $k(a, b)$ reflects the tariff choice subject to the optimal share of irrigated area $\left(x_{i}^{i r r *}\right)$. The first tariff scheme $\left[T^{a}\left(x_{i}\right)\right]$, being disconnected from the irrigated farmland, does not affect water consumption $\left[\partial T^{a}\left(x_{i}\right) / \partial x_{i}^{i r r}=0\right]$. In contrast, assuming a positive correlation between water consumption and irrigated areas, $T^{b}\left(x_{i}^{\text {irr }}\right)$ is able to influence water uses $\left(\partial T^{b}\left(x_{i}^{i r r}\right) / \partial x_{i}^{i r r}=T^{b}\right)$. Consequently, given the technology, producers subject to the first tariff scheme will maximize profits at higher shares of irrigated areas than would farmers who choose the other tariff. Then, from the first order condition of the above problem we achieve the farmland share at which producers direct their own choices, which in turn is a function of the marginal tariffs $\left[x_{i}^{i r * *}=f\left(T_{i}^{k^{\prime}}\right)\right.$ with $\left.f^{\prime}\left(T_{i}^{k^{\prime}}\right)<0\right]$.

26. In fact, the optional scheme in force in the case study area induces few farmers to choose the incentive tariff. Their numbers proved to be too inconsistent for the identification of the five main farm types populating the RIB's area. As a result, the optional tariff seems to have no discriminatory power.

27. European Union. Directive 2000/60/EC of the European parliament and of the council establishing a framework for community action in the field of water policy. Off. J. Eur. Communit. 2000, 327, 1-72. 


\title{
An Assessment of Disproportionate Costs in WFD: The Experience of Emilia-Romagna
}

\section{Francesco Galioto, Valentina Marconi, Meri Raggi and Davide Viaggi}

\begin{abstract}
This study develops a methodology for the assessment of disproportionate costs according to the Water Framework Directive guidelines. The originality of the approach lies in the focus on the interdependencies between water bodies and the consideration of the multiple interactions between measures and pressures. However, the broad architecture of the study fits into a wider assessment procedure, already developed in recent studies. Specifically, a cost effectiveness analysis, implemented to select an efficient combination of measures, is integrated with a cost benefit analysis, which allows for the evaluation of the economic feasibility of the proposed actions. This methodology is applied to the Emilia-Romagna Region (Italy). In spite of the uncertainties in the estimations of costs and benefits, the study enables the identification of areas where disproportionate costs are more likely to occur. The results show that disproportionality tends to increase from foothill regions, where most of the functional uses of regional water resources are found, to plain areas, where the sources of pressure tend to be located. Finally, the study offers policy direction for the selection of measures in the case study region.
\end{abstract}

Reprinted from Water. Cite as: Galioto, F.; Marconi, V.; Raggi, M.; Viaggi, D. An Assessment of Disproportionate Costs in WFD: The Experience of Emilia-Romagna. Water 2014, 6, 1967-1995.

\section{Introduction}

The European Water Framework Directive (WFD) [1] provides the principles that should drive the water policies of EU Member States (MS) for both the choice of economic instruments required to control the use of water resources (the incentive pricing principle, the full cost recovery and the polluter pay principle) and the choice of methods for assessing the costs needed to achieve policy objectives (cost benefit analysis and cost effectiveness analysis; [2]).

According to the WFD, EU water quality objectives should be achieved by 2015. Potential derogations (article 4, par. 4, 5, 7 [1]) are allowed both for technical infeasibility or disproportionate costs [2,3]. Technical infeasibility justifies the possibility of extending the deadline for the achievement of Good Ecological Status (GES) up to 2027; disproportionate costs justify the setting of lower targets, i.e., reaching an "acceptable ecological state".

The European Commission has developed guidelines for the assessment of disproportionate costs [4,5]. These guidelines offer alternative assessment instruments that justify the adoption of significantly different strategies and policies within each MS. The assessment process is designed to support policy in the decision making process and to ensure transparency [6,7]. However, the generic nature of the European guidelines fails to suggest a practical procedure whereby a country can carry out a disproportionate cost analysis [8]. Postle et al. (2004) [9] try to solve such regulatory ambiguities. Other contributions are provided by Courtequisse (2005) [10], Laurans (2006) [11], Klauer (2007) [12], Brower (2010) [13], Berbel et al. (2012) [14] and Jensen et al. (2013) [8]. These 
studies define a number of rules and criteria upon which derogation decisions can be based and the application of which would reduce the inherent subjectivity of derogation decisions. More recently, Martin-Ortega et al. (2013) [15] provided a critical review of the key challenges of the WFD's disproportionality analysis. Specifically, they propose the adoption of guiding principles for the assessment of cost disproportionality by tackling various key issues, such as the spatial and temporal scale of assessment, cost and benefit distributional effects and uncertainty. These issues are not properly addressed in most of the studies dealing with disproportionate costs, as cost benefit analysis (CBA) is usually carried out by focusing attention on individual pressures without considering that multiple pressures can contribute to the deterioration of water resources with multiple impacts.

The objective of this study is to develop and apply a methodology for the assessment of disproportionate costs according to the Water Framework Directive guidelines. In particular, the purpose of the study is to enable economic assessment at different scales of aggregation (driven by water body interdependencies) by considering the cross interaction between pressures and measures. The methodology keeps track of the geographical distribution of pressures at all levels of aggregation for both non-point and point pollutants. Water scarcity is also taken into account in parallel with qualitative pressures. However, aggregation is not designed for sizing interventions, but rather follows the level at which benefits are generated in order to account for the distribution of both the sources of pollution and the relevant impacts. To this end, the suggested approach contributes to framing the linkage of ecosystem service assessments with the practical implementation of WFD, as this represents one of the main challenges in water policy implementation [16].

The present study contributes to further deepening the existing literature on the evaluation of disproportionate costs by focusing, in particular, on the choice of the assessment method, the comparison criteria and the spatial scale of assessment. These three factors converge in the suggested approach: both cost effectiveness analysis (CEA) and CBA methods are first applied at the scale of the smallest hydrographic unit (the water body), leading to a comprehensive screening of the entire region. In the following step, we identify homogeneous areas in terms of pressures (and related costs) and functions (implying service provisions). This process is the basis for the definition of an appropriate (multiple) spatial scale of assessment, which makes it possible to overcome operational difficulties in connecting the technical representation of spatially complex phenomena, whilst providing insights into disproportionality at scales that are meaningful for policy design purposes. Critical issues include: interactions between water bodies, multiple pressures and double counting due to the cross effects of measures that simultaneously affect surface and groundwater.

Although, according to the WFD, the area of analysis should correspond to river basin district management, in this paper, an application of the methodology is provided for the Emilia-Romagna Region in Northern Italy. This is primary due to the requirements of the institution funding this study (see the Acknowledgments), justified by the fact that, in the Italian legal system, the regions are the administrative institutions charged with ensuring the implementation of the measures included in the river basin district plans. In connection to this, the assessment of cost disproportionality supports local administrations' participation in the selection of the range of feasible measures and the criteria to be adopted at the river basin level, which includes more administrative regions (the same region can also include areas belonging to other river basins). 
Given the specificities of Emilia-Romagna, the paper demonstrates how the approach works for a region characterized by water bodies that are mostly undermined by diffuse pollutants. However, the approach is not case study-specific and is suitable for a broader range of environmental conditions.

Section 2 provides the literature background concerning the assessment of cost disproportionality. Section 3 illustrates the methodology with the two-fold purpose of tackling the problem of the interdependencies between water bodies for the assessment of disproportionate costs and the problem of multiple interaction between pressures and measures. Section 4 shows the outcomes of the application of the model for the Emilia-Romagna case study, outlining the set of measures and the relevant costs needed to achieve the WFD water status objectives. The section also describes the benefits generated by the achievement of the GES, providing an estimation of both use and non-use values. Moreover, this section includes the results of a sensitivity analysis performed for key factors in order to deal with uncertainty, due to the lack of detailed information. Finally, the section illustrates the resulting set of measures required to reach the GES and identifies where disproportionate costs are most likely to occur within the region. Section 5 concludes with a discussion of the strengths and limitations of the study.

\section{Literature Background}

Analyses of cost disproportionality have been carried out in various countries, such as Spain [17], Scotland [18], Germany [12], France [10,11], England [9], Denmark [8], and The Netherlands [6]. and Most of the studies only address qualitative pressures (Martin-Ortega, 2012) [16] and focus on surface water rather than groundwater. None of these studies follow a common methodology. This is mainly due to the fact that economic assessment methodologies are adaptive and change considerably between different socio-economic and environmental frameworks. However, according to Ward (2009) [19], the estimation of disproportionate costs should follow three main steps: (1) the choice of the assessment method (how to quantify the social, economic and environmental impacts; (2) the choice of the comparison criteria and the threshold of proportionality; and (3) the choice of the scale of comparison (basin, sub-basin).

\subsection{Assessment Method}

Cost effectiveness analysis (CEA) and cost benefit analysis (CBA) are the two main methods adopted for economic assessment. CEA usually compares monetary costs and physical benefits (i.e., the ratio between the restoration costs and the level of pollutant abatement). CBA, for its part, compares monetarily valued costs and benefits (the ratio between direct or indirect monetary benefits due to the level of abatement and recovery costs). CEA avoids the controversial monetization of intangible assets, such as the environment, and is usually designed for the comparative assessment of alternative measures, rather than for a clear-cut judgment on the feasibility of a project/policy. CBA is designed to assess the viability of the intervention, as it requires an estimation of costs and both tangible and intangible benefits [3]. All of the previously mentioned studies assess cost disproportionality mainly by way of a cost effectiveness analysis, as benefit estimation is onerous. However, for England, Scotland, France (Seine, Normandy), the Netherlands and Denmark, 
cost-effectiveness was replaced by a cost-benefit analysis. In order to contain the economic effort required to assess benefits, scholars offer two alternative strategies: (a) limiting the application of CBA to those water bodies where CEA do not meet the requirements of acceptability set by local stakeholders; (b) exploiting the estimation of benefits from other studies with similar aims and in similar contexts. The first strategy was suggested by Postel et al. (2004) [9] in England and by Interviews et al. (2005) [18] in Scotland, while the second strategy, known as the Benefit Transfer Method [6], was used by Laurans (2006) [11] and by Jensen et al. (2013) [8], respectively, for disproportionate cost assessment in Normandy and Denmark.

\subsection{Comparison Criteria}

The results of the CBA can be given, alternatively, by the difference or the ratio between benefits and costs. The action/project is feasible when the difference is greater than zero and the ratio greater than one. In any case, both criteria make it possible to arrive at the same judgment. CEA is strongly conditioned by the terms of comparison. This suggests the need for a set of complementary indicators that offer multiple perspectives of assessment. The implementation costs of measures could be compared to the pressure abatement level, to the size of the areas that benefit from the intervention and to the financial capacity of those actors called to support the restoration costs.

For CEA, the costs required to achieve GES are acceptable if they are lower than a given threshold. Exceeding that threshold implies the need to reformulate the time horizon (WFD, Article 4.4) [1] and/or the need to address measures with less ambitious environmental objectives (WFD, Article 4.5) [1]. Scholars also suggest that thresholds should be related to the financial capacity of those users expected to pay for the restoration of water bodies. This threshold ranges between $2 \%$ and $4 \%$ of the per capita income of citizens [10,20,21]. However, the WFD does not specify either the type of indicators or the relevant threshold level, hence leaving the choice implicitly up to the discretion of the local authorities.

\subsection{Scale of Comparison}

The choice of the assessment method and the comparison criteria are complemented by the identification of the most appropriate spatial scale of analysis for economic assessments. Costs may be disproportionate at the regional or sectoral level, but economically sustainable at a higher level of aggregation [6]. Large reference areas make it possible to endogenize otherwise not appreciable economies of scale and offer an approximate estimation of specific local conditions. Therefore, it is advisable to identify management areas that are as homogeneous as possible in terms of both natural and socio-economic conditions. In this regard, Stemplewsky et al. (2008) [7] suggest aggregating water bodies in sub-basins in order to include relevant interactions. However, cost disproportionality has been assessed at different levels of aggregation, including both geographical $[3,8,10,11,17]$ and administrative boundaries [12]. The first option is driven by the need to emphasize the interaction between water bodies and the last option by the need to estimate the financial burden that local authorities should bear in order to reach water status objectives. Thus, both levels of analysis should be addressed in order to achieve integrated estimations of environmental and economic impacts. 


\section{The Conceptual Model and Methodology}

The following methodological approach is based mostly on official guidelines [5] for the exemptions to the environmental objectives of the WFD and takes into account existing theoretical $[7,9,19]$ and applied literature on disproportionate costs $[3,8,11,18]$.

The evaluation process reflects the optimization rationale illustrated by the following model:

$$
\max Z_{a}=B_{a}-K_{a} \forall a \in A
$$

Subject to:

$$
\begin{gathered}
K_{a}=\sum_{i} k_{a, i}\left(x_{i}\right) \\
\sum_{i=1}^{n} p_{a, j, i}\left(x_{i}\right) \geq P_{a, j} \quad \forall j \in J \\
x_{i} \in I, \quad x_{i} \geq 0
\end{gathered}
$$

where: $a=$ the level of aggregation; $Z_{a}=$ total net benefit; $B_{a}=$ total benefit; $K_{a}=$ total cost; $x_{i}=$ the degree of activation of measures $i ; k_{a, i}\left(x_{i}\right)=$ the cost function for measure $i$; $p_{a, j, i}\left(x_{i}\right)=$ the reduction function of pressures $j$ for the degree of activation of measure $i$ and at the level of aggregation $a ; P_{a, j}=$ the level of pressure reduction $j$ needed to achieve the good hydrological status and $I=$ the set of the feasible solutions.

The model can be applied at different levels of aggregation, $a$. The water body is the reference unit on which the aggregates are built and the endpoint to which interventions can be targeted.

Equation (1) is the ideal social objective, namely, to maximize the differences between the benefits and costs of intervention. The cost of measures is computed in Equation (2), constrained by the requirement that the degree of activation of measures achieves the pre-established water status target, Equation (3). This constraint highlights the need to simultaneously obtain the reduction of all pressures needed to achieve the directive's water status objectives, considering that more measures can contribute to the reduction of the same pressure and that more pressures can be solved by the same measure. The last would enable the endogenization of multiple effects due to a given intervention. The model is further tied to the feasibility (e.g., measures intended to reduce the application of fertilizer in a given region are limited by the coverage of the target crops) and the non-negativity conditions [Equation (4)]. The decision variable of the model consists of the level of activation of each measure.

If $B_{a}$ is approximated by achievement of the required water status, i.e., adds no information compared to the right-hand side of Equation (3), the problem shifts to a cost-effectiveness perspective, in which the choice of the best set of measures relies on the criterion of cost minimization.

The conceptual model illustrated above is implemented through the procedure illustrated in Figure 1. 
Figure 1. The application procedure. CEA, cost effectiveness analysis; CBA, cost benefit analysis.

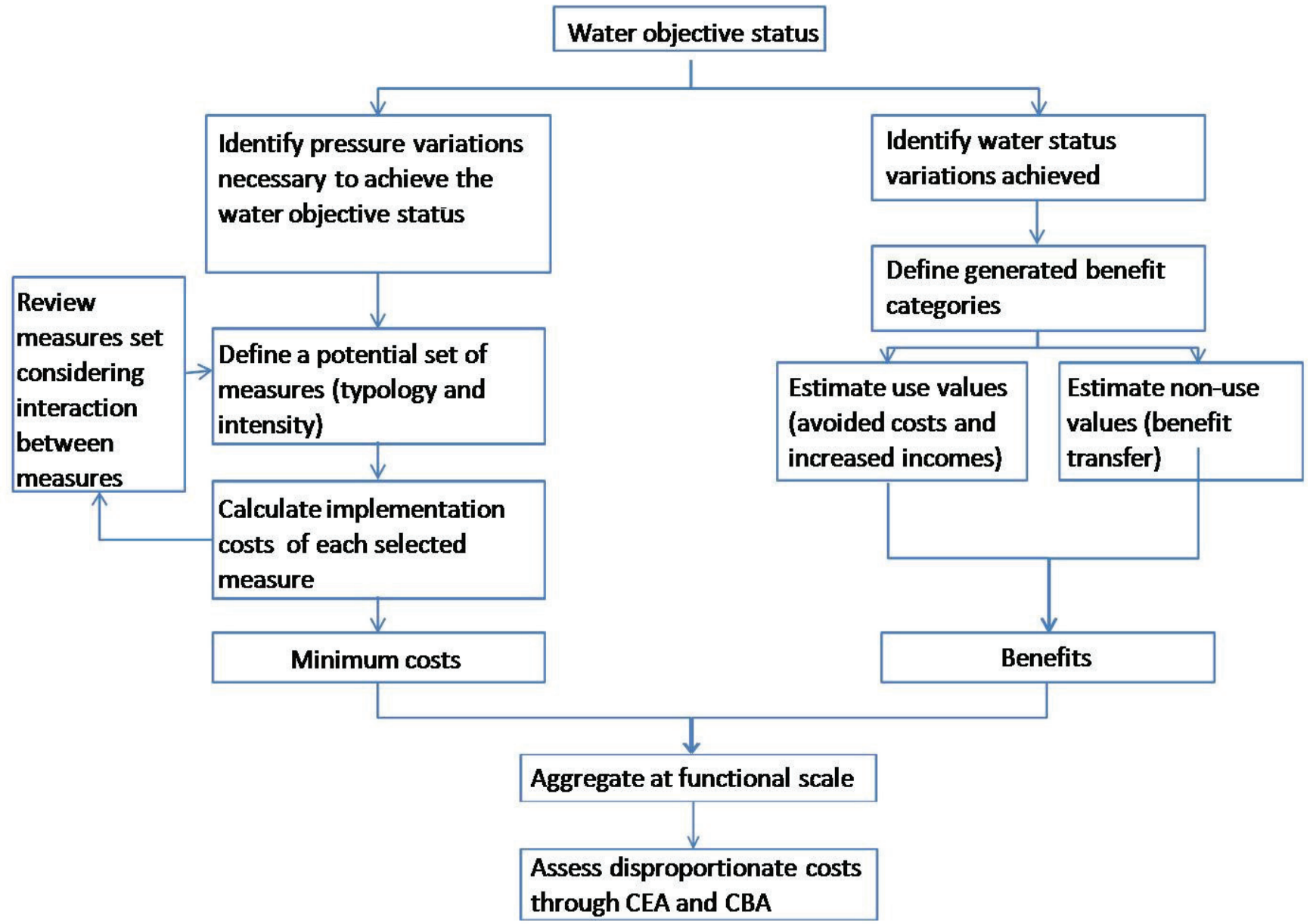

The assessment of disproportionality builds on the definition of the objective status and measures and leads to the screening of the actions needed to achieve economically feasible objectives. This goes through two parallel pathways for costs and benefits. On the one hand, cost estimation entailed the establishment of a set of measures, followed by the calculation of the cost and, based on this, on the revision of the set of measures up until the point at which no cost improvement was possible. On the other hand, the value of benefits was calculated, based on a classification of the positive effects of the achievement of objectives. After this was done at the lowest possible scale, different levels of aggregation were performed and, at these levels, CEA and CBA were then carried out.

The water body is the reference unit for the achievement of the water status objectives, the minimum level at which each MS should identify pressures and uses for both surface and groundwater [4]. However, the identification of the relevant level of analysis for the assessment of disproportionate costs, what we call here "functional scale", is not well defined either in official guidelines or in the relevant literature. The level of aggregation is a key factor influencing the disproportionate cost assessment. In our perspective, there are two fundamental aspects underpinning a reasonable aggregation: (a) the interaction between measures and pressures for both surface and groundwater; and (b) the influence between adjacent water bodies.

For the first aspect, a measure intended to solve a given pressure for surface water could affect groundwater, as well, and a measure aimed at groundwater could also influence the quality of surface 
waters with a two-fold benefit. For the second aspect, the mutual influence exerted by adjacent water bodies imposes the need to identify an aggregation layer that includes all of the relevant sources of pressure conditioning the status of each water body. For each level of aggregation, the assessment of cost disproportionality should include two different hypothesis: one in which it is assumed that water body restoration will affect the whole region (river basin) and the other where it is assumed that the assessment focuses only on a given aggregate within the whole region. For the latter, the achievement of the objective status should also include the contribution of pressures from adjacent aggregates in the deterioration of the pertaining water resources.

The approach used is built for the assessment of disproportionate costs and does not directly manage the issue of technical unfeasibility that would justify temporal derogations. However, the need for temporal derogation is implicit in setting the range of feasible measures, the implementation of which may take longer to abate pollutants below the levels imposed by the directives.

Lack of information and/or high levels of uncertainty for some key technical and economic estimates would justify the adoption of a threshold lower than those usually expected in CBA (i.e., zero when considering benefits and cost differences; one when considering benefits and costs ratios). However, this condition could lead to a dangerous state of arbitrariness that would likely compromise the informative capacity of the assessment tool. A way to reduce such arbitrariness is to combine cost benefit and cost effective indicators. Policy prescriptions could then go in the direction of suggesting a priority for intervention in those areas showing best estimates for both types of assessment tools.

The methodology is consistent with the assessment procedure developed in Jensen et al. (2013) [8], who highlighted the informative role of the analysis supporting policy decisions. The assessment procedure begins with the description of the geographical scale of analysis, identifying pressures and relevant impacts and the set of measures required to reach the GES. This is followed by the definition of the aggregation pattern. Then, costs and benefits are estimated for each water body. Uncertainty in the estimations are managed through a sensitivity analysis. Finally, the results are elaborated according to the aggregation pattern previously described, in order to provide support for decisions related to intervention.

\section{Implementation: Cost and Benefit Estimation in the Emilia-Romagna Region}

\subsection{Case Study Description}

In this section, the implementation of the methodology in the Emilia-Romagna region is described. Emilia-Romagna, an administrative region of Northern Italy, has an area of 22,446 km² and accounts for 4.4 million inhabitants. The region falls into three river basin districts; the Po River Basin, the Northern Apennines River Basin and the Central Apennines River Basin. Nearly half of the region (48\%) consists of plains, while $27 \%$ is hilly and $25 \%$ mountainous. Emilia-Romagna is one of the richest, most developed regions in Europe, and claims the third highest GDP per capita in Italy. In general, the regional economy is well balanced and comprises agriculture, as well as mechanical industries. 
Industry in the region presents a varied and complex picture, including the food industry, as well as the ceramic industry. Tourism is increasingly important, especially along the Adriatic coast and at historical sites. All of these sectors, including the urban sphere, contribute to the generation of pressures that contribute to, or are likely to affect, the quality of water bodies and benefit from the availability of good hydrological status.

The Regional Environmental Agency estimated to which extent each sector (agriculture, civil, industry) is responsible for each type of pressure (qualitative/quantitative, point/no point). Most of the point sources of pollution are represented by industries (responsible for water pollutants, such as organohalogens and metals), while agriculture and livestock contribute mostly with no point pollutants (nitrogen and phosphorus, pesticides) and quantitative pressures (overexploitation of water resources). Morphological alterations are mostly related to the extraction of raw materials.

The functional destination of each water body is usually represented either by drinking water, bath water or water for the protection of fish and mollusk life. In the region, bath waters generally have a good ecological status, while water designed to protect fish life shows deterioration, due to natural causes. Pressures, mostly in the form of nutrient loads and low water flows, threaten mollusk life on the northern coastline and compromise the use of drinking water in the northern inland plain [22].

\subsection{Adaptation of the Methodology to the Case Study Area}

Cost disproportionality is assessed at the regional scale. This seems to contradict most of the relevant literature on cost disproportionality that recognizes the river basin level $[3,8,10,11]$ to be the ideal scale of assessment. However, as previously discussed, this choice is driven by the local legislation and reveals the important role that the local administration plays in defining priorities for both the identification of areas of intervention and the selection of measures to be implemented.

The use of administrative boundaries also implies the assumption that water courses do not pass through other regions before crossing Emilia-Romagna. This assumption basically holds in the case of Emilia-Romagna (Annex 1 of the regional Water Protection Plan, Piano di Tutela delle Acque, PTA, 2005) [22], with the exception of the Po River. In the Emilia-Romagna Region, in fact, the hydrological boundaries roughly match with administrative borders: the Po River almost coincides with the northern border, the Adriatic Sea is the eastern border and the crests of the Apennines chain are the south-western border. Thus, by referring to administrative boundaries, we excluded from the assessment the Po River, as it passes through the border with the Veneto Region, and coastal water (sea water proximal to the region), which is the domain of a number of regions. This implies that we did not consider the impact of low water ecological status on both tourism (bath water) and the fish industry (mollusk life). Moreover, it was not possible to estimate the impact of water overexploitation on salt intrusion, as this phenomenon is caused by a complex interaction between both natural (natural subsidence, climate change) and anthropic causes (subsidence induced by hydrocarbon extractions, mechanical drainage of reclaimed lands) that go beyond the objectives of this analysis.

Furthermore, a simplification was made on the different levels of water ecological status for the calculation of benefits. In the regional Water Protection Plan [22], ecological status is classified based on the distribution of water bodies on a five-point scale, going from bad to optimum. In this study, we rearranged this scale into a two-point scale: lower and equal/greater than good. This simplification 
was needed to ensure the comparability and usability of benefit estimates from other studies as references for benefit calculations in this study (see below).

The analysis was first carried out at the water body level (base unit) and then at different levels of aggregation, as described in the next sections. All of the water bodies' aggregations are sub-regional units, meaning that their extension is always included within the study area boundaries. Therefore, when describing the interactions between water bodies (e.g., rivers upstream-downstream interdependencies, see next sections for details), these are always internal to the Emilia-Romagna region, where all the considered rivers have both heads and outlets.

\subsection{Description of Pressures and Measures}

A set of alternative and complementary measures has been identified according to the relevant sources of pressure, which are likely to affect the hydrological status of most of the water bodies in the case study region (Table 1). The identification of a feasible set of alternative/complementary measures has been accomplished thanks to stakeholder meetings involving both the manager of the regional Water Protection Plan and the manager of the regional Environmental Agency. The selection of measures was carried out by excluding measures already compulsory, due to the implementation of other directives (i.e., Nitrate Directive, Habitat Directive).

Nutrients, pesticides, heavy-metals, morphological alterations and water overuse threaten the regional water resources at different degrees of relevance. Specifically, $43 \%$ of the regional water bodies are threatened by a high concentration of nitrogen and phosphorus, $3 \%$ by pesticides, $4 \%$ by other pollutants, $5 \%$ by water scarcity and $19 \%$ by morphological alterations [22].

No point sources of pollution, in particular nitrogen and phosphorous, are the main pressures conditioning the ecological status of most of the regional water bodies.

Both the civil and agricultural sectors are responsible for these types of pressures. However, while the civil sector contributes to the deterioration of the water body status, overloading wastewater mostly in correspondence with large urban sites, the agricultural sector discharges nutrients especially in the inland plain. As a result, point measures with limited economic impact are feasible only for the urban sector and not for agriculture.

Table 1 shows a synthesis of the interaction between pressures and measures. In the case of the industrial and civil sectors, specific measures are directed to solve single pressures, tracing back to localized sources of pollution (point sources of pollution). Concerning the agricultural sector, several measures can address the same pressure, and different types of pressures can be addressed by a single measures. 
Table 1. Interactions between measures and pressures ( $S=$ surface waters; $G=$ groundwater).

\begin{tabular}{|c|c|c|c|c|c|}
\hline \multirow[b]{2}{*}{ Measures } & \multicolumn{5}{|c|}{ Pressures } \\
\hline & Nutrients & Pesticides & $\begin{array}{l}\text { Industrial } \\
\text { chemicals }\end{array}$ & $\begin{array}{l}\text { Morphological } \\
\text { alterations }\end{array}$ & $\begin{array}{l}\text { Water } \\
\text { scarcity }\end{array}$ \\
\hline $\begin{array}{l}\text { Upgrade of urban waste water depuration } \\
\text { plants/construction of new sewer systems }\end{array}$ & $\mathrm{S}$ & & & & \\
\hline Agricultural extensivization & SG & SG & & & SG \\
\hline Buffer strip & $\mathrm{S}$ & & & & \\
\hline Management of livestock waste & $\mathrm{SG}$ & & & & \\
\hline $\begin{array}{l}\text { Pesticides prohibition, reduction } \\
\text { and substitution }\end{array}$ & & $\mathrm{SG}$ & & & \\
\hline $\begin{array}{l}\text { Remediation of contaminated brown } \\
\text { fields }\end{array}$ & & & G & & \\
\hline $\begin{array}{l}\text { Advanced chemical treatment for } \\
\text { industrial wastewater }\end{array}$ & & & $\mathrm{S}$ & & \\
\hline $\begin{array}{l}\text { Prohibition of inert extraction in } \\
\text { narrow rivers }\end{array}$ & & & & $\mathrm{S}$ & \\
\hline Prohibition of high water intensive crops & $\mathrm{SG}$ & $\mathrm{SG}$ & & & $\mathrm{SG}$ \\
\hline $\begin{array}{l}\text { Construction of reservoirs for irrigation } \\
\text { water storage }\end{array}$ & & & & & SG \\
\hline $\begin{array}{l}\text { Information/awareness campaign about } \\
\text { domestic water saving }\end{array}$ & & & & & G \\
\hline $\begin{array}{l}\text { Construction of new plants for storage } \\
\text { and treatment of drainage water } \\
\text { (for industrial use) }\end{array}$ & & & & & G \\
\hline
\end{tabular}

For the abatement of pollutants from urban waste water, we have assumed both empowering existing water treatment plants and resizing containment tanks. For the agricultural sector, pollutants are currently abated by way of both voluntary payment schemes for the uptake of low input agricultural techniques (measure 214, Rural Development Plan, 2007-2013) [23] and compulsory limitations in the use of fertilizers in Nitrate Vulnerable Zones (NVZ), (Nitrate Directive, 1991) [24]. In addition, we assume the enforcement of regulatory restrictions by obliging farmers to adopt extensive farming systems. The level of abatement of nutrient loads in surface and groundwater bodies, due to the transition from high intensive farming to low intensive farming, has been estimated by exploiting a formally official methodology developed by the Regional Environmental Agency [Agenzia Regionale per la Protezione dell'Ambiente, (ARPA)], which takes into account the geomorphology and soil texture (slope and permeability) of each water body, crop coverage, livestock density, climate, type of fertilizers used and the relevant distribution techniques (Annex 1 of the PTA, 2005 [22]). Alternatively, or complementarily to extensivization, the study suggests the use of buffer strips for nutrients loaded in surface waters. The retention power of the buffer strip is extremely variable and changes considerably according to the assortment of species, soil texture and the width of the strip [25]. On the basis of the literature review by Osborne and Kovacic (1993) [25] and in line with a recent study (Lago, 2008) [26], for the buffer strip, we consider a cautionary estimation of the width, $15 \mathrm{~m}$, and of the retention power, equal to $20 \%$ of the leached nutrients. 
Moreover, the management of wastewater could represent another alternative to the livestock density reduction for both surface and ground water bodies. The management of livestock wastewater is characterized by two steps: (1) plant treatment for the separation of the liquid and solid fractions of the waste water; and (2) transportation and distribution to non-nitrate vulnerable zones [27,28]. The preliminary treatment favors the subsequent stages of transportation and distribution, with the result of improving the land absorptive capacity up to $20 \%$ [29,30].

Another relevant pressure in the agricultural sector, besides nutrients, is that of pesticides. According to the intrinsic characteristics of each kind of pesticide, we considered the implementation of three alternative measures to restore water bodies that have chemical concentrations exceeding legal limits (Directive 2009/90/EC, implemented in Italy through Legislative Decree 2010/219) [31]: prohibition, dosage and substitution. Prohibition and substitution remove the pressure, while the environmental impact of dosage is uncertain. Thus, we assumed that the $30 \%$ reduction of the dosage is strong enough to abate pollutant loads on water bodies.

Besides pesticides and nutrients, which are derived mainly from the agricultural sector, most of the other qualitative pressures can be traced back to the industrial sector. Here, according to the most widespread categories of chemicals, we considered two types of measures: construction of new treatment plants for heavy metals and hydrocarbons and reclamation of brown field sites contaminated with organohalogens.

Industry is also primarily responsible for morphological alterations and the limitation of the extraction of raw materials from narrow rivers, for which we identified just one measure.

Concerning water scarcity, the agricultural sector is the main source of surface water overexploitation. In this case, three types of measures were adopted: substitution of water-intensive crops, construction of inter-farm reservoirs in hill/mountain areas and construction of reservoirs with low environmental impact in ex-river quarry areas. With the exception of the construction of inter-farm reservoirs in hill/mountain areas, the remaining measures were applied to reduce the overexploitation of groundwater occurring in aquifers located in the conoid belt. With respect to surface water, groundwater is also commonly extracted for civil and industrial uses. Therefore, two other specific measures were planned for the reduction of groundwater overuse in addition to those addressed to the agricultural sector. Water extraction for civil uses is limited through the implementation of a water saving awareness campaign, including educational initiatives, the advertisement of good practices and incentives for improving the efficiency of the domestic water distribution system. The limitations of extraction for industrial uses is achieved through the construction of treatment plants and distribution networks for drainage water, which can be re-used instead of being discharged into the sea (mechanical drainage involves most of the flat areas located in the alluvial and coastal plain of the region).

\subsection{Aggregation Pattern}

As described above, the identification of the aggregation pattern should follow the interaction between pressures and measures and interdependencies between adjacent water bodies. In the first case, most of the selected measures interfere with both the status of ground and surface waters, as is 
indicated in Table 1. This condition justifies the definition of a level of aggregation that includes both types of water bodies (Figure 2).

Figure 2. Levels of aggregation for ground and surface water bodies: mountain belt, hilly belt and plain region.

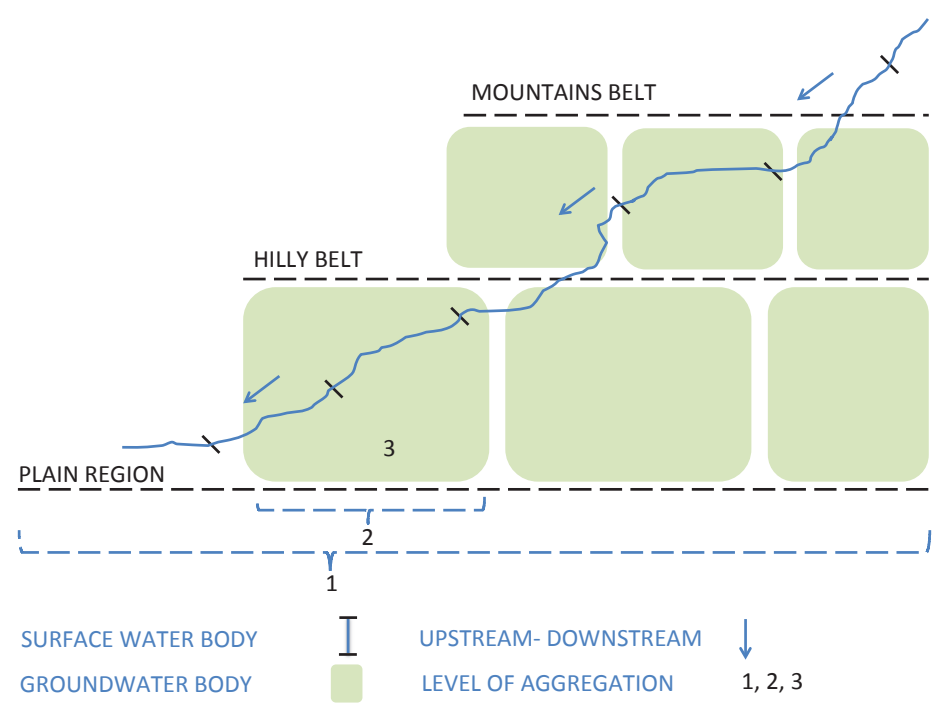

According to the regional hydrographic patterns and the distribution of pressures, it is possible to identify three main aggregates: the mountain belt (corresponding to the region overlying mountainous aquifers), the hilly belt (corresponding to the recharge area of alluvial aquifers and overlying conoid aquifers) and the plain region (corresponding to the artificial drainage area and overlying the phreatic aquifers of the alluvial plain). This first and broader level of aggregation is justified by the fact that the geographical distribution of costs and benefits within the region is unbalanced. The sources of pollution are concentrated mainly in the plain regions, where most of the industrial activities, urban sites and intensive agriculture are located. On the contrary, the benefits are concentrated mainly in the hilly belt, which hosts most of the sources of drinking water and most of the recreational sites in the region. If the estimated benefits are significantly lower than costs for these aggregates, then a finer scale analysis may be required.

A second and greater level of aggregation is at the water body scale for groundwater and includes all of the overlying surface water bodies. A detailed assessment allows for the identification of those areas where disproportionate costs are more likely to occur within each belt.

In a third and final level of analysis, the assessment of both surface and ground water bodies is handled separately. At this level, it would be possible to more accurately detect the single water bodies where disproportionality may occur, which, in turn, makes it possible to plan actions aimed at the achievement of GES in the adjacent units.

With respect to the mutual influence between adjacent water bodies, whereas it is particularly difficult to identify a clear interaction in between groundwater bodies and between groundwater and the overlying surface water, there is a clear interdependence between upstream and downstream surface water bodies (see arrows in Figure 2). 
The aggregation of surface water bodies according to the area overlying groundwater should also take into account all of the costs needed to achieve a good hydrological status and the relevant benefits from the beginning of each water course up to the boundaries of the groundwater body. The cumulative effect (upstream-downstream) must also be considered at a broader level of aggregation, hence the three belts identified by the dashed lines in Figure 2. From foothill to coastal areas, the interaction between groundwater bodies is unknown, as indicated by their representation as independent entities in Figure 2. This consideration leads to the definition of the two scenarios discussed in the methodology: one in which it is assumed that the intervention will affect the whole region and the other in which the implementation of measures only for specific aggregates is assumed.

\subsection{Cost Estimation}

Recent studies have pointed out that cost assessments related to the implementation of the WFD should not focus solely on additional costs (e.g., investment and operating costs), but should rather include income reduction associated with the implementation of the required measures, welfare costs (e.g., distortion effects due to taxation needed to finance the implementation of the WFD) and the value of side effects (e.g., increase/reduction of other types of emission). Moreover, costs should be converted to reflect consumer prices in order to obtain cost estimates that are consistent with the welfare economic theory underlying the CBA $[8,9,25]$.

In this study, we calculate the costs as they emerge from the reduction of pressures that each sector must meet in order to achieve good status. This implies no transfer (e.g., taxes, subsidies) from one sector or economic actor to another and no distinction between financial and economic costs. While it may be claimed that this choice is consistent with the polluter pays principle, in fact, it is largely motivated by the lack of detail regarding the actual implementation strategies for measures (e.g., who is going to pay for what), which did not allow for a more precise analysis.

Table 2 offers a list of the unit cost estimates for the two main categories of measures, direct investments and compensation payments, described below.

\subsubsection{Direct Investments}

Most of the data needed to assess structural projects were already available from previous works carried out by ARPA [32]. To reduce nutrients from the urban sector, we exploited a unit cost appraisal carried out by ARPA [32] for upgrading wastewater depuration plants and for the construction of new sewer systems. For the industrial sector, in the case of heavy metal pollution, we took references from ARPA's unit cost estimation for the construction of advanced treatment plants, while for the reclamation of brown field sites contaminated with organohalogens, we made use of technical information from two other recent studies carried out in Italy [33,34]. To reduce agricultural water overuses, we exploited both ARPA [32] estimations for existing regional reservoirs and estimations from the conversion of six ex-quarry areas in recent decades, respectively, inferring to inter-farm reservoirs and low environmental impact reservoirs. Costs associated with the implementation of water saving measures addressing the civil sector are based on the adaptation for Emilia-Romagna of the costs reported for a similar action implemented in Australia [35] . The costs 
of water saving measures addressing the industrial sector, like the construction of drainage water treatment plants and distribution networks, were also provided by ARPA.

Table 2. Average annual unit cost estimates for each measure (acronyms of data source are defined in the text).

\begin{tabular}{|c|c|c|c|c|}
\hline Measures & Main pressures & Source & $\begin{array}{c}\text { Unit of } \\
\text { measure }\end{array}$ & $\begin{array}{l}\text { Mean } \\
\text { value }\end{array}$ \\
\hline \multicolumn{5}{|c|}{ Direct investments } \\
\hline Upgrade of wastewater depuration plants & nitrogen and phosphorus & [32] & $€ / \mathrm{PE}^{*}$ & 13 \\
\hline Construction of new sewer systems & nitrogen and phosphorus & {$[32]$} & $€ / \mathrm{PE}$ & 100 \\
\hline Construction of advanced treatment plants & heavy metals & {$[32]$} & $€ / \mathrm{mc}^{* *}$ & 0.24 \\
\hline Reclamation of brown field sites & Organohalogens & {$[33,34]$} & $€ /$ site & 210.524 \\
\hline Construction of inter-farm reservoirs & water shortage & [32] & & 24 \\
\hline $\begin{array}{l}\text { Conversion of ex-Quarry Areas in } \\
\text { Reservoirs }\end{array}$ & water shortage & {$[32]$} & $€ / \mathrm{mc}$ & 7 \\
\hline $\begin{array}{l}\text { Information/awareness campaign about } \\
\text { domestic water saving }\end{array}$ & water shortage & {$[35]$} & $€ / \mathrm{mc}$ & 0.45 \\
\hline $\begin{array}{l}\text { Construction of new plants for distribution } \\
\text { and treatment of drainage water } \\
\text { (for industrial use) }\end{array}$ & water shortage & {$[32]$} & $€ / \mathrm{mc}$ & 0.38 \\
\hline \multicolumn{5}{|c|}{ Compensation payments } \\
\hline Extensivization for crops & $\begin{array}{l}\text { nitrogen and phosphorus, } \\
\text { pesticides, water } \\
\text { shortage }\end{array}$ & {$[36]$} & $€ /$ ha & 474 \\
\hline Extensivization for livestock & nitrogen and phosphorus & {$[36]$} & $€ / \mathrm{LU} * * *$ & 264 \\
\hline Plantation of buffer strip & nitrogen and phosphorus & {$[36]$} & $€ /$ ha & 250 \\
\hline Pesticide prohibition & Pesticides & {$[37]$} & $\begin{array}{l}\% \text { loss of } \\
\text { gross income }\end{array}$ & 30 \\
\hline Pesticides substitution & Pesticides & {$[37]$} & $\begin{array}{l}\% \text { loss of } \\
\text { gross income }\end{array}$ & 5 \\
\hline Dosage reduction & Pesticides & {$[23]$} & $€ /$ ha & 275 \\
\hline $\begin{array}{l}\text { Limitation for the extraction of row } \\
\text { materials }\end{array}$ & morphological alteration & {$[32]$} & $€ / \mathrm{mc}$ & 16 \\
\hline $\begin{array}{l}\text { Construction of plants for livestock } \\
\text { manure treatment }\end{array}$ & nitrogen and phosphorus & {$[28,29]$} & $€ / L U$ & 350 \\
\hline Transport of livestock manure outside NVZs & nitrogen and phosphorus & [38] & $€ / \mathrm{km}$ & 18 \\
\hline Distribution of livestock manure & nitrogen and phosphorus & {$[38]$} & $€ /$ ha & 150 \\
\hline
\end{tabular}

Notes: * PE, population equivalent; * mc, cubic meter; ***LU, livestock units.

Key factors conditioning the affordability of the investment are the discount rate, representing the reference parameter for the opportunity cost of capital in the long term, and the time horizon, representing the economic life of the investment. With regard to the assessment of disproportionate costs, we set a discount rate at 5\%, recommended by the European Commission for the programming period 2007-2013 [21]. In order to comply with the recommendation of the European Commission with regard to public investments, the time horizon was set at 30 years [39]. With respect to the WFD, 
both the discount rate and the time horizon should reflect the opportunity cost to achieve (or not) a good ecological status for future generations.

\subsubsection{Income Losses}

Income losses have been estimated both for the agricultural sector and industry. Estimations for agriculture were carried out by assuming regulatory restrictions on nutrients, pesticides and water uses. To this end, we exploited datasets on gross margins for each type of crop and livestock from the Italian Farm Accountancy Data Network (FADN) [36].

Specifically, with respect to restrictions on nutrients, in the case of vegetable crops, loss of income is given by the difference between per hectare gross margins of high value crops and low value crops times the area (hectares) of high value crops, which need to be substituted to achieve the GES. In the case of livestock, costs are equal to the loss in gross margin for each unit of animal times the absolute density reduction (number of heads) needed to achieve GES. The costs associated with the plantation of buffer strips, alternative/complementary to low input farming, were estimated in terms of losses in the gross margins of those agricultural areas converted to buffer strips, while the setup costs were not estimated, as they are considered to be negligible. The extension of buffer strips is given by the length of the water body times the width of the buffer strip itself.

For the restriction on pesticide use, the cost of the measures were estimated to be equal to a $30 \%$ reduction in gross income for crops treated with the banned chemicals. This loss is reduced to $5 \%$ in the case of the substitution of the banned pesticides with other accepted chemicals [37]. Finally, with regard to dosage reductions, the implementation cost corresponds to the reduction per hectare of the gross farm income associated with the application of integrated pest management, as estimated in Annex 3 of the Regional Rural Development Plan 2007-2013 [23].

In the case of irrigation, we considered the loss of income due to the substitution with non-irrigated crops in all areas receiving water from water bodies threatened by water scarcity. Industrial sector income losses have been estimated with respect to morphological alterations. In order to limit this type of pressure, we considered the severe limitation of the extraction of raw materials from narrow rivers. In this case, costs have been estimated to be equal to the loss of income, due to the extraction of aggregates from quarries rather than rivers. Estimations were carried out based on technical information provided by ARPA. The management of livestock manure is alternative/complementary to the livestock density reduction. To this end, we exploited the estimation of costs for plant treatment undertaken by Mantovi et al. (2010a, 2010b) [28,29] for livestock in the region, while transportation and distribution costs outside Nitrate Vulnerable Zones (NVZs) were estimated by exploiting datasets on unit costs for different agricultural mechanical practices from the National Union of Contractors [Unione Nazionale Imprese di Meccanizzazione Agricola, UNIMA)] [38]. Distances were calculated based on shape files provided by ARPA; land use information at the municipality level were provided by the Italian Institute of Statistics (ISTAT) [40]. 


\subsection{Estimation of Benefits}

For the assessment of benefits, we referred to Annex I of Guidance Document No. 20 [5]. Here, several categories of values (use value, non-use value, side effects with other sectors, cross effects with other environmental policies) are listed. The systematic analysis of all of these aspects would provide an exhaustive, yet extremely costly, estimation. In addition, some of the listed items turned out to be particularly difficult to quantify in monetary or even qualitative terms.

Accordingly, we opted to carry out an estimation of the benefits by considering the categories of use and non-use values, using the grid provided by the guidance document as a checklist of the more detailed components of these two main categories. In particular, the non-use value is based on perceptions, often conditioned by various factors, and tends to include more complex categories of value, such as side effects for which it was not possible to make direct evaluations.

In analogy with the costs, it is important to highlight a number of important issues for which simplified assumptions were required to ensure the feasibility of the study. For the assessment of the non-use value, scope effects are usually higher than size effects, as benefits are assumed to be perceived only when water bodies reach the good status $[8,41]$. This was to justify the choice of assessment based on just two states: bad status and good status. Thus, we did not consider the possibility of reaching intermediate levels of status improvement. Another important consideration is made for the substitution effect, which would imply that the value placed on a water body depends on the availability of substitute water bodies [42]. Economic theory would predict decreasing values with increasing substitution possibilities [8]. However, the assessment of the non-use value in this study is not site-specific, as it covers the entire region, and the resulting value is disaggregated to the level of the water body. As a result, substitution effects are assumed to be equal to zero. Another assumption is made for distance decay. We assume no distance decay, even if a negative effect has been proven on the value assessment of water bodies in a recent study (Bateman et al., 2006) [43]. Finally, several assumptions are incorporated into the benefit transfer method (BT), the method adopted to estimate the non-use value. This method adjusts non-use estimates concerning the subject of investigation by exploiting studies carried out in regions other than the study area. This process of adaptation generates biases, and to reduce such distorting effects, the socio-economic conditions of the policy site should be as close as possible to those of the study site, where the estimation of the non-use value was carried out [44]. For this reason Lindhjem and Navrud (2008) [45] highlighted that choosing a study that was carried out in the same country should be preferred when adopting BT. In this study, we exploit both Italian and foreign non-use value assessments, due to the absence of studies with similar goals conducted in Italy. With respect to BT, we assume no biases.

Table 3 offers a list of the unit estimates for the two main benefit categories: non-use values and use values (described below). 
Table 3. Average unit benefit estimates for good water status.

\begin{tabular}{|c|c|c|c|c|}
\hline Measures & Pressures & Source & Units of measure & Mean Value \\
\hline \multicolumn{5}{|l|}{ Use Value } \\
\hline $\begin{array}{l}\text { Cost saving for drinking } \\
\text { water treatment }\end{array}$ & nitrogen and phosphorus & {$[32]$} & $€ / \mathrm{mc}$ & 0.80 \\
\hline $\begin{array}{l}\text { Cost saving for drinking } \\
\text { water treatment }\end{array}$ & organohalogens & {$[32]$} & $€ / \mathrm{mc}$ & 0.09 \\
\hline $\begin{array}{l}\text { Cost saving for the } \\
\text { emergency interventions } \\
\text { in case of drought events }\end{array}$ & water overuse & [46] & $€ / \mathrm{mc}$ & 0.79 \\
\hline \multicolumn{5}{|l|}{ Non-use Value } \\
\hline Recreational value & pollutants & {$[44,47-$} & WTP $* /$ Household & 10.14 \\
\hline Ecological value & nitrogen and phosphorus & 49] & WTP/Household & 6.89 \\
\hline
\end{tabular}

Note: * WTP, willingness to pay.

\subsubsection{Non-Use Values}

The non-use value of an asset is usually estimated through methods based on the interpretation of economic perceptions (subjective values). This imposes the need to collect numerous (and, therefore, extremely expensive) interviews. The BT consists in the transfer of existing estimates of the non-market values of a given asset from site to site [50].

As previously stated, this paper exploits the BT method with respect to recent studies carried out in Italy and in other European countries. Specifically, we took advantage of the estimations of the annual households willingness to pay (WTO) for both the improvement of water quality $[44,50]$ and the restoration of water bodies in protected areas [48,49], which correspond, respectively, to the improvement of recreation standards and the improvement of the ecosystem quality. Estimates have been adapted to Emilia-Romagna according to the BT method developed by Raggi et al. [44], which takes into account three variables as the main determinants for WTP: the average number of family members, the mean per-capita income and the share of drinking water in the considered water reservoir (e.g., aquifer, river basin). These parameters were estimated in both the study site and the policy site, all three which were then used to adapt the benefit estimation. Mean values are shown in Table 3.

\subsubsection{Use Values}

The estimation of the use value is carried out for all those sectors that benefit from the availability of high quality water. This value is related to the functional destination of water resources (drinking water, bath water and water for the protection of fish and mollusk life) and the indirect damage caused by water overuse. In the study region, water pollutants mainly compromise drinking water. With respect to the use value, the achievement of a good ecological status results both in the reduction of costs needed to treat water for drinking standards and in the ability to face water scarcity during drought events. 
Benefits have been estimated in terms of cost savings. The achievement of GES, in fact, does not require the treatment of water contaminated by nutrients and the mitigation of the emergency caused by water scarcity. The unit cost for denitrification and for the treatment of water contaminated by organohalogens (bioremediation) were provided by ARPA [32]. The costs associated with the emergency interventions in the case of drought events were estimated based on the available records regarding costs incurred by the Emilia-Romagna region in the past decade [46].

\subsection{Sensitivity Analysis}

We decided to focus the sensitivity analysis on non-use benefit estimates, which are recognized to be more sensitive to uncertainty than cost estimates [51]. This choice is further motivated by the low accuracy of the method adopted to assess the non-use value (the BT method).

We carried out the sensitivity analysis in two different ways. First, we considered a generic percent variation of the non-use benefits estimation to account for uncertainty in values due to sample selection, response rates and, generally speaking, uncertainties in transposing sample estimates to the population. Second, we allowed for a variation of benefits in a range identified by the variability in the estimates available from existing studies.

As for the second sensitivity analysis mentioned above, a number of studies are available on the assessment of the non-use value of water resources in Europe: the Netherlands [13], Germany [52], Italy [44,48], Spain [47,53], Denmark [54], England and Wales [55], Scotland [56] and Ireland [57]. Most of the cited studies refer to water quality improvement [13,44,53-57], while a few studies focus on the improvement of recreational value $[48,49,56,57]$.

The range of benefits for the sensitivity analysis was identified by selecting two of the listed studies for the improvement of recreation standards and two for the improvement of ecosystem quality. The studies were selected according to two screening criteria: the degree of similarity to the reference area (more or less close to the site characteristics) and the relevance of the topic (recreational value/water status value). The first criterion prevailed when analyzing the improvement of ecosystem quality, while priority was given to the second criterion when assessing the recreational values. For the quality perspectives, we exploited information from Raggi et al. [44] and Hernandez and Salazar [47]. Both studies adopted the same criterion of benefit assignment according to the status of water bodies, described in Brower et al. [13]. The first study refers to the Po River Basin. The study adopted a BT method estimate based on Brower et al. [13] referring to the Scheldt Basin, Netherlands. According to the results of Brouwer et al. [13], a level of positive bidders of $18 \%$ was adopted. The analysis carried out by Raggi et al. [44] was readapted to the regional scale and to the year 2010 with the result of an annual WTP for reaching GES in surface water of $4.8 €$ /household and $9.1 € /$ household for achieving a good status of groundwater. The second study refers to the Guadiana River Basin, which covers part of both Spain and Portugal, and makes use of a contingent valuation method. By transposing the results from the Guadiana River Basin to the Emilia-Romagna Region, we obtain an annual WTP of $9 €$ /household with 50\% positive bidders.

With regard to the recreational perspective, we exploited information from Alberini et al. [48] and Bateman and Lagford [49]. Although there are noteworthy differences in the site characteristics, both studies estimate the recreational values of protected areas. The survey presented in Alberini et al. [48] 
was carried out on S. Erasmo Island, close to Venice, Italy, and made use of a Contingent Valuation Method. By transposing results from the site areas described in Alberini et al. [48] to the protected areas in Emilia-Romagna, we obtained an average annual WTP to reach a good recreational standard of $7 € /$ household with $35 \%$ positive bidders. The survey presented in Bateman and Lagford [49] was conducted in the Norfolk Broads, England. A contingent valuation method was also adopted in this study. After adaptation of benefit estimates, the average annual WTP to reach a good recreational standard for protected areas in Emilia-Romagna is $14 € /$ household, with a percentage of positive bidders of $16 \%$.

Low estimates of the non-use value for water quality and recreational standards were summed up to identify the lower bound of the benefit value, estimated at $32 \mathrm{M} €$; similarly, an upper bound was derived from the respective high estimates, equal to $64 \mathrm{M} €$.

\subsection{Results}

Rather than expressing the results in terms of net present value, which would be difficult to compare with measures that only produced annual effects without initial costs, we have reported all figures in annual equivalents and analyze the results as average expected costs and benefits per year.

The results refer both to the identification of regions where cost disproportionality is more likely to occur and the selection of the most cost-effective set of measures required to reach the GES.

Table 4 explains the level of intervention for all of the measures identified to achieve the directive water status objectives in Emilia-Romagna for each type of pollutants and for each source of pressure. Measure complementarity was found for diffuse pollutants both for the urban sector and agriculture. Cross interaction between measures is particularly low for the first sector, yet high when considering agriculture. In Table 4, the level of implementation of each measure is the ratio between the number of water bodies of interest by a given measure and the whole number of water bodies threatened by a given pressure for each sector. When the summation of the level of implementation of a set measures directed to solve a given pressure for each sector is higher than $100 \%$, there is measure complementarity (more measures contextually concur to fight a given pressure). When this summation is equal to $100 \%$, there is measure substitution. Complementarity occurs for most of the measures directed to diffuse pollutants. Substitution is present when dealing with pesticides or water shortages. 
Table 4. Level of implementation of each measure for each type of pollutant and for each source of pressure.

\begin{tabular}{|c|c|c|c|}
\hline Sectors & Main pressures & Measures & $\begin{array}{c}\text { Level of } \\
\text { implementation } \\
(\%)\end{array}$ \\
\hline \multirow{5}{*}{ Urban sector } & \multirow{5}{*}{$\begin{array}{l}\text { Nitrogen and } \\
\text { phosphorus }\end{array}$} & Upgrading of treatment plants & $45 \%$ \\
\hline & & $\begin{array}{l}\text { Construction of new } \\
\text { containment tanks }\end{array}$ & $61 \%$ \\
\hline & & Extensivization & $87 \%$ \\
\hline & & Livestock wastewater disposal & $12 \%$ \\
\hline & & Plantation of buffer strip & $52 \%$ \\
\hline \multirow{6}{*}{ Agriculture } & \multirow{3}{*}{ Water shortage } & $\begin{array}{c}\text { Construction of inter-farm } \\
\text { reservoirs }\end{array}$ & $32 \%$ \\
\hline & & $\begin{array}{l}\text { Conversion of ex-quarry } \\
\text { areas in reservoirs }\end{array}$ & $34 \%$ \\
\hline & & Extensivization & $34 \%$ \\
\hline & \multirow{3}{*}{ Pesticides } & Prohibition & $10 \%$ \\
\hline & & Substitution & $70 \%$ \\
\hline & & Dosage reduction & $20 \%$ \\
\hline \multirow{3}{*}{ Industry } & Heavy metals & $\begin{array}{l}\text { Construction of advanced } \\
\text { purification plants }\end{array}$ & $100 \%$ \\
\hline & Organohalogens & Reclamation of brown field sites & $100 \%$ \\
\hline & $\begin{array}{c}\text { Morphological } \\
\text { alterations }\end{array}$ & $\begin{array}{l}\text { Limitation for the extraction of } \\
\text { row materials }\end{array}$ & $100 \%$ \\
\hline
\end{tabular}

According to our estimations, the achievement of a good status for all of the regional surface waters costs about $330 \mathrm{M} €$ per year (Table 5). If we do not consider the interactions between measures described previously (Table 1), the costs needed to achieve this status for groundwater in Emilia-Romagna (only shallow aquifers) would be about $37 \mathrm{M}$ (Table 5). If we take into account that some of the measures planned to achieve a good status of surface waters will also improve the status of groundwater, the corresponding costs needed to achieve the good status of the regional shallow aquifers would be nearly halved (19 M€ in Table 5).

Table 5. Cost estimation at the level of aggregation of groundwater bodies. For groundwater, costs estimated when taking into account interactions between measures are also provided. GES, Good Ecological Status.

\begin{tabular}{|c|c|c|c|}
\hline \multirow[b]{2}{*}{$\begin{array}{l}\text { Aggregate } \\
\text { Area }\end{array}$} & \multirow{2}{*}{$\begin{array}{c}\text { Achievement of the GES of } \\
\text { surface water } \\
\text { Costs }(€)\end{array}$} & \multicolumn{2}{|c|}{ Achievement of the GES of groundwater } \\
\hline & & $\begin{array}{c}\text { Costs not considering } \\
\text { interaction of measures }(€)\end{array}$ & $\begin{array}{c}\text { Costs considering interaction } \\
\text { of measures }(€)\end{array}$ \\
\hline Mountains & $16,713,459$ & - & - \\
\hline Conoids & $17,998,915$ & $14,963,545$ & $9,020,863$ \\
\hline Phreatic & $295,351,881$ & $22,045,175$ & $9,950,848$ \\
\hline Region & $330,064,255$ & $37,008,720$ & $18,971,711$ \\
\hline
\end{tabular}


The overall costs needed to achieve the good status of both surface and groundwater bodies are about $349 \mathrm{M} € /$ year and the corresponding benefits are about $53 \mathrm{M} € /$ year, which leads to a ratio Benefits/Costs (B/C) of 0.15 for the region (Table 6).

These quantities are referred to in a scenario (hypothesis 1 in Table 6), in which all of the interventions needed to achieve the good status are implemented. As previously explained, due to the physical hierarchy of the surface water bodies, if the suggested measures are not implemented upstream (e.g., mountain areas), the costs to achieve a good status downstream (e.g., hill areas) will rise, (hypothesis 2 in Table 6). When presenting these results, it is worth reiterating the assumption made on the study area boundaries (Section 4.2) that the considered surface waters have both their origin and outlet in Emilia-Romagna (with the exception of the Po River, which was not included in the analysis).

Table 6. Cost and benefit estimation for both surface and groundwater at the level of aggregation of groundwater bodies.

\begin{tabular}{ccccccc}
\hline \multirow{2}{*}{ Aggregate } & \multicolumn{3}{c}{ Hypothesis 1 } & \multicolumn{3}{c}{ Hypothesis 2 } \\
& \multicolumn{2}{c}{ Recovery of Water Status for All Areas } & \multicolumn{2}{c}{ Recovery of Water Status for Single Area } \\
\cline { 2 - 7 } & Costs $(€)$ & Benefits $(€)$ & $\begin{array}{c}\text { Benefits/ } \\
\text { Costs }\end{array}$ & Costs $(€)$ & Benefits $(€)$ & $\begin{array}{c}\text { Benefits/ } \\
\text { Costs }\end{array}$ \\
\hline Mountains & $16,713,458$ & $2,955,827$ & 0.18 & $16,713,458$ & $2,955,827$ & 0.18 \\
Conoids & $27,019,778$ & $17,986,184$ & 0.67 & $39,927,067$ & $17,986,184$ & 0.45 \\
Phreatic & $305,302,729$ & $32,457,678$ & 0.11 & $403,699,677$ & $32,457,678$ & 0.08 \\
Region & $349,035,966$ & $53,399,689$ & 0.15 & $443,626,744$ & $53,399,689$ & 0.12 \\
\hline
\end{tabular}

Table 6 also shows that the ratio between benefits and costs tends to decrease from the hill belt (conoids) to the plain areas (phreatic).

This is the case, as most of the benefits tend to be concentrated in the foot belt strip, both because of the functional destination of water resources and because of the non-use value perceived for those areas. Indeed, most of the water for drinking purposes is extracted from both surface and groundwater bodies in conoid areas, hence allowing for an estimation of the use value of water resources. Moreover, most of the protected areas overlap conoids, hence increasing the estimation of the non-use value of water resources. On the other hand, costs tend to focus on plain areas (corresponding to phreatic aquifers), where industrial, urban and agricultural pressures are greater.

According to the aggregation pattern developed in the methodology, net benefit estimations are too low for all of the aggregates discussed above, even if the estimates vary significantly within the aggregates. This justifies the need to further deepen the analysis for the entire region. This should be accomplished by considering the second (more detailed) level of aggregation, the groundwater body level and, at this level, analyzing the cross interaction between cost benefit and cost effectiveness indicators.

Figure 3 displays the relationship between two CBA and CEA indicators (benefits/costs and costs/areas, respectively). The quadrants are defined by two lines representing the average values of the two indicators. As a result, the main contribution of this representation is simply to facilitate data interpretation based on relative results. 
Figure 3. Crossing CBA indicators and CEA indicators at the level of aggregation of groundwater bodies: according to their location stratified with respect to the conoids, the phreatic aquifer area and the mountain belt.

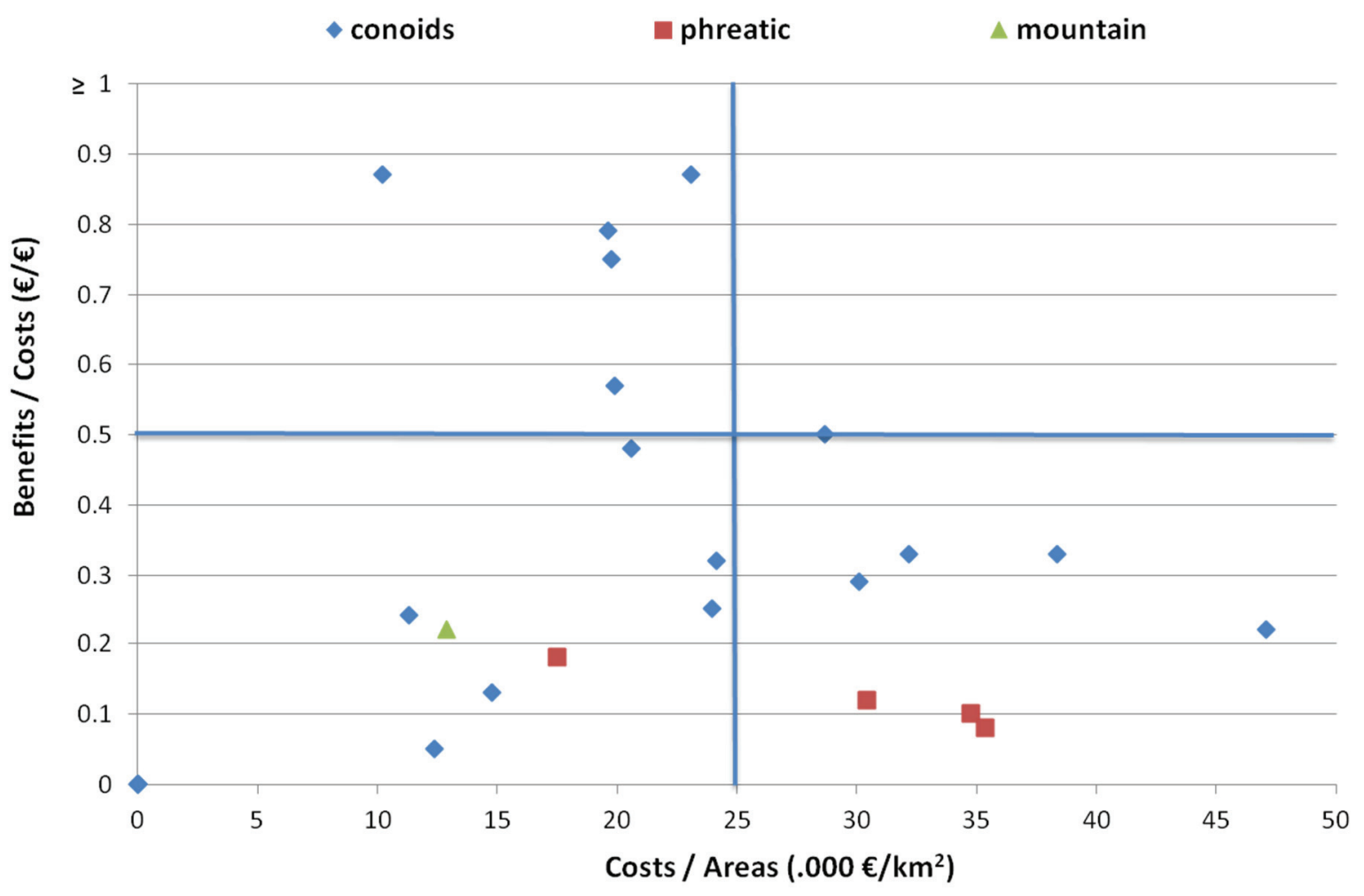

The chart shows that most of the conoid areas tend to be located in the upper left quadrant of the figure, while the phreatic areas are in the lower quadrants (mainly in the lower left one). Thus, the assessment of cost proportionality, both in a cost/benefit and a cost/effective perspective, is positive for most of the conoid areas (hence reinforcing their prioritization for intervention) and negative for phreatic regions.

Finally, Figures 4 and 5 show the results of a sensitivity analysis with respect to the non-use value component of benefit estimates. In Figure 4, the trend of the CBA indicator is plotted against the increasing level of benefit variation with respect to the reference value. The reference value is provided by summarizing both benefit estimates for the use value and the average non-use value described above. The vertical lines in the chart represent the band within which the estimated value is expected to fall. In this area, on average, the CBA indicator ranges from 0.10 to 0.20 for the whole region. This range tends to be lower for the plain region, while it is higher for the hilly belt. This is highlighted by the differences in slope for the trend lines in the chart. For the hilly belt, the CBA index reaches the threshold of one when benefit estimates increase by $+150 \%$ with respect to the most likely estimated value. This variation increases significantly when considering plain areas. This is due to the fact that non-use benefit estimates mainly focus on the hilly belt, where both recreational and ecological components are likely to occur, while, on the other hand, costs for pressure abatements are much higher in plain areas.

Given that the sensitivity analysis is carried out only with respect to the non-use value, the use value component is shown by the interception of the $\mathrm{B} / \mathrm{C}$ trend with the $\mathrm{y}$-axis. The intercept is 
greater than zero for the hilly belt, where most of the functional impacts occur. On the contrary, in the plain areas, water bodies do not show any functional use. This is reflected on a B/C trend intercepting the $y$-axis at the origin.

Figure 5 shows the change in levels of the B/C index with different levels of available/acceptable funding to implement the measures, in the range of benefit estimates given by the sensitivity analysis illustrated above. The results show a very marked reduction in the marginal cost/benefit ratio with increasing expenditure. This reduction is much more evident in the first part of the curve. Under the optimistic scenario, $20 \%$ of water bodies show a benefits/costs ratio higher than one, while under the pessimistic scenario, only $5 \%$ of water bodies exceed this threshold. Given a threshold of one, the percentage of water bodies for which the assessment recommends the intervention is high if considering that, on average, the $\mathrm{B} / \mathrm{C}$ index is 0.15 for the whole region. This further confirms the strong difference between areas of impact (the hilly belt) and the sources of pressures (the plain regions).

Figure 4. Benefit and cost ratio trend on the benefit variation with respect to reference values.

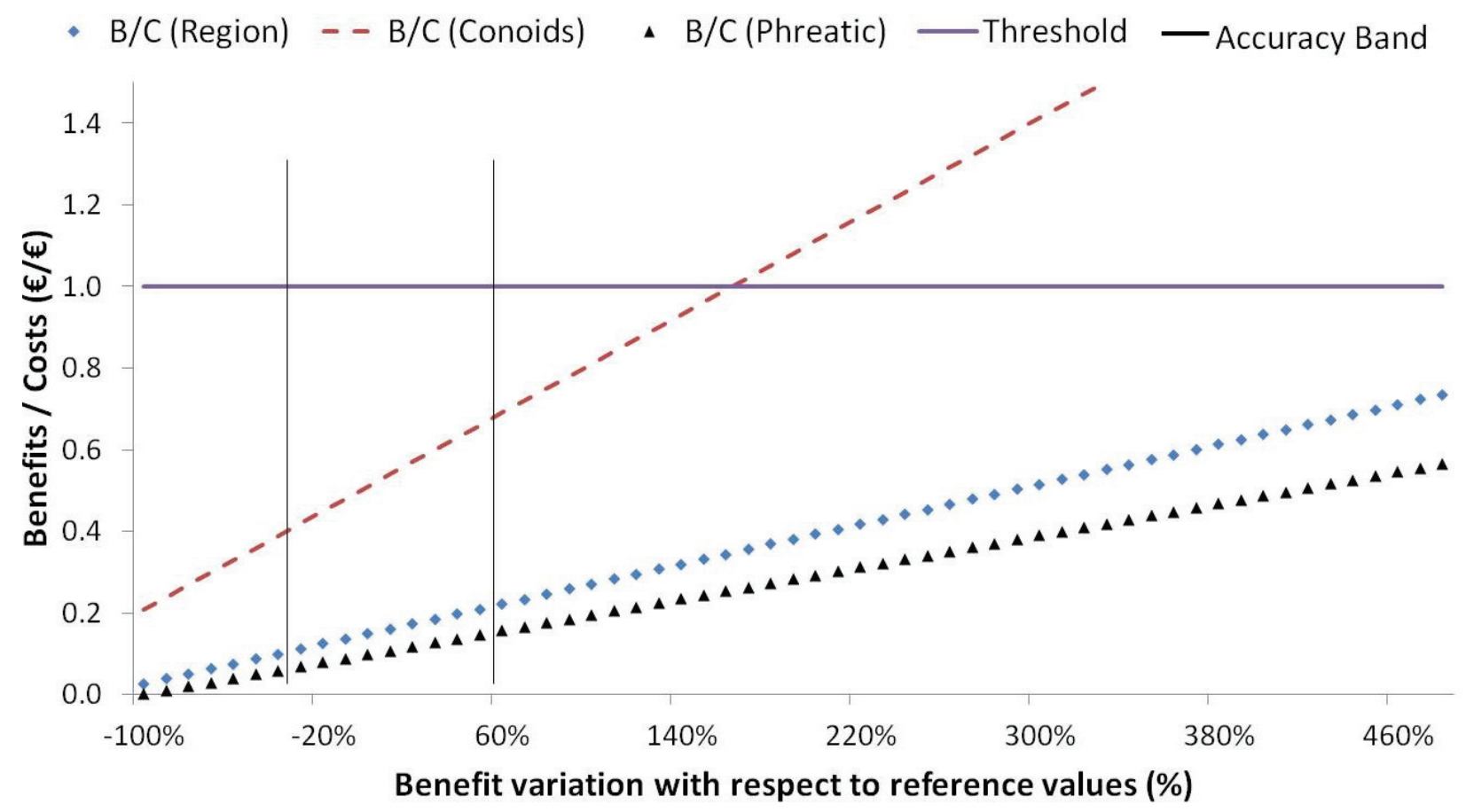


Figure 5. Variation of the benefit and cost ratio as a function of the acceptable expenditure to improve the ecological status of water resources for both under- and over-estimation of non-use benefits.

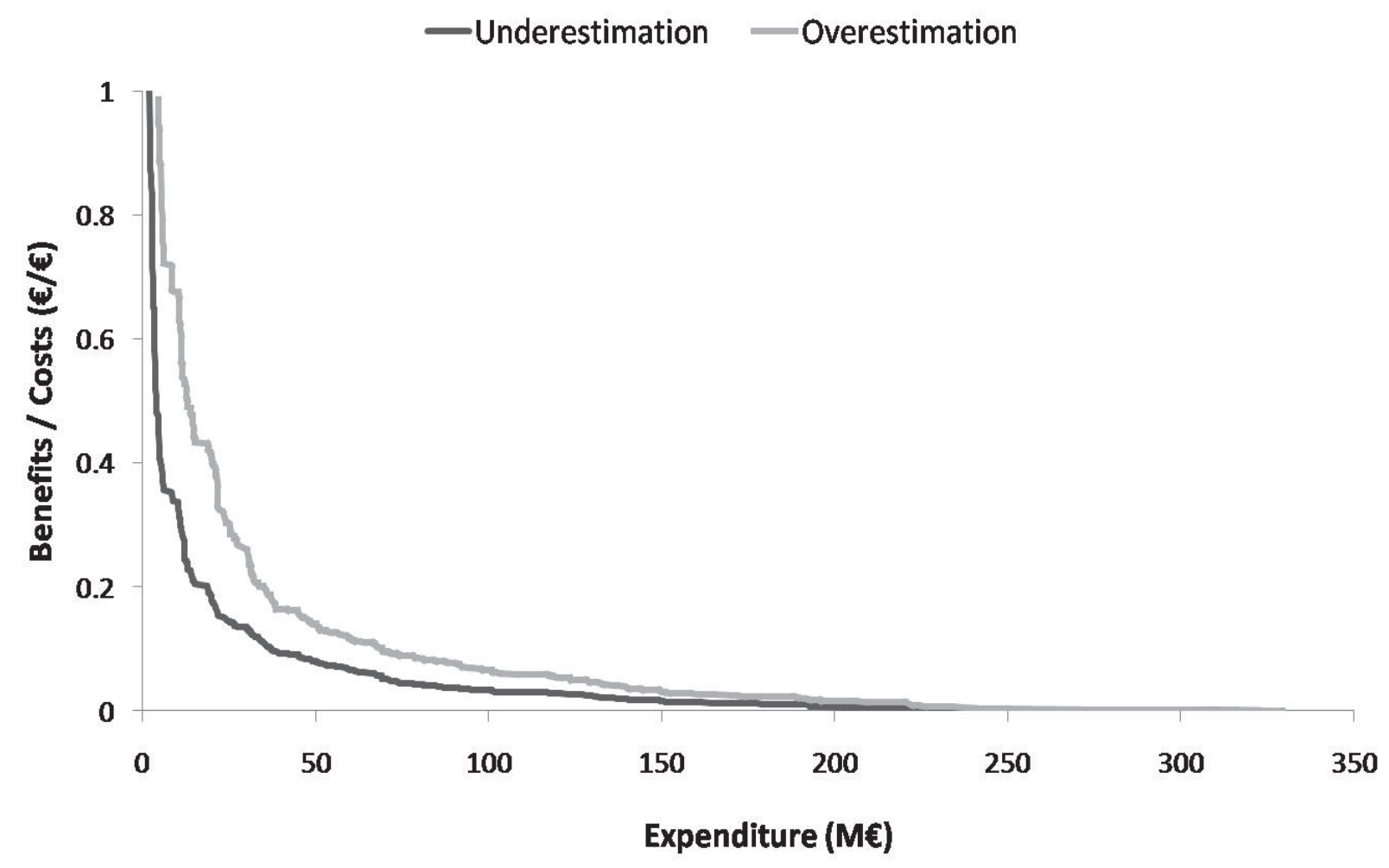

\section{Discussion and Conclusions}

In this paper, we estimate costs and benefits associated with WFD implementation in Emilia-Romagna for the purpose of assessing disproportionate costs. As mentioned above, the implementation of the methodology at the regional level, driven by Italian legislation, has the main function of complementing district level provisions by supporting the local administration in charge of measure implementation.

The cost and benefit assessment was driven by the water status objectives of the Emilia-Romagna Region. Once the types of pressures threatening water resources in the region were defined, a consultation with local stakeholders enabled the identification of a number of measures for each type of pressure. Then, in light of the water status objectives, a cost minimization analysis allowed for the identification of the most efficient set of measures and the related levels of activation. The procedure presented in this study takes into account both qualitative and quantitative pressures affecting ground and surface waters. Thus, the risk of "overshooting", which could occur by separately considering the effect of measures on pressures (nutrients, pesticides, etc.) and on water bodies (groundwater, surface waters), is avoided. This effect, not considered in previous studies, arises as measures can contextually solve more than one problem (in terms of pressures and areas of interest).

With regard to benefits, this paper separately estimates changes in water status that are related to water uses and changes associated with non-use effects. For use values, available information 
enabled the estimation of cost savings for the treatment of drinking water and emergency interventions in case of drought events.

One limitation in this study with respect to the benefit component is that other secondary effects on the economy and society have not been considered. Non-use values have been estimated exploiting other studies through the application of the Benefit-Transfer Method. Both the perceived value of protected areas and water quality have been estimated. As we were aware of the limitations of this method, a sensitivity analysis was hence performed, allowing for the identification of the range of variation within which the real perceived value would likely fall. However, the way benefits were estimated remains a limitation of this study and would hence benefit from further investigation by way of an original evaluation in the region.

Another area of possible improvement concerns the treatment of uncertainty. Uncertainty derives from technical factors, as well as economic variables. Errors in estimating these factors affect both the overall output of the assessment (similarly to benefits) and the recommended policy decisions from the selection of one option of intervention or another. The consequences connected to uncertainty also need to be properly developed by referring to approaches that are more sophisticated than the ones adopted for this analysis, such as stochastic models [58], Monte Carlo simulations [59] or Bayesian models [60].

Another relevant issue that was not addressed by this study is the financial aspect of measure implementation and disproportionality analysis, which would need to be investigated prior to the implementation of measures.

According to the results of this study, the benefits/costs ratio tends to decrease from the hilly belt of the region to the plain area. This is caused by the fact that benefits tend to focus on conoid aquifers located in the hilly belt and costs in the plain side of the region. Yet, for the mountain belt, the level of the benefits/costs indicator is low. In this belt, there are no effects on groundwater, so surface waters are the only sources of benefits.

The general low value of the CBA indicator suggests the reasonable insight that, in most of the region, the costs to achieve the GES are too high in comparison with the benefits. However, information gaps on the side of benefits may have led to a somewhat unbalanced estimation of costs and benefits in favor of the former. In order to partially overcome this issue, and for a more robust assessment, the study suggests a cross-evaluation using different cost benefits and cost effectiveness indicators, in order to identify areas that are more likely to be a priority for intervention.

Altogether, the procedure was largely driven by data availability and time constraints. This is also the main cause of limitations in the coverage and economic sophistication of this study, but also hints at the need for a better understanding of local assessment conditions in order to develop practical solutions for economic assessments in the directive.

This work is also amenable to development in various other directions, in addition to those already mentioned above. On the practical side, the procedure could be made more effective through a more explicit use of a two-step approach, based on a screening of hotspot areas, followed by in-depth analyses of selected areas. On the research and decision-making support side, the procedure presented here could be developed into a model of regional pressures/water quality/quantity relationships, allowing for a finer assessment of policies and water quality objectives for the future. 


\section{Acknowledgments}

This study was developed through collaboration with the Emilia-Romagna Regional Environmental Agency [Agenzia Regionale per la Protezione dell'Ambiente (ARPA)], who has provided data and technical information, in the context of a project entitled: "Analysis of the economic and social costs required to achieve the good hydrological status indicated by the WFD for both surface and groundwater in order to assess technical infeasibility and cost disproportionality". The project was funded by the Emilia-Romagna Regional Environment and Urban Requalification Directorate. The authors wish to thank ARPA, the anonymous referees for the fruitful suggestions and David Cuming for English language editing. The responsibility for the contents of the study lies solely with the authors.

\section{Conflicts of Interest}

The authors declare no conflict of interest.

\section{References}

1. European Commission. Directive 2000/60/EC (Water Framework Directive); Official of the European Communities: Brussels, Belgium, 2000.

2. Balana, B.B.; Vinten, A.; Slee, B. A review on cost-effectiveness analysis of agri-environmental measures related to the EU WFD: Key issues, methods, and applications. Ecol. Econ. 2011, 70, 1021-1031.

3. Molinos-Senante, M.; Hernández-Sancho, F.; Sala-Garrido, R. Assessing disproportionate costs to achieve good ecological status of water bodies in a Mediterranean river basin. J. Environ. Monit. 2011, 13, 2091-2101.

4. Water Economics Working Group of the European Commission (WATECO) Common Implementation Strategy for the Water Framework Directive (2000/60/EC). In Economics and Environment, the Implementation Challenge of the WFD; European Commission: Luxembourg, Luxembourg, 2003.

5. European Commission. Common Implementation Strategy for the Water Framework Directive. In Guidance Document on Exemptions to the Environmental Objectives, Guidance Document No. 20; European Commission: Luxembourg, Luxembourg, 2009; pp. 1-49.

6. Brouwer, R. The potential role of stated preference methods in the Water Framework Directive to assess disproportionate costs. J. Environ. Plan. Manag. 2008, 51, 597-614.

7. Stemplewski, J.; Krull, D.; Wermter, P.; Nafo, I.I.; Palm, N.; Lange, C. Integrative socio-economic planning of measures in the context of the water framework directive. Water Environ. J. 2008, $22,250-257$.

8. Jensen, C.L.; Jacobsen, B.H.; Olsen, S.B.; Dubgaard, A.; Hasler, B. A practical CBA-based screening procedure for identification of river basins where the costs of fulfilling the WFD requirements may be disproportionate-Applied to the case of Denmark. J. Environ. Econ. Policy 2013, 2, 164-200. 
9. Postle, M.; Fenn, T.; Foottit, A.; Salado, R. CEA and Developing a Methodology for Assessing Disproportionate Costs. In Final Report for Department for Environment, Food and Rural Affairs (Defra), Welsh Assembly Government (WAG), Scottish Executive (SE) and Department of the Environment in Northern Ireland (DOENI); Risk \& Policy Analysts Limited (RPA): Norfolk, UK, 2004; pp. 1-72.

10. Courtequisse, A. Water Prices and Households' Available Income: Key Indicators for the Assessment of Potential Disproportionate Costs-Illustration from the Artois-Picardie Basin (in France). In Proceedings of the International Work Session on Water Statistics, Wien, Austria, 20-22 June 2005.

11. Laurans, Y. Implementing Cost-Effectiveness Analysis: Perspectives Based on Recent French Pilot Studies. In Proceedings of Vortrag auf der Messe Wasser, Berlin, Germany, 5 April 2006.

12. Klauer, B.; Mewes, M.; Sigel, K.; Unnerstall, H.; Görlach, B.B.; Bräuer, I.; Höllander, R.; Pielen, B. Verhältnismäßigkeit der Maßnahmenkosten im Sinne der EG- WasserrahmenrichtlinieKomplementäre Kriterien zur Kosten-Nutzen-Analyse (Proportionality of Costs in the Water Framework Directive - Complementary Criteria for the Cost-benefit Analysis). In Auftrag der Bund/Länderarbeitsgemeinschaft Wasser; Helmholtz-Zentrum für Umweltforschung (UFZ): Leipzig, Germany, 2007; pp. 1-97.

13. Brouwer, R.; Hess, S.; Beevart, M.; Meinardi, K. The Socio-Economic Costs and Benefits of Environmental Groundwater Treshold Values in the Sheldt Basin in the Netherlands; Institute for Environmental Studies (IVM) Report R06-05 (Bridge project); IVM: Amsterdam, The Netherlands, 2006.

14. Berbel, J.; Kolberg, S.; Martin-Ortega, J. Assessment of the draft hydrological basin plan of the Guadalquivir river basin (Spain). Int. J. Water Resour. Dev. 2012, 28, 43-55.

15. Martin-Ortega, J.; Skuras, D.; Perni, A.; Holen, S.; Psaltopoulos, D. The Disproportionality Principle in the WFD: How to Actually Apply it? In Economics of Water Management in Agriculture; Bournaris, T., Berbel, J., Manos, B., Viaggi, D. Eds.; Science Publishers: Enfield, New Hampshire, USA, in press.

16. Martin-Ortega, J. Economic prescriptions and policy applications in the implementation of the European Water Framework Directive. Environ. Sci. Policy 2012, 24, 83-91.

17. Berbel, J.; Martin-Ortega, J.; Mesa, P. A cost-effectiveness analysis of water-saving measures for the water framework directive: The case of the Guadalquivir River Basin in Southern Spain. Water Resour. Manag. 2011, 25, 630-640.

18. Interwies, E.; Gorlach, B.; Strosser, P.; Ozdemiroglu, E.; Brouwer, R. The Case for Valuation Studies in the Water Framework Directive; Scotland and Northern Ireland Forum for Environmental Research: Edinburgh, UK, 2005; pp. 1-97.

19. Ward, F. Economics in integrated water management. Environ. Model. Softw. 2009, 24, 948-958.

20. Borkey, P. Keeping Water Safe to Drink; Organisation for Economic Co-operation \& Development: Paris, France, 2006; pp. 1-8. 
21. European Commission (EC). DG Regional Policy. In Guidance on the Methodology for Carrying out Cost-Benefit Analysis, The New Programming Period 2007-2013, Methodological Working Document No. 4; EC: Brussels, Belgium, 2006; pp. 1-23.

22. Regione Emilia-Romagna (RER), Assessorato all'Ambiente. Piano di Tutela delle Acque (PTA, Annex 1). In Applicazione della Direttiva 2000/60/CE: Analisi delle Pressioni e degli Impatti (Application of the Directives 2000/60/CE: Analysis of Pressures and Impacts); Emilia-Romagna, Assessorato all'Ambiente: Bologna, Italy, 2005.

23. Regione Emilia-Romagna (RER), Direzione Generale Agricoltura (FEASR). Regolamento (CE) No. 1698/2005-Programma di Sviluppo Rurale 2007-2013; Emilia-Romagna, Assessorato all'Agricoltura: Bologna, Italy, 2006.

24. European Council. Directive 91/676/EEC (Nitrate Directive); Official of the European Communities: Brussels, Belgium, 1991.

25. Kovacic, D.A. Riparian vagetated buffer strips in water-quality restoration and stream management. Freshw. Biol. 1993, 29, 243-258.

26. Lago, M.A. An Investigation of Regulatory Efficiency with Reference to the EU Water Framework Directive: An Application to Scottish Agriculture; The University of Edinburgh: Edinburgh, UK, 2008.

27. Mantovi, P.; Bortolazzo, E.; Tabaglio, V. Il liquame bovino su prato non comporta perdite di nitrati. Inf. Agrar. 2010, 29, 44-48.

28. Mantovi, P. La concentrazione di nitrati e la richiesta di deroga. Terra e Vita 2010b, 4, 5-8.

29. Rossi, P.; Gastaldo, A. Effluenti Zootecnici: I sistemi di stoccaggio. Inf. Zootec. 2009, 1, $57-60$.

30. Rossi, P.; Gastaldo, A. Deiezioni: I costi di costruzione possono superare i due milioni. Informatore Zootecnico 2010, 1, 66-69.

31. European Commission. Directive 2009/90/EC (Quality Assurance Quality Control Directive); Official of the European Communities: Brussels, Belgium, 2009.

32. Arpa Emilia Romagna. Available online: http://www.arpa.emr.it/ (accessed on 10 June 2012).

33. Federambiente. Rapporto Bonifiche Federambiente 2010; Federambiente: Rome, Italy, 2010; pp. 1-388.

34. Andretta, A.M.F. Analisi dei costi di bonifica. In Proceedings of Ecomondo, Rimini, Italy, 5-8 November 2008.

35. Sidney Water. Water conservation strategy 2010-2015; Sidney Water: Sidney, Australia, 2010.

36. Italian FADN (Farm Accountancy Data Network), Italy. Available online: http://www.rica.inea.it/ public/it/ index.php (accessed on 21 September 2012).

37. Arora, K.; Mickelson, S.K.; Helmers, J.M.; Baker, L.J. Review of pesticide retention processes occurring in buffer strips receiving agricultural runoff. J. Am. Resour. Assoc. 2010, 46, 618-647.

38. National Association of Agricultural Contractors (UNIMA), Italy. Available online: http://www.unima.it/ (accessed on 30 October 2012) 
39. European Commission. DG Regional Policy. In Guide to Cost-Benefit Analysis on Investment Projects, Structural Funds, Cohesion Funds and Instrument for Pre-Accession; European Commission: Bruxelles, Belgium, 2008.

40. ISTAT (National Statistical Institute), Italy. Available online: http://www.istat.it/it/ (accessed on 5 September 2012)

41. Bateman, I.J.; Cole, M.; Cooper, P.; Georgiou, S.; Hadley, D.; Poe, G.L. On visible choice sets and scope sensitivity. J. Environ. Econ. Manag. 2004, 47, 71-93.

42. Sutherland, R.J.; Walsh, R.G. Effect of distance on the preservation value of water quality. Land Econ. 1985, 61, 281-291.

43. Bateman, I.J.; Brouwer R.; Davies, H.; Day, B.H.; Deflandre, A.; di Falco, S.; Georgiou, S. Analysing the agricultural costs and non-market benefits of implementing the water framework directive. J. Agric. Econ. 2006, 57, 221-237.

44. Raggi, M.; Ronchi, D.; Viaggi, D. Valutazione economica del miglioramento qualitativo della risorsa idrica: Un'applicazione di benefit transfer al bacino del Po. In Acqua, agricoltura e ambiente, nuovi scenari di politica comunitaria; Casini, L., Gallerani, V., Viaggi, D., Eds.; Franco Angeli: Milano, Italy, 2008; pp. 49-66.

45. Lindhjem, H.; Navrud, S. How reliable are meta-analyses for international benefit transfers? Ecol. Econ. 2008, 66, 425-435.

46. Siccità, Regione chiederà riconoscimento di "evento eccezionale". The Regional Environmental Agency. Available online: http://www.regione.emilia-romagna.it/notizie/2012/agosto/siccitaRegione-chiedera-riconoscimento-di-evento-eccezionale (accessed on 19 April 2013).

47. Ramajo-Hernandez, J.; del Saz-Salazar, S. Estimating the non-market benefits of water quality improvement for a case study in Spain: A contingent valuation approaches. Environ. Sci. Policy 2012, 22, 47-59.

48. Alberini, A.; Longo, A.; Rosato, P.; Zanatta, V. Il valore di non uso nell'analisi coti benefici della salvaguardia ambientale. Aestimum 2003, 43, 1-24.

49. Bateman, I.J.; Langford, I.H. Non users' willingness to pay for a national park: An application and critique of the contigent valuation method. Reg. Stud. 1996, 31, 571-582.

50. Boyle, K.J.; Bergstrom, J.C. Benefit transfer studies: Myths, pragmatism, and idealism. Water Resour. Res. 1992, 28, 675-683.

51. Siegel, K.; Kauer, B.; Pahl-Wostl, C. Conceptualising uncertainty in environmental decision-making: The example of the EU Water Framework Directive. Ecol. Econ. 2010, 69, 502-510.

52. Meyerhoff, J.; Boeri, M.; Hartje, V. The Value of Achieving Water Quality Improvements in the Rivers of the Metropolitan Region of Berlin and Brandenburg, Working Paper on Management in Environmental Planning No. 32; Berlin, Germany, 2013.

53. Alcon, F.; Martin-Ortega, J.; Berbel, J.; de Miguel, M.D. Environmental benefits of reclaimed water: An economic assessment in the context of the Water Framework Directive. Water Policy 2012, 14, 148-159. 
54. Hasler, B.; Brodersen, S.L.; Christensen, L.P.; Christensen, T.; Dubgaard, A.; Hansen, H.E.; Kataria, M.; Martinsen, L.; Nissen, C.J.; Wulff, A.F. Assessing Economic Benefits of Good Ecological Status under the EU Water Framework Directive; Testing Practical Guidelines in Odense River Basin. Case Study Report—Denmark, Aquamoney Project, VU University of Amterdam: Amsterdam, The Netherlands, 2006.

55. Metcalfe, P.; Baker, P.W.; Andrews, K.; Atkinson, G.; Bateman, I.J.; Butler, S.; Carson, R.T.; East, J.; Guéron, Y.; Sheldon, R.; et al. An assessment of the nonmarket benefits of the Water Framework Directive for households in England and Wales. Water Resour. Res. 2012, in press.

56. Glenk, K.; Lago, M.; Moran, D. Public preferences for water quality improvements: Implications for the implementation of the EC Water Framework Directive in Scotland. Water Policy 2011, 13, 645-662.

57. Stithou, M.; Hynes, S.; Hanley, N.; Campbell, D. Estimating the value of achieving "Good Ecological Status" in the Boyne River Catchment in Ireland using choice experiments. Econ. Soc. Rev. 2012, 43, 397-422.

58. Guo, P.; Huang, G.H.; Zhu, H. Interval-parameter two-stage stochastic semi-infinite programming: Application to water resource management under uncertainty. Water Resour. Manag. 2009, 23, 1001-1023.

59. Brouwer, R.; de Blois, C. Integrated modeling of risk and uncertainty underlying the cost andeffectiveness of water quality measures. Environ. Model. Softw. 2008, 23, 922-937.

60. Barton, D.A.; Saloranta, T.; Bakkent, T.H.; Solheim, A.L.; Moe, J.; Selvik, J.R.; Vagstad, N. Using Bayesian Network models to incorporate uncertainty in the economic analysis of pollution abatement under the Water Framework Directive. Water Sci. Technol. Water Supply 2005, 5, 95-104. 


\title{
Simulating Volumetric Pricing for Irrigation Water Operational Cost Recovery under Complete and Perfect Information
}

\section{Luca Giraldo, Raffaele Cortignani and Gabriele Dono}

\begin{abstract}
This study evaluated the implementation of a volumetric and cost-recovery pricing method for irrigation water under symmetric information conditions without the inclusion of implementation costs. The study was carried out in two steps. First, a cost function was estimated for irrigation water supplied by a water user association to a typical Mediterranean agricultural area, based on a translog function. Second, the economic impact of a pricing method designed according to this cost function was simulated using a mathematical programming territorial model for the same agricultural area. The outcomes were compared with those for the current pricing method. The impacts of this pricing method are discussed in terms of its neutral effects on total farm income and, conversely, the importance of the redistributive effects.
\end{abstract}

Reprinted from Water. Cite as: Giraldo, L.; Cortignani, R.; Dono, G. Simulating Volumetric Pricing for Irrigation Water Operational Cost Recovery under Complete and Perfect Information. Water 2014, 6, 1204-1220.

\section{Introduction}

In addition to the controversial interpretation of the European Water Framework Directive 60/2000 (WFD) [1], the European Union National Associations of Water Suppliers and Waste Water Services issued a position paper [2] for development of a guideline on water service costs that should be recovered from water service users, and the extent to which water users should contribute to recovery of the costs of water service operators. The WFD presented a number of cost recovery issues associated with water services, efficient water management, and water protection, in relation to its various forms and availability [3].

Economic analysis of irrigation water can: (i) inform sustainable water management; (ii) be used for implementing the WFD [4]; and (iii) identify possible problems in policy design. In particular, under the conditions of the irrigation-based agriculture practiced in arid areas of the European Mediterranean, complying with the general principles of the WFD could be inconsistent with meeting its individual objectives. For example, recovery of the complete cost of water services by increasing irrigation payments could lead to problems in protecting the resource, as it would encourage farmers to use alternative water sources [5], including groundwater or rivers [6]. Furthermore, in the case of under-utilization of facilities for irrigation water supply, attaining full cost recovery involves fees calculated on the basis of average costs; this could result in fees much higher than marginal costs [7]. The recovery of costs would then be in conflict with efficiency. Pursuing the recovery of costs by increasing irrigation payments could generate a vicious cycle if it produces a gradual reduction in the use of water supplied by water utilities, such as the Water User Associations (WUAs) [8]. 
As outlined by Tsur [9], implementation costs theoretically change the performance of pricing methods, and hence can change their order of efficiency. In the absence of implementation costs, volumetric pricing methods are capable of achieving a first-best allocation (i.e., an outcome that maximizes the net benefit that can be generated using the available water). The maximum benefit that can be attained using input or output pricing would, in general, be smaller than the benefit attainable using volumetric pricing (i.e., the first-best outcome). This is because the water charges imposed on other inputs or outputs can distort input/output decisions. However, these charges are still chosen to maximize a social benefit function, although a distorted one. Input/output pricing is generally referred to as second-best efficient (efficient, because it maximizes benefit; second-best, because the benefit capable of being achieved is less than that under volumetric pricing).

Another factor markedly affecting the performance of pricing schemes is asymmetric information, which contrasts with the assumption of perfect information required by neoclassical economics. It occurs where decisions are made, but some of those affected have more or less information than others. Within the scope of this study, this can take three basic forms: (i) private individual water use (unmetered water); (ii) water production technologies at the farm level that are unknown to the regulator [9]; and (iii) water service production function at the WUA level that is unknown to the farmers [7].

The objective of this study was to evaluate the implementation of a cost-recovery and volumetric pricing method under symmetric information conditions, without the inclusion of implementation costs. It was carried out in two steps. First, a cost function was estimated for the water distribution cost (WDC) in a typical Mediterranean agricultural area, considering the various outputs and inputs. Second, two pricing methods, the existing method and one designed according to the estimated cost function, were simulated using a mathematical programming territorial model that represented the area in which the cost function was estimated. The results obtained enabled assessment of the merits of implementing the hypothetical and theoretically flawless pricing method.

\section{Materials and Methods}

\subsection{The Study Area}

The study area is the land covered by the "Consorzio di Bonifica dell'Oristanese" (CBO-WUA) Water User Association in Sardinia, Italy. Irrigation networks were installed following drainage of the area in the early 1900, and since then has gradually been extended and modernized. The study area covers 85,363 ha, of which 36,000 ha are equipped with irrigation and drainage facilities provided by the CBO-WUA. The major crops are cereals (mainly corn and rice) and fodder crops (in particular alfalfa and ryegrass); large areas of land are also cropped using glasshouse vegetable production, with artichoke and tomato being the most important. The remaining production comes from orchards, with the northern area being famous for orange, vineyard, and olive production. The southern side of the CBO-WUA specializes in dairy production, for which it is recognized nationally. It has a plant for treating and packaging milk collected from the farms in the area. The most widely used irrigation techniques involve sprinklers for fodder crops, cereals, and some vegetables including potatoes, and micro-irrigation for most of the vegetables, orchards, vineyards, and greenhouses. 
Figure 1. The study area in western Sardinia (Italy), showing the borders of the irrigation districts. Source: [10].

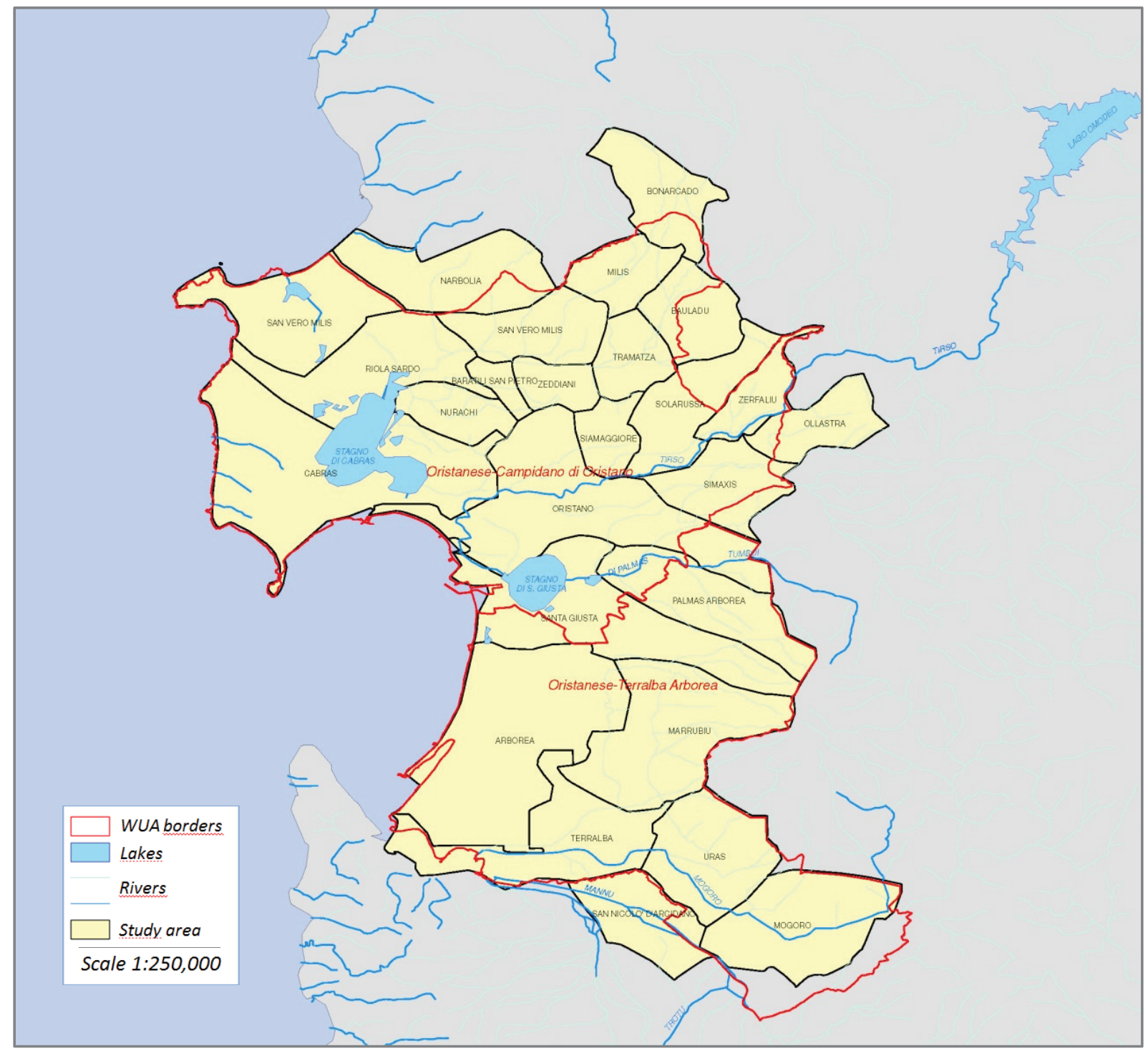

The area not served by the CBO-WUA irrigation facilities is mainly rain-fed, although some farms are irrigated with groundwater drawn from private wells. In addition to the importance of cereal and fodder crops, 55\% of the area comprises pastures that are often not cropped or are woods, tare and set-aside. Sheep breeding is the major livestock activity in the area. It involves 372,000 head and the presence of several milk processing plants for sheep cheese production.

The water delivery system of the CBO-WUA involves irrigation water obtained from a reservoir on the Tirso River; the reservoir is located at a higher elevation than the irrigated area. The reservoir came into operation in 2003 and can store approximately 500 million cubic meters. Prior to 2003, irrigation water was obtained from a smaller reservoir with a capacity of 130 million cubic meters. The irrigation network of the CBO-WUA consists of pipelines for the supply of water under pressure to certain districts, and open channels for gravity distribution to other districts. The gravity system mainly supplies water to rice-growing and marginal areas, but is progressively being replaced with pipelines. 


\subsection{The Economic Territorial Model}

The economic model used in the study is a supply territorial model comprising five categories of district $(m d)$ and 13 farm types (ty). The model is divided into 25 blocks, as not all farm types are present in all five districts. Each block can be considered to be a macro-farm representative of the area.

The objective function of the model, $\mathbf{z}$, has the structure defined by Equation (1):

$$
\begin{aligned}
& \mathrm{z}=\sum_{\mathrm{j}, \mathrm{md}, \mathrm{ty}} \mathrm{P}_{\mathrm{j}, \mathrm{md}, \mathrm{ty}} \times \mathrm{Y}_{\mathrm{j}, \mathrm{md}, \mathrm{ty}} \times \mathrm{x}_{\mathrm{j}, \mathrm{md}, \mathrm{ty}}+\sum_{\mathrm{tyc}} \text { Pmilkc } \times \mathrm{Qmilkc}_{\mathrm{tyc}}+\sum_{\mathrm{tys}} \text { Pmil } \times \mathrm{Qmilkc}_{\mathrm{tys}} \\
& +\sum_{j, m d, t y} \mathrm{CA}_{\mathrm{j}} \times \mathrm{x}_{\mathrm{j}, \mathrm{md}, \mathrm{ty}}+\sum_{\mathrm{md,ty}}^{\mathrm{tyc}} \mathrm{sfp}_{\mathrm{ty}} \times \text { heleg }_{\mathrm{md}, \mathrm{ty}}-\sum_{\mathrm{md}, \mathrm{ty}}^{\mathrm{tys}} \bmod _{\mathrm{md}, \mathrm{ty}} \\
& -\sum_{j, m d, t y, t y, \text { inp }} \operatorname{Pinp}_{m d, t y, \text { inp }} \times \operatorname{Qinp}_{\mathrm{j}, \mathrm{md}, \mathrm{ty}, \text { inp }} \times \mathrm{x}_{\mathrm{j}, \mathrm{md}, \mathrm{ty}} \\
& -\sum_{j, m d, t y} \text { Twatha }_{j, m d} \times x_{j, m d, t y}-\sum_{m d, t y, t} \text { Cpump }_{m d} \times \text { watpump }_{m d, t y, t} \\
& -\sum_{\mathrm{md,ty,t}} \text { Plabext } \times \text { labext }_{\mathrm{md}, \mathrm{ty}, \mathrm{t}} \\
& -\sum_{\text {feedc,md,tyc }}^{\text {ma,ty,t }} \text { Palimc }_{\text {feedc }} \times \text { alimc }_{\text {feedc,md,tyc }} \\
& -\sum_{\text {feeds,md,tys }} \text { Palims }_{\text {feeds }} \times \text { alims }_{\text {feeds,md,tys }}
\end{aligned}
$$

where $\mathbf{z}$ is the expected gross margin; $\mathbf{P}_{\mathbf{j}, \mathbf{m d} \text {,ty }}$ are the output prices for each of the $\boldsymbol{j}$ crops, for each district $\boldsymbol{m} \boldsymbol{d}$ and for each farm type $\boldsymbol{t} \boldsymbol{y} ; \mathbf{Y}_{\mathbf{j}, \mathbf{m d}, \mathrm{ty}}$ are the respective crop yields; $\boldsymbol{x}_{\boldsymbol{j}, \boldsymbol{m \boldsymbol { d }}, \boldsymbol{t} \boldsymbol{y}}$ are the areas of each activity $\boldsymbol{j}$ (in hectares); Pmilkc is the price of dairy milk; $\boldsymbol{Q m i l k}_{\boldsymbol{t y c}}$ is the milk production in the cattle farm types (tyc); Pmilks is the price of sheep milk; $\boldsymbol{Q m i l k s}_{\boldsymbol{t y s}}$ is the milk production in the sheep farm types (tys); $\boldsymbol{C A}_{\boldsymbol{j}}$ are the coupled payments under the Common Agricultural Policy (CAP); $\boldsymbol{s} \boldsymbol{f}_{\boldsymbol{t y}}$, hele $\boldsymbol{g}_{\boldsymbol{m} \boldsymbol{d}, \boldsymbol{t} \boldsymbol{y}}$ and $\boldsymbol{m o d}_{\boldsymbol{m} \boldsymbol{d}, \boldsymbol{t} \boldsymbol{y}}$ are (respectively) the Single Farm Payment (SFP), the eligible area, and the value of the SFP lost by the farm because of subsidies modulated according to the CAP; $\boldsymbol{P i n p}_{\boldsymbol{m d}, \boldsymbol{t y , i n \boldsymbol { p }}}$ and $\boldsymbol{Q i n p}_{\boldsymbol{j}, \boldsymbol{m d}, \boldsymbol{t y}, \boldsymbol{i n p}}$ are the prices and the quantities for the various inputs inp, respectively; $\boldsymbol{T} \boldsymbol{w a t h} \boldsymbol{a}_{\boldsymbol{j}, \boldsymbol{m \boldsymbol { d }}}$ are the water tariffs currently imposed on the various crops and applied per hectare by the WUA; $\boldsymbol{C p u m p} \boldsymbol{p}_{\boldsymbol{m} \boldsymbol{d}}$ and $\boldsymbol{w a t p u m p} \boldsymbol{p}_{\boldsymbol{m}, \boldsymbol{t y}, \boldsymbol{t}}$ are the costs to pump water from private wells on the farms and the quantity of water pumped in each period $t$ (10-day periods), respectively; Plabext and labext $_{\boldsymbol{m d}, \boldsymbol{t} y, \boldsymbol{t}}$ are the price and the availability of temporary wage labor, respectively; $\boldsymbol{P a l i m c}_{\text {feedc }}$ and alimc $_{\boldsymbol{f e e d c , m d , t y c}}$ are the prices and quantities of feed (feedc), respectively, purchased by the cattle farms; and Palims feeds $_{\text {s }}$ and alims $_{\text {feeds,md,tys }}$ are the prices and quantities of different feed (feeds), respectively, purchased by the sheep farms.

The model contains constraints on land, labor, animal feeding and water. The land constraints include total farm type availability, fixed crops, irrigable land and greenhouses. The labor constraints concern farm and external labor. As some farm types have animals requiring feeding, their requirements are satisfied using farm-produced fodder crops and feeds purchased on the market; the 
scheme has a dedicated constraint in the model. The water constraints are defined according to Equations (2)-(6), as follows:

$$
\begin{aligned}
\sum_{j, m d w u a, t y} \text { Rwater }_{j, m d w u a, t y, t i r r} & \times x_{j, m d w u a, t y} \\
\leq & \text { awater }_{\text {tirr }}+\sum_{m d w, t y} \text { watpump }_{m d w u a, t y, t i r r} \forall \text { tirr }
\end{aligned}
$$

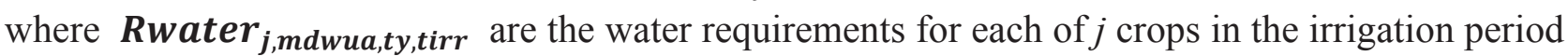
(tirr; 10-day periods from April to October); $\boldsymbol{a w a t e r}_{\text {tirr }}$ is the availability of agricultural water in the reservoir during the irrigation period, according to the WUA plan. The water availability is a variable calculated according to Equation (3):

$$
\text { awater }_{\text {tirr }+1}=\text { awater }_{\text {tirr }}-\sum_{j, m d w, t y} \text { Rwater }_{j, \text { mdwua,ty,tirr }} \times x_{j, m d w, t y} \forall \text { tirr }+1
$$

where water availability in the next 10 -day period depends on water availability minus the irrigation water consumed in the current 10-day period.

$\sum_{j}$ Rwater $_{j, m d w u a, t y, t n i r r} \times x_{j, m d w u a, t y} \leq$ watpump $_{\text {mdwua,ty,tnirr }} \forall$ mdwua,ty,tnirr

The WUA distributes water from April to October, and in other months farms can irrigate by pumping water from wells: the variable indicates the extent of these uses.

$$
\sum_{\mathrm{j}} \text { Rwater }_{\mathrm{j}, \text { mdrain,ty,t }} \times \mathrm{x}_{\mathrm{j}, \text { mdrain,ty }} \leq \text { watpump }_{\text {mdrain,ty,t }} \forall \text { mdrain, ty, } \mathrm{t}
$$

In the area not serviced by the CBO-WUA it is possible to pump water from wells.

$$
\text { watpump }_{\mathrm{md}, \mathrm{ty}, \mathrm{t}} \leq \text { Awell }_{\mathrm{md}, \mathrm{ty}, \mathrm{t}} \forall \mathrm{md} \text {, ty, } \mathrm{t}
$$

The potential to pump is constrained by the $\boldsymbol{A w}_{\boldsymbol{w}} \boldsymbol{l l}_{\mathbf{m d}, \mathrm{ty}, \mathbf{t}}$ availability, which depends on the number and capacity of the wells.

Model Calibration: Risk Aversion and Positive Mathematical Programming

The calibration procedure was based on two steps [11] that are widely used for calibration in this type of mathematical programming model. The risk approach considers the market risk exposure of the farmer, and positive mathematical programming (PMP) enables representation of cost geometry that is more consistent with neoclassical economic theory. In the first step, a risk aversion coefficient was used to calibrate the model and to obtain the best fit between the observed crop pattern and the model's predicted crop pattern. The goodness of this fit was assessed statistically using the Finger-Kreinin similarity index [12]. The aim of this step was to ensure that the model produced acceptable results before proceeding to the second step. The model is a risk programming model that takes the risk into account through the mean-standard deviation method, in which the expected utility is defined by two arguments: the expected income and its standard deviation [13].

In the second step the PMP methodology was used to calibrate the model to the observed situation. In developing the PMP methodology, a profit-maximizing equilibrium in the reference period was assumed in calibrating agricultural supply. This recovered additional information from the observed activity levels, enabling specification of a non-linear objective function such that the resulting non-linear model exactly reproduced the observed behavior of farmers [14-17]. In recent years, the 
PMP methodology has been applied in various research areas and has been improved to consider many relevant aspects [18-26]. Heckelei et al. [27] recently reviewed the more important PMP models that have been development and used.

\subsection{Operational Cost for Water Distribution}

Dono and Giraldo [7] estimated a flexible cost function for the operational costs incurred by the $\mathrm{CBO}-W U A$ in supplying irrigation water to farmers. They used a flexible functional form as it eliminates prior restrictions on its first and second derivatives (as preferred in empirical analyses), and chose the translog (TL) specification, as it is the most parsimonious for the parameters to be estimated [28]. The four estimated functions, one for each distribution technology adopted, were also explored in [7] and [29]: HP and LP refer to systems of pipelines delivering water at high (HP) and low pressure (LP), respectively; GR stands for gravity, and refers to the delivery of water in open channels by gravity; the fourth technology modeled was RG (referring to gravity channels that involve some pumping because of minor hilly sections). The latter technology was not considered in this study as it was very marginal.

$$
\ln C(z)=\alpha_{0}+\sum_{i} \alpha_{i} \ln \left(z_{i}\right)+1 / 2 \sum_{i} \sum_{j} \alpha_{i j} \ln \left(z_{i}\right) \ln \left(z_{j}\right), \quad, \alpha_{i j}=\alpha_{j i} .
$$

In the form represented in Equation (7), the TL is a quadratic function of the logarithm of $z$. However, for convenience of notation consider $z=\left(z_{1}, z_{2} \ldots z_{n+3}\right)=\left(y_{1}, y_{2}, w_{1} \ldots w_{n}, \lambda_{1}\right)$, where the first elements of $z$ are the quantity of outputs $(y)$, the second group $(w)$ is the price of inputs, and the third $(\lambda)$ refers to environmental variables that represent structural or environmental features that affect the system performance. This model, together with $n-1$ equations of the cost share of each input derived from Shephard's lemma, constituted the system estimated using the seemingly unrelated regression (SUR) method proposed by Zellner [30], which was improved based on the suggestions of Weninger [31] and Battese [32] for treating null values, and according to Dono and Giraldo [7] and Dono et al. [29].

The observations used in the study were derived from annual data for the 25 irrigation districts of the CBO-WUA over the 11 years from 1995 to 2005. This time scale was chosen because the current water price was based on annual costs, and more detailed and sub-yearly data were not available. The functions were structured as multi-output, as suggested in previous studies involving the water sector [33], and two variables were identified: the irrigated agricultural surface area and the watering intensity (the provision of a volume of water per irrigated hectare). The product of these two variables provided the volume of water delivered by the WUA, but splitting it into these two components permitted assessment of their individual contributions to the water service operational costs.

Table 1 shows the estimated elasticity for each of the two outputs, expressed as the percent variation of costs with respect to percent changes in each output. 
Table 1. Elasticity of cost to outputs under the various Consorzio di Bonifica dell'Oristanese" Water User Association CBO-WUA distribution technologies.

\begin{tabular}{cccc}
\hline Output & HP pipelines & LP pipelines & GR channels \\
\hline Irrigated land & 0.798 & 0.824 & 0.897 \\
Water/hectare & 0.378 & $-0.084 * *$ & 0.498 \\
\hline
\end{tabular}

Note: $* *$ this estimate is not significantly different from zero at $p=0.37$.

The study of cost functions gives information on the elasticity of costs to outputs; in the TL case, the elasticities are given by the parameters $\alpha$ relative to the variables $y$. This analysis showed that the elasticities were always less than 1 , indicating that the system was generally operating below its capabilities. It also showed that the marginal costs were lower than the average costs, indicating that the optimal price (efficiency price) would not cover the cost (it would be possible using average cost as price).

\subsection{Simulation of Hypothetical Payment Scheme under Complete and Perfect Information}

\subsubsection{Baseline Scenario}

The model run set comprised two simulations. The first was the Baseline scenario, in which the model was run as calibrated, and represented the actual behavior of the 2010 farmers with respect to the use of resources. In this scenario farmers paid the CBO-WUA for irrigation water based on the surface area supplied and the estimated irrigation requirements of the specific crop under cultivation.

$$
\sum_{j, m d, t y} \text { Twatha }_{j, m d} \times x_{j, m d, t y}
$$

Equation (8) is the component of the objective function in Equation (1) accounting for CBO-WUA water payments, where $\boldsymbol{T w a t h a}_{\boldsymbol{j}, \boldsymbol{m} \boldsymbol{d}}$ is the water tariff currently imposed by the CBO-WUA on various crops $(j)$, differentiated by distribution technology $(m d)$ and applied per hectare $(x)$.

Table 2 shows the price per hectare requested by the CBO-WUA and how it varied according to the crop and the technology used in the district. These prices complied with Regional Law N.6/2003, which sets the maximum price level [34]. The Arborea district, which consists almost entirely of dairy farms supplied with water at high pressure $(\mathrm{HPa})$, is distinguished from the other high-pressure districts $(\mathrm{HPb})$, where dairy farms are absent. That is because the Arborea district has soil characteristics and farmer behaviors that differ from those of the other districts, and the CBO-WUA chose to apply different prices. 
Table 2. Water price, expressed in $€ /$ ha, currently required by the CBO-WUA under the irrigated hectare pricing scheme.

\begin{tabular}{ccccc}
\hline Crop & HPa & HPb & LP & GR \\
\hline $\begin{array}{c}\text { Melons } \\
\text { Ryegrass } \\
\text { Clementine } \\
\text { Orange }\end{array}$ & 72 & 58 & & \\
\cline { 3 - 3 } & & 73 & & 26 \\
Carrot & & & & \\
$\begin{array}{c}\text { Strawberry } \\
\text { Lettuce } \\
\text { Pepper } \\
\text { Potato }\end{array}$ & 103 & 83 & 60 & 37 \\
Artichoke & 134 & 110 & 78 & 48 \\
\hline Tomato & 165 & 133 & 96 & 59 \\
\hline $\begin{array}{c}\text { Maize } \\
\text { Sorghum }\end{array}$ & 141 & & \\
\hline Alfalfa & 248 & 200 & 144 & 88 \\
\hline Rice & & & &
\end{tabular}

\subsubsection{Simulated Scenario}

The Simulated scenario is hypothetical: it entails theoretical conditions that are quite extreme and largely implausible, but because of this can be helpful in understanding the possible consequences of their acceptance. The represented condition is one in which farmers share and compete for resources while aiming to achieve maximum income. In this kind of model it is assumed that every player (i.e., farmer) knows the rules and is aware of the pay-offs associated with every move. In simultaneous models with complete and perfect information, every player knows the pay-offs and the strategies available to other players; in addition, every player moves simultaneously with the others, and at the same time knows all moves being made $[35,36]$.

In this scenario, every farmer has knowledge of the underlying CBO-WUA cost function for water distribution, and they know how their choices of irrigated land allocation and watering intensity affect the cost of water being supplied. In addition, every farmer knows how the cropping and watering decisions of other farmers contribute to his/her costs of supply with CBO-WUA irrigation water. This is defined as "perfect and complete information on cost recovery". Assuming this condition helps in assessment of the advantages and disadvantages of the application of volumetric pricing, by perfectly reflecting the operational cost structure in Mediterranean areas.

Representing this condition is achieved by integrating the water distribution cost reported in Equation (7) into the territorial model of Equation (1), such that every farm type pays exactly for the water used and the surface irrigated, and the price paid covers the cost. 
$W D C M D_{m d w u a}$

$$
\begin{aligned}
& =\exp \left(\alpha_{0_{\text {mdwua }}}+\sum_{i} \alpha_{i_{\text {mdwua }}} \times \log \left(y_{i_{\text {mdwua }}}\right)\right. \\
& \left.+\frac{1}{2} \sum_{i} \sum_{j} \alpha_{i j_{\text {mdwua }}} \times \log \left(y_{i_{\text {mdwua }}}\right) \times \log \left(y_{j_{\text {mdwua }}}\right)\right)
\end{aligned}
$$

Based on Equation (7), in Equation (9) the parameter $y$ represents the irrigated land and the water per hectare applied within each irrigation district. The cost calculated according to Equation (9) is relative to the irrigation district and is shared proportionately among all farm types according to the volume of water used by each type; this achieves volumetric water pricing defined by the district and the farm type. It is derived by inserting Equation (10) into the objective function of Equation (1), replacing the Baseline scenario water payments as in Equation (8).

$$
\begin{aligned}
W D C_{\text {mdwua,ty }} & =\frac{W D C M D_{\text {mdwua }}}{\sum_{j, t i r r, t y}\left(\text { Rwater }_{j, \text { mdwua,ty,tirr }} * x_{j, m d w u a, t y}\right)} \\
& \times \sum_{j, t i r r}\left(\text { Rwater }_{j, \text { mdwua,ty,tirr }} * x_{j, \text { mdwua,ty }}\right)
\end{aligned}
$$

In the Simulated scenario the only difference from the Baseline scenario concerns the water payment scheme.

\section{Results and Discussion}

\subsection{Results}

Table 3 summarizes the impact on aggregated economic variables for the entire area and shows their values in the Baseline and Simulated scenarios and their absolute and percentage variations. In the Baseline scenario, water pricing does not fully cover the total WDC (61\%). As reported in Table 2, Regional Law N.6/2003 sets the maximum price imposed by the CBO-WUA on farmers for the irrigation service and establishes that the costs not covered are funded by regional support. Currently, these additional costs are completely recovered through public support [34]; in Table 3 this is referred to as "Rest-of-society coverage". In the Simulated scenario, by definition the total WDC is fully covered (100\%) by water pricing. The higher price of water for farmers reduces the CBO-WUA water demand and the use of its facilities, decreasing the total WDC (Table 4). Given the condition of elasticities less than 1 (Table 1), the sustainability of the CBO-WUA is at risk because of increasing underutilization of its facilities, which also results in higher average costs to farmers through their irrigation payments. Under the Simulated scenario the society is not responsible for any part of the WDC (society contribution $=0$ ), saving $€ 1,380,000$. However, the increased cost to farmers through water payments offsets this social gain by approximately $€ 1,055,000$. The WDC changes from being partially to fully internalized in the CBO-WUA payment scheme, and represents a total gain of $€ 325,000$ (the difference between the $€ 1,380,000$ saved by the society and the increase farmer water payments of $€ 1,055,000$ ). The net income of farmers decreases more than the increase in sole water payments, which also has an amplifying effect on the production process. Farmers 
reduce the use of water as a reaction to the higher water price, resulting in a reduction of some irrigated crops, because the trade-off between the water price and the water benefit is no longer advantageous. Hence, the consequent drop of net income is $€ 1,390,000$, which balances the savings to the society and gives a negligible total net loss of $€ 10,000$.

Table 3. Economic variables for the total area under the Baseline and Simulated scenarios, and their absolute and percentage variations.

\begin{tabular}{ccccc}
\hline '000 EUR & Baseline & Simulated & Absolute variation & Percentage variation \\
\hline Water Distribution Cost & 3,524 & 3,199 & -325 & -9.2 \\
Pricing Coverage & $2,144(61 \%)$ & $3,199(100 \%)$ & 1,055 & 49.2 \\
Rest-of-society coverage & 1,380 & 0 & $-1,380$ & -100.0 \\
Farmers' Net Margin & 77,488 & 76,097 & $-1,390$ & -1.8 \\
Total social gain & & & -10 & \\
\hline
\end{tabular}

A negative benefit, although small in magnitude, is evident for the entire system when the societal gain (no requirement to pay for costs not covered by the quota) and the loss of net farmer income are compared (Table 3). However, the negative total social gain is very close to zero only because of the basic assumption of zero implementation cost. In the Simulated scenario, while it is assumed that the hypothetical payment scheme is operating perfectly, no account is made for any cost in its implementation, maintenance and enforcement. Volumetric pricing requires metering of water use at the farm level, implying that every farm has to be equipped with water meters, and that the meters are maintained in perfect working condition. Including these costs could further reduce use of the CBO-WUA facilities, and so increase its average cost; such costs would certainly decrease farm income and make introduction of this system less favorable. Despite the decrease in social welfare, such costs have to be taken into account in considering the merits of switching to a volumetric and cost-recovery pricing method.

Table 4 shows the impact on the use of water and labor resources in the area, including total values for the two scenarios, and the absolute and percentage variations between them. Groundwater in this area is mainly used to complement surface CBO-WUA water; the use of groundwater declines with reduced CBO-WUA water demand. In the long term, a growing demand for cheaper water may result in increased exploitation of groundwater through an increase in the number of wells or they capacity. It could also reduce the employment of hired labor because of contraction of agricultural business, and employment of farm family labor could be similarly affected (Table 4).

\subsection{Impact among Districts and Farm Types}

It is interesting to compare the overall small economic impact with the redistributive effects within the CBO-WUA, particularly the effects on districts having different water supply technologies (and therefore costs), and on different types of farms. The CBO-WUA charges farmers by allocating the water distribution costs and also takes into account the supposed benefit farmers get from the irrigation. In the Simulated scenario farmers are charged according to their share of the water distribution cost, which differs depending on the water distribution technology used in the district 
and the level of use of the water resource. These data are shown in Table 5, which reports the price per irrigated hectare and per cubic meter of water in the irrigation districts under the two scenarios, (The price per cubic meter in the current payment system is implicit: it is obtained by dividing the fee for "hectare crop" by the cubic meters of water allocated to each crop) their percentage differences and the elasticity of response in switching to the Simulated model.

Table 4. Use of water and labor resources in the area under the Baseline and Simulated scenarios, and their absolute and percentage variations.

\begin{tabular}{ccccc}
\hline Resource & Baseline & Simulated & Absolute variation & Percentage variation \\
\hline Total Water ('000 $\left.\mathrm{m}^{3}\right)$ & 122,145 & 117,252 & $-4,893$ & -4 \\
CBO-WUA water & 115,156 & 110,497 & $-4,659$ & -4 \\
Groundwater & 6,989 & 6,756 & -233 & -3 \\
\hline Total Labour (hours) & 5,223 & 5,148 & -75 & -1 \\
Farm Labour & 4,315 & 4,276 & -39 & -1 \\
External Labour & 908 & 872 & -36 & -4 \\
\hline
\end{tabular}

Table 5. Water price and elasticity with respect to surface and volume water price for each distribution technology.

\begin{tabular}{ccccc}
\hline Water Price $(\boldsymbol{\epsilon} / \mathbf{h a})$ & Baseline & Simulated & Percentage variation & Elasticity \\
\hline High Pressure a & 127 & 192 & 51.0 & -0.189 \\
High Pressure b & 100 & 192 & 92.5 & -0.087 \\
Low Pressure & 77 & 197 & 155.0 & -0.026 \\
Gravity & 78 & 18 & -77.0 & -0.001 \\
Total & 104 & 166 & 59.9 & -0.112 \\
\hline Water Price $\left(\boldsymbol{(} / \mathbf{m}^{\mathbf{3}}\right)$ & & & & \\
\hline High Pressure a & 0.0359 & 0.0512 & 42.8 & -0.103 \\
High Pressure b & 0.0197 & 0.0367 & 86.1 & -0.056 \\
Low Pressure & 0.0144 & 0.0390 & 170.9 & -0.056 \\
Gravity & 0.0062 & 0.0014 & -77.0 & -0.001 \\
Total & 0.0186 & 0.0289 & 55.5 & -0.073 \\
\hline
\end{tabular}

In both cases there is a shift in cost recovery from gravity-channel districts towards pipe-supplied districts. As shown previously, the water distribution cost is strongly affected by the pressure required, which is related to the use of electric power. In the Simulated scenario, gravity-channel farmers would be charged a lower price than at present; this indicates that these farmers are currently paying more than the cost they generate in being supplied with water by the CBO-WUA.

In terms of understanding how implementing the Simulated scenario would affect the various farm types modeled, Tables 6 and 7 report the return on equity (ROE) and the hourly remuneration for farm labor (RFL) for each farm type. 


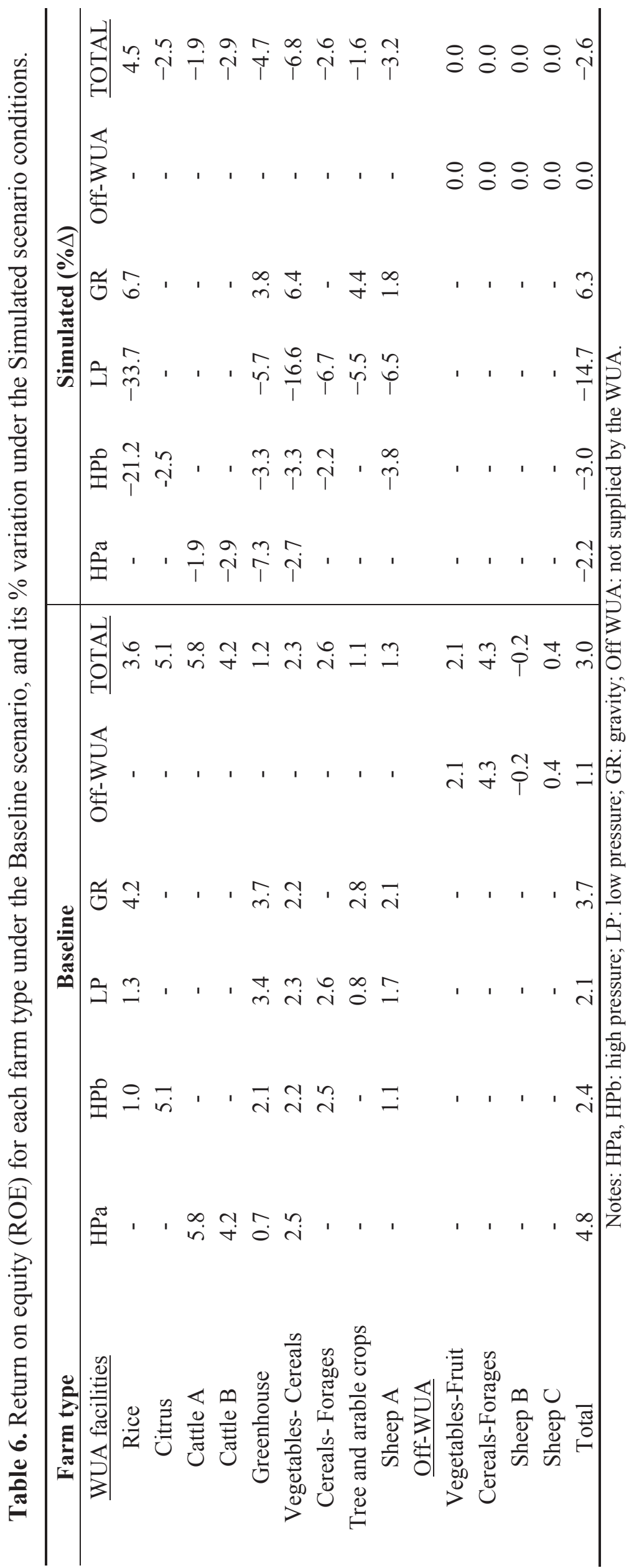




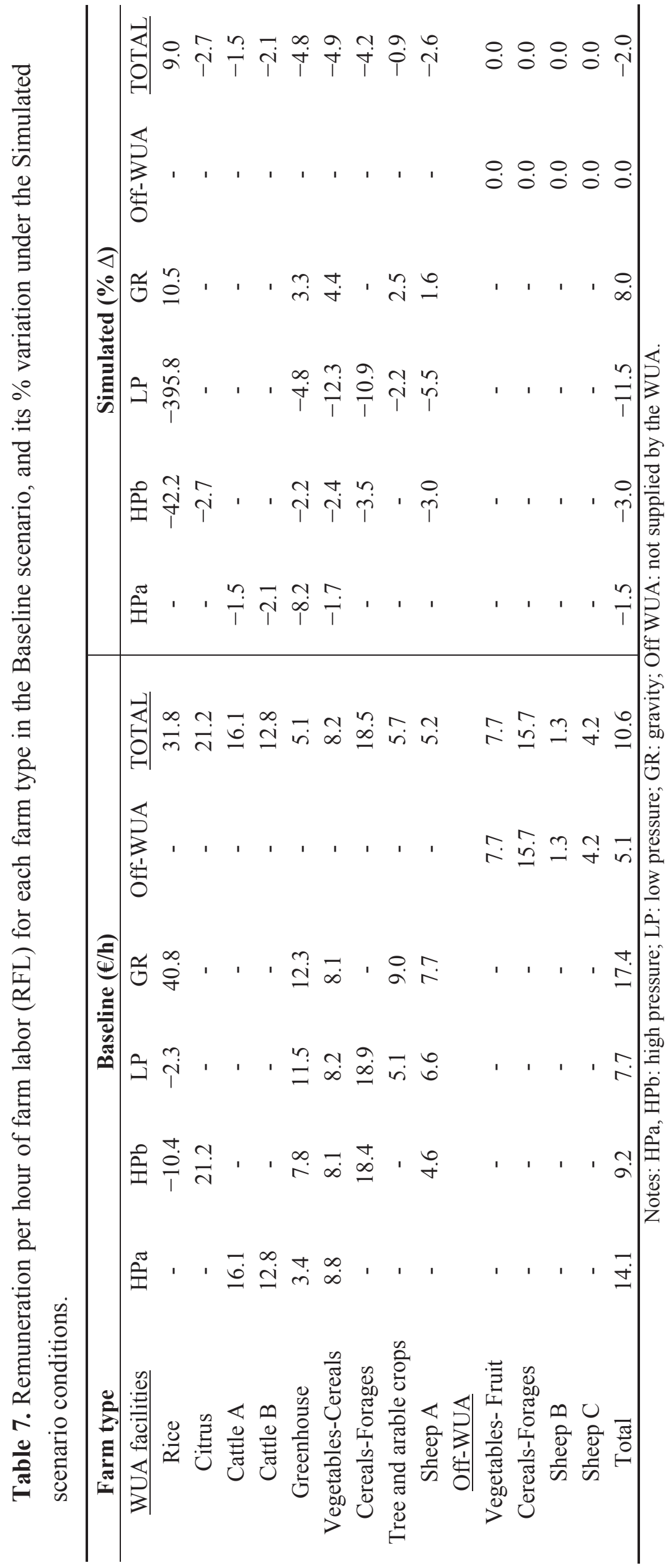


$\mathrm{ROE}$ is the ratio of the income that remains to remunerate the equity (after all other factors are compensated) to the value of the equity (including land value). Thus, it is a measure of the productivity of the invested property capital and a synthetic expression of the economic performance [37]. ROE disregards a crucial objective of family farms, which is to maximize labor use, and is not sufficient for assessing the economic performance of these types of units. However, it provides a good indication of the productivity of the capital invested. The upper section of Table 6 contains the values of ROE in the Baseline scenario and for different farm types. Intensive farming appears to be more valuable in terms of ROE, with higher values for citrus growers and dairy farms. The worst performing in terms of ROE are the sheep breeders whose farms are located outside the area served by the CBO-WUA. The lower section of Table 6 shows the percent variation in ROE under the Simulated scenario. As expected from the previous discussion, all farms serviced by gravity channels show some benefit under this scenario. This is because of the lower price resulting from charging farmers for the contribution they make to generation of the water distribution cost. Rice growers are mainly located in gravity-fed districts, so their ROE increases, even if a minor part of their operations occur in other districts and is heavily and negatively affected. The others in general charged with the full WDC are those already showing very low ROE in the Baseline scenario, such as sheep breeders and greenhouse farmers.

As maximization of the ROE is not always the major objective of family farms, the use of indicators of employment and the ability to compensate for family labor help in understanding the impact on farm performance. The results of this aspect of the study are shown in Table 7.

As noted above, rice growers are on average favored under the simulated condition through increased remuneration for labor, although because the farms are located in LP districts and are in the Baseline, they would probably cease production or transform to a different type of farming.

\section{Conclusions}

In this study we simulated the application of a hypothetical water policy in a Mediterranean agricultural area using basic principles of water pricing. Currently, as represented by the Baseline scenario, farmers in the area pay for irrigation water provided by a WUA that manages the water distribution facilities. The charges are based on irrigated area/crop pricing. The first step in the study involved estimating a translog cost function for the production of irrigation water by the WUA. This showed that the water distribution cost was based on the area of land supplied with water and the watering intensity on that land. The second step was to design a pricing method that considered all the information derived from the first step and to simulate implementation of the pricing method using a mathematical programming territorial model. This was undertaken with no accounting for implementation costs, but using complete and perfect information conditions (i.e., symmetric information). This procedure was over-compliant with the WFD but provided insights into the possible consequences for irrigated and water-constrained agriculture. Although the simulated pricing scheme is considered a "first best method", the total gain from its application was barely neutral, but would be negative if implementation costs were included, and this was exacerbated by the reduction of labor and appeared unrealistic about the information available to farmers about the behavior of other farmers and the WUA cost structure. 
The results of this case study confirm the results of previous theoretical studies $[12,38]$. Among these results, the neutral effect on total revenue and the importance of distributional effects are noteworthy. Of particular concern are the consequences of the sharp fall in the price of gravity-fed water supply in the Simulated scenario, which could lead to inefficient use of water resources. However, in other areas affected by specific water scarcity problems, and where the competition for water use is greater, the application of other tariff systems might be more efficient. For example, Alarcón et al. (2011) showed that water pricing and over-consumption penalties facilitated efficient utilization and also the ability to adjust consumption to resource availability and current economic and market situations, especially in response to crop subsidies [39].

In conclusion, assessment of the overall performance of a pricing method must include implementation costs. It is possible (and not uncommon where irrigation water is limited) that an inefficient per-area pricing method outperforms an efficient volumetric pricing method, especially if the difference in implementation costs between the two methods outweighs the efficiency difference, if any.

\section{Acknowledgments}

The study was funded by the Italian Ministry of Agriculture within the Agroscenari research project.

\section{Author Contributions}

Luca Giraldo prepared the paper, estimated the water distribution cost (WDC) function and plugged it into the territorial model. Raffaele Cortignani worked on the territorial model and performed the two-step calibration. Gabriele Dono had the original idea, contributed to the economic discussion and supervised the research. All three authors discussed the results and are responsible for the presented shape of the paper.

\section{Conflicts of Interest}

The authors declare no conflict of interest.

\section{References}

1. European Parliament and the Council of EU. OJEC L 327: Directive 2000/60/EC Establishing a Framework for Community Action in the Field of Water Policy; European Parliament and the Council of EU: Aberdeen, UK, 2000.

2. European Union of National Association of Water Suppliers and Waste Water Services. Water Framework Directive-Determination of Cost Recovery; European Federation of National Associations of Water Services: Brussels, Belgium, 2004. 
3. WATECO Group. Economics and the Environment - The Implementation Challenge of the Water Framework Directive. In CIS Guidance Document 01 Common Implementation Strategy for the Water Framework Directive (2000/60/EC); European Communities: Luxemburg, 2003; ISBN: 92-894-4144-5.

4. Berbel, J.; Azahara Mesa-Jurado, M.; Pistón, J.M. Value of irrigation water in Guadalquivir basin (Spain) by residual value method. Water Resour. Manag. 2011, 25, 1565-1579.

5. Venot, J.P.; Molle, F. Groundwater depletion in the Jordan highlands: Can pricing policies regulate irrigation water use? Water Resour. Manag. 2008, 22, 1925-1941.

6. Dono, G.; Giraldo, L.; Severini, S. Pricing Irrigation Water under alternative charging methods: Possible shortcomings of a volumetric approach. Agric. Water Manag. 2010, 97, 1795-1805.

7. Dono, G.; Giraldo, L. Un'analisi dei costi per la distribuzione dell'acqua in agricoltura. Riv. Econ. Agrar. 2009, 3-4, 339-357.

8. Azevedo, L.G.T.; Baltar, A.M. Water pricing reforms: Issues and challenges of implementation. Water Resour. Dev. 2005, 11, 19-29.

9. Tsur, Y. Water regulation via pricing: The role of implementation costs and asymmetric information. In The Political Economy of Water Pricing Reforms; Dinar, A., Ed.; World Bank Publications: Washington, DC, USA, 2000.

10. National Institute of Agricultural Economics (INEA), Rome, Italy. Unpublished work, 2014.

11. Van Ittersum, M.K.; Ewert, F.; Heckelei, T.; Wery, J.; Olsson, J.A.; Andersen, E.; Bezlepkina, I.; Brouwer, F.M.; Donatelli, M.; Flichman, G.; et al. Integrated assessment of agricultural systems-A component-based framework for the European Union (SEAMLESS). Agric. Syst. 2008, 96, 1-3.

12. Finger, J.M.; Kreinin, M.E. A measure of export similarity and its possible uses. Econ. J. 1979, 89, 905-912.

13. Louhichi, K.; Kanellopoulos, A.; Janssen, S.; Flichman, G.; Blanco, M.; Hengsdijk, H.; Heckelei, T.; Berentsen, P.; Lansink, A.O.; Ittersum, M.V. FSSIM, a bio-economic farm model for simulating the response of EU farming systems to agricultural and environmental policies. Agric. Syst. 2010, 103, 585-597.

14. Arfini, F.; Paris, Q. A positive mathematical programming model for regional analysis of agricultural policies. In The Regional Dimension in Agricultural Economics and Policies, Proceedings of the 40th EAAE Seminar, Ancona, Italy, 26-28 June 1995; pp. 17-35.

15. Howitt, R.E. Positive mathematical programming. Am. J. Agric. Econ. 1995, 77, 329-342.

16. Paris, Q.; Howitt, R. An analysis of ill-posed production problems using maximum entropy. Am. J. Agric. Econ. 1998, 85, 254-265.

17. Heckelei, T.; Wolff, H. Estimation of constrained optimisation models for agricultural supply analysis based on generalised maximum entropy. Eur. Rev. Agric. Econ. 2003, 30, 27-50.

18. Judez, L.; Chaya, C.; Martinez, S.; Gonzalez, A.A. Effects of the measures envisaged in "Agenda 2000" on arable crop producers and beef and veal producers: An application of positive Mathematical Programming to representative farms of a Spanish region. Agric. Syst. 2001, 67, $121-138$. 
19. Röhm, O.; Dabbert, S. Integrating agri-environmental programs into regional production models: An extension of positive mathematical programming. Am. J. Agric. Econ. 2003, 85, 254-265.

20. Calatrava, J.; Garrido, A. Modelling water markets under uncertain water supply. Eur. Rev. Agric. Econ. 2005, 32, 119-142.

21. Buysse, J.; Fernagut, B.; Harmignie, O.; de-Frahan, B.H.; Lauwers, L.; Polome P.; van-Huylenbroeck, G.; van-Meensel, J. Farm-based modelling of the EU sugar reform impact on Belgian sugar beet suppliers. Eur. Rev. Agric. Econ. 2007, 34, 21-52.

22. Henry de Frahan, B.; Buysse, J.; Polomé, P.; Fernagut, B.; Harmignie, O.; Lauwers, L.; van Huylenbroeck, G.; van Meensel, J. Positive mathematical programming for agricultural and environmental policy analysis: Review and practice. In Handbook of Operations Research in Natural Resources; Weintraub, A., Bjorndal, T., Epstein, R., Romero, C., Eds.; Kluwer Academic Publishers: Dordrecht, The Netherlands, 2007; pp. 129-157.

23. Iglesias, E.; Blanco, M. New directions in water resources management: The role of water pricing policies. Water Resour. Res. 2008, 44, doi:10.1029/2006WR005708.

24. Cortignani, R.; Severini, S. Modeling farm-level adoption of deficit irrigation using Positive Mathematical Programming. Agric. Water Manag. 2009, 96, 1785-1791.

25. Cortignani, R.; Severini, S. A constrained optimization model based on generalized maximum entropy to assess the impact of reforming agricultural policy on the sustainability of irrigated areas. Agric. Econ. 2012, 43, 621-633.

26. Arfini, F.; Donati, M. Organic production and the capacity to respond to market signals and policies: An empirical analysis of a sample of FADN farms. Agroecol. Sustain. Food Syst. 2013, 37, 149-171.

27. Heckelei, T.; Britz, W.; Zhang, Y. Positive mathematical programming approaches-Recent developments in literature and applied modelling. Bio Based Appl. Econ. 2012, 1, 109-124.

28. Christensen, L.; Jorgensen, D.; Lau, L. Transcendental logarithmic production frontiers. Rev. Econ. Stat. 1973, 55, 28-45.

29. Dono, G.; Giraldo, L.; Severini, S. The cost of irrigation water delivery: An attempt to reconcile the concepts of cost and efficiency. Water Resour. Manag. 2012, 26, 1865-1877.

30. Zellner, A. An efficient method of estimating seemingly unrelated regressions and tests for aggregation bias. J. Am. Stat. Assoc. 1962, 57, 348-368.

31. Weninger, Q. Estimating multiproduct costs when some outputs are not produced. Empir. Econ. 2003, 28, 753-765.

32. Battese, G.E. A note on the estimation of Cobb-Douglas production functions when some explanatory variables have zero values. J. Agric.Econ. 2008, 48, 250-252.

33. Barabaschi, N. Analisi delle strutture di costo dell'industria idrica italiana: Le economie di scala, di densità e di scopo. Quaderni di Ricerca REF 2007, 43. Available on line: http://www.ref-e.com/downloads/abstract_q43ref.pdf (accessed on 04 April 2014).

34. Regional Law of Regione Sardegna of 23 May 2008, n. 6, Art.44. Available online: $h t t p s: / / w w w . r e g i o n e . s a r d e g n a . i t / j / v / 80 ? s=85010 \& v=2 \& c=4426 \& t=1 \quad$ (accessed on 30 January 2014). 
35. Fudenberg, D.; Tirole, J. Game Theory; MIT Press: Cambridge, MA, USA, 1993; Chapter 6, Section 1.

36. Thomas, L.C. Games, Theory and Applications; Dover Publications: New York, NY, USA, 2003; p. 19.

37. Woolridge, J.R.; Gray, G. Applied Principles of Finance; Kendall Hunt Publishing Company: Dubuque, IA, USA, 2006.

38. Tsur, Y.; Roe, T.; Doukkali, R.; Dinar, A. Pricing Irrigation Water: Principles and Cases from Developing Countries; Resources for the Future: Washington, DC, USA, 2004.

39. Alarcón, J.; Mesa-Jurado, M.A.; Berbel, J. Devising irrigation water tariffs with overconsumption penalties. Span. J. Agric. Res. 2011, 9, 971-980. 


\title{
Integrated Groundwater Resources Management Using the DPSIR Approach in a GIS Environment: A Case Study from the Gallikos River Basin, North Greece
}

\section{Christos Mattas, Konstantinos S. Voudouris and Andreas Panagopoulos}

\begin{abstract}
The Gallikos River basin is located in the northern part of Greece, and the coastal section is part of a deltaic system. The basin has been influenced by anthropogenic activities during the last decades, leading to continuous water resource degradation. The holistic approach of the Driver-Pressure-State-Impact-Response (DPSIR) framework was applied in order to investigate the main causes and origins of pressures and to optimize the measures for sustainable management of water resources. The major driving forces that affect the Gallikos River basin are urbanization, intensive agriculture, industry and the regional development strategy. The main pressures on water resources are the overexploitation of aquifers, water quality degradation, and decrease of river discharge. Recommended responses were based on the Water Framework Directive (WFD) $2000 / 60 / E C$, and sum up to rationalization of water resources, land use management and appropriate utilization of waste, especially so effluent. The application of the DPSIR analysis in this paper links the socioeconomic drivers to the water resource pressures, the responses based on the WFD and the national legislation and is as a useful tool for land-use planning and decision making in the area of water protection.
\end{abstract}

Reprinted from Water. Cite as: Mattas, C.; Voudouris, K.S.; Panagopoulos, A. Integrated Groundwater Resources Management Using the DPSIR Approach in a GIS Environment: A Case Study from the Gallikos River Basin, North Greece. Water 2014, 6, 1043-1068.

\section{Introduction}

Several changes are noted at the European river basins, especially their coastal parts, due to land use alterations, urbanization, shrinkage of estuarine zones etc [1]. These changes are attributed predominantly to human activities in conjunction with poor management practices, which have caused numerous negative consequences such as development of deficient water balance and reduction of groundwater resources, water resource quality degradation [2], groundwater head decline, saline water intrusion along coastal areas and surface and ground water quality deterioration $[3,4]$.

The Water Framework Directive (WFD) 2000/60/EC clearly sets the basis and principles for effective protection of groundwater, internal, transitional and coastal waters at the river basin scale. Several techniques and methodologies have been proposed for the optimization of water resource management at this scale, and the Driver-Pressure-State-Impact-Response (DPSIR) methodology [5] is one of the methods that is being extensively applied in the framework of integrated water resource management [6-8].

In this paper the DPSIR technique is applied in a geographic information system (GIS) environment aiming at contributing to the optimization of water resources management of Gallikos 
River basin and developing a useful tool for local authorities, stakeholders and the regional water authority that is by law responsible for setting up the regional water resources policy. Through its application it also aims at proposing a suite of measures and actions towards rational development and sustainable management of the water resources. The selection of the GIS environment ensures that the results of the DPSIR analysis will be presented in a dynamic context that will be easily modified, as new data will be added and the comparison or change over the oldest data will be simple.

A preceding hydrogeological survey enabled, amongst other things, identification of the aquifer units that exist within the river basin and an estimation of their exploitable resources. This was the first attempt to study the water resources of the basin based on systematic measurements at specified time intervals. Monitoring points of the network had an adequate spatial distribution that sufficiently covered the entire basin. In a consequent phase, water demands per use were calculated and a thorough assessment of the quantity and chemical quality of water resources was performed. At the time that the fieldwork was conducted, the research team was in continuous communication with the farmers/breeders of the area and had established sincere cooperation. Most of the farmers were willing to assist with the monitoring network operation, in contrast to some local authorities that exhibited strong reservations to any cooperation on the assessment of environmental parameters. Based on these results, the DPSIR technique was applied and actions for measures for the sustainable management of the river basin's water resources were proposed. The presentation of the proposed approach serves as a demonstration of the applicability of the proposed methodology in other basins, opting for efficient and effective data analysis that leads to reliable, easy and precise water resource management practiced with the help of a dynamic and versatile tool.

\section{Materials and Methods}

\subsection{Regional Setting}

The Gallikos River is located in northern Greece and flows across the Prefectures of Kilkis and Thessaloniki before discharging into the Gulf of Thermaikos, northern Aegean Sea. The hydrological basin was delineated using ArcView GIS (Figure 1) and it was measured at approximately $1050 \mathrm{~km}^{2}$. Most of the area lays at elevations of lower than $600 \mathrm{~m}$ whilst in the northeast its watershed boundary reaches an altitude of $1180 \mathrm{~m}$. The mean altitude was calculated at $308.5 \mathrm{~m}$. The coastal part of this basin forms part of an extensive estuarine system that has an extension of $428 \mathrm{~km}^{2}$. The sediment discharges of Gallikos, Axios, Aliakmon and Loudias rivers have resulted in the addition of a coastal plain that covers an area of $1500 \mathrm{~km}^{2}$ [9].

The Gallikos River is of high importance due to the proximity of the basin to Thessaloniki, the second largest city of Greece. The total length of the river is about $73 \mathrm{~km}$. It is characterized by shallow water depths, the gradient of which is, of course, relatively high. Consequently, the river flow characteristics resemble both a river and a torrent. This may also be concluded by the seasonality and peak discharge events that characterize its flow regime. Maximum discharges occur during summer and have been estimated at $700 \mathrm{~m}^{3} / \mathrm{s}$ [10]. The predominant flow direction is from NNE towards SSW and the basin comprises four sub-basins that are discharged by the four main tributaries of the river. The high density of the basin's hydrologic network suggests a high runoff percentage 
compared to infiltration, which essentially suggests that the geological formations of the basin are impervious.

Figure 1. Topographic map of the Gallikos River basin.

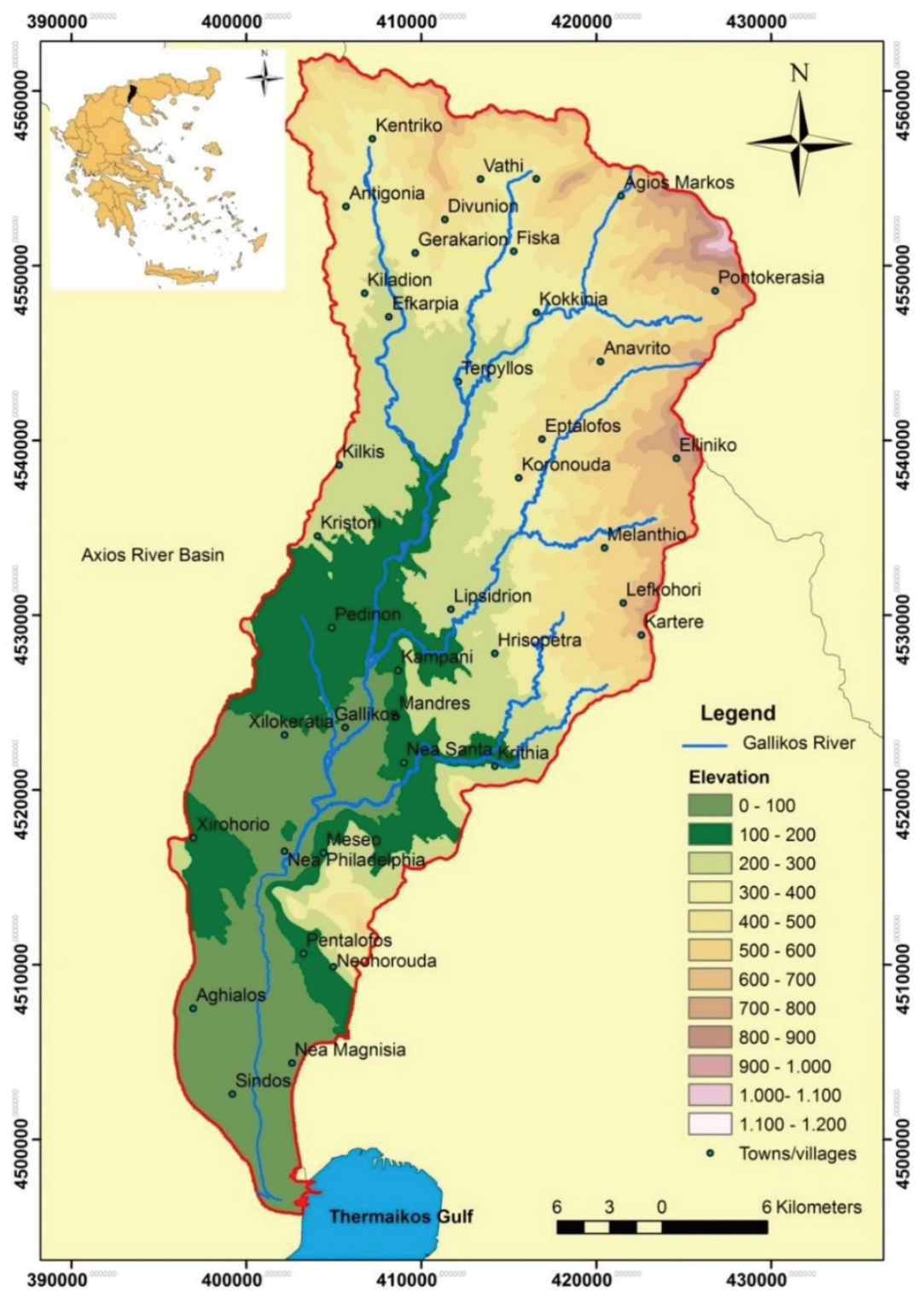

The mean annual precipitation and temperature over the basin is about $480 \mathrm{~mm}$ and $16.5{ }^{\circ} \mathrm{C}$ respectively [10] and the mean annual surface runoff is about $45 \times 10^{6} \mathrm{~m}^{3}$ as measured at its exit at Nea Philadelphia monitoring station over the period of 2005-2006. Although the flow of the Gallikos River is seasonal, at Nea Philadelphia the river exhibits a permanent flow, except for very dry years. According to Poulos and Chronis [11], the annual load of suspended solids is $4 \mathrm{t} / \mathrm{km}^{2}$ and the annual load of diluted solids is $0.51 \times 10^{3} \mathrm{t} / \mathrm{km}^{2}$. A denudation rate of $320 \mathrm{~m}^{3} / \mathrm{km}^{2}$ has been estimated by Eumorphopoulos [12].

The vertical continental moves to which the wider region has been subjected during the recent geological times, along with the considerable sedimentation processes of the rivers Axios, Aliakmonas, Gallikos and Loudias, have resulted in the rapid withdrawal of the sea and the creation of new land 
thereby delimiting the Gulf of Thermaikos [13]. Based on existing data, Konstandinidis [10] also suggests withdrawal of the sea in favor of the land during historical times and up to date.

Geodetic surveys carried out at the coastal part of the basin (Kalochori) over the period of 1992-1998 reveal subsidence phenomena in the order of 2.8-5 cm/year and an overall subsidence of $2.5 \mathrm{~m}$ for a time period of thirty years [9]. These phenomena are attributed to overpumping of groundwater and to the ongoing compaction and solidification of the contemporary loose silty-clay deposits and the quick sand phenomenon that occur along the coastal environment of the system $[14,15]$.

Geologically, the Gallikos basin is filled with Quaternary and Tertiary sediments. Quaternary sediments consist of fluviolacustrine deposits, whereas Tertiary sediments essentially are comprised of Neogene marls. The total thickness of these deposits, which form the main aquifer system of the basin, is up to $160 \mathrm{~m}$ at the downstream flat parts of the basin and has an average of about $32.5 \mathrm{~m}$. They thin out progressively towards the upstream northern part of the basin, which is bounded by the bedrock alpine formations. The bedrock of the basin is formed of argillaceous schists, limestones to dolimites, quartzites and gneiss [16-18].

\subsection{Socio Economic Features}

In the catchment area there is a spatial differentiation regarding the economic activities. Agricultural activities and livestock are the main occupation of the majority of the inhabitants, especially at the areas along the Gallikos River. The industrial sector is developed in two zones close to the main urban areas. The industrial zone, south of Kilkis city, consists of small and medium size enterprises, while the industrial zone of Sindos town consists of large-scale enterprises since it is part of the industrial zone of the broader metropolitan area of Thessaloniki. The areas of service provision, transport and trade are also developed near major urban areas. A domestic effluent treatment plant operates in the areas of Sindos (Figure 1) and Kilkis. Despite the existence of the aforementioned operating treatment plants, the Gallikos River still remains receptor of untreated sewages from small size settlements that are located along the riverbed. The river is also affected by agricultural and industrial effluents.

\subsection{DPSIR Analysis Approach}

The widely used Driver-Pressure-State-Impact-Response (DPSIR) analytical framework has been adapted to the definitions given in Groundwater Risk Assessment; Technical report developed on the basis of the Guidance Document 2004, No. 3 [19]; as follows:

- Driver: An anthropogenic activity that may have an environmental effect. Drivers produce a series of pressures and are quantified by aggregated data, e.g., population density, hectares of irrigated land, industrial units etc.

- Pressure: The direct effect of the driver. Pressures form the manifestation of the effects the Driving Forces have on the water bodies. Pressures degrade the State of water bodies and have an Impact on them as well as on humans. Increased irrigation-industrial- 
domestic demands, precipitation decrease, point or non-point source pollution could be considered as pressures.

- State: The condition of the water body resulting from both natural and anthropogenic factors (e.g. chemical or ecological characteristics, water quantity, etc.).

- Impact: The effect upon human well being.

- Response: The measures taken to improve the state of the water body.

The DPSIR framework for Gallikos river basin is illustratively and briefly presented in Figure 2. Despite having been frequently employed in the environmental domain, DPSIR has been criticized for several shortcomings [20,21]. The main criticism is that the framework creates stable indicators and cannot take into account the dynamics of the system. Another criticism related to the aforementioned is that the framework cannot capture trends, but it analyses them by repeating the same indicators at regular intervals [20,22]. Finally critics argue that it suggests linear unidirectional causal chains of environmental problems and that it provides unclear cause-effect relationships of complex environmental problems [20,22]. The response to criticism is that the focus should be on the links between the nodes of DPSIR by applying specific socio-economic and natural science based models so as to understand the cause-effect dynamics [20,23].

The implementation of the DPSIR framework in a GIS for the Gallikos River basin is based on water resource quality and quantity data. The selected key indicators for the monitoring of the water resources quality are some easily measured physicochemical parameters. These parameters are related to the anthropogenic activities that are in accordance with the socio-economic processes in the area. The changes in measured quantity parameters such as groundwater level or river discharge can be attributed to climate changes in a long-term examination or to anthropogenic activities in a short-term examination. For the Gallikos River basin, the recorded changes in quantity parameters are in line with the increased anthropogenic activities during recent years. The application of the DPSIR framework in a GIS environment allows the spatial visualization and better integration of the various indicators [7]. For example, the GIS application gives the opportunity to depict in the same picture the areas of intense industrial or agricultural activities (cause) and the spatial distribution of the surface or groundwater resources that show an excess of the admissible values (impact) of the associated pollutants (nitrate from agriculture, sodium and potassium form industrial activities in the Gallikos River basin). The GIS environment is dynamic since it enables the stakeholders to adapt the available information according to the problem they have to confront at that time. The great advantage of the GIS is that it can lead to a clear relationship between cause (driving forces), pressure (environmental problem), and impacts, which is a very useful tool for the planning of the appropriate measures for sustainability by the water resources decision makers. 
Figure 2. A generic DPSIR framework for water resources of Gallikos River basin (illustrated by the authors based on the framework of Kristensen [24]).

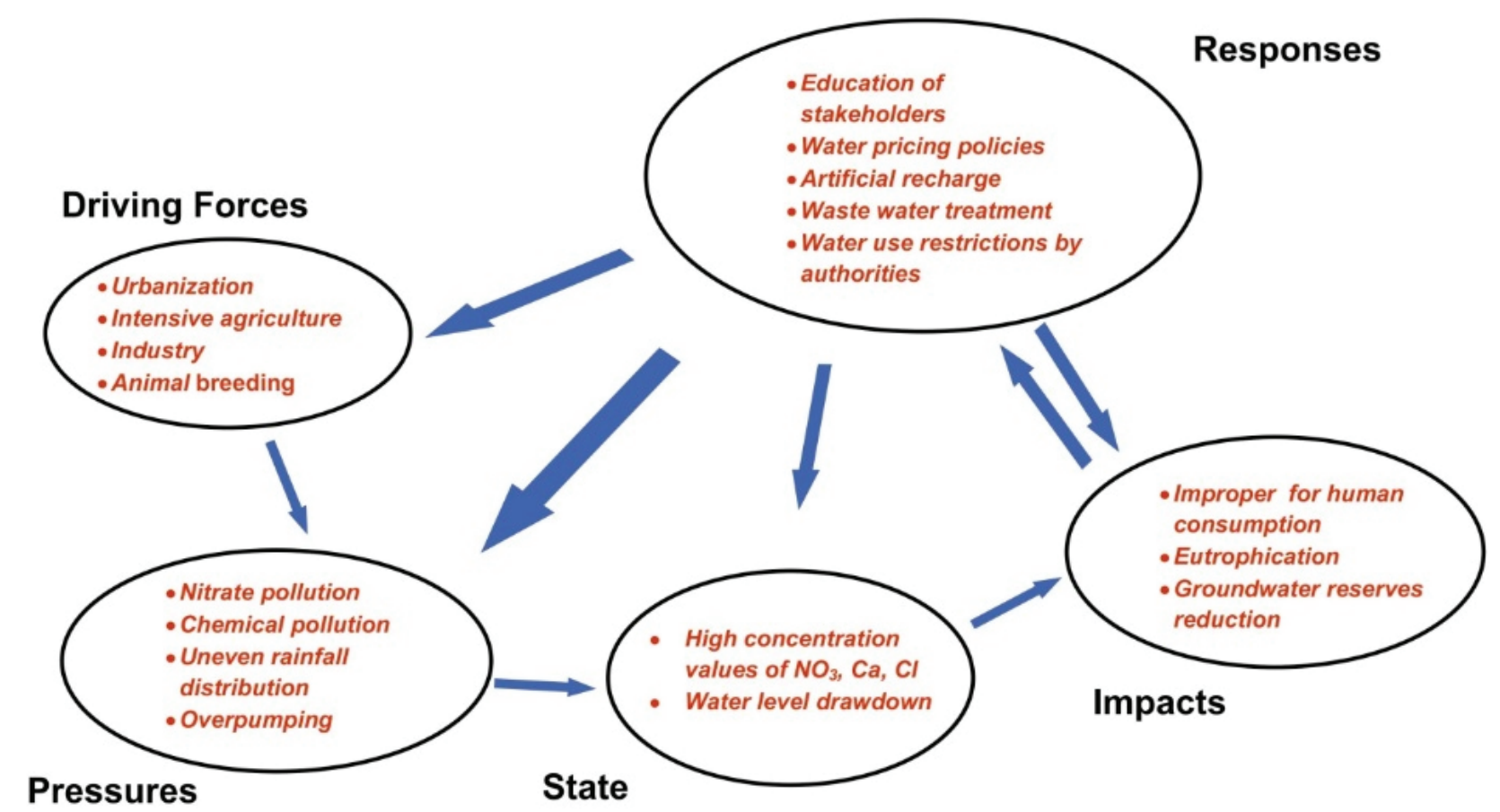

\subsection{Data Collection, Sampling, Methodology}

In the framework of a supporting new doctoral researchers program (project name: ECHEDOROS) funded by the General Secretariat for Research and Technology, data concerning the hydrogeological investigation of the Gallikos River basin were collected for the time period of 2004-2006. Surface and groundwater samples were collected two times a year (in April and September). These periods represent the highest and lowest ground and surface water levels, respectively, and are thus considered to be the most appropriate to study possible hydrochemical variations. The sampling points were chosen in order to have an adequate spatial distribution. Samples were shipped chilled to the laboratory in an appropriate isothermal, box. Samples collected for determination of heavy metals were filtered in situ through $45 \mu \mathrm{m}$ filters and treated with $\mathrm{HNO}_{3}$. In situ measurements of pH, Electrical Conductivity (E.C.), Dissolved Oxygen (D.O.) and water temperature were also taken. Samples were analyzed in the Laboratory of the Land Reclamation Institute (National Agricultural Research Foundation, Thessaloniki, Greece), and the following parameters were determined: $\mathrm{Ca}$, $\mathrm{Mg}, \mathrm{Na}, \mathrm{K}, \mathrm{Cl}, \mathrm{NO}_{3}, \mathrm{NO}_{2}, \mathrm{SO}_{4}, \mathrm{~B}, \mathrm{HCO}_{3}, \mathrm{Fe}, \mathrm{Mn}, \mathrm{Cu}, \mathrm{Pb}, \mathrm{Cd}, \mathrm{Zn}$. Meteorological data were derived from the existing operating meteorological stations. In addition, the Laboratory of Engineering Geology and Hydrogeology, installed three extra rain gauges to complete the network. River discharge measurements were carried out at regular intervals at the upper part of the basin, near the Nea Philadelphia village. Data concerning cultivated land in the region were obtained from the appropriate local authorities.

Evaluation of hydrochemical results, i.e., water quality examination, was performed in line with the WFD principles and the methodological approach adopted by Greece in the characterization of groundwater bodies [25], where in absence of specific ecological indices and/or threshold values, the 
maximum admissible concentrations (MAC) for water intended for human consumption have been adopted. This approach, which is also adopted by other Member States, is justified by the fact that in most of the basins a multitude of water uses occurs, amongst which domestic use is considered the most sensitive due to the final receptor. In fact, based on the adopted methodology, as a threshold of $75 \%$ of the MAC value is adopted $\mathrm{n}$ an attempt to set strict environmental quality criteria and also to account for the lack of comprehensive modeling tools that influence projections of future evolution of water quality. With regards to surface water bodies, the same principles were applied, with the exception of $\mathrm{NO}_{3}$ concentrations, whereby the threshold concentration of $15 \mathrm{mg} / \mathrm{L}$ was adopted. This is $75 \%$ of $20 \mathrm{mg} / \mathrm{L}$, which is one of the concentration levels above which eutrophication phenomena occur. This particular concentration refers to wintertime average values. According to other researchers, this value should be decreased to $10 \mathrm{mg} / \mathrm{L}$. This approach is also incorporated in the national water resources management plans and is also followed by several Member States in the framework of the Nitrates Directive. In principle, characterization in the framework of aforementioned approach is based on the P90 values, except for the cases where data are too sparse or inadequate to perform such an analysis. In such cases, the median or mean approach is preferred. This is especially the case for surface waters for which winter-time average values are not readily available.

Prior to all the aforementioned works that were carried out, all the available data from the databases of local authorities, public services and relevant references had been collected. The evaluation of these data was used to identify the "driving forces" and "pressures" of the Gallikos River basin. Data obtained from the above-described monitoring program were used to illustrate the "state" of the water resources. From the analysis of the three first parameters of the DPSIR methodology it is possible to identify the "impacts" and to propose a "response" to the appropriate set of measurements for water resources management in accordance with the WDF.

\section{Results}

\subsection{Driving Forces}

Urbanization, intensive agriculture, industry - especially along the coastal part of the basin - and to a minor extent animal breeding along the mountainous region, form the main driving forces of the study area (Figure 3). Quantification of driving forces is based on population density and the spatial distribution of agricultural land, industry and animal breeding units. 
Figure 3. Land cover in the Gallikos River basin (illustrated by the authors, based on available online digital archives [26]).

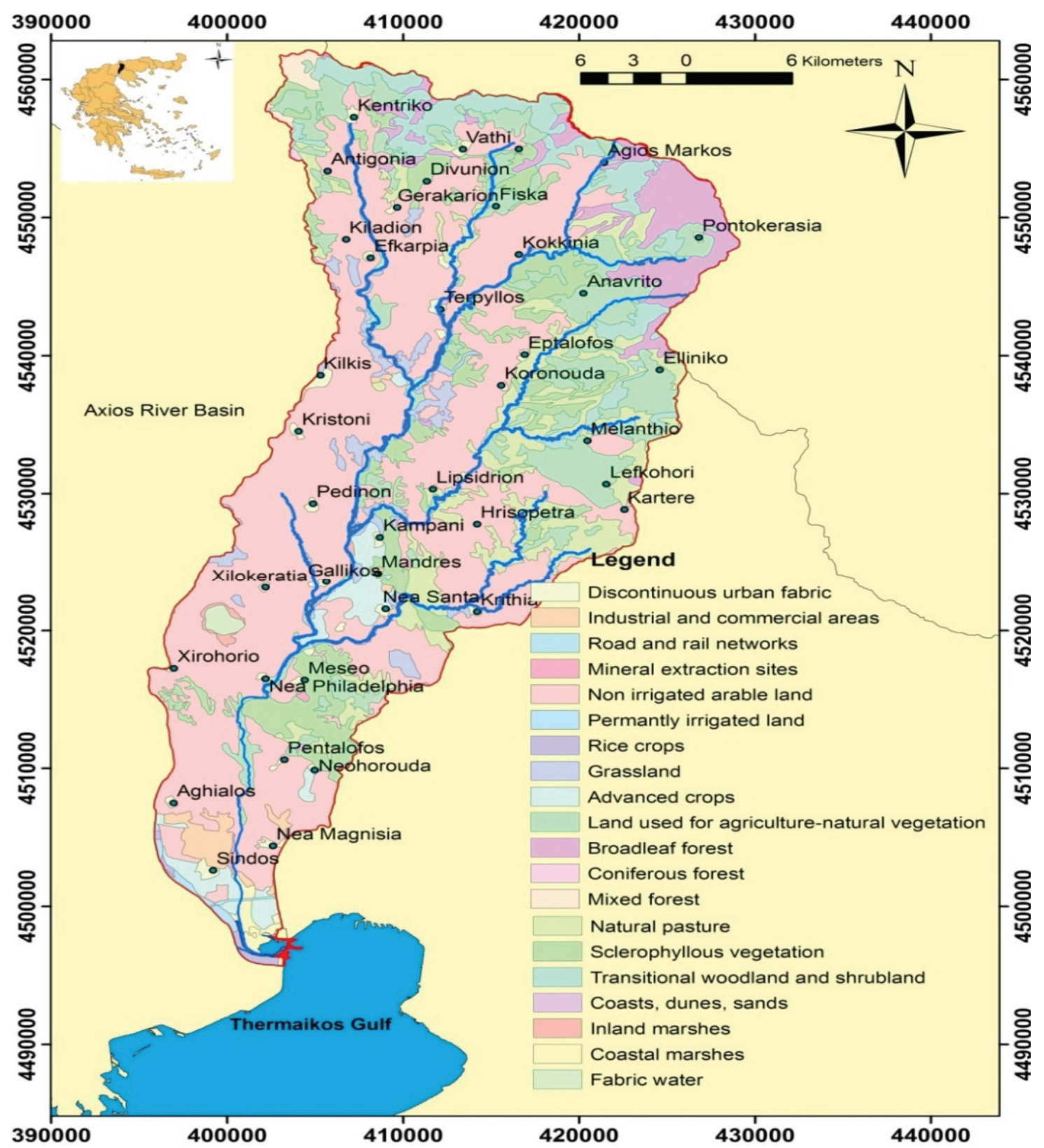

The Municipality of Kilkis, which is the capital city of the homonymous Prefecture, has by far the largest population amongst the Municipalities of the study area. According to the National Statistical Service of Greece, over the period of 2001-2011, the population exhibited an increasing trend (6.42\%). The population of the basin was 55,359 residents in 2001 and reached 58,915 in 2011 [27]. In the area of Sindos, population growth is substantial and follows a considerable expansion of urban development, both of which are attributed to the establishment of the Technological Educational Institute of Thessaloniki. Population density varies from 58.41 inhabitants $/ \mathrm{km}^{2}$ in the lowland area, to 10.22 inhabitants $/ \mathrm{km}^{2}$ in the mountainous part of the studied region. Total cultivated land is 14,448 stremmas (i.e., ca 1448.8 ha) $57.6 \%$ of which is irrigated. Arable land (corn, tobacco, 
cotton, sunflower) accounts for most of the cultivated land and is fully irrigated. Cereals for forage, trees (mainly almonds and oil producing olives) and vegetables are also cultivated (Figure 4).

Figure 4. Irrigated land (in stremmas, 1 ha $=10$ stremmas) in the upper part of the Gallikos River basin.

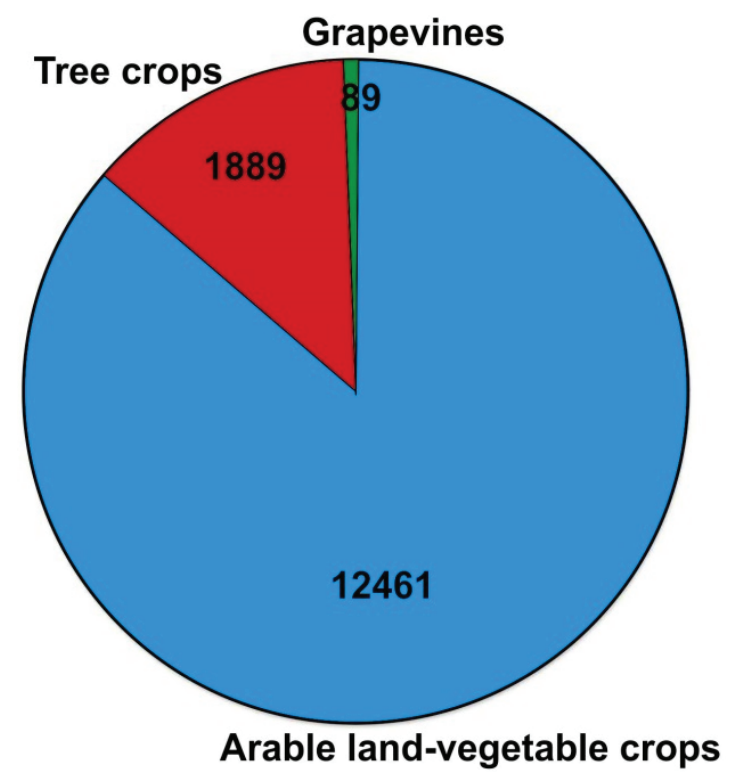

Stabled and non-stabled livestock is a very important driving force since the Kilkis Prefecture is one of the most productive in this field. More than 100 industries operate within the boundaries of the Gallikos River basin in various sectors like food, chemical products, plastics, paints and varnishes, production and processing of iron and steel, production of oil refining products, textile dyeing, etc. There are 14 industries [26], which are mainly located in the southern part of the basin, that lie within the requirements of Seveso Directive whilst the number rises to approximately 30 if those located in short distances are included. Mines and quarries exist as well. In the basin there are many sand extraction sites, without any control in most of the cases. Many of the villages do not have sewage a network or wastewater treatment plants, and this forms another very important driving force for the area.

\subsection{Pressures}

Thoughtless use of fertilizers - especially in the framework of documented and practiced intensive agriculture - leads to nitrate pollution and elevation of phosphorus compounds in both surface and ground waters, since there is no direct control by any state agency of the used amounts of fertilizers and pesticides. The total load of nitrogen and phosphorous from agricultural activities that pollute surface waters is estimated to be $2049 \mathrm{tn} / \mathrm{yr}$ and $25.6 \mathrm{tn} / \mathrm{yr}$, respectively. Superficial receptors receive an annual load of approximately 806.6 th of nitrogen and 102.5 th of phosphorous from stabled and non-stabled livestock [21]. The urban effluent that ends up in superficial receptors consists of $1240 \mathrm{tn} / \mathrm{y}$ of nitrogen and $199 \mathrm{tn} / \mathrm{yr}$ of phosphorous.

Water demands for irrigation combined with uneven rainfall distribution throughout the year is also a major pressure related to agricultural activities. The overpumping of boreholes leads to 
groundwater level drawdown resulting in a decrease of reserves. Pressure due to the industrial activities is expressed in terms of chemical pollution of predominantly surface waters, but also of ground waters due to existing hydraulic interactions. The majority of the industries do not have wastewater treatment plants and the river and aquifers are the direct receptors of their effluents. However, industries are not wide spread within the study area. They are mainly located at the south part of the basin and the area near the city of Kilkis. The most important identified pollutants in this area were $\mathrm{Na}^{+}$and $\mathrm{Cl}^{-}$ions from the textile dyeing industries.

\subsection{State}

The current state of surface and ground water is based on sampling, groundwater level measurements, surface water discharge measurements and chemical analyses and is discussed in details by Mattas et al. [28,29]. A brief description of the surface and ground water state is provided in the following paragraphs.

\subsubsection{Surface Water Quality}

The water quality of the Gallikos River is influenced by the geological structure, agricultural activities as well as the untreated waste effluent that is discharged from the city of Kilkis and of numerous villages and industrial units spread along the river basin. Hydrochemical data from 49 samples were used in order to assess the water quality (Table 1) and estimate the nutrient inputs from the river to the Thermaikos Gulf. Aforementioned samples were collected from fourteen sites (Figure 5) of the hydrographic network during the period of 2004-2005. Four sampling campaigns were conducted for the wet (April-May) and dry periods (September-October). Dry period sampling was not always possible, since some of them had already dried out.

Table 1. Summary statistics for concentrations of surface water samples.

\begin{tabular}{ccccc}
\hline Parameters & Minimum & Maximum & Mean value & Standard deviation \\
\hline $\mathrm{pH}$ & 7.42 & 9.01 & 8.21 & 0.39 \\
E.C. $\left(\mu \mathrm{S} / \mathrm{cm}\right.$ at $\left.25{ }^{\circ} \mathrm{C}\right)$ & 210.0 & 1760.0 & 768.0 & 313.0 \\
$\mathrm{~T}\left({ }^{\circ} \mathrm{C}\right)$ & 6.2 & 26.0 & 14.17 & 5.92 \\
$\mathrm{Ca}^{2+}(\mathrm{mg} / \mathrm{L})$ & 24.0 & 136.3 & 72.11 & 23.12 \\
$\mathrm{Mg}^{2+}(\mathrm{mg} / \mathrm{L})$ & 18.0 & 68.0 & 38.93 & 11.79 \\
$\mathrm{Na}^{+}(\mathrm{mg} / \mathrm{L})$ & 17.0 & 220.0 & 50.0 & 40.0 \\
$\mathrm{~K}^{+}(\mathrm{mg} / \mathrm{L})$ & 2.0 & 16.0 & 4.86 & 2.85 \\
$\mathrm{HCO}_{3}^{-}(\mathrm{mg} / \mathrm{L})$ & 214.0 & 536.8 & 329.88 & 69.42 \\
$\mathrm{Cl}^{-}(\mathrm{mg} / \mathrm{L})$ & 17.8 & 332.4 & 67.81 & 74.47 \\
$\mathrm{SO}_{4}{ }^{-2}(\mathrm{mg} / \mathrm{L})$ & 11.1 & 135.6 & 51.65 & 30.92 \\
$\mathrm{NO}_{3}{ }^{-}(\mathrm{mg} / \mathrm{L})$ & 0.5 & 28.55 & 10.03 & 7.04 \\
\hline
\end{tabular}

Surface water temperature ranges from 6.2 to $26{ }^{\circ} \mathrm{C}$, depending on atmospheric temperature fluctuations. Electrical conductivity ranges between 210 and $1760 \mu \mathrm{S} / \mathrm{cm}$; the highest values are recorded at the Nea Philadelphia sampling point and are attributed to anthropogenic pollution. In general, the composition of the surface water for cations is $\mathrm{Ca}^{2+}>\mathrm{Mg}^{2+}>\mathrm{Na}^{+}>\mathrm{K}^{+}$. The composition of the surface water for anions is $\mathrm{HCO}_{3}^{-}>\mathrm{Cl}^{-}$or $\mathrm{SO}_{4}{ }^{2-}>\mathrm{NO}_{3}{ }^{-}$. 
Iron $(\mathrm{Fe})$ and manganese $(\mathrm{Mn})$ concentrations are below the detection limit (d.1.), which is less than 0.1 and $0.03 \mathrm{mg} / \mathrm{L}$, respectively, in most of the examined samples. Likewise, the zinc (Zn) concentration in the majority of water samples is under $0.05 \mathrm{mg} / \mathrm{L}$, which is the d.1.; whereas a maximum value of $0.24 \mathrm{mg} / \mathrm{L}$ is recorded in a sample from a location adjacent to an industrial area.

Dissolved oxygen concentrations are reasonable for potable use, apart from a sampling point near Kolhida village (EN9 sampling point, Figure 5), where the minimum value of $0.35 \mathrm{mg} / \mathrm{L}$ is recorded. The same situation exists for the oxygen saturation, which ranges from $4 \%$ to $182 \%$.

Figure 5. Surface water sampling points.

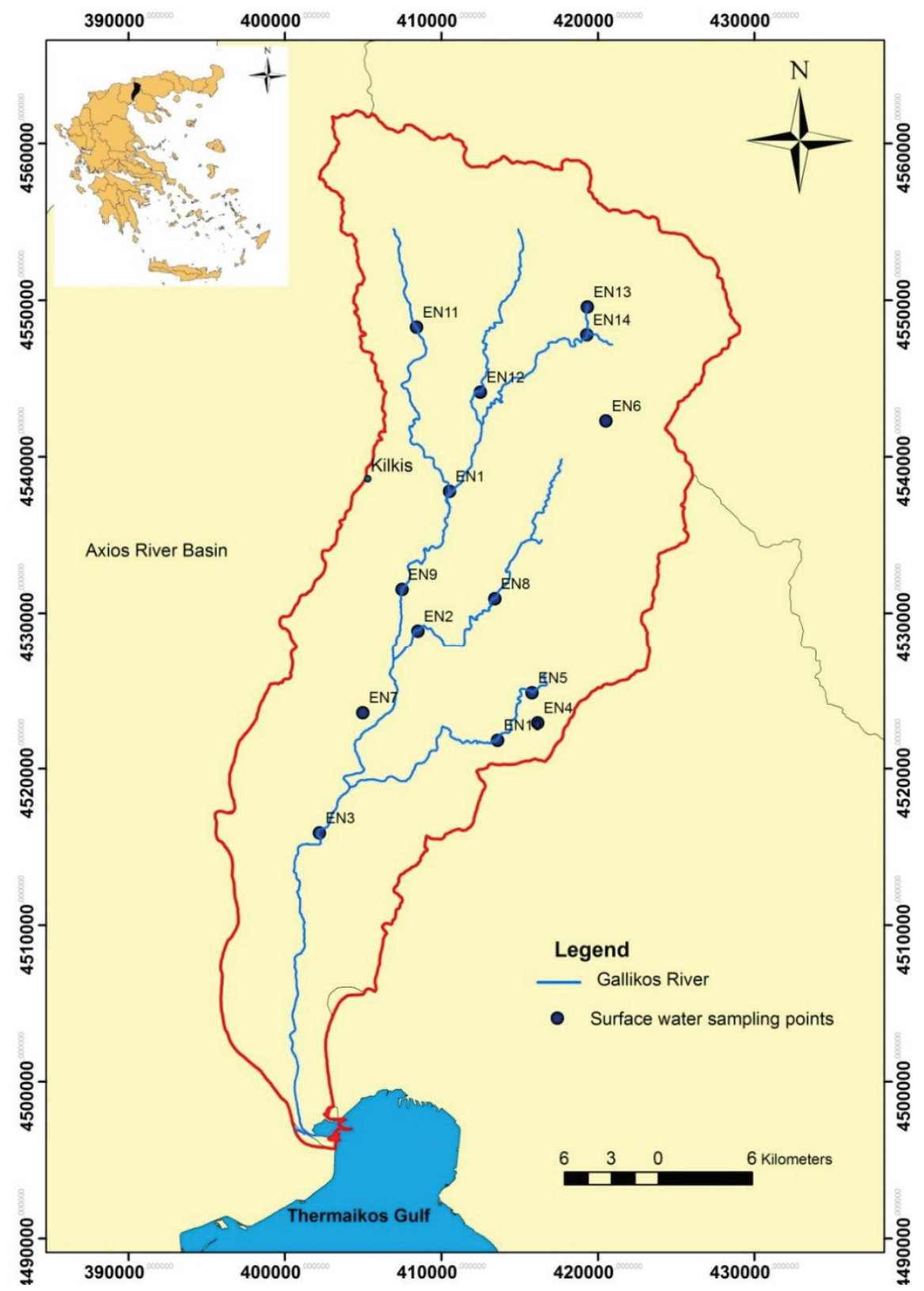

Oxygen content of the surface water depends mainly on the surface water temperature, but is also highly dependable on its pollution loads. Significant temporal and spatial variations of the chemical oxygen demand COD (from 0 to $87.1 \mathrm{mg} / \mathrm{L}$ ) are noted, the highest values are recorded in the Nea Philadelphia area (EN3 sampling point). The majority of the samples have biochemical oxygen 
demand (BOD5) values under d.1., which is $2.4-3 \mathrm{mg} / \mathrm{L}$, depending on the sample quantity. Higher values $(8 \mathrm{mg} / \mathrm{L})$ are recorded at a sampling point near Kolhida village (EN9). In general, as river discharge decreases, both $\mathrm{BOD}_{5}$ and COD values increase.

River water seepage is known to considerably contribute to groundwater recharge of aquifers of the Gallikos River basin. Thus, surface water quality affects groundwater quality of the aquifer system that is formed in the basin, which is the main source of potable water [29]. Eutrophication has been recorded in the Thermaikos Gulf, and this is the major problem that requires management action [6].

\subsubsection{Surface Water Discharge}

The mean annual discharge of the Gallikos River at the Nea Philadelphia station over the period of 2004-2006 is $45 \mathrm{Mm}^{3}$. Based on the analysis of monitored discharge data over this period (Figure 6), it becomes apparent that the flow regime is not regular throughout the year. On the contrary, discharge exhibits distinctive temporal variations that resemble a torrential character. Lowest discharge rates are exhibited during the dry season, whilst peak discharges are normally exhibited during spring time. In the past years, several flood discharge events have occurred, the most extreme of which being the one of 18 June 2004, which resulted in extensive damage to infrastructure, including the destruction of the monitoring station.

Figure 6. Mean monthly discharge of Gallikos River for period 2004-2006.

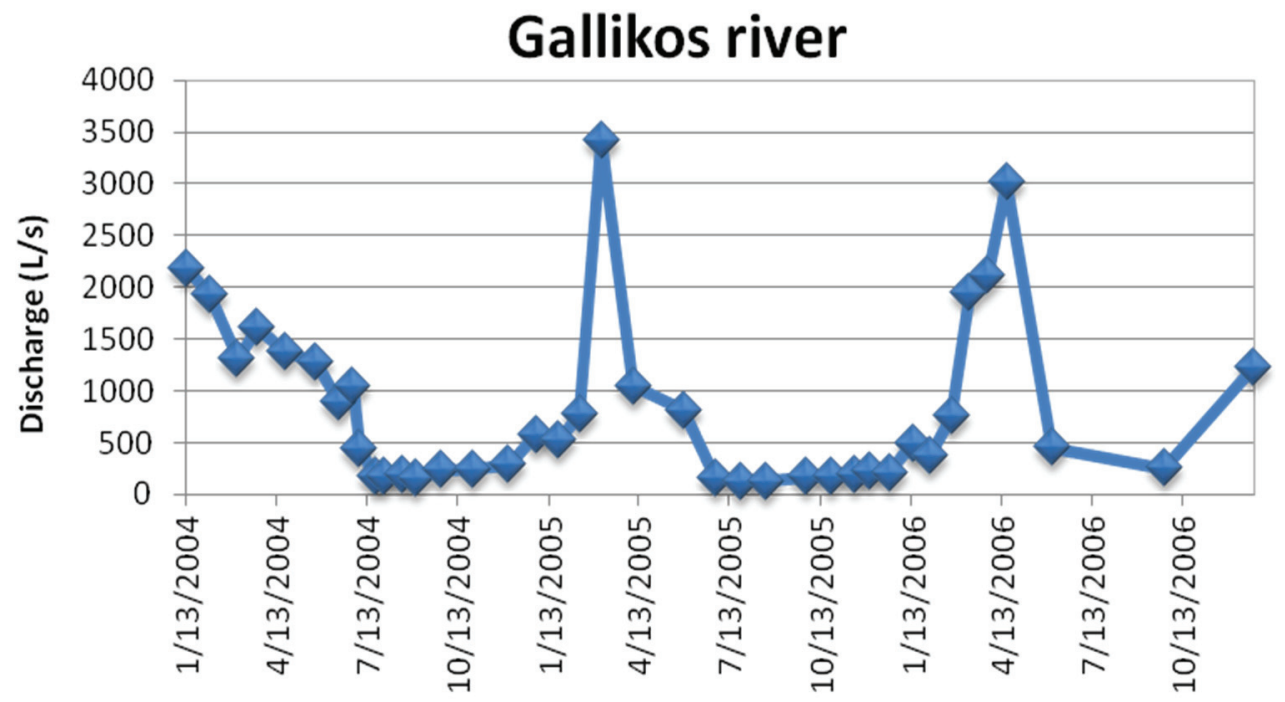

Over the period of 2004-2006, the minimum and maximum recorded discharge rates were $0.13 \mathrm{~m}^{3} / \mathrm{s}$ and $3.42 \mathrm{~m}^{3} / \mathrm{s}$, respectively. Due to the documented hydraulic relationship between the Gallikos River sediments and the underlying aquifer system, surface runoff contributes significantly to groundwater balance, and this is the main reason that domestic water needs of the city of Kilkis are covered by a well field located within the fluvial deposits of the Gallikos River, the same is true for the well field that operated until recently for the domestic needs of the metropolitan area of Thessaloniki. Part of the summer-time base flow is used for the irrigation of cultivations along the river course. 
Numerous springs of low potential emerge that discharge from the weathered zone of the crystalline rocks. Average discharge rates of these springs range between 5 and $30 \mathrm{~m}^{3} /$ day, according to a recent study conducted in the region [30]. Several springs emerge at the contact of the karstified limestones with the crystalline rocks, and according to the same study estimated discharge averages to $0.5-3 \mathrm{~m}^{3} / \mathrm{h}$. Spring water serves as a means for partial coverage of local domestic and animal breeding needs.

\subsubsection{Groundwater Quality}

The main aquifer of the basin is formed in the permeable sediments (Quaternary deposits), whilst the karstified carbonate rocks are also considered hydrogeologically important. On the contrary, the crystalline rocks only play a secondary role to regional water resources. The spatial distribution of the three identified aquifers of the basin is illustrated in Figure 7.

Results of 34 chemical analyses from representative samples of the three aquifer systems collected during the wet and dry periods of 2005 are presented in Table 2 in order to outline the chemical characteristics of each aquifer. These samples were considered as representative because-according to their lithological profiles - they capture water from one aquifer and not a complex of aquifers. During the field survey that was conducted in the time period of 2004-2005, a much greater number of the samples was collected. The following conclusions can be drawn.

Table 2. Summary statistics for concentrations of groundwater samples (min-max and mean value) from 34 samples.

\begin{tabular}{cccc}
\hline Parameters & $\begin{array}{c}\text { Aquifer of permeable } \\
\text { sediments }\end{array}$ & Karst aquifer & $\begin{array}{c}\text { Aquifer of } \\
\text { crystalline rocks }\end{array}$ \\
\hline $\mathrm{pH}$ & $(6.24-8.00) 7.01$ & $(7.29-7.89) 7.64$ & $(6.56-7.82) 7.4$ \\
$\mathrm{E} . \mathrm{C} .\left(\mu \mathrm{SS} / \mathrm{cm}\right.$ at $\left.25{ }^{\circ} \mathrm{C}\right)$ & $(786-3810) 1873.9$ & $(447-790) 651.85$ & $(282-1220) 756.55$ \\
$\mathrm{Ca}^{2+}(\mathrm{mg} / \mathrm{L})$ & $(72.1-308.6) 167.62$ & $(76.3-96) 87.15$ & $(60.1-138) 75.82$ \\
$\mathrm{Mg}^{2+}(\mathrm{mg} / \mathrm{L})$ & $(32-116.7) 60.65$ & $(19.5-31.6) 26.05$ & $(16-87.6) 53$ \\
$\mathrm{Na}^{+}(\mathrm{mg} / \mathrm{L})$ & $(31-850) 158.17$ & $(15-61) 28.8$ & $(15-73) 50.22$ \\
$\mathrm{~K}^{+}(\mathrm{mg} / \mathrm{L})$ & $(1.9-28) 7.26$ & $(1.2-22) 9.61$ & $(6.3-45) 15.51$ \\
$\mathrm{HCO}^{-}(\mathrm{mg} / \mathrm{L})$ & $(280.7-524.8) 429.9$ & $(305.1-366.1) 341.7$ & $(122-561.4) 345.77$ \\
$\mathrm{Cl}^{-}(\mathrm{mg} / \mathrm{L})$ & $(56.7-1519.4) 342.8$ & $(21.3-63.8) 41.04$ & $(24.8-99.3) 67.76$ \\
$\mathrm{SO}_{4}{ }^{2-}(\mathrm{mg} / \mathrm{L})$ & $(0-530.7) 114.9$ & $(2.5-39) 19.85$ & $(18.5-145.4) 65.02$ \\
$\mathrm{NO}_{3}{ }^{-}(\mathrm{mg} / \mathrm{L})$ & $(0.7-88.3) 41.8$ & $(12.2-25.9) 18.2$ & $(0-52) 12.4$ \\
$\mathrm{Total} \mathrm{Hardness}(\mathrm{mg} / \mathrm{L} \mathrm{CaCO})$ & 667.6 & 324.6 & 407.9 \\
\hline
\end{tabular}

High E.C. values are recorded in the Quaternary deposits aquifer at sampling point, which is located in an agricultural and industrial area (Figure 8). The groundwater quality of the karst aquifer is better than the other aquifers. The $\mathrm{Ca}(\mathrm{Mg})-\mathrm{HCO}_{3}$ water type is the dominant type in the basin. Nitrate concentrations in excess of the threshold value of $37.5 \mathrm{mg} / \mathrm{L}$, which is $75 \%$ of the maximum admissible concentration of $50 \mathrm{mg} / \mathrm{L}$ set by the EU Council for drinking water, are documented on several occasions, especially in the shallow aquifer of the permeable sediments as is shown by the 
contours in Figure 8 that were drawn using the kriging method. Nitrate sources are agricultural activities and sewage effluent through seepage from septic tanks. Increased concentration values of $\mathrm{Na}^{+}$and $\mathrm{Cl}^{-}$due to human activities are recorded at the southern part of the basin (near Nea Philadelphia area). The maximum admissible values for $\mathrm{Na}^{+}$and $\mathrm{Cl}^{-}$are $200 \mathrm{mg} / \mathrm{L}$ and $250 \mathrm{mg} / \mathrm{L}$, respectively. The threshold value is $150 \mathrm{mg} / \mathrm{L}$ for $\mathrm{Na}^{+}$and $187.5 \mathrm{mg} / \mathrm{L}$ for $\mathrm{Cl}^{-}$. The increased values of the aforementioned parameters lead to degradation of water resources making them inappropriate for certain uses, such as human consumption or irrigation. During the sampling period (2004-2005) textile dyeing factories were in operation. As it is shown in Table 2, exceedance of the maximum admissible values was recorded in the aquifer of the permeable sediments. The karstic aquifer seems to be of quite good quality.

Figure 7. Grouped geological formations in the Gallikos River basin.

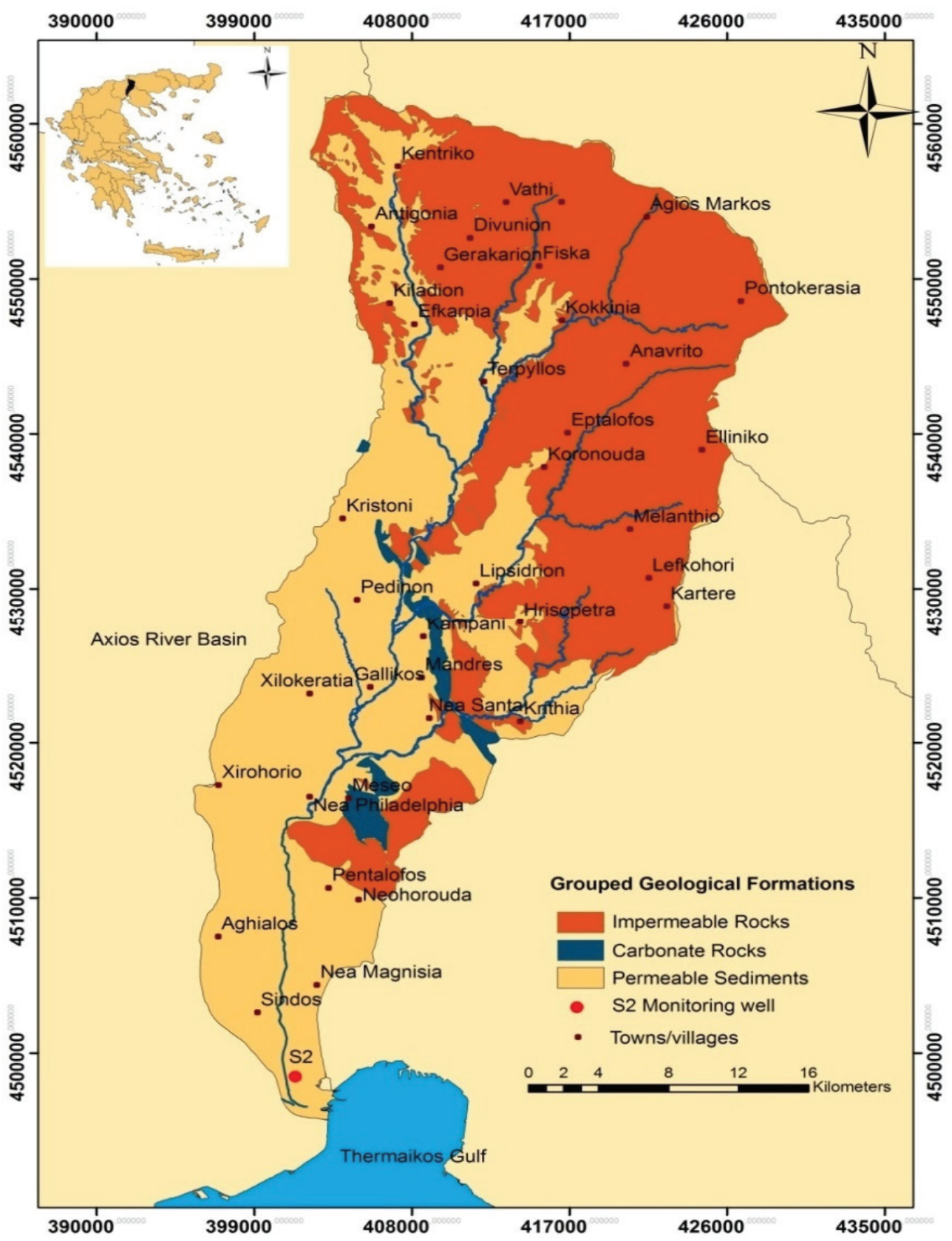


Figure 8. Spatial distribution of electrical conductivity, nitrates, sodium and chloride for the upper part of the Gallikos River basin.
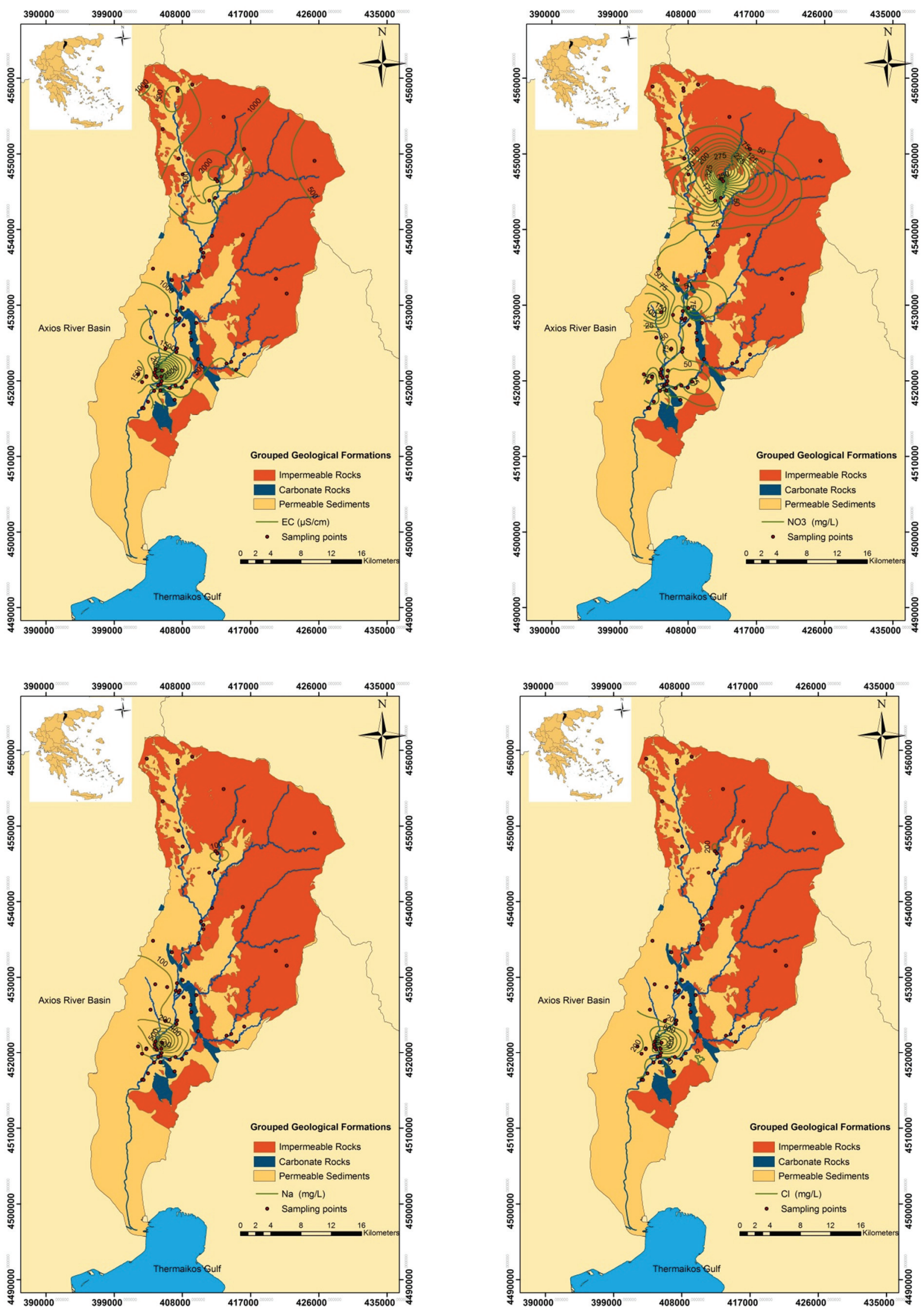
Groundwater is characterized by relatively low heavy metal concentrations. High concentrations of $\mathrm{Fe}$ and $\mathrm{Mn}$ are recorded in the crystalline rocks and are attributed to the lithological composition of the area. In some cases the values are over the maximum acceptable limit for drinking water, making the treatment of the water with the appropriate filters obligatory for the local authorities in order to meet the domestic needs.

The values of Dissolved Oxygen (D.O.) and Oxygen Saturation (\%), which were determined in situ, are obviously lower than in surface water, and in general, they decrease proportionally to the distance of the wells from the river course. It is therefore suggested that [25] the uncontrollable discharge of untreated domestic and industrial effluent into the river leads to groundwater quality deterioration due to infiltration of water of the Gallikos River basin into the aquifer systems.

\subsubsection{Groundwater Resources}

According to the available data from the field survey that was carried out during the time period 2004-2006 for the upper part of the Gallikos River basin (from the mountainous area to Nea Philadelphia village) the general characteristics of the main aquifers are described below:

\section{(1) Permeable Sediments Aquifer}

The alluvial aquifer, defined by permeable sediments is being exploited through numerous shallow boreholes and large diameter wells that have been constructed along the courses of the Gallikos River and its tributaries in order to cover irrigation demands and the domestic needs of the city of Kilkis. The preference of that particular zone lays on the deposition of essentially coarse fluvial deposits along the river courses, namely intercalations of sands, gravels, pebbles and clays. On the one hand, these deposits favor infiltration of precipitation and deep percolation of river water and on the other hand, they are characterized by high water storage capacities (high storativitiy) and ease of groundwater withdrawal (high transmissivity).

In hydrologically dry years, many of these boreholes become dry over the peak water demand irrigation period. Groundwater level fluctuation between the dry (October) and the wet period (April) of the hydrologic year 2004 was 0.08 to $3.41 \mathrm{~m}$. Similarly, for the year 2005, groundwater level fluctuation between the dry and the wet period was 0.13 to $8.84 \mathrm{~m}$. The continuous groundwater water level decline causes major problems for the financial sustainability of the farmers, because it deteriorates the amount of their production, it restricts the type of crop that they can cultivate and forces them to spend money to ensure new water resources, mainly by drilling new boreholes, which is linked with considerable costs.

A well field for domestic water supplies to the metropolitan area of Thessaloniki exists at the area of Sindos and has a nominal operation capacity of about $10.5 \times 10^{6} \mathrm{~m}^{3} /$ year. Nowadays it acts as an auxiliary reserve. Since pumping was discontinued from this well field in the year 2004, a considerable groundwater head recovery is documented from borehole S2, as illustrated in Figure 9.

The exploitable dynamic groundwater reserve of the studied system $\left(Q_{\text {ed }}\right)$ is calculated using the following equation:

$$
Q_{\mathrm{ed}}=A \times S_{y} \times l_{d}
$$


where, $A=$ effective area of groundwater recharge $\left(\mathrm{km}^{2}\right) ; S_{y}=$ specific yield; $l_{d}=$ average water level decline $(\mathrm{m})$ in dry period.

In the loose quaternary deposits aquifer that has an areal extent of $345 \mathrm{~km}^{2}$, the mean annual groundwater level fluctuation is $1.15 \mathrm{~m}$ (from April 2004 to April 2005 a decline trend is observed). Assuming an average value of specific yield $S_{y}=0.09$ [26,28], Equation (1) yields the annually exploitable groundwater reserves: $Q_{\mathrm{ed}}=345 \times 10^{6} \mathrm{~m}^{2} \times 0.09 \times 1.15 \mathrm{~m}=35,707,500 \mathrm{~m}^{3}=35.7 \mathrm{Mm}^{3}$.

Figure 9. Groundwater level fluctuation in the S2 monitoring well located in the Sindos area. Values represent absolute elevation relative to the mean sea level.

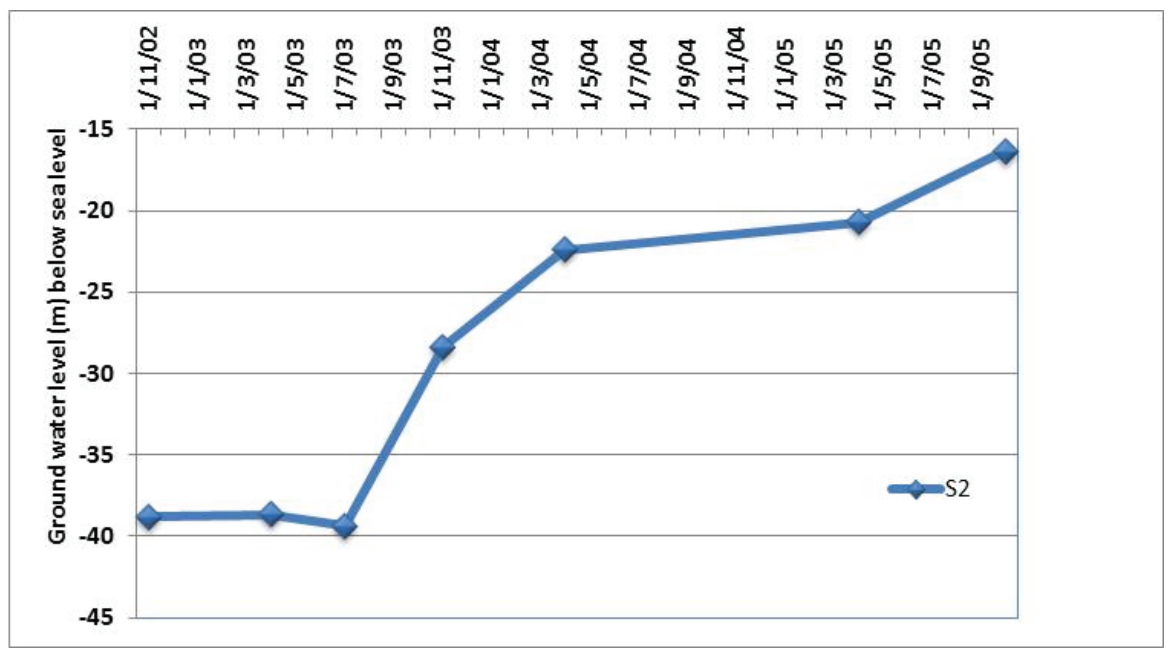

It should be mentioned that according to other studies the estimation of the annually exploitable groundwater reserves varies in respect to the available data and other assumptions. Kalousi [30] estimated the reserves to be approximately $4.4 \times 10^{6} \mathrm{~m}^{3}$ for a different time period and different active area but did not take into consideration the area of the Gallikos River bank deposits.

(2) Karstic Aquifer

It is characterized by considerable resources and the production rate of the wells ranges between 40 and $90 \mathrm{~m}^{3} / \mathrm{h}$ and the average value is $60 \mathrm{~m}^{3} / \mathrm{h}$. In the year 2004 , groundwater level fluctuation between the dry and the wet period was 0.18 to $5.95 \mathrm{~m}$. In the year 2005 groundwater level fluctuation between the dry and the wet period was 1.20 to $4.03 \mathrm{~m}$. The effective recharge area of the karst system was $22 \mathrm{~km}^{2}$. The average annual groundwater head decline is $1.88 \mathrm{~m}$ (from April 2004 to April 2005) and assuming an average specific yield value $S_{y}=0.1$ [31,32], the annually exploitable groundwater reserves were estimated to be (Equation 1): $Q_{\text {ed }}=22 \times 10^{6} \mathrm{~m}^{2} \times 0.1 \times 1.88 \mathrm{~m}=4,136,000 \mathrm{~m}^{3}=4.13 \mathrm{Mm}^{3}$.

The need to conserve the reserves of this aquifer is very important since it is the main supplier of water intended for human consumption.

(3) Aquifer of the Crystalline Rocks

The crystalline rocks that form the bedrock of the basin are normally classified as impermeable. Limited water reserves exist predominantly due to the secondary porosity of the weathered zone of 
these rocks. A limited number of large diameter wells and boreholes have been constructed to meet water demands mainly of the hilly and mountainous zones of the basin.

In the year 2004 groundwater level fluctuation between the dry and the wet period was 1.22 to $2.54 \mathrm{~m}$. In the year 2005 groundwater level fluctuation between the dry and the wet period was 0.30 to $3.21 \mathrm{~m}$. The effective recharge area was $505 \mathrm{~km}^{2}$ and the average annual groundwater head decline was $1 \mathrm{~m}$ (April 2004 to April 2005). Assuming an average specific yield value $S_{y}=0.04$ [26,28], the annually exploitable groundwater reserves were estimated to be (Equation 1): $Q_{\text {ed }}=505 \times 10^{6} \mathrm{~m}^{2} \times 0.04 \times 1 \mathrm{~m}=20,200,000 \mathrm{~m}^{3}=20.2 \mathrm{Mm}^{3}$.

The estimation of the reserves of the crystalline rock aquifer poses significant error possibility, since the hydrogeological behavior and hydraulic characteristics of these rocks differ from place to place and the aquifers are of local interest. Table 3 lists the main hydrogeological characteristics of the identified aquifers of the Gallikos River basin.

Table 3. Hydrogeological characteristics of the Gallikos River basin aquifers. $(\mathrm{A}=$ effective area, $D_{\mathrm{av}}=$ average thickness, $T=$ average transmissivity, $K=$ average hydraulic conductivity, $S_{y}=$ specific yield, $Q_{\text {ed }}=$ exploitable dynamic groundwater reserves).

\begin{tabular}{|c|c|c|}
\hline Aquifer & Geological formations & Hydraulic characteristics \\
\hline Permeable sediments aquifer & $\begin{array}{l}\text { Alluvial deposits; } \\
\text { Sand-gravel-clay }\end{array}$ & $\begin{array}{l}A=345 \mathrm{~km}^{2} \\
D_{\text {av }}=33 \mathrm{~m} \\
K=2.4 \times 10^{-4} \mathrm{~m} / \mathrm{s} \\
T=4 \times 10^{-3} \mathrm{~m}^{2} / \mathrm{s} \\
S_{y}=0.09 \\
Q_{\text {ed }}=54.33 \mathrm{Mm}^{3} / \text { year }\end{array}$ \\
\hline Karstic aquifer & Carbonate rocks & $\begin{array}{l}A=22 \mathrm{~km}^{2} \\
D_{\mathrm{av}}=76 \mathrm{~m} \\
K=2.4 \times 10^{-3} \mathrm{~m} / \mathrm{s} \\
T=2 \times 10^{-1} \mathrm{~m}^{2} / \mathrm{s} \\
S_{y}=0.1 \\
Q_{\text {ed }}=4.79 \mathrm{Mm}^{3} / \text { year }\end{array}$ \\
\hline Crystalline rocks aquifer & $\begin{array}{l}\text { Crystalline rocks; } \\
\text { Schists, quartzites, } \\
\text { gneiss }\end{array}$ & $\begin{array}{l}A=505 \mathrm{~km}^{2} \\
D_{\mathrm{av}}=230 \mathrm{~m} \\
K=4.8 \times 10^{-6} \mathrm{~m} / \mathrm{s} \\
T=4 \times 10^{-4} \mathrm{~m}^{2} / \mathrm{s} \\
S_{y}=0.04 \\
Q_{\text {ed }}=26.05 \mathrm{Mm}^{3} / \text { year }\end{array}$ \\
\hline
\end{tabular}

(4) Treated Domestic Effluent

The domestic effluent treatment plant of the metropolitan area of Thessaloniki operates in the area of Sindos and processes on average $200,000 \mathrm{~m}^{3}$ of effluent daily. Normally, processed water is discharged to the sea (Gulf of Thermaikos) through a submerged pipeline. In addition a treatment plant that handles the industrial effluent of the adjacent industrial zone of Thessaloniki exists, and treated water is discharged to the sea via an open gravitational canal. 
Long-term experiments have been conducted in the area, followed by extensive feasibility studies on the potential to utilize the treated domestic effluent of Thessaloniki to cover part of the irrigation needs of the homonymous basin where some 100,000 ha are being cultivated. The results of the long-term experiments clearly suggest that rational and controlled application of this valuable resource would alleviate the water shortage problem leading to excellent results regarding crop yields [33].

In addition it would lead to the actual utilization of a considerable volume of essentially usable water, whilst in parallel it would be beneficial to the plants due to the rich content in nutrients and the growers due to the reduced requirements for fertilization. Indeed, over the summer of 2007 the severe drought conditions that led to prolonged water shortage over the plant growing period were successfully faced with the systematic and carefully controlled use of this resource in irrigation.

\subsection{Impacts}

Impacts are essentially focused on the well-being of humans. Within the study area, water is mainly used for domestic needs and for animal breeding and agriculture, the latter being by far the biggest consumer. Intensive and thoughtless fertilization results in aquifer pollution and renders groundwater improper for human consumption. Several municipalities already suffer from this effect, especially south of Kilkis and north of Nea Philadelphia according to primary data that were collected by the authors. Another side effect of the intensive agricultural practices is the overpumping that has as a result the reduction of the reserves. An increase of the karstic aquifer exploitation has been recorded in the recent years in order to cover the human consumption needs of the settlements that are located in the flat area. In other cases, such as in municipal compartments at the N-NE part of the basin (e.g., villages of Antigonia, Vathi, Pontokerasia, Terpillos), groundwater is improper for human consumption due to elevated concentrations of $\mathrm{Fe}$ and $\mathrm{Mn}$ that are attributed to the geological structure of the region. Although in the framework of the management by local authorities the water is treated using the appropriate filters, it is not always possible to achieve the desired effect. Hence according to residents, the water is sometimes slightly colored, has a faint smell or sometimes stains household items. In some cases treatment is not possible and water transfer takes place between the villages via a local network.

Shifting from rain-fed to irrigated farming will increase irrigation water demands, part of which are currently met by surface water from the Gallikos River, although this might lead to increased pollution incidents. Groundwater overpumping in recent years has led to river water drying, as reported in newspaper articles and posts on the internet. Abandonment of water consuming-crops and the use of efficient irrigation methods, such as drip irrigation, can lead to considerable reduction of groundwater abstractions for irrigation purposes that account for the highest percentage of used water resources. Utilization of treated waste effluent can contribute significantly to the reduction of groundwater use. Uncontrolled disposal of industrial effluent in conjunction with discharge of treated domestic effluent from the Sindos plant into the Gallikos River is bound to worsen eutrophication of the Gulf of Thermaikos. 


\subsection{Responses}

Education of farmers on the implementation of European Laws and Directives on environmental protection and water resource management is a major issue. The importance of integrated water resources management is emphasized in the European Water Framework Directive (2000/60/EC), which, amongst other things, promotes new opportunities and view points for the sustainable management of water resources. A major objective is to reach a good quantitative and chemical status of groundwater within 15 years from implementation. In response to this directive, Greek authorities have taken suitable initiatives to harmonize the Greek water policy [34]. It is pointed out that Greece is ranked among the last countries in relation to the implementation of the directive and is quite behind schedule compared to other European countries [35].

A comprehensive Code for Good Agricultural Practice (COGAP) has been compiled on the basis of the elaborated action plan for the wider study region. It addresses the effective reduction of nitrate groundwater pollution of agricultural origin through reduction and appropriate application of fertilization. This Code [36], includes specific rules and instructions for the periods of time during which fertilization should not be applied, on the application methodologies and doses at which fertilizers should be applied depending on the soil type and conditions, and also on the crop and the irrigation method adopted. Moreover, it informs about specific fertilization plans per plot and crop, taking into account, amongst other things, nitrate background concentrations in the groundwater [37].

COGAP also informs about the use of logbooks for fertilizer handling and application and also for land management. In parallel, set-aside and crop rotation practices are proposed. As clearly examined and suggested in the action plan compiled for the vulnerable area of the Imathia Prefecture, which is located in Central Macedonia Region, proposed fertilization schemes may lead to a $30 \%-40 \%$ or even higher reduction in the applied fertilizers per year, whilst at the same time maintaining maximum crop yields [38]. It therefore follows that environmentally friendly policies and measures do not necessarily imply economic destruction of farmers, or at least shrinkage of their income. On the contrary, presented data suggests that environmentally friendly policies may also result in the increase of the farmers' income by cutting down their operational costs. In the study area, the proposed fertilization as calculated in the framework of the compiled action plan varies from 30 to $340 \mathrm{~kg} / \mathrm{ha} / \mathrm{year}$, with an average of $167 \mathrm{~kg} / \mathrm{ha} / \mathrm{year}$, i.e., a reduction from $62.5 \%$ to $3 \%$, or $22 \%$ on average, depending on crop type and soil conditions, compared to the discussed required amounts of nitrogen fertilization.

The idea of reduction and appropriate application of fertilization sounds good in theory, but if it is not accompanied by financial incentives that will ensure the income of the farmers, such as subsidies, then it cannot be realistic. In this sense, experience from other parts of the country where a reward scheme with a strong financial element was applied, has shown quite promising results: fertilizer application was reduced up to $40 \%$ or even $50 \%$ and yields were maintained at high levels. It has to be stressed that in those occasions appropriate fertilization doses and application methods were dictated to participating farmers. A specific legislative framework exists for the protection of the coastal estuarine part of the basin. According to the Joint Ministerial Decision 14874/3291 [39], the areas of Gallikos estuary and the Kalochori lagoon were designated as ecological important areas to be protected. 
The Thessaloniki water supply and sewerage company S.A. (E.Y.A.Th., Thessaloniki, Greece) has undertaken a major project supervised and funded by the Greek Ministry of Environment, Physical Planning and Public Works to assess the impact of groundwater artificial recharge by means of injection of treated domestic effluent into a confined aquifer via deep boreholes at the area of Sindos [40]. Recycled water potentially represents one important portion of the water resources for covering the increased water demands in the basin. The reuse of treated waste will be diverted for artificial recharge and recovered to be used for irrigation or industrial use.

Furthermore, groundwater artificial recharge using the large volumes of winter-time runoff that are currently being discharged to the sea, is a well-documented method to initially delay aquifer mining and progressively achieve its replenishment and restoration.

Replacement of obsolete domestic water networks in order to reduce current losses, utilization of the mountainous zone springs, and informative campaigns to sensitize citizens to rational water use are only some extra measures in the framework of rational and sustainable management of water resources at the basin scale. Last year, the Greek State proceeded in licensing rights for existing water use, even for boreholes operating illegally. As part of this procedure the installation of flow meters will become mandatory. Depending on the registered crop, a maximum amount of water for irrigation will be allowed. Water pricing is a key issue in protection and restoration of water resources. Appointment and operation of landfill sites and appropriate waste effluent treatment and utilization instead of simple discharge into the local rivers and torrents would also contribute to groundwater quality restoration.

It is very important that the authorities and stakeholders that are involved in water resources management have clear responsibilities without overlaps that lead to an increased complexity of the decision system. It is also of major importance that the authorities-especially local authorities that are directly involved in the issue-have the power and the ability to control the implementation of the decisions and to impose penalties when violations are detected. Unfortunately, until recently, local authorities did not have this ability, and regional actors showed great reluctance in enforcing established regulations and acts regarding water resources management and environmental protection.

\section{Discussion and Conclusions}

In the case of the Gallikos River basin, application of DPSIR enabled the identification of the main driving forces and their direct effects on the studied system, it allowed a facilitated linkage of these with the state of the system and the identified impacts, thus in the end making it possible to suggest easier, comprehensive and focused measures in the framework of rehabilitation and protection of the system. There are two main issues to be addressed. The first is the degradation of the quality of water resources due to the untreated waste disposal and nitrate pollution resulting from anthropogenic activities. The second issue is in regard to the groundwater reserve reduction due to overpumping in order to cover the demands of any kind of activity (domestic, industrial, agricultural) in the basin. The water resource degradation has impacts on human well-being. The insufficient presence of state or regional control mechanisms and the lack of available data, as there is no network for systematic water resource measurements, have led to an ineffective and late response of the 
authorities. In current days things are worsening in this direction. The poor economic conditions of Greece do not favor efforts in the direction of protection and restoration of the environment, since priorities have changed and such efforts are considered a "luxury". Despite the difficulties, some of the following actions are proposed. Some of these actions have already been implemented but they need to be implemented in a more systematic way:

(a) Programmed-precision irrigation, which will both reduce the volume of water thoughtlessly used for agriculture whilst at the same time optimally covering the irrigation demands. Appropriate irrigation water pricing policies, which are in-line with the guidelines set by the Water Framework Directive. Further reduction could be achieved through crop restructuring patterns in the framework of the new Common Agricultural Policy (CAP), opting for less water-consuming crops that at the same time present a high added value to the producers, accompanied by subsidies that will cover the cost for the substitution of the crops and probably the income losses of the farmers.

(b) Optimized fertilization based on detailed knowledge of the soil characteristics and the crop needs may also dramatically reduce the pollutant loads whilst at the same time improving the competitiveness of the crop production through reduced production costs. To this end, a Code for Good Agricultural Practice (COGAP) has been compiled and specific fertilization plans have been issued.

(c) Improved management of livestock units shall only benefit the environment and the annual turnover from this activity. Proper management of manure and its subsequent utilization as a fertilizer will minimize health risks to the livestock, improve their breeding conditions and hence improve the turnover of the breeding units, minimize potential point pollution to the water receptors of the basin and cut down on the fertilization costs of crops in the region.

(d) Appropriate treatment and management of livestock breeding, industrial and domestic effluent can also turn into an asset for the region, both in terms of water resources and also nutrient source for agriculture, whilst in parallel safeguarding the environment. Dramatic improvement in the operation of the existing effluent treatment plants that operate in the region has been achieved over the past decade to ensure that such point pollution sources are progressively eliminated. Reuse of treated domestic effluent is has proven to be a viable solution to crop irrigation in the region, capable of addressing prolonged droughts whist also partially accounting for the nutrient needs of the plants. Hence, such practices are nowadays promoted through the regional government and are well-governed by legislative acts.

(e) Progressive abandonment of uncontrolled landfills to properly managed domestic waste sites is also under way in the region, thus reducing the number of potential point pollution sources of domestic origin.

It is important that these actions are realistic, since they do not always increase costs, but some of them are a matter of proper management and policy drawing. Many of the proposed action have been adopted by the Greek state and some have been adapted from European policies.

Rationalization of water and land use through the above discussed suite of measures has already been applied in the region exhibiting signs of recovery of the system in terms of quality and quantity characteristics. Signs are more apparent so far in the soil resources of the region based the systematic surveys carried out in the framework of the Nitrates Directive implementation in the region. The 
extensive depression cone and salinization fronts documented at the southern margins of the basin as a result of groundwater over-exploitation are not yet recovered. This phenomenon evolved over a long period of time and, based on international experience, will take several decades to be restored. Undoubtedly, some of the impacts of the miss-management are non-reversible, such as the extensive subsidence along the coastal zone; however it is imperative and feasible that it be avoided that the phenomenon evolves further.

Identification of key drivers and pressures to the studied basin enables structuring and adoption of the appropriate measures towards alleviation of the impacts it suffers, and overall protection of the studied system. The proposed suite of measures is not only seen as a means to protect the system and attempt to restore it to its prior good state, but also as a guarding shield in the direction of preparedness and adaptation to climate changes.

DPSIR technique in a GIS environment is a valuable tool that contributes to the integrated appraisal of environmental and socio-economic pressures and their effects on the water resources at the basin scale. It provides a common basis of understanding and encoding of valuable information that can be easily conceived and reviewed in the framework of strategic planning and evaluation. This way, it enables direct correlation to adjacent basins, or comparative studies of the same basin at various points in time, whilst at the same time contributing to effectively designing and implementing site and problem specific measures towards protection and restoration of a given hydrogeological environment.

\section{Acknowledgments}

The authors would like to thank the Greek Ministry of Development, since part of this work (for the upper part of Gallikos River basin) was elaborated in the framework of a research project funded by the Directorate General for Research and Technology that belongs to the aforementioned Ministry. Furthermore, the authors greatly appreciate the careful revisions of three anonymous referees.

\section{Author Contributions}

Christos Mattas collected the data and applied the methodology in collaboration with the other authors. He also constructed the maps in geographic information system (GIS) environment. Konstantinos Voudouris proposed the conceptual framework of the paper and evaluated the data. He also checked the results and enhanced the writings of the paper in collaboration with Andreas Panagopoulos.

\section{Conflicts of Interest}

The authors declare no conflict of interest. 


\section{References}

1. United Nations Educational, Scientific and Cultural Organization (UNESCO). Summary and Recommendations of the International Conference on World Water Resources at the Beginning of the 21st Century "Water: A Looming Crisis"; UNESCO: Paris, France, 1998.

2. Meybeck, M. Riverine quality at the Anthropocene: Propositions for global space and time analysis, illustrated by the Seine River. Aquat. Sci. 2002, 64, 376-393.

3. Daskalaki, P.; Voudouris, K. Groundwater quality of porous aquifers in Greece: A synoptic review. Environ. Geol. 2008, 54, 505-513.

4. Gaaloul, N.; Pliakas, F.; Kallioras, A.; Schuth, C.; Marinos, P. Simulation of seawater intrusion in coastal aquifers: Forty five-years exploitation in an eastern coast aquifer in NE Tunisia. Open Hydrol. J. 2012, 6, 31-44.

5. European Environmental Agency (EEA). The DPSIR framework used by the EEA. Available online: http://glossary.eea.europa.eu//terminology/sitesearch?term=DPSIR (accessed on 1 April 2014).

6. Karageorgis, A.P.; Skourtos, M.S.; Kapsimalis, V.; Kontogianni, A.D.; Skoulikidis, N.T.; Pagou, K.; Nikolaidis, N.P. An integrated approach to watershed management within the DPSIR framework: Axios river catchment and Thermaikos Gulf. Reg. Environ. Chang. 2005, 5, $138-160$.

7. Mourão, I.; Caeiro, S.M.H.; Ramos, T.B.; Painho M. Application of the DPSIR model to the Sado Estuary in a GIS context-Social and Economical Pressures. In Proceedings of the 7th Conference on Geographic Information Science (AGILE 2004), Crete, Greece, 29 April-1 May 2004; Toppen, F., Prastacos, P., Eds.; Crete University Press: Crete, Greece, 2004; pp. 391-402.

8. Kagalou, I.; Leonardos, I.; Anastasiadou, C.; Neofytou, C. The DPSIR approach for an integrated river management framework. A preliminary application on a Mediterranean site (Kalamas river-NW Greece). Water Resour. Manag. 2012, 26, 1677-1692.

9. Poulos, S.; Papadopoulos, A.; Collins, M.B. Deltaic progradation in Thermaikos Bay, Northern Greece and its Socio-Economical Implications. Ocean Coast. Manag. 1994, 22, 229-247.

10. Konstantinidis, K.A. Land Reclamation Project of the Plain of Thessaloniki; Geotechnical Chamber of Greece: Thessaloniki, Greece, 1989. (In Greek)

11. Poulos, S.; Chronis, G. The importance of the Greek river systems in the evolution of the Greek coastline. In Transformations and Evolution of the Mediterranean Coastline; Special No. 18, CIESM Science Series No. 3; Briand, F., Maldolado, A., Eds.; Bulletin de l' Institut Oceanographique; Albert Ier, Monaco, 1997; pp. 75-96.

12. Eumorphopoulos, L. Verandermingen des Golfes von Thessaloniki. Geogr. Elv. 1964, 19, 269-277. (In German)

13. Mitsopoulos, M. Geological and paleontological study of the meta-tertiary deposits of Thessaloniki plain. Lectureship Thesis, Aristotle University, Thessaloniki, Greece, 1938.

14. Dimopoulos, G. Investigation of the conditions generating soil settlements in the Sindos-Kalochori area of Thessaloniki. In Proceedings of the 7th Hellenic Conference on Hydrogeology, Athens, Greece, 5-6 October 2005. (In Greek) 
15. Lambrakis, N.; Voudouris, K.; Tiniakos, L.; Kallergis, G. Impacts of drought and overpumping on the Quaternary aquifers of the Glafkos basin (Patras region, Greece). Environ. Geol. 1997, 29, 209-216.

16. Mercier, J. Etude geologique des zones internes des Hellenides en Macedoine centrale (Grèce). Ann. Geol. Pays Hell. 1968, 20, 1-792. (In French)

17. Kockel F.; Ioannides K. Geological Map of Greece, Kilkis Sheet (Scale 1:50000); Institute of Geology and Mineral Exploration: Athens, Greece, 1979. (In Greek)

18. Stais, A. Evolution Geodynamique des Basins Mesozoiques Vardariens: Domains de Peoniaset d' Almopias. Ph.D. Thesis, University de Lille, Lille, France, 1993. (In French)

19. European Commission. Common implementation strategy for the Water Framework Directive (2000/60 EC); Groundwater Risk Assessment; Technical report developed on the basis of the Guidance Document 2004. Available online: http://www.eurogeologists.de/images/content/ panels_of_experts/hydrogeology/081F8d01.pdf (accessed on 1 April 2014).

20. Song, X.; Frostell, B. The DPSIR framework and a pressure-oriented water quality monitoring approach to ecological river restoration. Water 2012, 4, 670-682.

21. Rekolainen, S.; Kamari, J.; Hiltunen, M.; Saloranta, T.M. A conceptual framework for identifying the need and role of models in the implementation of the Water Framework Directive. Int. J. River Basin Manag. 2003, 1, 347-352.

22. Carr, E.; Wingard, P.; Yorty, S.; Thompson, M.; Jensen, N.; Roberson, J. Applying DPSIR to sustainable development. Int. J. Sustain. Dev. World Ecol. 2007, 14, 543-555.

23. Karageorgis, A.; Kapsimalis, V.; Kontogianni, A.; Skourtos, M.; Turner, K.; Salomons, W. Impact of 100-year human interventions on the Deltaic Coastal Zone of the Inner Thermaikos Gulf (Greece): A DPSIR framework analysis. Environ. Manag. 2006, 38, 304-315.

24. Kristensen, P. The DPSIR Framework. In Proceedings of the Workshop on a Comprehensive/ Detailed Assessment of the Vulnerability of Water Resources to Environmental Change in Africa Using River Basin Approach, UNEP Headquarters, Nairobi, Kenya, 27-29 September 2004.

25. Panagopoulos, A.; Kassapi, A.; Arampatzis, G.; Perleros, B.; Drakopoulou, S.; Tziritis, E.; Chrysafi, A.; Vrouhakis, I. Assessment of chemical and quantitative status of groundwater systems in Pinios hydrological basin-Greece. In Proceedings of the International Conference "Protection Restoration of the environment XI", Thessaloniki, Greece, 3-6 July 2012.

26. Institute for the Management of Information Systems of the "Athena" Research and Innovation Center in Information, Communication and Knowledge Technologies, geodata.gov.gr. Available online: http://www.geodata.gov.gr/geodata/index.php?option=com_sobi2\& sobi2Task=sobi2Details\&catid=16\&sobi2Id=54\&Itemid= (assessed on 16 December 2013).

27. Ministry of Environment, Energy \& Climate Change. Strategic study of Environmental Impacts. Water District of Central Macedonia (GR10), 2014. Available online: http://wfd.opengov.gr/ index.php?option $=$ com_content\&task=view\&id=110\&Itemid=18 (assessed on 1 April 2014). (In Greek) 
28. Mattas, C.; Soulios, G.; Dimopoulos, G.; Diamantis, J.; Panagopoulos, A.; Voudouris, K. Groundwater quality in Gallikos basin, Prefecture of Kilkis. In Proceedings of the 7th Hellenic Conference on Hydrogeology, Athens, Greece, 5-6 October 2005. (In Greek)

29. Mattas, C.; Soulios, G.; Panagopoulos, A.; Voudouris, K.; Panoras, A. Hydrochemical characteristics of the Gallikos river water, Prefecture of Kilkis, Greece. Glob. Nest 2007, 9, 251-258.

30. Kalousi, E. Rational Water Resources Management Study of the Prefecture of Kilkis; Institute of Geology and Mineral Exploration: Athens, Greece, 2002. (In Greek)

31. Kruseman, G.P.; de Ridder, N.A. Analysis and Evaluation of Pumping Test Data, 2nd ed.; International Institute for Land Reclamation and Improvement: Wageningen, The Netherlands, 1990.

32. Driscoll, F.G. Groundwater and Wells, 2nd ed.; Johnson Screens: Saint Paul, MN, USA, 1986.

33. Panoras, A.; Ilias, A. Assessing the suitability of Thessaloniki reclaimed municipal wastewater for irrigation. Agric. Eng. 2003, 5-6, 139-142.

34. Protection and management of waters-Harmonization with $2000 / 60 / \mathrm{EC}$ of the European Parliament and the European Council of 23rd October 2000. Law 3199/2003. Official Government Gazette 280A'/9-12-2003, Athens, Greece, 4281-4228.

35. Mimikou, M.A. Water resources in Greece: Present and future. Glob. Nest J. 2005, 7, 313-322.

36. Measures of and conditions for water protection from nitrate pollution from activity of agricultural origin. Joint Ministerial Decision 16190/1335/97. Official Government Gazette 519 B'/25-6-1997, Athens, Greece, 5913-5920.

37. Voudouris, K.; Panagopoulos, A.; Koumantakis, J. Nitrate pollution in the coastal aquifer system of the Korinthos Prefecture (Greece). Glob. Nest 2004, 6, 31-38.

38. Karyotis, T.; Panagopoulos, A.; Alexiou, J.; Kalfountzos, D.; Pateras, D.; Argyropoulos, G.; Panoras, A. Nitrates pollution in a vulnerable zone of Greece. Commun. Biometry Crop Sci. 2006, 1, 72-78.

39. Measures for the protection of the wetland of Aliki Kitrous, the lower part and Delta of rivers Aliakmon, Loudias, Axios, Gallikos, of the Kalochori lagoon and their broader area. Joint Ministerial Desicion 14874/3291/98. Official Government Gazette 687 B'/6-7-1998, Athens, Greece, 7453-7446.

40. Tsourlos, P.; Vargemezis, G.; Voudouris, K.; Spachos, T.; Stampolidis, A. Monitoring recycled water injection into a confined aquifer in Sindos (Thessaloniki) using electrical resistivity tomography (ERT): Installation and preliminary results. In Bulletin of the Geological Society of Greece, Proceedings of the 11th International Congress, Athens, Greece, 23 May 2007. 


\title{
3. Governance Aspects
}

\section{Understanding Subjectivities in the Regulation of Local Water Services: A Q-Methodology Study of Elected Public Officers in Italy}

\begin{abstract}
Alberto Asquer
Abstract: In sub-national governments, elected public officers can exercise considerable influence on the regulation of local water services, in such ways as, for example, contributing to the design of local regulatory institutions, to the formulation of tariff rules, and to the supervision of water firms. Relatively little we know, however, about how elected public officers think about the regulation of local water services. This Q methodology study provides some evidence of the variety of opinions held on how local water services are delivered, how well they perform, and how they should be regulated among elected public officers in local governments in Italy. The study shows that the policy discourse on water regulation in Italy is highly fragmented into alternative and partially conflicting views. These findings bear some relevance for better understanding sources of stability and change of water regulatory regimes at the local level.
\end{abstract}

Reprinted from Water. Cite as: Asquer, A. Understanding Subjectivities in the Regulation of Local Water Services: A Q-Methodology Study of Elected Public Officers in Italy. Water 2014, 6, $670-693$.

\section{Introduction}

The regulation of local water services typically leaves considerable room for agency by elected public officers, who are able to shape, and sometimes to determine, the institutional design for the provision of local water services. For instance, elected public officers contribute to deliberations concerning whether local water services should be delivered by local government owned firms or tendered out to business firms that are subjected to the terms and conditions stipulated in concession or franchise contracts. More generally, elected public officers exercise political discretion over aspects of the design of the regulatory system for local water services that have important consequences for the performance of water firms, the quality of water services, and the regime of transparency and accountability of water service providers. However, what understanding of the regulation of local water services do elected public officers have, and how can we access and analyse such understandings?

Within the area of study of regulation, the issue of how elected public officers understand the regulation of public services in general has been relatively little researched so far. In part, the lack of interest towards individuals' understanding of the regulation of public services can be explained by the secondary role that individual beliefs and opinions have within economic theories of regulation. In the "public interest" theories of regulation, individuals who hold public authority positions are 
typically assumed to supply regulation taking into account the interest of the society [1-3]. In the "private interest" or "capture" theories of regulation, individuals are assumed to rationally pursue their own interest, especially in the form of transfer of wealth or attainment of rent positions through the formulation of fitting regulations [4-6]. In both these streams of theoretical work, individuals' understandings of regulation and of the regulatory scenario are not problematic. Rather, attention is primarily placed on how individuals' objectives are achieved and what are the performance effects of the regulatory choices made.

The role of individuals' understanding of the regulation of public services is also relatively silent in the emerging theory of mechanism design of regulatory policy. Recent works highlighted that the principles of mechanism design [7-10] can inform the solution of social problems such as the regulation of infrastructure [11,12]. Building on this approach, Araral [13] argued that a "second-generation" research agenda on policy design should focus on the role of incentive compatible (self-enforcing) mechanisms, especially in the context of developing countries where regulatory capacity is weak, unaccountable, corrupted, or not credible. While greater attention towards the role of mechanisms in minimising transaction costs is welcome, also this approach papers over the possibility that individuals may hold different understandings of regulation and the regulatory scenario and that they may react differently to the incentive structures on the basis of such different belief or opinion premises.

Differently from the theoretical approaches briefly reviewed thus far, other streams of research highlight the role of individuals' ideas in the political economy of regulation. For example, Lodge and Wegrich [14] argued that individuals are inclined to favour alternative principles of regulatory design depending on their cultural orientation [15]. Individuals who lean towards "individualistic" values tend to advocate market-based mechanisms of regulation, those who hold "egalitarian" values grant primacy to transparency and accountability, those who embrace "hierarchical" values prefer centralised command-and-control styles of guidance, and those who cling to "fatalistic" values grant some merits to randomised checks and other accidental forms of regulation. According to this view, individuals' beliefs and opinions towards the regulation of public services are shaped by cultural factors no less than the canons of instrumental rationality in the pursue of individual objectives.

How do elected public officers think that the regulation of local water services should be designed? How do they take the interests of different stakeholders into account in their understanding of the "public interest" associated with the provision of water services? How do cultural factors influence - if they do - their understanding of the 'public interest' in this particular policy domain? These issues are important because elected public officers hold relevant positions within the political arenas where deliberations over the regulation of local water services delivery systems are made. In addition, they call for the investigation of the kind of beliefs and opinions held by elected public officers. Elected public officers may be reasonably expected to declare to care about pursuing the public interest in the open political discourse. However, they also hold a particular understanding of what constitutes the public interest that is reflected in the kind of regulatory design principles and choices that they advocate. The aims of the paper, accordingly, is to contribute to research on the regulation of local water services by investigating the subjectivities of elected public officers, i.e., 
the ideas that they hold about how local water services are delivered, how well they perform, and how they should be regulated.

The paper provides, first, a review of the literature on the design of local water regulatory systems, with focused attention placed on alternative regulatory design principles (i.e., regulation through private contracts, regulation through concession contracts, discretionary regulation, and regulation through public enterprises) and regulatory design choices. Section 3 will outline the research design and illustrate how Q methodology provides a helpful tool for investigating the subjectivities of elected public officers. The approach is consistent with the one followed in other scholarly works that aimed to identify typologies of roles of individuals (e.g., policy analyst and public managers) through the empirical identification of their subjective viewpoints. Section 4 will illustrate the results from the analysis. Section 5 will discuss the results of the analysis and provide some tentative identification of subjectivities of elected public officers towards the regulation of local water services. Finally, the conclusions will discuss the contribution of the study to the research on the regulation of local water services.

\section{Ideas about the Regulation of Local Water Services}

Regulation of water services is a relatively large area of scholarly inquiry. Several works have been done on the design of water regulatory systems [16-23], on the assessment of water regulatory institutions [24-28] and on the making and implementation of regulatory reforms in the water sector [29-32]. The present study is especially concerned with ideas about the regulation of water services at the local level.

The role of ideas in the policy process, as a general kind of phenomenon, has been widely researched but it remains somehow controversial. Some scholars argue that ideas (in the forms of cognitive paradigms, world views, norms, beliefs, opinions, frames, and policy programmes), rather than self-interest, exert a significant influence on policy-making outcomes [33,34]. Others, instead, hold that ideas play a minor role in the policy process with respect to institutions and structures that orient the conduct of individuals [35]. If ideas matter in the policy process, a great deal of theoretical and empirical work is needed in order to clarify how exactly they come into play in shaping the issues at stake, the policy agenda, the policy alternatives and the selection of policy options within historically specific political discourses and institutional venues for political deliberation.

One way for ideas to play a role in the regulation of local water services is through the agency of elected public officers of local governments. Local governments typically enjoy some discretion in the design of regulatory institutions and in the arrangement of regulatory systems for the delivery of local water supply and sanitation services. In France, for example, municipalities can decide whether to contract out the provision of water services to business firms selected through tender offer competitions or to retain the management of water services within municipal departments. Ideas, especially in the form of beliefs and opinions about how local water services are delivered, how well they perform, and how they should be regulated, can play an important role in determining the inclination of elected public officers who sit in municipal councils towards the desired configuration of the system of water service provision within the municipality. Anecdotal evidence from the cases of "remunicipalisation" of water service provision (e.g., in Grenoble in 2001 and in Paris in 2010) 
suggests that, indeed, ideas may contribute determining policy reversals under conditions of seemingly stable institutional arrangements.

Ideas about the regulation of local water services typically include the belief that water service provision should be subjected to economic regulation, especially because of the natural monopoly features of water infrastructure. These features include, in particular, the role of economies of scale that produce advantages for larger operators, of network economies that benefit operators of larger infrastructure networks, and of the presence of durable and immobile assets that discourage entry from potential competitors [36]. Relatively less consensus exists, however, on how precisely water services should be regulated. Generic policy options typically include regulating the water services provided by business companies through independent regulatory authorities (such as OFWAT in England and Wales), or through franchise contracts (as it is often done in France), or through the retention of water services under full public ownership and control (as it is often the case in Germany and Italy) or under semi-privatised water utilities (i.e., mixed public-private ownership firms). More specifically, policy options include various ways for regulating tariffs (e.g., through price-cap mechanism, or rate-of-return, or other formulas), financing investments (e.g., through water charges or public funds), stimulating investments and service improvements (e.g., through contractual standards or benchmarking practices), and so on.

Issues related to the regulation of water services are especially sensitive at the local level. Actors of local water industries are typically embedded within dense networks of social relationships, which entail potential conflicts of interests between duties and responsibilities attached to organisational roles on the one hand, and partisan views and inclinations related to personal ties on the other one [37]. Mechanisms of "revolving doors" [38-40], for example, may blur the boundaries between the roles attached to positions within local authorities, regulators, and water utilities. Elected public officers may possess a complex understanding of the issues related to the regulation of water services that includes careful consideration for the diverse interests and expectations held by various stakeholders of the local water industries. Access to the understanding of elected public officers, therefore, may shed some light onto the repertoire of ideas that populate the policy discourse on the regulation of local water services.

Ideas on the regulation of local water services may be articulated along several dimensions. A tentative, a priori, classification includes ideas about (a) the normative stance towards values that should be protected, including a position about the allocation of costs and benefits between users and taxpayers and between generations; (b) the general regulatory design principles that should be followed; (c) initial conditions that characterise the present state of affairs in the local water industry; (d) process conditions that relate to features of the conduct of the regulatory process; and (e) context conditions that relate to features of environmental circumstances. These dimensions provide a frame of reference for classifying and analysing the subjectivities of elected public officers with respect to the topic of local water services regulation. In other words, ideas held along these dimensions form "policy views" that elected public officers hold on the topic under consideration. The analysis of these policy views can reveal whether elected public officers share a mutual understanding of the regulation of local water services or whether they hold different positions on how local water services are delivered, how well they perform, and how they should be regulated. 
Of course, ideas on the regulation of local water services should be understood as participating in contextually located political discourses. In principle, it is not possible to assert whether ideas tend to align with any dominant, or even hegemonic, policy programme or whether they tend to reflect diverse positions within a fragmented and discordant policy arena. It is plausible to argue, however, that ideas on the regulation of local water services are strategically formulated and expressed on the basis of actors' understanding of the political economy of the regulation of local water services. For example, some beliefs and opinions may relate to policy views that tend to protect the interests of present water users, while others may be associated with the interests of taxpayers at large or next generations of water users. Evidence provided by the analysis of the subjectivities of elected public officers, therefore, should be careful interpreted on the basis of information about the historical context and structural features of the water policy domain that actors participate to.

Understanding the subjectivities towards water regulation is relevant for arguing about the inclinations that individuals have towards water regulatory institutions and policies. For example, individuals who hold beliefs and opinions that are congruent with the design principles of existing regulatory institutions may be predisposed to preserve the present institutional arrangements, while those whose beliefs and opinions contrast with the performance or distributional effects of the existing regulatory regime may be oriented towards advocating and effecting change of the present regulatory institutions. Individuals' beliefs and opinions, therefore, may play the role of a component factor of explanatory arguments for stability and change of regulatory institutions and service delivery systems.

\section{Research Design}

This study broadly follows an "interpretive" approach to the study of social phenomena, i.e., one that grants primacy to detecting and understanding individuals' beliefs, preferences, meanings and reasons for acting rather than to focusing on the institutional and organisational aspects of the social domain under consideration. Research on the regulation of local water services calls for such kind of approach. Elected public officers play an important role in the making of local regulatory policies that includes, for example, the selection of the regulatory design principles, the formulation of tariff rules, and the supervision of water firms. An inquiry into their subjectivities seems important, therefore, to better understand how they frame water regulation problems, how they search and assess alternative regulatory tools, and how they make decisions about the design of local water regulatory systems.

Investigating individuals' beliefs and opinions towards the regulation of local water services poses a significant methodological challenge. How can we access such subjectivities? Standard methodologies such as semi-structured interviews and surveys do not really retrieve the inner worlds of individuals, especially because they may not adequately capture the nuances of alternative regulatory design principles and choices or the relative importance that individuals grant to alternative normative views. Individuals' beliefs and opinions, however, can be investigated by using the so-called Q methodology, a technique that helps identifying the patterns of subjective perspectives held by a group of interviewees [41,42]. The technique has been applied in various fields, including the governance of public networks [43] and public service co-production [44]. In 
this study, the methodology is applied to answer the question of what are the beliefs and opinions of elected public officers towards the regulation of local water services.

Q methodology is often regarded as a way to access and measure human subjectivity $[41,42]$. Unlike other forms of quantitative analysis, the technique is not intended to test hypothesised causal relationships and the results of the analysis are subjected to the interpretive skills of the researcher. Dissimilarly from other forms of qualitative research, moreover, Q methodology provides the researcher a statistical basis for inferring associations between claims and therefore supporting the interpretation of alternative viewpoints on the issue under consideration. This research methodology, then, is consistent with the interpretive approach that is followed here and with the scholarly aspiration of making the analysis of empirical data transparent and systematic [45]. In broad terms, the methodology is applied by making each participant of a population sample (called P sample) sort a series of statements (called Q sample) that is representative of the variety of claims around an issue (the so-called concourse) into a distribution of preferences (called Q sort). Statistical analysis, then, allows to derive significant factors that are subjected to interpretation of the researcher.

Q methodology is generally implemented through five different stages. First, the technique provides the construction of the so-called "concourse", i.e., the breadth of the debate around a particular topic. This task can be accomplished in various means, such as interviews with highly informed participants [46], focus groups [47], analysis of textual and other media resources [48], or a combination of these. Second, the researchers survey the concourse in search for as many sentences that are believed to adequately convey the variety of beliefs and opinions about the topic under consideration. The statements (which may number into the hundreds) should make use of the same lexicon as the one of the empirical field under consideration (i.e., the "emic" knowledge of the individuals; [49]). Third, these statements are reduced to a manageable size (between about 30 and 60 ) to form the Q sample. The reason for the reduction from the sentences of the concourse to those of the Q sample primarily is a practical one, provided that interviewees may not possess the time or will to sort too many sentences. The construction of the Q sample is generally driven by a theoretical or an argumentative framework, which provides the criteria for arranging the sentences into a limited number of categories. Various techniques may help in this task, especially including the use of matrix tables to distinguish types of statements and discard duplicates. Fourth, a sample of individuals is purposively selected (in the number of between about 25 and 75) among the population of participants to the discourse about the topic under consideration. The P sample is not intended to be representative of the population, in the sense that the results from the analysis conducted on the basis of the evidence collected from the sample should be generalizable to the population. Rather, the $\mathrm{P}$ sample is constructed with the aim of gathering as much variety as possible of views about the topic under consideration on the basis of a priori knowledge and assumptions about the population and its relationship with the concourse. Fifth, the participants sort the statements of the Q sample into three piles (depending on whether they agree, disagree, or are neutral with the claims) and then they refine the sort by placing the statements into a forced half-normal distribution, that typically is represented as an inverted pyramid made of "slots" arranged along a scale (i.e., from -4 to +4 or from -5 to +5 ). The grid forces the participants to make hard choices to rank the order of statements relative to each other, rather than purely expressing the extent to which they agree or not (i.e., as it would be normally 
done in a questionnaire survey). Finally, the responses ( $\mathrm{Q}$ sorts) are analysed through a by-person factor analysis [41] to reveal correlated groups of statement preferences. The researcher, eventually, interprets the meaning of the synthesised factors on the basis of the correlated statements. Factors, in this sense, identify groups of claims that can be related to particular "worldviews" held by respondents.

The present study builds on the analysis of empirical evidence collected among elected public officers of local governments in Italy. The selection of the country case deserves some remarks. Water service provision in Italy was largely conducted by full public ownership firms in the past, until a reform of the water sector in 1994 [50] mandated the reorganisation of the water governance system, introduced novel regulatory institutions and tools, and paved the way for the partial privatisation of the water industry. A stream of reforms of local public services between 2001 and 2008 [51-54], moreover, entailed the gradual opening of the water sector to private operators and investors, which was eventually halted by a referendum in 2011 that resulted in the abrogation of legislative provisions about the tender out of water concessions and the inclusion of a return to investment in water charges. At the time of this study, these reforms resulted in heterogeneous forms of water service regulation across the country. Most water utilities were retained under public sector ownership, while others were partially privatised or floated in the Milan stock exchange. More importantly, for the sake of this study, the making and implementation of these reforms were accompanied by the emergence of contrasting arguments within the domestic policy discourse, which included both support towards the re-regulation and privatisation of the water sector (especially from the side of the financial sector and municipal government coalitions that embraced privatisation) and acrimony against the "marketisation" (as it was occasionally put) of water services.

The present regulatory regime for water services in Italy is heterogeneous across the country. About two-thirds of the water industry still consists of utilities owned and controlled by local governments, albeit they have been typically re-incorporated under company laws rather than left operating as municipal agencies or departments [32]. In the rest of the water industry, utilities are owned by both local governments and private operators and investors, that include, for instance, French water multinational firms, local banks, and financial investors. The provision of water services is typically regulated through concession contracts that stipulate infrastructure development, quality standards, and tariff. Whatever the particular configuration of the local water industry, local governments play a pivotal role. Where water utilities are owned by local governments, elected public officers may have diverse views as to whether the present arrangement is advantageous with respect to any form of involvement of private actors or whether full public ownership entails that the water utilities have limited capacity to cope with growing pressures to infrastructure development and increase of efficiency and service quality. Where water utilities are jointly owned by local governments and private operators and investors, elected public officers may be variously inclined towards the extent to which the water utilities should pursue of the interests of the private partners with respect to those of the local communities. Features of the particular water governance and regulatory regime, therefore, seem important to account for the possibility that elected public officers hold the variety views towards the regulation of water services that this study is set to investigate.

The presumed variety of views about how local water services are delivered, how well they perform, and how they should be regulated may be related to several kinds of conditions. Members 
of coalition governments that decided to re-regulate and privatise water service provision within their municipality, for example, may be favourably inclined towards these policies. Members of minority parties or members of coalition governments that resisted privatisation, instead, may lean towards alternative or opposite policy positions. Apart from party affiliation, moreover, individuals' beliefs and opinions may relate to their value systems, their ties with local communities, and their understanding of issues related to the development and management of the water technical system. In addition, individuals may hold partially conflicting or contradicting views about component parts of the whole regulatory system, such as, for instance, beliefs and opinions about the desirability of alternative regulatory tools and of alternative forms of privatisation. The question as to what elected public officers of local governments in Italy think about the regulation of local water services, therefore, is open to empirical investigation.

This study begun with the development of a concourse of about 150 statements about the regulation of local water services that had emerged from documentary sources and from about 20 interviews with elected public officers of both the national and local government level, water regulators, water utility managers, and mayors that were collected in previous research on water regulation and regulatory reform in Italy [30-32] (i.e., the concourse was formed by identifying claims about how local water services are delivered, how well they perform, and how they should be regulated as expressed by interviewees in the course of previous fieldworks). Then, the number of statements of the concourse was reduced to a Q sample made of 30 claims that related to five convenient a priori categories of features about the regulation of water services. The five categories originated from the distinction, drawn from argumentation theory, between descriptive, normative, advocative claims, where the descriptive claims are further detailed into claims about initial conditions, context conditions, and process conditions about the working of the present regulatory system. The reduction of the number of statements into the five categories was primarily conducted by discarding statements whose meanings were understood as broadly corresponding to those of other statements that were preserved in the Q sample. Admittedly, this process entailed that some statements were discarded although they contained some nuances that were not completely incorporated in the remaining statements of the Q sample. The simplification of the set of statements that were considered adequate to represent the variety of beliefs and opinions about the regulation of local water services was justified, however, on the basis of the practical concern with constructing a Q sample of manageable size for the sorting exercise. The resulting Q sample is shown in Table 1. As statements were originally formulated in Italian, the reader should be warned that the English translation that is presented here may not completely convey the meaning that the elected public officers could have attributed to the original sentences. As a way to partially address this issue, Table 1 also contains (in brackets) the original formulation of the sentences in Italian. In addition, the discussion of the results of the analysis will pay attention to how the original formulation of the sentences in Italian could have been understood by elected public officers rather than the English corresponding translation. 


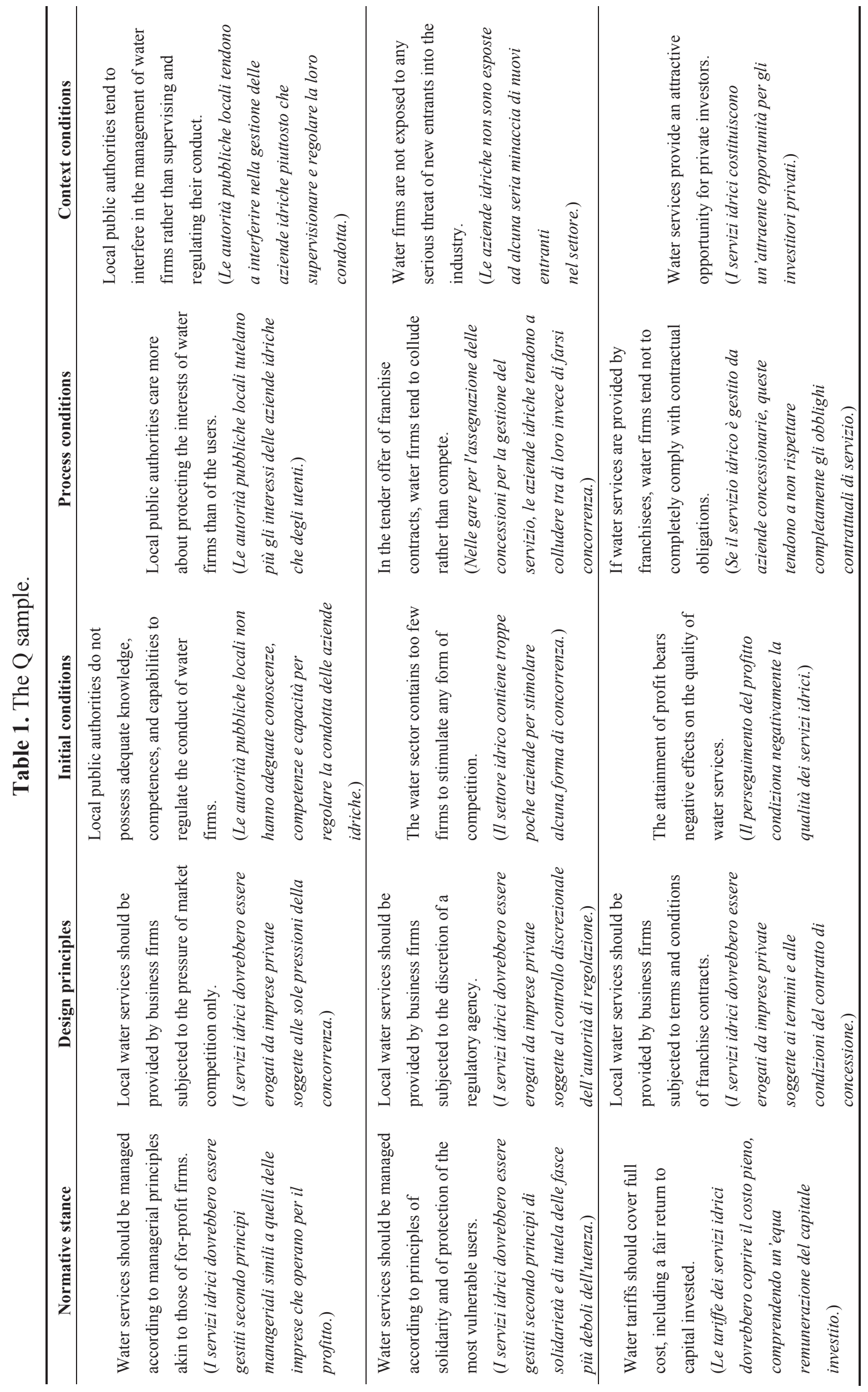




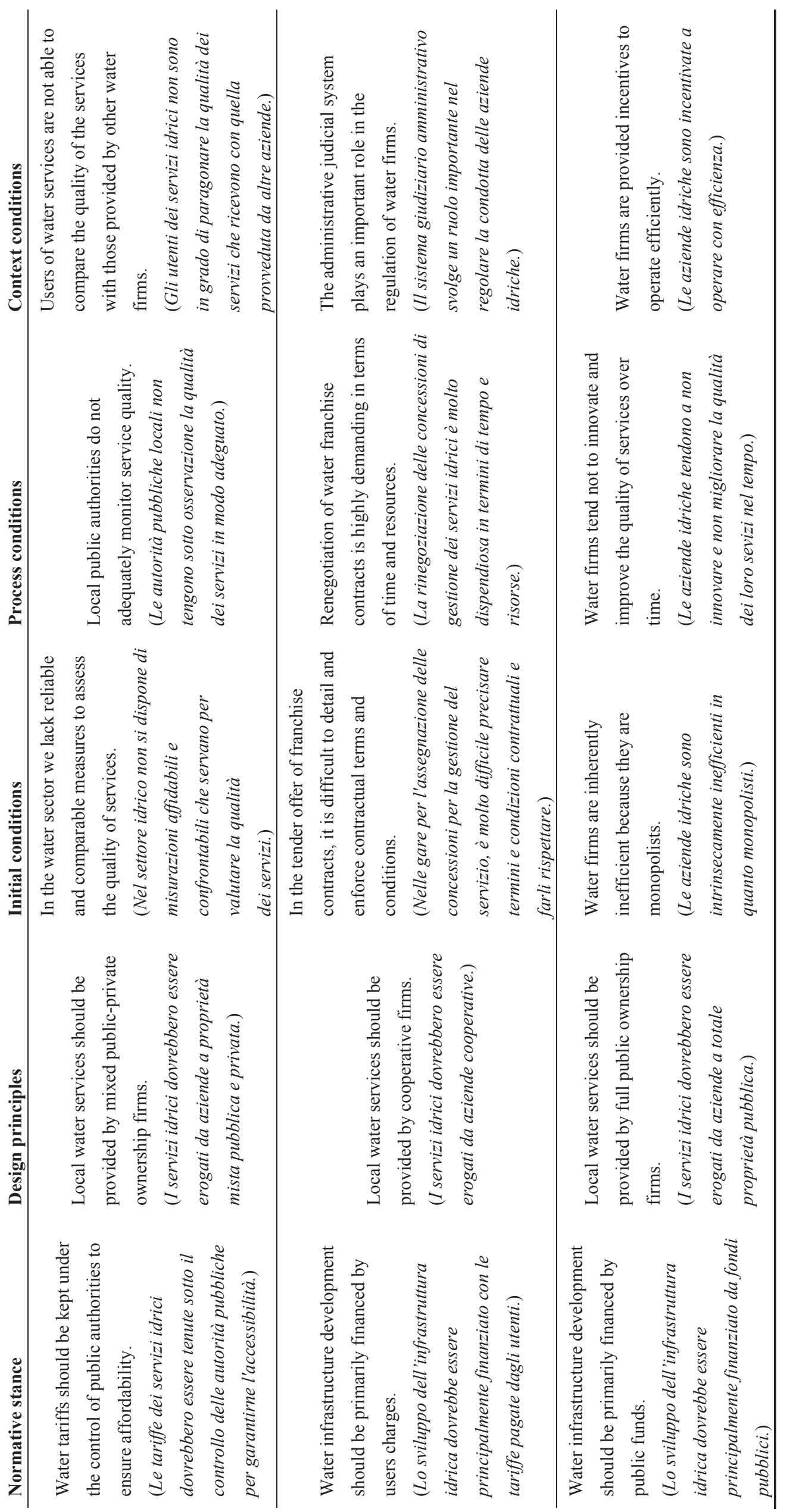


The P sample was composed of elected public officers in local governments in Italy. An invitation to participate to the Q methodology survey was sent to a total number of 481 elected public officers of 19 municipalities of the country, selected among 135 "middle-range" cities by population, i.e., with between 50,000 and 500,000 inhabitants. The 19 municipalities were purposively chosen in order to provide variety in terms of both geographical location and mode of water service delivery. The list of the municipalities is shown in Table 2. The number of respondents was 24 (5\%). By itself, however, the relatively small number of respondents does not compromise Q methodology, provided that the P sample is usually smaller than the Q sample $[55,56]$.

Table 2. List of municipalities whose elected public officers were invited to the $\mathrm{Q}$ methodology survey [57].

\begin{tabular}{cccc}
\hline Title & Municipality & Region & Inhabitants \\
\hline & Bologna & Emilia-Romagna & 383,577 \\
& Verona & Veneto & 258,553 \\
Northern & Modena & Emilia-Romagna & 179,180 \\
Italy & Parma & Emilia-Romagna & 178,723 \\
& Reggio Emilia & Emilia-Romagna & 165,001 \\
& Novara & Piemonte & 102,012 \\
& Cuneo & Piemonte & 55,613 \\
& Pordenone & Friuli Venezia Giulia & 51,512 \\
\hline \multirow{4}{*}{ Central Italy } & Prato & Tuscany & 187.530 \\
& Terni & Umbria & 111,792 \\
& Arezzo & Tuscany & 98,562 \\
& Pisa & Tuscany & 86,492 \\
& Fano & Marche & 63,009 \\
Southern & Chieti & Abruzzo & 51,226 \\
\hline \multirow{2}{*}{ Italy } & Salerno & Campania & 131,637 \\
& Marsala & Sicily & 80,564 \\
& Caltanisetta & Sicily & 75,662 \\
& Caserta & Campania & 74,838 \\
& Scafati & Campania & 50,227 \\
\hline
\end{tabular}

The Q sort was performed through a web application, named FlashQ software [58]. The software enabled respondents to sort the statements online by dragging virtual "cards" onto the inverse pyramid grid with values ranging from -5 to +5 . Respondents were primarily of male gender (21), with average age 50.4 years (median 50.5, maximum 67, minimum 30 ), and with average seven years experience in the regulation of local water services (median 5, maximum 20, minimum 1). Respondents declared themselves as politically oriented to "right" (RT) parties (2), "centre-right" (CR) (3), “centre” (C) (3), "centre-left" (CL) (6), "left" (LF) (6), and "other/independent" (OT) (4) (because of the many and diverse parties in local government councils, respondents were requested to state their political inclinations rather than the party affiliation). 


\section{Results from the Analysis}

The analysis of the data was conducted with a centroid factor analysis and a varimax rotation using PQ method [59]. Various rotations were performed, checking for explained variance and eigenvalue, the number of significant persons confounded across more than one factor, and the correlation between factors. At the end, five factors were identified. Table 3 shows the factor matrix with defining sorts (in bold). Table 4 exhibits the factor Q sort values for each statement. Table 5 provides the correlations between factor scores.

Table 3. Factor matrix with defining sorts (in bold).

\begin{tabular}{ccccccc}
\hline \multirow{2}{*}{ Respondent No. } & Respondent ID & \multicolumn{5}{c}{ Factors } \\
\cline { 3 - 7 } & & $\mathbf{1}$ & $\mathbf{2}$ & $\mathbf{3}$ & $\mathbf{4}$ & $\mathbf{5}$ \\
\hline 1 & CR1 & 0.3066 & -0.0665 & 0.5351 & 0.1606 & -0.1501 \\
2 & CL1 & 0.3117 & 0.3461 & 0.4480 & 0.1291 & -0.5067 \\
3 & CL2 & 0.0652 & 0.1304 & $\mathbf{0 . 6 0 8 3}$ & 0.2813 & 0.1059 \\
4 & C1 & 0.2396 & -0.1540 & $\mathbf{0 . 6 8 3 6}$ & 0.2407 & -0.1217 \\
5 & LF1 & 0.3565 & $\mathbf{0 . 6 3 4 6}$ & 0.3367 & 0.2255 & 0.0480 \\
6 & CL3 & -0.0560 & 0.0601 & 0.1556 & 0.0163 & 0.1611 \\
7 & RT1 & 0.3671 & $\mathbf{0 . 7 6 3 9}$ & 0.0070 & 0.0214 & 0.0446 \\
8 & LF2 & $\mathbf{0 . 6 2 7 3}$ & 0.1554 & 0.3089 & -0.0863 & -0.0713 \\
9 & C2 & 0.0481 & 0.2961 & -0.0507 & 0.0444 & $\mathbf{0 . 9 0 2 7}$ \\
10 & OT1 & 0.2153 & 0.0798 & 0.1132 & $\mathbf{0 . 6 4 9 5}$ & 0.1094 \\
11 & LF3 & $\mathbf{0 . 7 8 9 8}$ & 0.1444 & 0.1440 & -0.0324 & -0.1707 \\
12 & OT2 & $\mathbf{0 . 7 2 3 7}$ & 0.1412 & 0.0435 & 0.0708 & -0.2788 \\
13 & CR1 & -0.2277 & 0.0515 & 0.0391 & 0.0688 & $\mathbf{0 . 4 2 6 5}$ \\
14 & OT3 & $\mathbf{0 . 8 0 5 3}$ & 0.3106 & 0.1547 & 0.1055 & 0.0945 \\
15 & LF4 & -0.4282 & -0.0336 & 0.1534 & 0.3831 & 0.2295 \\
16 & OT4 & $\mathbf{0 . 8 0 3 9}$ & 0.1200 & 0.1104 & 0.1356 & 0.0284 \\
17 & CL4 & -0.1263 & -0.3549 & 0.2376 & 0.0078 & -0.3511 \\
18 & RT2 & 0.0516 & 0.4528 & -0.2500 & 0.1721 & 0.0091 \\
19 & CR2 & 0.2216 & $\mathbf{0 . 5 5 5 8}$ & 0.1123 & 0.0046 & 0.2062 \\
20 & LF5 & $\mathbf{0 . 8 0 6 5}$ & 0.0361 & 0.2702 & 0.1859 & -0.0893 \\
21 & C3 & 0.1647 & 0.1793 & $\mathbf{0 . 4 1 8 9}$ & -0.1098 & 0.0299 \\
22 & CR3 & 0.2585 & -0.1208 & -0.0058 & 0.3498 & -0.1032 \\
23 & CL5 & $\mathbf{0 . 7 2 2 9}$ & -0.1483 & -0.1830 & 0.2606 & -0.0427 \\
24 & CL6 & 0.1023 & 0.1816 & 0.2093 & $\mathbf{0 . 4 4 3 4}$ & -0.0443 \\
\hline$\%$ explained variance & 21 & 9 & 9 & 5 & 7 \\
\hline & & & & & &
\end{tabular}

Some of the factors are relatively correlated with each other (e.g., factors 1 and 2, whose correlation is 0.4999 ). The correlation does not negatively affect the results of the analysis, provided that - differently from linear regression studies - Q methodology is intended to single out factors that are sufficiently distinctive to call for an interpretative effort. The discussion below seeks to construct meaningful interpretations of the factors that have been identified in the analysis, also with the support of additional evidence provided by qualitative data in the form of comments included by the respondents about the statements they agreed and disagreed most with. 
Table 4. Factor Q sort values for each statement.

\begin{tabular}{|c|c|c|c|c|c|c|}
\hline & \multirow{2}{*}{ Statements } & \multicolumn{5}{|c|}{ Factors } \\
\hline & & 1 & 2 & 3 & 4 & 5 \\
\hline 1 & $\begin{array}{l}\text { Water services should be managed according to business principles akin to those of } \\
\text { for-profit firms. }\end{array}$ & -3 & -3 & 2 & -5 & -2 \\
\hline 2 & $\begin{array}{l}\text { Water services should be managed according to principles of solidarity and of } \\
\text { protection of the most vulnerable users. }\end{array}$ & 4 & 1 & 5 & 5 & -1 \\
\hline 3 & Water tariffs should cover full cost, including a fair return to capital invested. & -4 & 1 & 4 & -2 & 0 \\
\hline 4 & Water tariffs should be kept under the control of public authorities to ensure affordability. & 4 & 1 & 4 & 4 & 1 \\
\hline 5 & Water infrastructure development should be primarily financed by users charges. & -1 & -4 & 3 & 3 & -1 \\
\hline 6 & Water infrastructure development should be primarily financed by public funds. & 2 & 0 & -1 & 3 & -1 \\
\hline 7 & $\begin{array}{l}\text { Local public authorities care more about protecting the interests of water firms than of } \\
\text { the users. }\end{array}$ & 0 & 2 & -4 & -2 & 3 \\
\hline 8 & In the tender offer of franchise contracts, water firms tend to collude rather than compete. & 1 & 0 & -3 & 1 & 1 \\
\hline 9 & $\begin{array}{l}\text { If water services are provided by franchisees, water firms tend not to completely } \\
\text { comply with contractual obligations. }\end{array}$ & 3 & 2 & 0 & -3 & 1 \\
\hline 10 & Local public authorities do not adequately monitor service quality. & 2 & 3 & 1 & 4 & 0 \\
\hline 11 & $\begin{array}{l}\text { Renegotiation of water franchise contracts is highly demanding in terms of time and } \\
\text { resources. }\end{array}$ & -3 & 1 & -1 & 0 & -4 \\
\hline 12 & Water firms tend not to innovate and improve the quality of services over time. & 1 & 2 & 3 & -1 & -2 \\
\hline 13 & $\begin{array}{l}\text { Local public authorities do not possess adequate knowledge, competences, and } \\
\text { capabilities to regulate the conduct of water firms. }\end{array}$ & -1 & 3 & 1 & 0 & 3 \\
\hline 14 & The water sector contains too few firms to stimulate any form of competition. & -2 & -2 & 0 & 1 & 1 \\
\hline 15 & The attainment of profit bears negative effects on the quality of water services. & 3 & 5 & -2 & 2 & -2 \\
\hline 16 & $\begin{array}{l}\text { In the water sector we lack reliable and comparable measures to } \\
\text { assess the quality of services. }\end{array}$ & -1 & -1 & 1 & 3 & 2 \\
\hline 17 & $\begin{array}{l}\text { In the tender offer of franchise contracts, it is difficult to detail and enforce contractual } \\
\text { terms and conditions. }\end{array}$ & 0 & -1 & -3 & -3 & 0 \\
\hline 18 & Water firms are inherently inefficient because they are monopolists. & 1 & -1 & -1 & -4 & 0 \\
\hline 19 & $\begin{array}{l}\text { Local public authorities tend to interfere in the management of water firms rather than } \\
\text { supervising and regulating their conduct. }\end{array}$ & 0 & 4 & 0 & -1 & 2 \\
\hline 20 & Water firms are not exposed to any serious threat of new entrants into the industry. & 0 & -2 & 0 & 1 & 3 \\
\hline 21 & Water services provide an attractive opportunity for private investors. & 3 & 3 & 1 & 0 & 4 \\
\hline 22 & $\begin{array}{l}\text { Users of water services are not able to compare the quality of the services with those } \\
\text { provided by other water firms. }\end{array}$ & 2 & 0 & 3 & 1 & 2 \\
\hline 23 & The administrative judicial system plays an important role in the regulation of water firms. & -1 & -3 & 2 & -1 & -5 \\
\hline 24 & Water firms are provided incentives to operate efficiently. & -2 & -4 & -2 & -2 & -3 \\
\hline 25 & $\begin{array}{l}\text { Local water services should be provided by business firms subjected to the pressure of } \\
\text { market competition only. }\end{array}$ & -5 & -3 & -5 & -1 & -3 \\
\hline 26 & $\begin{array}{l}\text { Local water services should be provided by business firms subjected to the discretion } \\
\text { of a regulatory agency. }\end{array}$ & -3 & -2 & -1 & -3 & 4 \\
\hline 27 & $\begin{array}{l}\text { Local water services should be provided by business firms subjected to terms and } \\
\text { conditions of franchise contracts. }\end{array}$ & -4 & 0 & -4 & 2 & -1 \\
\hline 28 & Local water services should be provided by mixed public-private ownership firms. & -2 & -1 & -2 & 1 & 5 \\
\hline 29 & Local water services should be provided by cooperative firms. & 1 & -5 & -3 & -4 & -4 \\
\hline 30 & Local water services should be provided by full public ownership firms. & 5 & 4 & 2 & 0 & -3 \\
\hline
\end{tabular}


Table 5. Correlations between factor scores.

\begin{tabular}{cccccc}
\hline & $\mathbf{1}$ & $\mathbf{2}$ & $\mathbf{3}$ & $\mathbf{4}$ & $\mathbf{5}$ \\
\hline 1 & 1 & 0.4999 & 0.3761 & 0.3301 & -0.0263 \\
2 & 0.4999 & 1 & 0.2324 & 0.2891 & 0.2852 \\
3 & 0.3761 & 0.2324 & 1 & 0.3693 & 0.0118 \\
4 & 0.3301 & 0.2891 & 0.3693 & 1 & 0.1430 \\
5 & -0.0263 & 0.2852 & 0.0118 & 0.1430 & 1 \\
\hline
\end{tabular}

As a way to make the results of the analysis more accessible, Table 6 exhibits the defining statements for each factor, i.e., those statements individuals tend to agree and disagree most. On the basis of these defining statements, we can draw tentative interpretations of subjective views about the regulation of local water services and attribute speculative "labels" to characterise the kind of worldview held by elected public officers. In addition, the analysis reveals that some statements (so-called "consensus statements") do not distinguish between any pair of factors in a statistically significant way. The two statements are that "In the tender offer of franchise contracts, it is difficult to detail and enforce contractual terms and conditions" (statement 17) and "Users of water services are not able to compare the quality of the services with those provided by other water firms" (statement 22). Both statements can be understood as factual beliefs or opinions that relate to issues that are generally uncontested within the water services domain.

Table 6. Defining statements for each factor (Z-scores greater than 1 or lower than -1$)$.

\begin{tabular}{|c|c|c|c|}
\hline \multicolumn{2}{|c|}{ Factor No. 1} & Rank & Z-score \\
\hline \multicolumn{4}{|c|}{ Agrees especially with the following statements } \\
\hline s30 & Local water services should be provided by full public ownership firms. & 5 & 2.249 \\
\hline s2 & $\begin{array}{l}\text { Water services should be managed according to principles of solidarity and of protection of the most vulnerable } \\
\text { users. }\end{array}$ & 4 & 1.578 \\
\hline s4 & Water tariffs should be kept under the control of public authorities to ensure affordability. & 4 & 1.499 \\
\hline s15 & The attainment of profit bears negative effects on the quality of water services. & 3 & 1.235 \\
\hline s21 & Water services provide an attractive opportunity for private investors. & 3 & 1.026 \\
\hline \multicolumn{4}{|c|}{ Disagrees especially with the following statements } \\
\hline s26 & Local water services should be provided by business firms subjected to the discretion of a regulatory agency. & -3 & -1.341 \\
\hline s27 & $\begin{array}{l}\text { Local water services should be provided by business firms subjected to terms and conditions of } \\
\text { franchise contracts. }\end{array}$ & -4 & -1.435 \\
\hline s3 & Water tariffs should cover full cost, including a fair return to capital invested. & -4 & -1.686 \\
\hline s25 & $\begin{array}{l}\text { Local water services should be provided by business firms subjected to the pressure of } \\
\text { market competition only. }\end{array}$ & -5 & -1.894 \\
\hline \multicolumn{4}{|c|}{ Factor No. 2} \\
\hline \multicolumn{4}{|c|}{ Agrees especially with the following statements } \\
\hline s15 & The attainment of profit bears negative effects on the quality of water services. & 5 & 1.592 \\
\hline s19 & $\begin{array}{l}\text { Local public authorities tend to interfere in the management of water firms rather than supervising and regulating } \\
\text { their conduct. }\end{array}$ & 4 & 1.546 \\
\hline s30 & Local water services should be provided by full public ownership firms. & 4 & 1.446 \\
\hline s10 & Local public authorities do not adequately monitor service quality. & 3 & 1.199 \\
\hline $\mathrm{s} 21$ & Water services provide an attractive opportunity for private investors. & 3 & 1.152 \\
\hline s13 & $\begin{array}{l}\text { Local public authorities do not possess adequate knowledge, competences, and capabilities to regulate the conduct of } \\
\text { water firms. }\end{array}$ & 3 & 1.052 \\
\hline
\end{tabular}


Table 6. Cont.

\begin{tabular}{|c|c|c|c|}
\hline \multicolumn{2}{|c|}{ Factor No. 2} & Rank & Z-score \\
\hline \multicolumn{4}{|c|}{ Disagrees especially with the following statements } \\
\hline s25 & $\begin{array}{l}\text { Local water services should be provided by business firms subjected to the pressure of market } \\
\text { competition only. }\end{array}$ & -3 & -1.538 \\
\hline s5 & Water infrastructure development should be primarily financed by users charges. & -4 & -1.592 \\
\hline s24 & Water firms are provided incentives to operate efficiently. & -4 & -1.848 \\
\hline s29 & Local water services should be provided by cooperative firms. & -5 & -1.894 \\
\hline \multicolumn{4}{|c|}{ Factor No. 3} \\
\hline \multicolumn{4}{|c|}{ Agrees especially with the following statements } \\
\hline s2 & Water services should be managed according to principles of solidarity and of protection of the most vulnerable users. & 5 & 1.896 \\
\hline s4 & Water tariffs should be kept under the control of public authorities to ensure affordability. & 4 & 1.809 \\
\hline s3 & Water tariffs should cover full cost, including a fair return to capital invested. & 4 & 1.494 \\
\hline \multicolumn{4}{|c|}{ Disagrees especially with the following statements } \\
\hline s27 & $\begin{array}{l}\text { Local water services should be provided by business firms subjected to terms } \\
\text { and conditions of franchise contracts. }\end{array}$ & -4 & -1.653 \\
\hline s7 & Local public authorities care more about protecting the interests of water firms than of the users. & -4 & -1.735 \\
\hline s 25 & Local water services should be provided by business firms subjected to the pressure of market competition only. & 5 & -2.367 \\
\hline \multicolumn{4}{|c|}{ Factor No. 4} \\
\hline \multicolumn{4}{|c|}{ Agrees especially with the following statements } \\
\hline s2 & Water services should be managed according to principles of solidarity and of protection of the most vulnerable users. & 5 & 2.287 \\
\hline s4 & Water tariffs should be kept under the control of public authorities to ensure affordability. & 4 & 1.679 \\
\hline s10 & Local public authorities do not adequately monitor service quality. & 4 & 1.378 \\
\hline s5 & Water infrastructure development should be primarily financed by users charges. & 3 & 1.071 \\
\hline s16 & In the water sector we lack reliable and comparable measures to assess the quality of services. & 3 & 1.071 \\
\hline \multicolumn{4}{|c|}{ Disagrees especially with the following statements } \\
\hline s9 & If water services are provided by franchisees, water firms tend not to completely comply with contractual obligations. & -3 & -1.523 \\
\hline s29 & Local water services should be provided by cooperative firms. & -4 & -1.528 \\
\hline s18 & Water firms are inherently inefficient because they are monopolists. & -4 & -1.679 \\
\hline s1 & Water services should be managed according to business principles akin to those of for-profit firms. & -5 & -1.986 \\
\hline \multicolumn{4}{|c|}{ Factor No. 5} \\
\hline \multicolumn{4}{|c|}{ Agrees especially with the following statements } \\
\hline $\mathrm{s} 28$ & Local water services should be provided by mixed public-private ownership firms. & 5 & 1.923 \\
\hline s21 & Water services provide an attractive opportunity for private investors. & 4 & 1.406 \\
\hline s26 & Local water services should be provided by business firms subjected to the discretion of a regulatory agency. & 4 & 1.406 \\
\hline s20 & Water firms are not exposed to any serious threat of new entrants into the industry. & 3 & 1.162 \\
\hline s13 & $\begin{array}{l}\text { Local public authorities do not possess adequate knowledge, competences, and capabilities to regulate the conduct of } \\
\text { water firms. }\end{array}$ & 3 & 1.123 \\
\hline s7 & Local public authorities care more about protecting the interests of water firms than of the users. & 3 & 1.084 \\
\hline \multicolumn{4}{|c|}{ Disagrees especially with the following statements } \\
\hline s24 & Water firms are provided incentives to operate efficiently. & -3 & -1.162 \\
\hline s 25 & Local water services should be provided by business firms subjected to the pressure of market competition only. & -3 & -1.201 \\
\hline s30 & Local water services should be provided by full public ownership firms. & -3 & -1.201 \\
\hline s11 & Renegotiation of water franchise contracts is highly demanding in terms of time and resources. & -4 & -1.366 \\
\hline s29 & Local water services should be provided by cooperative firms. & -4 & -1.601 \\
\hline s23 & The administrative judicial system plays an important role in the regulation of water firms. & -5 & -1.923 \\
\hline
\end{tabular}




\section{Discussion}

The results of the analysis can be interpreted by recollecting the distinctive sentences associated with each factor in meaningful wholes. The first factor can be called a "public sector interventionist" view of local water services regulation. Individuals who hold this view agree that water services should be provided by full public ownership firms (statement 30), that they should be managed according to principles of solidarity and of protection of the most vulnerable users (statement 2), and that they should be subjected to tariff controls by public authorities to ensure affordability (statement 4). In addition, proponents of this view agree that the water sector provides an attractive opportunity for private investors (statement 21), but also that the attainment of profit bears negative effects on the quality of water services (statement 15). Proponents of this view would also disagree with the ideas that water services should be provided by business firms subjected to the pressure of market competition only (statement 25), or subjected to the discretion of a regulatory agency (statement 26), or subjected to terms and conditions of franchise contracts (statement 27). Also, they challenge the idea that water tariff should cover full cost, including a fair return to capital invested (statement 3 ). An illustration of this view is provided by the following comment:

"Water is a natural public good. It is a good from which profit is unconceivable. Tariffs should exactly correspond to the operative costs and investments in new infrastructure. Private firms tend to make profits because of their very nature, and also public participation in business ventures would follow the same logic" (respondent No. 20).

The second factor can be called a "pessimistic" view of local water services regulation. Individuals who hold this view agree with statements that highlight unresolved issues with the present regulatory process. For example, they agree that the attainment of profit bears negative effects on the quality of water services (sentence 15), that local public authorities tend to interfere in the management of water firms rather than supervising and regulating their conduct (sentence 19), that local public authorities do not adequately monitor service quality (sentence 10), that local public authorities do not possess adequate knowledge, competences, and capabilities to regulate the conduct of water firms (statement 13). As a matter of policy inclination, individuals who hold this view acknowledge that water services provide an attractive opportunity for private investors (statement 21), but they hold that water services should be provided by full public ownership firms (statement 30 ).

The third factor can be called a 'pragmatist' view of local water services regulation. Individuals who hold this view acknowledge that the water services should be managed according to principles of solidarity and of protection of the most vulnerable users (statement 2) and agree with the policy that water tariffs should be kept under the control of public authorities to ensure affordability (statement 4). However, they also admit that water tariff should cover full cost, including a fair return to capital invested (statement 4). They are generally sceptical of the role of business firms in the provision of local water services irrespective to whether firms are subjected to terms and conditions of franchise contracts (statement 27) or to the pressure of market competition (statement 25) and of the possibility that local public authorities can be captured by water firms to serve their interests rather than those of the users (statement 7). The following comment provides an illustration of this view: 
"Water is a common good, therefore the management of water services cannot contradict this absolute principle. The management of water services should be effective and efficient as in the best business companies, but with the constraint to protect weakest users" (respondent No. 4)

The fourth factor can be called a "cautious privatiser" view of local water services regulation. Individuals who hold this view agree that water infrastructure development should be primarily financed by user charges (statement 5), but, as water services should be managed according to principles of solidarity and of protection of the most vulnerable users (statement 2), water tariffs should be kept under the control of public authorities to ensure affordability (statement 4). Holders of this view, however, believe that local public authorities do not adequately monitor service quality (statement 10) and that in the water sector we lack reliable and comparable measures to assess the quality of services (statement 16). They also disagree that water services should be manager according to business principles akin to those of for-profit firms (statement 1) and that water firms are inherently inefficient because they are monopolists (statement 18). They also tend to disagree that water firms do not completely comply with contractual obligations of franchise contracts (statement 9).

Finally, the fifth factor can be called a "fatalist privatiser" view of local water services regulation. Individuals who hold this view agree that local water services should be provided by mixed public-private ownership firms (statement 28) or by business firms subjected to the discretion of a regulatory agency (statement 26). They see, in fact, that local water services provide an attractive opportunity for private investors (statement 21). With rather fatalistic tones, however, they also hold that water firms are not exposed to any serious threat of new entrants into the industry (statement 20), that local public authorities do not possess adequate knowledge, competences, and capabilities to regulate the conduct of water firms (statement 13), and that they rather care more about protecting the interests of water firms than of the users (statement 7). An illustration of this view is provided by the following comment:

"Water goods must be protected by public authorities but the contribution of private capital is needed for an effective management, development and distribution. Mixed ownership firms would enable to implement this model. It would be possible to attain the same results also with a full public ownership firm, but national politics have largely disappointed us, and therefore we need for a public-private partnership in order to provide incentives (to water firms), provided that there is no collusion between public and private actors" (respondent No. 9).

The five types of views about the regulation of local water services constitute tentative interpretations of sets of beliefs and opinions of the elected public officers in coherent wholes. The interpretations clearly require some amount of flexibility for accommodating apparently unrelated claims into meaningful arguments. The five types of view that resulted from the analysis, in fact, can not be easily mapped onto simplistic categories of "advocates" and "opponents" of re-regulation and privatisation of local water service provision. Rather than "advocates" of re-regulation and privatisation, the analysis led to the identification of "pragmatists" (who may embrace re-regulation and privatisation for practical benefits), "cautious privatisers" (who may half-heartedly accord privatisation while maintaining forms of public control on the provision of local water services), and "fatalist privatisers" (who may passively accept privatisation as inevitable). Rather than "opponents" of re-regulation and privatisation, the types of view identified from the analysis include a distinction 
between a "public sector interventionist" perspective (whose proponents believe of the merits of full public ownership and control of water utilities) and a "pessimistic" perspective (whose holders rather criticise re-regulation and privatisation in place of advocating for any particular alternative). The five types of views, therefore, are not plainly correspondent to a priori categories as they rather relate to particular combinations of beliefs and opinions.

A first question arises, then, concerning what explains the apparent heterogeneity of views about the regulation of local water services among elected public officers in Italy. A tentative answer can be formulated by taking into consideration the historical context of the study. As briefly recalled above, the water sector of Italy was shaken by various reforms and legislative changes that took place over a period of almost two decades (1994-2011), with the resulting effect that differences emerged in the modes of governance, regulation, and service delivery across the country. The variety of individuals' subjectivities identified in the present study may be related to the diversity of partisan views towards privatisation of local water services and towards the desirability of alternative regulatory systems and ownership structures, which may be related to the particular trajectories of re-regulation and privatisation experienced at the local level. Far from developing a "hegemonic" perspective, the discourse on the regulation and ownership structure of water utilities in Italy remained fragmented into diverse views held within political circles that either endorsed regulatory reform and privatisation or resisted them. Variety of initial conditions, political orientation, and occurrence of reform or legislative changes - among others - count as relevant factors for explaining the diversity of individuals' subjectivities on the regulation of local water service provision.

Next question, then, is whether and how findings from this study-namely, the variety of views about regulation of local water services in Italy - matters, both within the context of the discussion about the regulation of the water sector in the country and of the design of water regulatory systems more generally. The presence of fragmented views about the regulation of water services in Italy poses some sources of potential instability within the present water regulatory regime. Within both the governance and regulatory regimes in place where water utilities are fully owned and controlled by local governments and where they are jointly owned by local governments and private operators and investors, some influential actors - elected public officers - hold believes and opinions that are dissonant, or even run against, the present mode of water service regulation and delivery. Implications of such diverse set of views about water regulation include the possibility that these actors can be especially sensitive to detect possible sources of discredit of the present regime (such as poor water service performance or dissatisfactory distributional effects of water service provision) and to frame the policy issue of how local water regulation should be reconfigured.

In a broader perspective, findings from this study also bear some relevance for the general discussion about the design of water regulatory systems. Evidence of the variety of ideas about the regulation of local water services suggests that individuals' beliefs and opinions may be related to particular value premises, pragmatic concerns, and opportunistic considerations rather than to mere adherence to shared understanding of principles of economic regulation. If ideas matter in the policy process, then variety of beliefs and opinions held by elected public officers may help accounting for the features of the design of water regulatory systems. For instance, pragmatic concerns may induce individuals to welcome the opening of the water industry to private operators and investors as a way 
to stimulate efficiency and financial self-sufficiency of water utilities on the one hand, and to restrain the conduct of water utilities through stringent regulatory measures intended to protect weakest users on the other one. The design of water regulatory systems, therefore, should be understood on the basis of the specific conditions that occur within given historical and political circumstances, including the variety of individual views about how water services should be regulated.

Finally, findings from this study may bear some relevance for other research works on the institutional features of water governance, especially in comparative perspective. Works done by Araral [16], and Araral and $\mathrm{Yu}$ [60], for example, argue that the design of appropriate governance systems for water service provision is important for improving service quality and that the quality of water governance seems related to the level of economic development. The present study suggests that paying attention to individual subjectivities may be relevant to account for similarities and differences of water governance systems across countries. Q methodology, as employed in this study, could help identifying the features of the discourse on water regulation and privatisation in different country case contexts. The characteristics of such discourse - in terms of both structure and variety of views held by individuals of the water policy domain - may be important to explain part of the observed variance of water governance systems across countries, especially developing ones with respect to industrialised ones.

\section{Conclusions}

This study provides an analysis of the subjectivities of elected public officers towards the regulation of local water services in Italy. By using Q methodology, the study showed that there are five different sets of beliefs and opinions held by elected public officers about how local water services are delivered, how well they perform, and how they should be regulated. One set of ideas, called "public sector interventionists", are favourably inclined towards full public ownership of water firms and an influential role played by public authorities in the management of water services more generally. Another set of ideas, called a "pessimistic" view, primarily agrees on the presence of various problems in the regulation of local water services but is relatively uncommitted to any articulated policy approach. One more set of ideas, called a "pragmatic" view, aims at reconciling contrasting objectives, such as managing water firms in a business-like fashion while retaining concern with issues of water tariff affordability, within a common policy approach. Finally, two more sets of ideas tend to support some form of privatisation of water services. In the "cautious privatiser" variant, ideas include the need for public control of water charges and awareness of issues related to lack of attention of local public authorities towards monitoring service quality and of reliable and comparable measures to assess the quality of services. In the "fatalist privatiser" variant, ideas include awareness of various shortcomings of privatisation schemes, such as the lack of adequate knowledge, competences, and capabilities of local public authorities to regulate the conduct of water firms, the lack of threat of new entrants into the industry, and the somehow cynical view that local public authorities care more about protecting the interests of water firms than of the users.

This study contributes enriching our understanding of ideas about the regulation of local water services in ways that transcend more conventional categories of modes of regulation of infrastructure services. A result of the analysis that is relevant, in this respect, is that individuals hold idiosyncratic 
sets of ideas about how local water services are delivered, how well they perform, and how they should be regulated that contain particular "nuances". For example, "pragmatists" strive to compromise between social concerns on the one hand, and the need to adequately finance the management of water services and the development of water infrastructure on the other one. This finding is consistent with those of other works that highlighted that regulatory policies sometimes take the shape of "hybrids" by combining selected features of alternative regulatory models [31,61]. This study suggests that analysing the ideas on the regulation of local water services is important in order to contribute to the efforts to understand the origins of the design of regulatory systems.

If elected public officers play any role in the design of water regulatory systems at the local level, then this study shows that attention to the beliefs and opinions held by these individuals may be especially relevant. The interpretive approach to regulation can complement theoretical arguments put forward by the "public interest" and the "capture" theories in ways that highlight the importance of taking the variety of individuals' views into account for explaining how regulations are made and implemented. With respect to the "public interest" theories of regulation, the inquiry into the subjectivities of elected public officers suggests that individuals may hold quite diverse understanding and attitudes towards ways to attain public objectives. With reference to the "capture" theories of regulation, this study suggests that elected public officers may hold reservations towards the privatisation of water service provision, which may entail the presence of an inclination to potentially reconsider - if not to revoke - the award of concession or franchise contracts under changed political circumstances. A similar argument could be made, moreover, about the role of individual subjectivities within mechanism design theories of infrastructure regulation [13]. Mechanism design theory holds that fitting incentive structures can minimise transaction costs in the provision of infrastructure services. The study of individuals' subjectivities suggests, however, that we can not rule out the possibility that, while conforming their conduct to canons of instrumental rationality, individuals may nevertheless hold reservations about the institutional arrangement despite of any apparent net benefits, especially if the design principles or effects do not conform to individuals' values. Additional issues arise, then, concerning whether designed mechanisms are exposed to the threat of being dismantled or whether any design effort should include ways to safeguard mechanisms from being taken apart.

Finally, this study enables us to reflect upon the possibilities offered by Q methodology as well as its limitations. On the one hand, Q methodology provides researchers with a rigorous and transparent way for collecting and analysing data on individuals' subjectivities. On the other one, the methodological approach exhibits some weaknesses especially because the results are dependent on the selection of sentences of the Q sample, which may be affected by practical considerations for the limited amount of time and effort that respondents are willing to spend on the sorting task, and ultimately on the subjective interpretation of the researcher. In addition, the Q method is limited to providing the mapping of the beliefs and opinions held within the discourse on water regulation and privatisation. Questions about whether and how subjectivities matter for the formation of regulatory and privatisation policies or for the performance effects of water governance systems can not be addressed. Additional research is needed, therefore, to explore how findings from Q methodology 
may be fruitfully combined with other approaches in order to improve our understanding of the determinants of the design and performance effects of water governance systems.

\section{Acknowledgments}

I would like to thank Peter Mollinga, James Nickum, Laurence Smith, and Kate Bayliss of the Centre for Water and Development of the School of Oriental and African Studies, University of London, for their insightful and constructive comments on an earlier version of this study. I also would like to thank the University of Cagliari for funding this publication. I also thank the three anonymous reviewers for their constructive comments to this paper.

\section{Conflicts of Interest}

The author declares no conflict of interest.

\section{References}

1. Pigou, A.C. The Economics of Welfare; Macmillan: London, UK, 1932.

2. Posner, R.A. Theories of Economic Regulation. Bell J. Econ. 1974, 2, 335-358.

3. Ogus, A.I. Regulation: Legal Form and Economic Theory; Clarendon Press: Oxford, UK, 1994.

4. Stigler, G.J. The theory of economic regulation. Bell J. Econ. Manag. Sci. 1971, 2, 3-21.

5. Becker, G.S. A theory of competition among pressure groups for political influence. Q. J. Econ. 1983, 98, 371-400.

6. Peltzman, S. Toward a more general theory of regulation. J. Law Econ. 1989, 19, 211-240.

7. Hurwicz, L. Economic design, adjustment processes, mechanisms, and institutions. Rev. Econ. Des. 1994, 1, 1-14.

8. Hurwicz, L.; Reiter, S. Designing Economic Mechanisms; Cambridge University Press: Cambridge, UK, 2006.

9. Maskin, E.S. Mechanism design: How to implement social goals. Am. Econ. Rev. 2005, 98, 567-576.

10. Myerson, R.B. Perspectives on mechanism design in economic theory. Am. Econ. Rev. 2008, 98, 586-603.

11. Estache, A.; Martimort, D. Politics, Transaction Costs, and the Design of Regulatory Institutions; World Bank Policy Research Working Paper; World Bank: Washington, DC, USA, 1999.

12. Laffont, J.J.; Tirole, J. A Theory of Incentives in Procurement and Regulation; MIT Press: Cambridge, MA, USA, 1993.

13. Araral, E. Mechanism design and transaction cost approach to regulatory design in developing countries. Policy Sci. 2013, December, doi:10.1007/s11077-013-9192-z.

14. Lodge, M.; Wegrich, K. Managing Regulation: Regulatory Analysis, Politics and Policy; Palgrave Macmillan: Basingstoke, UK, 2012.

15. Douglas, M. In the Active Voice; Routledge: London, UK, 1982. 
16. Araral, E. Public provision of urban water: Getting prices and governance right. Governance 2008, 21, 527-549.

17. Barraqué, B. Les Politiques de l'eau en Europe; La Découverte: Paris, France, 1995.

18. Dinar, A. The Political Economy of Water Pricing Reforms; The International Bank for Reconstruction and Development/The World Bank: Washington, DC, USA, 2000.

19. Joskow, P.L. Regulation of Natural Monopolies; Center for Energy and Environmental Policy Research Working Paper; Massachusetts Institute of Technology: Cambridge, MA, USA, 2005.

20. Littlechild, S. Economic regulation of privatized water authorities and some further reflections. Oxford Rev. Econ. Policy 1986, 4, 40-67.

21. Rouse, M. Institutional Governance and Regulation of Water Services; IWA Publishing: London, UK, 2007.

22. Spulber, N.; Sabbaghi, A. Economics of Water Resources: From Regulation to Privatization; Kluwer Academic Publishing: Berlin, Germany, 1994.

23. Winpenny, J. Managing Water as An Economic Resource; Routledge: London, UK, 1994.

24. Balance, A.; Taylor, A. Competition and Economic Regulation in Water: The Future of the European Water Industry; IWA Publishing: London, UK, 2005.

25. Finger, M.; Allouche, J. Water Privatisation: Trans-National Corporations and the Re-Regulation of the Water Industry; Spon Press: London, UK, 2003.

26. Kallis, G.; Nijkamp, P. Evolution of EU Water Policy: A Critical Assessment and a Hopeful Perspective. J. Env. Law Policy 2000, 3, 301-355.

27. Rees, J.A. Regulation and private participation in the water and sanitation sector. Nat. Resour. Forum 1998, 22, 95-105.

28. Wackerbauer, J. Regulation and privatization of the public water supply in England, France, and Germany. Compet. Regul. Netw. Ind. 2007, 8, 101-116.

29. Araral, E. The failure of water utilities privatisation: Synthesis of evidence and implications. Policy Soc. 2009, 27, 221-228.

30. Asquer, A. The regulatory reform of water infrastructure in Italy: Overall design and local variations. Water Policy 2010, 12 (Suppl. S1), 66-83.

31. Asquer, A. The Regulation of Water Infrastructure in Italy: Evolution and Effects. In Infrastructure Regulation: What Works, Why, and How do We Know it? Lessons from Asia and Beyond; Jarvis, D., Ramesh, M., Xun, W., Eds.; World Scientific: Singapore, 2011.

32. Asquer, A. Liberalization and regulatory reform of network industries: A comparative analysis of Italian public utilities. Util. Policy 2011, 19, 172-184.

33. Campbell, J.L. Institutional analysis and the role of ideas in political economy. Theory Soc. 1998, 27, 377-409.

34. Campbell, J.L. Ideas, politics, and public policy. Annu. Rev. Sociol. 2002, 28, 21-38.

35. Peters, G. Governance and political theory. Crit. Policy Stud. 2011, 5, 63-72.

36. Gómez Ibáňez, J.A. Regulating Infrastructure: Monopoly, Contracts, and Discretion; Harvard University Press: Cambridge, MA, USA, 2003. 
37. Becchis, F.; Vanin, E.; Russolillo, D. FIELD: A Methodology for the Analysis of Local Actors, Incentives and Information Endowment in Regulation of Local Public Services. In Proceedings of the 6th Annual Conference on Competition and Regulation in Network Industries, Brussels, Belgium, 22 November 2013.

38. Che, Y.-K. Revolving doors and the optimal tolerance for agency collusion. RAND J. Econ. 1995, 26, 378-397.

39. Makkai, T.; Braithwaite, J. In and out of the revolving door: Making sense of regulatory capture. J. Public Policy 1992, 12, 61-78.

40. Salant, D. Behind the revolving door: A new view of public utility regulation. RAND J. Econ. 1995, 26, 362-377.

41. Stephenson, W. The Study of Behavior: Q-technique and its Methodology; University of Chicago Press: Chicago, IL, USA, 1953.

42. Brown, S. Political Subjectivity; Yale University Press: New Haven, CT, USA, 1980.

43. Jeffares, S.; Skelcher, C. Democratic subjectivities in network governance: A Q methodology study of English and Dutch public managers. Public Adm. 2011, 89, 1253-1273.

44. Steen, T.; van Eijk, C. Comprehending Citizens' Motivations to Participate in Co- Production of Public Services. In Proceedings of the Workshop on "Co-production: The State of the Art", Corvinus University, Budapest, Hungary, 22-23 November 2012.

45. Yanow, D.; Schwatz-Shea, P. Interpretation and Method: Empirical Research Methods and the Interpretive Turn; ME Sharpe: London, UK, 2006.

46. Steelman, T.; Maguire, L. Understanding participant perspectives: Q-methodology in the national forest management. J. Policy Anal. Manag. 1995, 18, 361-388.

47. Dryzek, J.S.; Holmes, L. Post-Communist Democratization: Political Discourses across 13 Countries; Cambridge University Press: Cambridge, UK, 2002.

48. Dryzek, J.S.; Berejikian, J. Reconstitutive democratic theory. Am. Polit. Sci. Rev. 1993, 87, 48-60.

49. Lett, J. Emics and Etics: Notes on the Epistemology of Anthropology. In Emics and Etics: The Insider/Outsider Debate; Headland, T.N., Harris, M., Pike, K.L., Eds.; SAGE Publications: London, UK, 1990; pp. 127-142.

50. Disposizioni in materia di risorse idriche; Law No. 36 Official Bulletin of the Republic of Italy No. 14, Ordinary Supplement No. 11; Ministry of Justice of the Republic of Italy: Rome, Italy, 19 January 1994.

51. Disposizioni per la formazione del bilancio annuale e pluriennale dello Stato llegge finanziaria 2002); Law No. 448 Official Bulletin of the Republic of Italy No. 301, Ordinary Supplement No. 285; Ministry of Justice of the Republic of Italy: Rome, Italy, 28 December 2001.

52. Disposizioni urgenti per favorire lo sviluppo e per la correzione dell'andamento dei conti pubblici; Law Decree No. 269 Official Bulletin of the Republic of Italy No. 229, Ordinary Supplement No. 157; Ministry of Justice of the Republic of Italy: Rome, Italy, 30 September 2003.

53. Disposizioni per la formazione del bilancio annuale e pluriennale dello Stato legge finanziaria 2004); Law No. 350 Official Bulletin of the Republic of Italy No. 299, Ordinary Supplement No. 196; Ministry of Justice of the Republic of Italy: Rome, Italy, 24 December 2003. 
54. Disposizioni urgenti per lo sviluppo economico, la semplificazione, la competitivita', la stabilizzazione della finanza pubblica e la perequazione Tributaria; Law No. 112 Official Bulletin of the Republic of Italy No. 147, Ordinary Supplement No. 196; Ministry of Justice of the Republic of Italy: Rome, Italy, 24 December 2003.

55. Brouwer, M. Q is accounting for tastes. J. Advert. Res. 1999, 39, 35-39.

56. Van Exel, J.; de Graaf, G. Q Methodology: A Sneak Preview, Mimeo. Available online: http://www.jobvanexel.nl (accessed on 30 December 2013).

57. Italian National Institute of Statistics (ISTAT). Bilancio demografico mensile. ISTAT: Rome, Italy, 10 October 2013.

58. Braehler, G.; Hackert, C. FlashQ 1.0, Q Sorting via the Internet. Available online: http://www.hackert.biz/flashq (accessed on 30 December 2013).

59. Schmolck, P. PQMethod version 2.33. Available online: http://schmolck.userweb.mwn.de/ qmethod/ (accessed on 30 December 2013).

60. Araral, E.; Yu, D. Comparative water law, policies and administration in Asia: evidence from 17 countries. Water Resour. Res. 2013, 49, 5307-5316.

61. Groom, E.; Halpern, J.; Ehrhardt, D. Explanatory notes on key topics in the regulation of water and sanitation services. In Water Supply and Sanitation Sector Board Discussion Paper Series, Paper No. 6; World Bank: Washington, DC, USA, 2006. 
MDPI AG

Klybeckstrasse 64

4057 Basel, Switzerland

Tel. +41616837734

Fax +41613028918

http://www.mdpi.com/

Water Editorial Office

E-mail:water@mdpi.com

http://www.mdpi.com/journal/water 

回器 $\mathrm{MDPI} \cdot$ Basel $\cdot$ Beijing $\cdot$ Wuhan $\cdot$ Barcelona 15BN 978-3-03842-013-2 